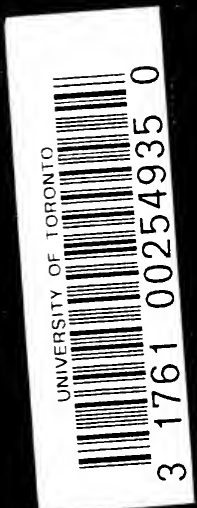




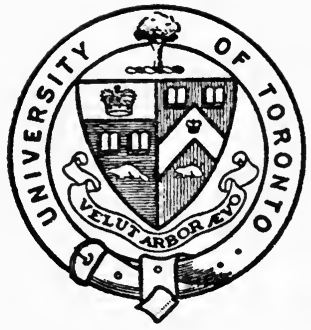

坊resented to The Tithrary uf the

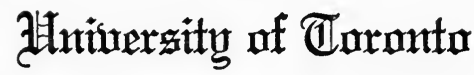
by

S. Gross, Esq. 
$\checkmark$

Digitized by microsont in 
Digitized for Microsoft Corporation by the Internet Archive in 2007.

From University of Toronto.

May be used for non-commercial, personal, research, or educational purposes, or any fair use. May not be indexed in a commercial service. 
Digitized by Microsoft ${ }^{\circledR}$ 
Digitized by Microsoft $\mathbb{B}$ 


\section{IMMANUEL KANT}

\section{KRITIK DER \\ PRAKTISCHEN VERNUNFT}

ACHTE A UFLAGE

HERAUSGEGEBEN MIT EINER EINLEITUNG SOWIE EINEM PERISONEN- UND SACHREGISTER VERSEHEN

$\nabla 0 \mathrm{~N}$

\section{KARL VORLÄNDER}

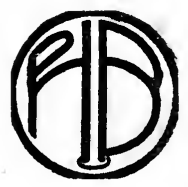

DER PHILOSOPHISCHEN BIBLIOTHEK BAND 38 LEIPZIG 1922 VERLAG VON FELIX MEINER 
B

2770

1922

$\frac{6.99959}{24.1 .57}$

Druck von Gustav Pritz \& Co., Leipzig-Stö.

Digitized by Microsoft ${ }^{\circledR}$ 


\section{Vorwort zur fünften Auflage.}

Auch die Einrichtung dieses Kantbandes entspricht ganz derjenigen der bereits früher von mir herausgegebenen (Bd. 39-41, 45 und 46 der Philosophischen Bibliothek). Für den Text und die Entstehungsgeschichte der Schrift konnte ich zu meiner Freude bereits die Korrekturbogen der von Paul Natorp besorgten Akademie-Ausgabe der Kritik der praktischen Vernunft benutzen, die mir mein verehrter Freund, Professor Natorp, dankenswerterweise zur Verfügung stellte, während ich mich an der Durchsicht des Textes für eben diese Akademie-Ausgabe beteiligt hatte. Die Seitenzahlen der letzteren sind von uns in eckigen Klammern am Rande angegeben; für die Entstehungsgeschichte waren die betreffenden Seitenziffern von Natorps Einleitung und sachlichen Erläuterungen beim Abschluß dieses Druckes noch nicht vorhanden.

Solingen, 31. Juli 1906.

Prof. Dr. Karl Vorländer.

\section{Zur sechsten Auflage.}

In der Einleitung, besonders den Lesarten, haben alle seit Erscheinen der vorigen Auflage veröffentlichten Beiträge (s. unten S. XLVI) gewissenhafte $\mathrm{Be}$ rücksichtigung erfahren.

Ein merkwürdiges Zusammentreffen der Umstände will es, daß diese Neuauflage von Kants ethischem 
Hauptwerk zu derselben Zeit notwendig geworden ist, wo ein furchtbarer Krieg Europa, ja den ganzen Erdkreis durchtobt. Möge Kants kategorischer Imperativ der Pflicht, der unser Volk diesen von seiner großen Mehrheit nicht gewollten Krieg bisher zu ertragen und heldenmütig zu führen gelehrt hat, es bis zum siegreichen Durchhalten begleiten! Möge aber auch, sobald ein ehrenvoller Friede erreicht ist, Kants Menschheitsgedanke uns antreiben, trotz alledem von neuem unbeirrt den unverlierbaren idealen Gütern der Menschheit nachzujagen.

Solingen, im November 1914.

Karl Vorländer. 


\section{In halt.}

Seite

Vorwort des Herausgebers : . . : . . . . . . III

Einleitang des Herausgebers . . . . . . . VII

Kants Kritik der praktischen Vernunft . . . 1

Vorrede . . . . . . . . . . . . . .

Einleitang . . . . . . . . . . . 18

Erster Teil. Elementarlehreder reinen praktischen Vernanft . . . . . . . 21

I. Bach. Analytik der reinen praktischen

Vernunft . . . . . . . . . .

1. Hauptstück. Von den Grundsätzen der reinen praktischen Vernunft . . .

\$1. Erklärung, S. 23. - § 2. Lehrsatz I, S. 26.

- \$ 3. Lehrsatz II, S. 27; Anmerkung I, S. 28; Anmerkang II, S. 31. - § 4. Lehrsatz II, S. 34; Anmerknng, S. 35. - 5 . Aufgabe I, S. 36; Aufgabe II mit Anmerkung S. 37. 8 7. Grundgesetz der reinen praktischen Vernunft mit Anmerkangen, S. 39. - § 8. Lehr. satz IV, S. 43; Anmerkung I, S. 44; Anmerkung II, S. 46.

I. Von der Deduktion der Grandsätze der reinen praktischen Vernunft . •

II. Erweiterung im praktischen Gebrauche

2. Ha uptstück. Von dem Begriffe eines Gegenstandes der reinen praktischen Vernunft Tafel der Kategorien der Freiheit . . . .

Typik der reinen praktischen Urteilskraft .

8. Hauptstück. Von den Triebfedern der reinen praktischen Vernunft . . . . 93

Kritische Beleuchtung der Analytik . . . 116

II. Buch. Dialektik der reinen praktischen

Vernunft . . . . . . . . . . 138

1. Ha uptstück. Von einer Dialektik der reinen praktischen Vernanft überhanpt . . 138 
2. Hauptstäck. Dialektik der reinen Vernunft in Bestimmang des Begriffs vom hochsten Gat . . . . . . . . . . .

I. Antinomie der pr. V., S. 145. - II. Kritische Aufhebung ders. S. 146. - III. Primat der r. pr. V., S 153. - IV. Die Unsterblichkeit der Seele als ein Postulat der r. pr. V., S. 156. - V. Das Dasein Gottes als ein Postulat usw., S. 158. - VI. Die Postalate der r. pr. V. überhaupt, S. 168. - VII. Von einer Erweiterung der Vernunft in praktischer Absicht usw., S. 171. - VIIL. Vom Fürwahrhalten aus einem Bedürfnis d. r. V., S. 180. - IX. Von der der praktischen Bestimmung des Menschen weislich angemessenen Proportion seiner Erkenntnisvermogen, S. 186.

Zweiter Teil. Methodenlehre der reinen praktischen Vernunft . . . . . . . . . . . . 189 Beschla $B$

Register des Heraugebers. . . . . . . . 208 


\section{Einleitung.}

\section{Entstehungsgeschichte und erste Wirkung der Schrift.}

$\mathrm{Zu}$ dem ersten Abschnitt vgl. Natorps genaue Unter. suchung in der Einleitung zu seiner Ausgabe in der AkademieAusgabe von Kants S. W. Bd. V. Die Stellen aus dem Briefwechsel Kants und anderer sind aus dem bereits $B d .40$, S. $V$ der Phil. Bibl. von uns angegebenen Grunde nur nach dem Datum zitiert.

1. Die Geschichto von Kants ethischer Schriftstellerei, genauer gesagt seiner auf die Ethik bezüglichen schriftstellerischen Pläne, bis zum Erscheinen der Grundlegung zur Metaphysik der Sitten (1785) habe ich bereits in meiner Ausgabe dieser Schrift (Phil. Bibl. $B d$. 41) S. VII-XIV in knappem Umriß geschildert. Den Plan einer besonderen „Kritik der praktischen Vernunft" neben der in zehnjähriger Arbeit allmählich sich gestaltenden „Kritik der reinen Vernunft“ fanden wir in dieser Entwickelungsgeschichte nicht erwähnt. Vielmehr erscheint es fast gewiß, daß die Kritik der reinen Vernunft die kritische Grundlegung zum zweiten Teile seines Systems, der Ethik oder in der Sprache der Zeit der „Metaphysik der Sitten“, mit enthalten sollte. Das geht einmal aus der. a. a. 0. S. XI von uns abgedruckten Stelle seines nach dem Erscheinen der Kritik geschriebenen Briefes an Moses Mendelssohn

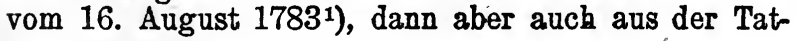

1) In zweiter Linie sind auch die a. a. O. S. X von mir benutzten Briefe Hamanns und Hartknochs sowie Schūtz' Brief an Kant rom 10. Juli 1784 za vergleichen. 
sache hervor, daß letzteres Werk nirgends eine $\mathrm{z}$ weite Kritik als daneben noch erforderlich ins Auge faßt, vielmehr mit der, wenn auch bloß theoretischen, Sicherung der Freiheitsidee die praktische Vernunft (Moral) mit begründet za haben meint. ${ }^{1)}$ Kerngedanken der beiden ethischen Hauptschriften (der Grundlegung von 1785 und Kritik der praktischen Vermunft von 1788) kommen denn auch bereits in der 1. Auflage der Eritik der reinen Vernunft (1781) vor, so: die Charakteristik des Sollens im Gegensatz zum Sein, die eben erwähnte Begründung der sittlichen Grundsätze auf die Freiheitsidee, die Postulate, die Unterscheidung des spekulativen and praktischen Vernunftgebrauchs. ${ }^{2}$ ) Am deutlichsten aber spricht sich die Architektonik d. r. V. (1. Auflage S. 840 f. und 850 f., 2. Auflage S. $868 \mathrm{f}$. und 878) über die uns hier interessierende Frage aus. Obwohl dort in der bestimmtesten Weise Gesetzgebung der Natur und der Freiheit, Metaphysik der Natur und der Sitten unterschieden werden, ist doch an keiner Stelle von einer noch kommen sollenden zweiten Kritik die Rede.

Als nun aber Kant nach Vollendung seiner ersten Kritik an die von Freund und Gegner erwartete „Metaphysik der Sitten" heranging, genügte ihm die immerhin doch nur gelegentliche, unter sich nicht straiff zusammenhängende Vorbereitung, die das theoretische Hauptwerk gegeben, nicht mehr. Es erschien, nach verschiedenen von uns a. a. 0 . dargestellten Wandlungen, die Grundlegung zur Metaphysik der Sitten (1785). - War nun aber nicht mit dieser der verlangten Forderung Genüge geleistet? Bot sie nicht die „metaphysischen Anfangsgründe der praktischen Weltweisheit", die Kant schon zwei Jahrzehnte zuvor hatte schreiben wollen? ${ }^{3}$ ) In der Tat scheint dies seine Meinung zur

1) Vgl. hierzu die äberzeugenden Einzelausführungen Natorps a. a. O. S. $489 \mathrm{ff}$. (2. Aufl.).

2) Vgl. über diese und andere Pankte das ausfübrliche Sachregister meiner Ausgabe der Kritik der reinen Vernunft (Hendel) S. 770-839.

8) Denn, daß er sie bereits vollendet and dann nur die Veroffentlichang unterlassen habe, wie ich in meiner Ein- 
Zeit, als er die Grundlegung herausgab, gewesen zu sein. Denn er erklärt ausdrücklich in deren Vorrede (in unserer Ausgabe S. 8), eine Kritik der praktischen Vernunft sei nicht so notwendig, weil „,die menschliche Vernunft im Moralischen selbst beim gemeinsten Verstand leicht zu großer Richtigkeit und Ausführlichkeit gebracht werden" könne; außerdem gehöre zu einer solchen die Darlegung der Einheit der praktischen und spekulativen Vernunft ,in einem gemeinschaftlichen Prinzip“, „weil es doch am Ende nur eine und dieselbe Vernunft sein kann, die bloß in der Anwendung unterschieden sein muß"; eine solche Darlegung aber lasse sich nicht geben, ,ohne Betrachtungen von ganz anderer Art herbeizuziehen und den Leser zu verwirren". tberdies glaubt er die, ,zu seiner Absicht hinlänglichen Hauptzüge" (S. 73) einer solchen Kritik in dem dritten Abschnitt seiner Schrift geliefert zu haben, der ja auch die Oberschrift „,bbergang von der Metaphysik der Sitten zur Kritik der reinen praletischen Vernunft" trägt. Jedenfalls erscheint ein besonderes Werk dieses Titels nicht geplant, dagegen wird mit voller Bestimmtheit (S. 8, vgl. 45 Anm.) eine Metaphysik der Sitten angekündigt, zu der eben die Grund. legung die Vorläúferin sein will.

Dieser Sachverhalt wird auch durch den Briefwechsel des Philosophen in der nächstfolgenden Zeit bestätigt. So schreibt er am 13. September 1785 an Schütz: "Jetzt gehe ich ungesäumt zur völligen Ausarbeitung der Metaphysik der Sitten." Und am 7. April 1786 an Bering: er werde die Bearbeitung der theoretischen Metaphysik noch mindestens zwei Jahre aufschieben, „um für das System der praktischen Weltweisheit Zeit zu gewinnen, welches mit dem ersteren vergeschwistert ist und einer ähnlichen $\mathrm{Be}$ arbeitung bedarf, wiewohl die Schwierigkeit bei demselben nicht so groß ist". Und noch am 14. Mai 1787 kann Jenisch an Kant schreiben: „Alles sieht nur mit Sehnsucht Ihrer Metaphysik der Sitten ent-

leitung zu der Grundlegung S. $\nabla I I$ annahm, geht - genan genommen - aus der dort zitierten Briefstelle nicht hervor, sondern bloß, daß ihr "Stoff fertig vor ihm lag". 
gegen“; wie auch Bering in Marburg zu seinem Be dauern im Leipziger Meßkatalog das längst gewünschto „System der reinen spekulativen und der praktischen Philosophie" aus der Feder Kants nicht gefunden hat (Bering an Kant, 28. Mai 1787). ${ }^{1}$ )

Freilich könnte die „ähnliche Bearbeitung“, von der Kant in dem Briefe an Bering spricht - vorher ist von der 2 weition Auflage der Kritik der reinen Vernunft im Vergleich mit der ersten die Rede gewesen auch auf eine Schrift von der Art unserer jetzigen Kritik der praktischen Vernunft gehen, zumal, da auch hier wieder, wie im gleichen Falle in der Grundlegung (s. oben), die geringere Schwierigkeit hervorgehoben wird. Noch einen anderen Plan muß Kant im Herbst 1786 gehabt haben: nämlich die Hineinarbeitung der Kritik der praktischen Vernunft in die damals in der Ausarbeitung begriffene zweite Auflag $\theta$ der Kritik der reinen Vernunft. Am 21. November 1786 erschien in der Jenaer Allgemeinen Literaturzeitung (Nr. 276) eine Ankündigung dieser zweiten Auflage, in deren Verlauf es hieß: „.... auch wird zu der in der ersten Auflage enthaltenen Kritik der reinen spekulativen Vernunft in der zweiten noch eine Kritik der reinen praktischen Vernunft hinzukommen, die dann ebenso das Prinzip der Sittlichkeit wider die gemachten oder noch zu machenden Einwürfe zu sichern und das Ganze der kritischen Untersuchungen, die vor dem System der Philosophie der reinen Vernunft vorhergehen müssen, zu vollenden, dienen kann." Diese Ankündigung aber war von Kant selbst veranlaßt worden; Schütz, der Herausgeber der Literaturzeitung, entschuldigt sich bei ihm in einem Brief vom 3. November 1786, daß er im Drange der Geschäfte ,diese mir selbst wie vielen höchst interessante Neuigkeit anzuzeigen unterlassen; nun habe ich aber die Notiz sogleich in die Druckerei geschickt," - "die Notiz, “ vermutlich also eine von Kant selbst abgefaßte oder doch nahe ge-

1) Vgl. anch den Brief Ewerbecks vom 3. April 1787: "O wie begierig erwarte ich den ausgeführten praktischen Teil Ihrer Philosophie". 
legte. Nun könnte man allerdings - so auffallend̉ klingt diese Nachricht - als möglich annehmen, da Schütz die Meinung Kants mißverstanden habe, und diese Annahme ist von B. Erdmann, der in der Akademie-Ausgabe ${ }^{1}$ ) jene Ankündigung zum ersten Male wieder abgedruckt hat, in der Tat gemacht worden. Allein nicht nur hätte dann Kant wohl protestiert, sondern unsere Nachricht wird vollauf bestätigt durch die von Erdmann wie auch von Natorp übersehene Tatsache, daß Professor Born in Leipzig zu gleicher Zeit dieselbe Nachricht von Kant empfing. Denn auf des letzteren Brief vom 24. September d. J. erwidert Born $a m$ 8. November: „Ubrigens freue ich mich ungemein schon im voraus über den wichtigen $\mathrm{Zu}$ satz einer Kritik der reinen praktischen Vernunft, womit Sie Ihr treffliches Werk noch mehr verschönern werden." Unmöglich wäre es sogar nicht, daß Kant jene Ankündigung schon am 26. Mai an Schütz gesandt hätte; denn an diesem Tage hatte er an Schütz wio an Born geschrieben (vgl. Akad.Ausgabe $X, S$. 445-448). Auf sie bezieht sich offenbar auch die Äußerung Hamanns in einem Briefe an Jacobi vom 30. Januar 1787: „Aus der Zeitung habe ich ersehen, daß selbige" - sc. die zweite Auflage

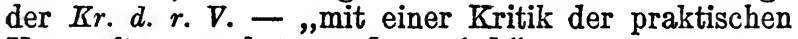
Vernunft vermehrt werden wird."

Wie dem nun auch sein mag, so muß Kant seine Absicht einer Vereinigung beider „Kritiken“ in einem und demselben Werk schon zwei Monate nach jener Ankündigung wieder aufgegeben haben. Vielleicht zu Anfang Januar 1787, wo er Hamann bei dessen Besuche klagte, daß ihm die neue Ausgabe der Kritik "schwer falle"; während er sich kurz darauf entschloß: „Die Woche darauf ist die Handschrift abgegangen" (Hamann an Jacobi, 30. Januar 1787). Jedenfalls erschien die zweite Auflage im Frühjahr 1787 - die neue Vorrede ist ,im Aprilmonat 1787“ datiert - ohne den angekündigten Zusatz. Anderseits war die Kritik der praktischen Vernunft bereits Ende Juni desselben Jahres beinahe druckfertig; Kant

1) Bd. III, S. 556; vgl. ebend. S. 557. 
schreibt am 25. Juni an Schütz: „Ich habe meine Kritik der praktischen Vernunft so weit fertig, daß ich sie denke künftige Woche nach Halle zum Druck zu geben."

Die nunmehr folgenden Worte dieses Briefes machen auch ersichtlich, welche Erwägungen den Verfasser in zweiter Linie zur Veröffentlichung seiner Schrift bestimmt haben. Er fährt fort: „Diese wird besser als alle Kontroversen mit Feder und Abel (deren der erste gar keine Erkenntnis a priori, der andere eine, die zwischen der empirischen und einer a priori das Mittel halten soll, behauptet), die Ergänzung dessen, was ich der spekulativen Vernunft absprach, durch reine praktische und die Möglichkeit derselben beweisen und faßlich machen, welches doch der eigentliche Stein des Anstoßes ist, der jene Männer nötigt, lieber die untunlichsten, ja gar ungereimte Wege einzuschlägen, um das spekulative Vermögen bis aufs Ubersinnliche ausdehnen zu können, ehe sie sich jener ihnen ganz trostlos scheinenden Sentenz der Kritik unterwürfen." Neben dem selbstverständlich in erster Reihe stehenden systematischen Motiv (auf das wir noch in dem zweiten Teile unserer Einleitung zurückzukommen haben werden), waren es also auch polemische Rücksichten, welche Kant zur baldigen Abfassung und Herausgabe der ruen Schrift bewogen.

Das wird auch durch weitere Selbstzeugnisse des Philosophen bestätigt. So schreibt er unmittelbar nach dem Erscheinen des Buches, am 28. Dezember 1787, an Reinhold: ,In diesem Büchlein werden viele Widersprüche, welche die Anhänger am Alten in meiner Kritik zu finden vermeinen, hinreichend gehoben; dagegen diejenigen, darin sie sich selbst unvermeidlich verwickeln, wenn sie ihr altes Flickwerk nicht aufgeben wollen, klar genug vor Augen gestellt." Schon vorher - nach Reicke wahrscheinlich am 11. September d. J. - hatte er sich gegen L. H. Jakob in Halle ähnlich über das noch im Druck befindliche Werk geäußert: es enthalte ,manches, welches die Mißverständnisse der (sc. Kritik) der theoretischen (sc. Vernunft) heben kann." Desgleichen spielt das 
fertige Buch selber an verschiedenen Stellen auf solche polemischen Beweggründe an: so namentlich S. $7 f$. ("Hierdurch verstehe ich bis helles Licht setzen"), S. 9 Anmerkung, S. $10 \mathrm{f}$. (von dem ,wahrheitliebenden Rezensenten "), S. 11 (,manche andere Einwürfe"), S. 12 (Mitte) der Vorrede und S. 183 (gegen Wizenmann). 1) Es erscheint daher am Platze, dem Leser wenigstens eine kurze Ubersicht derjenigen Gegenschriften bezw. gegnerischen Rezensionen zu geben, die von Kant in seiner Schrift mit Sicherheit berücksichtigt worden sind:

1) Die erste "Autorangelegenheit“, die unserem Philosophen, nach Hamanns Brief an Jacobi vom 13. Mai 1786, „im Kopfe herumging,“ war die Rezension der Grundlegung in den Tübinger gelehrten An. zeigen, 14. Stück vom 16. Februar 1786, S. $105 \mathrm{ff}$. Sie rührte von dem ständigen philosophischen Rezensenten dieser Zeitschrift, dem Tübinger Professor J. Fr. Flatt, her, der in ihr wie in seinen zahlreichen sonstigen Besprechungen kantfreundlicher und -feindlicher Schriften dem kritischen Philosophen besonders „Inkonsequenz" vorzuwerfen pflegte. Auf ihn gehen also wohl Stellen wie die Anmerkung zu S. 4 sowie der längere Absatz auf S. 6; vergleiche auch unser Sachregister unter konsequent.

2) Noch stärker berücksichtigt erscheint die schon in unserer Einleitung zur Grundlegung (S. XVIf.) erwähnte "Widerlegung" des Kirchenrats Gottlob August Tittel zu Karlsruhe in seiner Schrift: Uber Herrn Kants Moralreform. Frankfurt u. Leipzig 1786. Dieser Kommentator des bekannten Göttinger Kantgegners Feder tadelte an Kant den ,gar zu häufigen Gebrauch abstrakter Terminologien" (S. 4) und warf ihm immer wieder vor, daß er "längst bekannte Dinge in einer unvernehmlichen Sprache als neu verkündige" (S. 25); wogegen Kant sich S. $12^{28}$ fr. verwahrt. Auch erhob er gegen ihn den Vorwurf der "Mystik" und pries das von Kant so energisch auch in der neuen Schrift bekämpfte ,unschuldige und liebenswürdige System, das Glückseligkeit und Sittlichkeit

1) Die Seitenzahlon nach unserer Ausgabe. 
aufs innigste zusammen verknüpft" (S. 5). Namentlich aber ist die methodisch besonders wichtige Anmerkung Kants 'auf S. 9 durch Tittel veranlaßt worden. Der "Rezensent", der ,es besser getroffen, als er wohl selbst gemeint haben mag", war eben der badische Kirchenrat, der auf $\mathbf{S}$. 35 seiner Schrift gemeint hatte: „Soll denn die ganze Kantische Moralreform etwa nur auf eine neue Formel sich beschränken?“, vgl. S. 55: „Herr Kant, nachdem er auf diese Art sein vermeintes neues Prinzip der Sittenlehre ausgeführt und befestigt zu haben glaubt...“

3) Auf Tittels Meister, Feder selbst, nämlich gegen eine Stelle von dessen berüchtigter Umarbeitung der Garveschen Rezension der Rritik der reinen Vernunft, ${ }^{1}$ ) geht die Anmerkung zu S. 16. Er wie sein Kollege Meiners hatten sich verschiedentlich über die „neue Terminologie" abfällig geäußert. Gegen Feder und seine „unerwartete Entdeckung“, daß es überhaupt keine Erkenntnis a priori gebe - vgl. den obigen Brief Kants an Bering -, richtet sich ferner S. $14^{8} \mathrm{ff}$. Da Feders Schrift Ober Raum und Causalität, zur Prüfung der Kantischen Philosophie. Göttingen 1787, in der sich (bes. S. $35 \mathrm{ff}$.) solche Ausführungen finden, Frühjahr 1787 erschien, wird sie Kant bei der Abfassung seiner Vorrede höchstwahrscheinlich schon vorgelegen haben. ${ }^{2}$ )

4) Mit weit größerer Achtung als die vorigen behandelt Kant S. $10^{17}$ ff. den ,wahrheitliebenden und scharfen, dabei also doch immer achtungswürdigen Rezensenten" der Grundlegung, der ihm den Einwurf gemacht, er hätte den Begriff des Guten vor dem moralischen Prinzip festsetzen sollen. Es war der (anonyme) Verfasser einer Besprechung in Nicolais Allgemeiner Deutscher Bibliothek Bd. 66 S. 447-463, wie sich später herausstellte ${ }^{3}$, der Propst Pistorius auf

1) Vgl. über diese meine Einleitang za den Prolegomena (Ph. B. 40), S. IXff., S. $175 f f$.

3) Auch Bering (in Marbarg) kennt sie bereits am 28. Mai d. J., an dem er Kant schreibt.

8) Vgl. den Brief von D. Jenisch an Kant vom 14. Mai 1787. Pistorins hatte anch eine eingehende Rezension der 
Fehmarn; der außerdem auch, und zwar noch ausführlicher, ebd. S. $92 \mathrm{ff}$. in einer Rezension von Schultz' Erläuterungen Kants Anwendung der Kategorien auf die Noumena und seine Lehre von den Phänomenen und Noumenen überhaupt eingehend kritisiert, übrigens auch seinerseits den „ebenso wahrheitliebenden als tiefdenkenden Weltweisen" mit großer Achtung behandelt hatte. Auf ihn bezieht sich daher wohl ziemlich sicher die Selbstverteidigung Kants gegen di „,

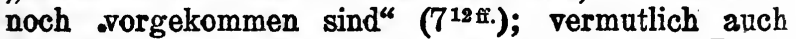
der an verschiedenen Stellen von unserem. Philosophen betonte Satz, daß sein Sittlichkeitsprinzip selbst der gemeinsten Menschenvernunft (vgl. diesen Artikel in unserem Sachregister) mit Leichtigkeit klarzumachen sei: was von Pistorius lebhaft bestritten worden war. - Letzterer erwiderte seinerseits auf die Bemerkung Kants in seiner Rezension der Kritik der praktischen Vernunft in der A. D. B. (Bd. 117, S. 78ff.).

5) Der einzige Kritiker, den Kant mit Namen nennt, ist der früh verstorbene Thomas Wizenmann. An der betreffenden Stelle (S. 183a)) habe ich in bezug auf seine Person auf dasjenige verwiesen, was ich bereits in meiner Einleitung zu Kants Abhandlung: Was heißt sich im Denken orientieren? ausgeführt habe. Die Berücksichtigung desselben ist wohl ebenso, wie die Erwähnung Mendelssohns (S. 130) und die Warnung vor dem Spinozismus (S. 131), als ein Nachhall des damals die philosophische Welt Deutschlands in zwei Heerlager spaltenden Streites zwischen Mendelssohn und Jacobi über Lessings Spinozismus ${ }^{1}$ ) zu betrachten. :

Zu den angeführten kamen noch weitere Gegenschriften von Abel, Selle, Ulrich u. an, die wir aber, da sio in der Kritik der praktischen Vernunft nicht berücksichtigt erscheinen, übergehen können. (Ihre Titel

Prolegomena geliefert; er soll für Nicolais A. D. B. im Laufe von 33 Jahren nicht weniger als 1000 Rezensionen geschrieben haben (B. Erdmann, Kants Kritizismus usw. S. 106).

1) Vgl. meine Skizzierung desselben in Ph. Bibl. Bd. $46^{b}$, S. $X \bar{X} \nabla I I f f$. 
8. in Natorps Sachlichen Erläuterungen in seiner Ausgabe S. 507f.)

Gegenüber diesen zahlreichen Kritikern scheint Kant anfangs eine rein polemisch gehaltene Gegenschrift beabsichtigt zu haben. Allein verschiedene seiner Anhänger und Freunde, wie Biester und Schütz, rieten ihm - wir werden heute sagen, mit Recht davon ab, seine kostbare Zeit mit derlei polemischem Kleinkram zu vergeuden. Dazu kam, daß ihm wenigstens im Sommerhalbjahr 1786 ein „,auf ihn gefallenes . a akademisches weitlänfigtes Geschäft", nämlich das Rektorat der Universität Königsberg, ,beinahe alle Zeit dazu raubte," sodaß er ,bis dahin schon alle schiefe, mitunter auch wohl hämische Urteile hingehen lassen" mußto (an Jakob, 26. Mai 1786). So ließ er es denn bei seinem im Oktober 1786 veröffentlichten Aufsatz über das Orientieren (s. oben) bewenden und beschäftigte sich statt dessen zunächst mit der Fertigstellung der zweiten Auflage der Kritite der reinen und nach deren Vollendung mit der Kritik der praktischen Vernunft. Wie er gegen Schluß seiner Vorrede zu der ersteren (S. XLIIIf. des Originals) schreibt, wollte er fortan mit seiner Zeit „sparsam verfahren" und die Verteidigung seines Systems wie die Aufhellung einzelner Dunkelheiten anderen „,verdienten Männern" überlassen. Seinerseits könne er sich ,auf Streitigkeiten von nun an nicht einlassen, ob ich zwar auf alle Winke, es sei von Freunden oder Gegnern, sorgfältig achten werde“. Er wollte statt dessen lieber seinen Plan ausführen, „die Metaphysik der Natur sowohl als der Sitten als Bestätigung der Richtigkeit der Kritik der spekulativen sowohl als praktischen Vernunft zu liefern“. Spätestens im März 17871) hatto er sich endgültig entschlossen, eine systematische Schrift abzufassen, in der er jedoch die wichtigsten der erhobenen Einwände polemisch berücksichtigen wollte. Jedenfalls haben die letzteren -

1) Vgl. Schütz' Brief an Kant vom 23. März 1787: "Vortrefflich ist es, daß Sie sich gar nicht selbst mit Widerlegungen anfhalten, sondern ruhig Thren Gang fortsetzen wollen". 
das hat Natorp durch die einfache Zusammenstellung der Tatsachen gezeigt - in höherem Grade, als man bisher annahm, den Entschluß zur baldigen Herausgabe seines Werkes in Kant zur Reife gebracht; denn nach seiner Meinung konnte ,nur eine ausführliche Kritik der praktischen Vernunft alle diese Mißdeutung heben und die konsequente Denkungsart, welche eben ihren größten Vorzug ausmacht, in ein helles Licht setzen" (Kr. d. pr. V., Vorrede S. 7f.).

Er hat deshalb auch den Text mit ungewöhnlicher Schnelligkeit ausgearbeitet. Nachdem eben erst (Juni 1787) die Neuauflage der Kritik der reinen Vernunft die Presse verlassen hatte, war am 25. Juni d. J., wie wir bereits sahen (S. XII oben), das neue Werk schon beinahe druckfertig. Doch zog sich der Druck wider Kants Wunsch und Erwarten in die Länge, weil der Drucker (Grunert in Halle) ,dieses Werk mit neuen und scharfen Lettern drucken" wollte, "welche der Schriftgießer noch nicht fertig hatte, sondern erst acht Tage nach' der Mich.-Messe lieferte" (Grunert an Kant, im Dezember 1787). Daher wurden erst um Weihnachten d. J. die Freiexemplare des Werks, über die er bereits am II. September Verfügung getroffen hatte, verschickt. ${ }^{1}$ )

2. Auch über die Wirkungen, welcho die zweite Vernunftkritik bei den Zeitgenossen hervorrief, sind wir heute durch' Kants Briefwechsel ziemlich gut unterrichtet. Am ersten und enthusiastischsten äußerto sich der bekannto Verkünder der Kantischen Phila sophio an der Universität Jena, Wielands Schwiegersohn Reinhold. „Was soll ich Ihnen ... über das unschätzbare Geschenk der Kritik der praktischen Vernunft, wovon ich heute das mir angewiesene Exemplar orhalten, die ich aber bereits vor acht Tagen verschlungen habe, sagen? Mein gegenwtrtiges Verstummen und mein ganzes künftiges Leben mag Ihnen danken. Wenn mir der Himmel einen Sohn schenkt.... so sollen Ihr Brief und jenes Exemplar die un291, 292.

1) Vgl. Kants Briefwechsel (Akademie-Ausgabe) Nr. 289, 
veräußerlichen Kleinodien sein, die ich ihm hinterlassen werde, und sie werden ihm als zuverlässige Dokumente von dem Werte seines Vaters heilig sein." Und weiter: „Wie lieb ist mir's nun, daß ich mich in meinen Briefen ïber die Kantische Philosophie bis jetzt noch nicht auf die eigentliche Erörterung des moralischen Erkenntnisgrundes der Grundwahrheiten der Religion eingelassen habe. Ich hätte da ein schwache Lämpchen aufgesteckt, wo Sie durch die Kr. d. pr. $\nabla$. eine Sonne hervorgerufen haben. Ich muß gestehen, daß mir ein solcher Grad von Evidenz, eine so ganz vollendete Befriedigung, als ich wirklich gefunden habe, unerwartet war." (Reinhold an Kant, 19. Januar 1788.) - Der greise Theologe Spalding in Berlin, den Kants Abweisung des Obersinnlichen aus der Sphäre der spekulativen Vernunft beunruhigt hatte, fühlte sich jetzt getröstet und in seiner Abneigung gegen den Eudämonismus bestärkt. Er dankte Kant dafür, daß er ,die Tugend in ihrer wahren; nackten und desto ehrfurchtwürdigeren Schönheit, als Recht und Gesetzmäßigkeit, auf den ihr gebührenden höchsten Thron festgesetzt und jeden noch so liebkosenden Usurpator davon verdrängt" habe (Spalding an Kant, 8. Februar 1788). - Auch Biester, der Herausgeber der Berlinischen Monatsschrift, dankte ,auf das verbindlichste“ für das "herrliche Geschenk Ihrer trefflichen, geiststärkenden und herzerhebenden Kritik der praktischen Vernunft" und versprach das zweite Exemplar (nach Kants Anweisung) Herrn von Zedlitz (dem bekannten freisinnigen Unterrichtsminister Friedrichs des Großen, dem Kant die erste Auflage seiner Kritik der reinen Vernunft gewidmet), sobald derselbe von seiner Reise zurück sei, zu übergeben (Biester an Kant, 10. Juni 1788). - Schütz, bis dahin durch Krankheit abgehalten, faßt in einem Briefe vom 23. Juni 1788 seine Empfindungen in die ,kurze Erklärung“ zusammen, „daß mich die Lektüre Ihrer Kritik der praktischen Vernunft wahrhaftig beseligt hat, und daß die Freude darüber noch durch den Gedanken erhöhet wird, daß eine große Anzahl trefflicher Männer, mit denen ich mich keineswegs messe, hierin mit mir völlig gleich empfinden." Er sendet ihm zugleich eine 
für die Allgemeine Literaturzeitung bestimmte Rezension "Ihres neusten erhabenen Werkes" von Rehberg (in Hannover) vor ihrer Drucklegung in Abschrift zu, damit-Kant seine Bemerkungen dazu mache oder ihm für die A. $L$. $Z$. einen Aufsatz sende, ,worin die vornehmsten Mißverständnisse, die von scharfsinnigen Rezensenten begangen werden, aufgeklärt würden". Ein solcher Aufsatz werde in der A. L.Z. die größtmöglich $\theta$ „Publizität" erlangen, diese besitze jetzt 40000 (!) Leser, denn - an einem der ,, wirklich dato debitierten" 2000 Exemplare läsen „oft nicht etwa 10 oder 20, sondern 30, 40, 50 Personen"! Außerdem enthält der Brief einen ausführlich begründeten Einwand gegen die vierte Rubrik der "Tafel der Kategorien der Freiheit" (in unserer Ausgabe S. 86). Eine Erwiderung Kants ist nieht erhalten, auch in dor zweiten Auflage an der betreffenden Stelle nichts geändert worden. - Auch auf eine Anfrage des Magisters Schmid in Jena, der 1786 ein Kantwörterbuch veröffentlicht hatte, betreffend die verschiedenen Arten von Pflicht und Verdienst (21. Februar 1789), ist eine Antwort des Philosophéen nicht erhalten. - Wohl dagegen wenigstens das Bruchstück einer solchen, auf ein Schreiben Jung-Stillings aus Marburg, der anfangs durch ,das Geschwätz Ihrer Gegner" über die Dunkelheit und Religionslosigkeit Kants sich von der Lektüre der Kantischen Schriften hatte abschrecken lassen, dann aber ",bei mehrmaliger Wiederholung" alles verstand und begriff, nun ,apodiktische Wahrheit und Gewißheit allenthalben" fand und in die Worte ausbricht: "Gott segne Sie! - Sie sind ein großes, sehr großes Werkzeug in der Hand Gottes; ich schmeichle nicht - Ihre Philosophie wird eine weit größere, gesegnetere und allgemeinere Revolution bewürken als Luthers Reformation. Denn sobald man die Kritik der Vernunft wohl gefaßt hat, so sieht man, daß keine Widerlegung möglich ist; folglich muB Ihre Philosophie ewig und unveränderlich sein, und Ihro wohltätigen Würkungen werden die Religion Jesu auf ihre ursprüngliche Reinigkeit, wo sie bloß Heiligkeit zum Zweck hat, führen; alle Wissenschaften werden systematischer, reiner und gewisser 
werden, und die Gesetzgebung besonders wird außerordentlich gewinnen." (Jung-Stilling an Kant, 1. März 1789.) Von Interesse für Kants Stellung zum Christentum ist eine Stelle seiner im Bruchstück erhaltenen Erwiderung: „Sie tun auch daran sehr wohl, daß Sie dio letzte Befriedigung Ihres nach einem sicheren Grund der Lehre und der Hoffnung strebenden Gemüts im Evangelium suchen, diesem unvergänglichén Leitfaden wahrer Weisheit, mit welchem nicht allein eine ihre Spekulation vollendende Vernunft zusammentrifft, sondern daher sio auch ein neues Licht in Ansehung dessen bekömmt, was, wenn sie gleich ihr ganzes Feld durchmessen hat, ihr noch immer dunkel bleibt, und wovon sie doch Belehrung bedarf." Der Rest, nur im Entwurf auf uns gekommen, gibt auf Jung-Stillings Anregung eine Anwendung der Kategorien auf die obersten rechtsphilosophischen Grundsätzo (Kants Briefwechsel XI, S. 10).

Der Prorektor des Breslauer Elisabeth-Gymnasiums, J. G. Schummel, preist den Mann, ,der schon so lange der Gegenstand des denkenden Deutschlands ist, der die ganze philosophische Welt in zwei Parteien teilt", als ihm ,wie vom Himmel gekommen", indem er die "morschen Säulen" des Wolfschen Systems auch für ihn zerstört habe. „Es wird, es muß eine Zeit kommen, da Ihre Philosophie populär wird: jetzt freilich noch nicht, da die Tittels und selbst die Göttinger Rezensenten Sie so unglaublich mißverstehen können". (Schummel an Kant, 28. März 1789.) In der Zueignung einer Schrift nennt L. Th. Kosegarten Kant u. a. den Mann, der ,mein moralisches Selbst mich recht würdigen und dem Idol des wahrhaftig aufgeklärten und rechtschaffenen Menschen, Pflicht genannt, mich einzig huldigen lehrte... Der in seinen Untersuchungen unseres praktischen Vernunftvermögens ebenso liebenswürdig, oinfältig und menschlich-schön erscheint, als or in der Analyse aller Spekulation anfangs furchtbar, abschreckend und grausam erscheinen mag". In einer Anmerkung dazu meint er, jetat worde auch' Herder seine ganz unnötigen Ereiferungen wider die Kantsche Philosophie in den Dialogen über Gott bereuen. 
„Unmöglich scheint es mir, jene letzte Kantische Schrift (sc. die Kr. d. pr. V.), wenigstens eine Menge Stellen darinnen, zu lesen, ohne ihrem ebenso gefühlvollen als tiefdenkenden Verfasser um den Hals zu fallen und alles Ereifern, Erhitzen, Poltern und Persiflieren, die Waffen der Leidenschaft und nicht der Ubberzeugung, wider ihn auf ewig zu verschwören" (datiert vom 4. Juni 1789, im Nachtrag zu Kants Briefwechsel XII S. 370). - Für J. S. Beck war ,die Kritik der praktischen Vernunft seit ihrer Erscheinung seine Bibel" (Beck an Kant, 6. Oktober 1791).

Magister J. H. Abicht in Erlangen dagegen, in seinem weitläufigen Briefergusse vom 22. April 1789, kämpft noch mit gewissen Bedenken: „Ich zweifelte mit anderen, ob Sie in der Kritik der praktischen Vernunft, da Sie die Triebfedern des Vergnügens von der Ehre der Priorität lossagten, jenem Grundsatz" - sc. der "Stimme der Natur, die in einem jeden widerhallt" - "Genüge getan hätten“, und spricht von dem „Eindruck, den diese Kritik nich't gemacht", obwohl er ,auf dio Sensationen und Urteile, die sie im Publiko hervorbringen würde, mit dem leisesten Ohre lauschte“. „Vieles konnte ich nicht genug reimen, und nähere Aufschlüsse suchte ich vergebens." Dennoch will er dem Siege der Philosophie desjenigen, dem er ,so manche selige Augenblicke $\mathrm{zu}$ verdanken hat", alle seine Kräfte weihen (Abicht an Kant, 22. April 1789). - Dagegen haben den Berliner Kammergerichtsrat Klein gerade Kants ,moralisch $\theta$ Grundsätze “ $\mathrm{zu}$ seinem Anhänger gemacht. Er hat sie angenommen, noch ehe er mit der Kritik der reinen Vernunft bekannt geworden ist, und war schon von sich aus früh ,auf den Gedanken gekommen, daß die Moral von der Theologie nicht abhängig sein könne", hatte demgemä $\beta$ auch bei der Erziehung seiner Kinder gehandelt (an Kant, 23. April 1789). Da die Richtigkeit von Kants Moralsystem ,gleich bei dem ersten ersten Anblick so in die Augen springt, weil es den moralischen Gefühlen und der biblischen Sittenlehre so angemessen ist", kann er sich in einem späteren Brief „nicht genug wundern", daß es den allgemeinen Beifall, den man erwarten sollte, noch 
nioht erhalten hat." (Klein an Kant, 15. Juni 1789, die Korrespondenz beider dreht sich im übrigen hauptsächlich um rechts- und staatsphilosophische Probleme, vgl. den Brief Kleins vom 22. Dezember 1789.)

Gleichwohl scheint die Kritik der praktischen Ver. nunft inzwischen doch ,zunehmende Verbreitung gefunden zu haben, denn der jtingere Hartknoch wünscht im August d. J. eine zweite Auflage, und zwar in der Höhe von 2000 Exemplaren, zu veranstalten (J. Fr. Hartknoch an Kant, 26. August 1789). Wenige Wochen darauf meldet er, daß der Drucker ,die Exemplare der beiden Kritiken" - zugleich sollte die 3. Auflage der Kritik der reinen Vernunft hergestellt werden - ,schon bekommen“ habe; ,der Druck kann also bald vorgenommen werden und wird zur künftigen Ostermesse gewiß fertig sein" (an Kant, 29. September „alten Stils“ 1789). In Wirklichkeit erschien jedoch nur die Neuauflage der theoretischen Vernunftkritik zu dem angektindigten Termin, die zweite Auflage unserer Schrift dagegen trägt die Jahreszahl $1792^{1}$ ).

Mit Schwierigkeiten hatte die Verbreitung von Kants Morallehre unter dem Wöllnerschen Regime allgemach immer mehr zu kämpfen. Schon am 15. Dezember 1789 berichtet Kiesewetter aus Berlin, daß in die erste seiner von etwa 25 Zuhörern, besonders aus dem Kaufmannsstande, besuchten Vorlesungen iber die Kritik der praktischen Vernunft sich oin fremder junger Mensch eingeschlichen habe, der "wörtlich meinen ganzen Vortrag nachschrieb und durch seine emsige Angstlichkeit die Aufmerksamkeit aller auf sich zog". Der vorher gewarnte Vortragende besaß deshalb auch die Vorsicht, gerade in dieser ersten Vorlesung von vornherein die Obereinstimmung des Kantischen Sittengesetzes mit den Lehren des Christentums zu betonen; soda.ß denn auch jener Spitzel

1) Vielloicht warde die Verspätang mit veranlaßt durch die Spannung, die zwischen Kant and dem jungen Hartknoch eintrat, weil der erstere zu anderen Verlegern übergegangen war (vgl. Hartknoohs Brief an Kant vom 20. Oktober 1790 ). 
nicht wieder kam (Kiesewetter an Kant, 15. Dezember 1789, vgl. auch den Brief vom 19. November d. J.). Auch J. Fr. Zöllner in Berlin meinte, es werde „freilich noch eine gute Zeit dauern, ehe der von Ihnen ausgestreute Same für das Volk Früchte bringt". Aber „unausbleiblich muß durch Ihr System nicht bloß in den Studierstuben, sondern auch eine allmählich in das große Publikum fortrückende Revolution bewirkt werden, deren unsere Enkel sich gewiß mit herzlich'em Dank gegen den Urheber derselben freuen werden". - Anderswo freilich kam Kants Moral sogar auf die Kanzel, so - allerdings außerhalb Freußens - in Eutin durch Voß' Schwager Boje in einer Predigt über den Spruch Apostelgeschichte 10, 34 f.: „Nun erfahre ich mit der Wahrheit, daß Gott die Yerson nicht ansieht, sondern in allerlei Volk, wer ihn fürchtet und recht tut, der ist ihm angenehm" (Hellwag an Kant, 13. Dezember 1790); worauf Kant seine Freude ausdrückte und meinte: „Eine solche Methode zu predigen wird aber nicht eher allgemein werden, als bis die Rechtschaffenheit der Gesinnungen bei Lehrern (die nicht damit zufrieden ist, daß gute Handlungen, gleich gut aus welchen Gründen, ausgeübt werden: sondern auf die Reinigkeit des $\mathrm{Be}$ wegungsgrundes alles anlegt) gleichfalls allgemein wird." (Kant an Hellwag, 3. Januar 1791.)1). - Von Kiel schreibt der mittlerweile dorthin gegangene Reinhold, 29. März 1795, daß ,auch hier das Evangelium der praktischen Vernunft nicht weniger als in Jena Eingang gefunden hat".

Am 21. Januar 1797 teilte der Verleger (J. Fr. Hartknoch in Riga) Kant mit, daß der Vorrat der Grundlegung und der Kritik der praktischen Vernunft vergriffen sei, und fragte an, ob die beiden Schriften unverändert wieder abgedruckt werden sollten oder nicht. Im ersteren Fall möchte or sie gern noch

1) Vgl. anch den Brief einer Landpredigers Koebler aus der Gegend von Crossen, der Kant um Bolehrung ther den Begriff der moralischen Notwendigkeit bittet (Briefwechsel XI, S. 235-237), sowio den Brief soines Schulert Jachmann aus Marienburg, vom 30. Mai 1796. 
bis zur Ostermesse d. J. fertigstellen. Der Philosoph antwortete auf Hartknochs Wunsch umgehend, am 28. Januar, und erbat sich zunächst eine Bedenkzeit von 14 Tagen, um eventuell - während der Druck der Arundlegung schon beginnen könne - zu überlegen, „ob er nicht einige Veränderungen in der Vorrede anzubringen gut fänd $\theta^{*}$. Dann aber besinnt er sich rasch eines anderen und fährt fort: „Da indessen diese auch nicht von sonderlicher Wichtigkeit sein könnten, meine jetzige Unpäßlichkeit mir auch alle Kopfarbeit sehr erschwert, so kann es auch beim Alten bleiben." (Briefwechsel XII, S. 145f.) Die so Ostern 1797 erschienene Auflage ist als die viertie bezeichnet. Von einer dritten hat sich bisher keine Spur gefunden. Viel für sich hat die Vermutung Natorps (a. a. O. S. 498), daß Hartknoch diese eigentlich dritte Auflage deshalb als vierte hat bezeichnen lassen, weil die zweite, statt wie sonst in 1000, in der Stärke von 2000 Exemplaren gedruckt worden war. Eine fünfte Auflage erschien 1818, eine sechste 1827: beide fast genau gleichzeitig mit den beiden letzten (6. und 7.) Auflagen der Kritik der reinen Vernunft; außerdem ein Nachdruck (Grätz 1796), zwei zu Frankfurt und Leipzig (1791 und 1795).

\section{Gedankengang der Schrift.}

a) Die Vorrede (S. 3-17)

beginnt sogleich mit der Erörterung sehr schwieriger Probleme, zu deren Verständnis eine genaue Kenntnis der Kritik der reinen Vernunft erforderlich ist, wie des Unterschiedes von praktischer Vernunft überhaupt und reiner praktischer Vernunft, der Vereinbarkeit des transzendentalen Freiheitsbegriffs mit dem der Naturnotwendigkeit und seines Zusammenhanges mit den Ideen von Gott und Unsterblichkeit: Dinge, die von Kant bereits in seinen drei ersten kritischen Hauptschriften (Kr. d. r. V., Prolegomena, Grundlegung) wiederholt erörtert, trotzdem aber mannigfachen Mißverständnissen ausgesetzt gewesen waren. Manches wird nur verständlich, wenn man die in unserer Entstehungs- 
geschichte kurz berührten „erheblichsten Einwürfe“ (S. 7) dieser Gegner genauer kennt. Der Anfänger tat daher am besten, nachdem er sich zuvor mit der Grundlegung zur Metaphysik der Sitten (Bd. 41 der Phil. Bibl.) gehörig vertraut gemacht, entweder sofort mit der Einleitung unserer Schrift (S. 18) oder doch erst mit dem Absatz Seite 9 unserer Ausgabe: „Ob ein solches System usw." zu beginnen. Die Bekanntschaft mit der Grundlegung setzt der Philosoph selbst voraus, wenigstens ,insofern, als diese mit dem Prinzip der Pflicht vorläufige Bekanntschaft macht und eine bestimmte Formel derselben angibt und rechtfertigt" (S. 9). Mit den gegen diese seine erste ethische Schrift erhobenen Einwänden beschäftigen sich dann die nächsten Seiten. Von methodischer Wichtigkeit ist besonders die Anmerkung S. 9 von dem Werte der Formel, die den auch heute noch so oft angegriffenen "Formalismus" der kritischen Ethik mit bewußter Klarheit hervorhebt und rechtfertigt. Als Aufgabe einer Kritik der praktischen Vernunft wird, ganz analog dem Verhältnis bei der theoretischen Vernunftkritik, bezeichnet: vollständige Bestimmung der Prinzipien ihrer Möglichkeit, ihres Umfangs und ihrer Grenzen; während ihre Beziehung auf die tatsächliche Beschaffenheit des Menschen (z. B. Aufzählung und Einteilung der Pflichten) einem späteren Werke vorbehalten bleiben soll (10). Auf einen das Verhältnis zwischen dem Moralprinzip und dem Begriff des Guten betreffenden Einwand will Kant im zweiten Kapitel seiner Analytik (es geschieht denn auch'S. 76 ff. unserer Ausgabe) antworten, während eine ausführliche Anmerkung das Verhältnis des Begehrungsvermögens zum Gefühl der Lust erörtert und dabei interessante Definitionen beider Begriffe sowie desjenigen des Lebens gibt. Gegenüber den Anhängern der „alten Systeme“ trägt unser Philosoph hier bereits ein starkes Selbstgefühl zur Schau (11 f.); auch den Vorwurf einer unverständlichen „neuen Sprache“, den man übrigens seiner jetzigen populäreren Schrift kaum machen werde, weist er mit Stolz zurück. Möge man ihn doch nur popularisieren! Er wolle „nur verstanden sein“. Nur auf einige seines Erachtens eher mißzuverstehende Aus- 
drücke weist die längere Anmerkung S. $13 \mathrm{ff}$. hin: nämlich die Unterscheidung von Erlaubt und Unerlaubt, von Weisheit und Heiligkeit und besonders den Terminus des Postulats (die Stellen der Schrift, auf die sich diese Anmerkung bezieht, findet man in unserem Sachregister bei den betreffenden Wörtern). - Der letzte Abschnitt der Vorrede endlich (S. 14 bis 17) verteidigt die Möglichkeit und Notwendigkeit einer apriorischen, rationalen Erkenntnis überhaupt gegenüber einem alle objektive Gültigkeit unseres Erkennens anzweifelnden allgemeinen Empirismus oder Skeptizismus, von dem doch selbst Hume die Mathematik ausgenommen habe. Die

\section{b) Einleltung (S. 18-20)}

ist ganz kurz. Sie beschränkt sich auf eine Recht fertigung des Titels und der Einteilung des Werkes. Im Unterschiede von der theoretischen, braucht hier - worauf schon der erste Absatz der Vorrede hinwies - die reine Vernunft nicht kritisiert, sondern bloß ihre Existenz dargetan, gezeigt zu werden, daß nicht allein empirische Bedingungen den Willen bestimmen. Demgemäß muß auch die Einteilung einen etwas veränderten Gang nehmen. Wohl kann auch das jetzige Werk in eine Elementar und Methodenlehre und jene wieder in eine Analytik und Dialektik zerfallen. Aber umgekehrt wie dort beginnt die Kritik der praktischen Vernunft mit den Grundsätzen (S. 23-74), geht von da zu den Begriffen (sc. eines Gegenstandes d. r. pr. V., S. 75-92) und von diesen "allererst womöglich zu den Sinnen" (in diesem Falle den ,Triebfedern“, S. 93-115) über.

Bei dieser Gelegenheit sei bemerkt, daß die Anlage der Schrift keineswegs, wie H. St. Chamberlain es von jedem einzelnen Buche Kants behauptet, „außerordentlich einfach und übersichtlich" ist. Sie ist vielmehr wenig übersichtlich und noch weniger symmetrisch. Von den beiden Hauptteilen enthält der erste (die Elementarlehre) 168, der zweito (die Methodenlehre) nur 13 Seiten, d. h. noch nicht $1 / 15$ des ganzen Werkes, während sie in der Kritik der reinen Vernunft doch wenigstens $1 / 6$ betrug. Und, während dort die Ana- 
lytik $2 / 7$, die Dialektik $3 / 7$ des Ganzen enthält, nimmt hler die erstere die Hälfte, die zweite nur ein Viertel ein. Von den drei Kapiteln der Analytik füllt das erste, die Lehre von den Grundsätzen, eigentlich nur 42 Seiten, worauf ein Abschnitt anderen Inhalts (S. 66-74) folgt; das zweite Kapitel (vom Gegenstande d. r. pr. V.) genau genommen nur 13, denen ein Abschnitt über die Typik der reinen praktischen $U r$ teilskraft (S. 87-92) angehängt ist; und das dritte (von den Triebfedern der r. pr. V.) 22 Seiten, denen ohne besondere Rubrizierung eine kritische Beleuchtung der gesamten Analytik auf weiteren 22 Seiten folgt. - Die Dialektik aber beginnt mit zwei kurzen Kapiteln von 4 bezw. 5 Seiten, um daran nicht weniger als 9 weitere Einzelabschnitte ohne Gesamtüberschrift zu schließen. Ein Inhaltsverzeichnis fehlt im Original gänzlich.

Im Gegensatz zu dem analytischen Verfahren der Grundlegung geht die Kritik der praktischen Vernunft synthetisch vor. Sie führt uns sofort in den Kern des Systems, in der Lehre

\section{c) Von den Grundsätzen der relnen praktischen Vernunft}

(S. 23-65, bezw. 74).

Außerlich fast an die Art des von unserem Philosophen so wenig geschätzten Spinoza (in seiner Ethik) gemahnend, setzt Kant mit einer „Erklärung“, genauer drei Definitionen ein, denen eine längere Anmerkung folgt (23-26), und entwickelt sodann in drei "Lehrsätzen“ mit angehängter „Folgerung“ (26ff.) und zwei „Aufgaben“" (36 ff.) das "Grundgesetz der reinen praktischen Vernunft" oder "Sittengesetz (39 bis 43), worauf dann noch ein vierter Lehrsatz (43f.) sich anschließt, der, ebenso wio die früheren, von längeren „Anmerkungen“ begleitet ist. Diese in acht Paragraphen zusammengedrängten Sätze enthalten in lückenloser Kette die Grundlegung der kritischen Ethik.

Die „praktischen Grundsätze“, welche als Voraussetzung und Ausgangspunkt jeder Ethik in Frage kommen, sind entweder 1. Maximen d. i. subjektive Grundsätze, von dem einzelnen und für den einsolnon 
angenommen, ohne Allgemeingültigkeit, oder 2. praktische Gesetze, d. i. für den Willen jedes vernünftigen Wesens gültige, also objektive Grundsätze.' Nur die letzteren sind daher auch Imperative im strengen, kategorischen Sinne, nur sie können für eine wissenschaftliche Ethik in Betracht kommen (§ 1). Nun sind aber alle praktischen Prinzipien, die ein Objekt unseres Begehrens als Bestimmungsgrund unseres Willens voraussetzen, empirisch und von der Lust oder Unlust des einzelnen abhängig, folglich für ein apriorisches Gesetz, wie es die Ethik fordert, nicht brauchbar (§ 2). Alle diese ,materialen" sittlichen Prinzipien fallen unter das Prinzip der Selbstliebe oder eigenen Glückseligkeit (\& 3). Woher das Lustgefühl stammt, ob aus sinnlichen oder geistigen Vorstellungen, ist dabei prinzipiell gleichguiltig; auch das Gefühl der eigenen Kraft (wir Modernen denken dabei an Nietzsche!) macht die Sach $\theta$ nicht besser. Auch die „überfein“ gedachte Materie bleibt immer Materie. Konsequenz aber ist die größte Obliegenheit eines Philosophen (Anmerkung I). Gewiß ist Glückseligkeit das Verlangen jedes endlichen, also bedürftigen Vernunftwesens, aber sie bleibt stets ein subjektives, bloß für den einzelnen gültiges Prinzip, und selbst allgemeine 'Einhelligkeit darüber wäre doch' nur zufällig (Anmerkung II). Also bleibt für die gesuchten praktischen Gesetze als einziger Maßstab nur übrig: ihre Fähigkeit, allgemein gesetzgebend zu sein (§ 4 . Die folgende Anmerkung führt dies dann weiter an einem - übrigens nicht besonders glücklich gewählten - Beispiel aus dem Leben aus). Ein Wille aber, der allein durch diese bloße gesetzgebende Form bestimmt wird, ist seinem Bestimmungsgrunde nach von dem Gesetz der Kausalität in der Natur unabhängig, d. h. frei ,im strengsten d. i. transzendentalen Verstande (§ 5). Und umgekehrt: ein freier Wille kann einzig und allein durch jene gesetzgebende Form bestimmt werden (§ 6). Freiheit und unbedingtes praktisches Gesetz weisen aufeinander zurück. Das moralische Gesetz, dessen wir uns unmittelbar bewußt werden, sobald wir uns Maximen bilden, führt auf den Begriff der Freiheit, den die spekulative Vernunft nicht zu 
lösen vermochte (Anmerkung). Aus dem bloßen, formalen Gedanken einer möglichen allgemeinen Gesetzgebung ergibt sich, als Grundgesetz der reinen praktischen Vernunft oder Sittengesetz, das Gebot: Handle so, da $\beta$ die Maxime deines Willens jederzeit zugleich als Prinzip einer allgemeinen Gesetzgebung gelten könne (§ 7). Das Bewußtsein dieses Grundgesetzes, das sich uns von selbst aufdringt, ist das einzige Faktum der reinen Vernunft (1. Anmerkung). Daraus entspringen eine Anzahl - bereits in der Grundlegung erörterter - Begriffe, wie: Allgemeingültigkeit für alle vernünftigen Wesen, Imperativ, Pflicht, unendlicher Progressus zum Ideale hin u. ä. (2. Anmerkung). Jene allgemeine Gesetzgebung aber geht aus dem freien Wollen des Menschen hervor, ist also Autonomie (Selbstgesetzgebung) des Willens im Gegensatz zu der „Heteronomie“ (,Fremdgesetzgebung") der Willkür (§ 8). Freilich muß alles Wollen einen Gegenstand haben; aber dieser, beispielsweise etwa die Glückseligkeit anderer, braucht nicht letzter Bestimmungsgrund derselben $\mathrm{zu}$ sein (Anmerkung I). Sittlichkeit und Egoismus, Pflicht und eigener Vorteil sind selbst für den gemeinen Mann leicht unterscheidbar. Selbst allgemeine Glückseligkeit als Ziel gedacht, kann das Glückseligkeitsprinzip höchstens generell, nicht universell sein, höchstens raten, aber nie gebieten. Auch das Gefühl der Strafwürdigkeit beweist unsere sittliche Anlage und spricht gegen den Eudämonismus. Und die Annahme eines besonderen moralischen Sinnes (z. B. bei dem Engländer Hutcheson) setzt die Idee des Sittengesetzes schon voraus (Anmerkung II).

So stellt sich Kants formale Ethik mit vollom Bewußtsein in den schärfsten Gegensatz zu allen bisherigen, "materialen" Sittlichkeitsprinzipien, die nun auf einer Tafel (S. 53) zusammengestellt werden, als da sind: Erziehung (Montaigne), Staatsverfassung (Mandeville), physisches oder moralisches Gefühl (Epikur, Hutcheson), Vollkommenheit (Stoiker, Wolff) und der Willen Gottes (Crusius und die Theologen). Daß das Prinzip der Vollkommenheit noch das relativ beste sei, aber auch nicht genüge (54), hatte schon die Grundlegung (S. 69-71 unserer Ausgabe) genauer ausgeführt. 
Dem orsten Kapitel sind noch zwei Abschnitte angehängt. Der erste (55-65) betitelt sich: Von der Deduktion der Grundsätze der reinen praktischen Vernunft. Doch wird zunächst eigentlich nur eine nochmalige „Exposition“ (S. 60 unten) des Sittengesetzes gegeben. Das Faktum unserer sittlichen Autonomie ist mit dem Bewußtsein der Willensfreiheit unzertrennlich verbunden und bestimmt positiv eine intelligible Welt (Ordnung der Dinge), die für die theoretische Vernunft unerklärlich war. Das Sittengesetz ist das Grundgesetz einer übersinnlichen Natur, d. $h$. einer Natur unter der Autonomie der reinen praktischen Vernunft. Wir stellen uns denn auch bei der sittlichen Beurteilung unserer Handlungen (z. B. falsches Zeugnis, Selbstmord), dieselben als allgemeines Naturgesetz vor. Auf den tatsächlichen Erfolg unseres Handelns kommt es dabei nicht an. Die Möglichkeit der Freiheit oder des sittlichen Bewußtseins selbst ist nicht weiter erklärbar (vgl. Grundlegung S. 89 ff.). Damit erst kommen wir zu der Frage der Deduktion des Sittengesetzes, d. h. der Rechtfertigung seiner allgemeinen Gültigkeit und Einsicht in seine apriorische Möglichkeit (S. 61 oben). Die Erfahrung läßt uns hier im Stich, und Grundkräfte oder -vermögen können nicht weiter abgeleitet werden. Etwas ganz ,Widersinnisches“ tritt vielmehr an die Stelle dieser vergeblich gesuchten Deduktion: das Sittengesetz selbst dient zum Deduktionsprinzip der Freiheit und beweist deren Wirklichkeit an uns, indem es den vorher bloß negativ gedachten Freiheitsbegriff positiv, nämlich als eine Kausalität der reinen Vernunft, bestimmt. Das Kausalgesetz der Natur wird dadurch weder aufgehoben noch über seine Grenzen erweitert - „der spekulativen Vernunft wächst an Einsicht nichts $\mathrm{zu}^{\prime \prime}(64)$-, aber dio Freiheit wird gesichert und realisiert.

Im Anschluß daran verbreitet sich' der zweite Anhang (66-74) nochmals über dio Befugnis der reinen Vernunft im praktischen Gebrauche zu einer Erweiterung, die ihr im spekulativen für sich nicht möglich ist, ohne eigentlich neue Gedanken zu bringen. Wiederum wird Humes empirischer Skeptizismus gegenüber dem Kausalittitsgesetz kritisiert, der nur duroh die in der 
Kritik der reinen Vernunft aufgestellte Unterscheidung von „Ding an sich“ und „Erscheinung“ gelöst werden könne. Objekte sind zu erkennen und zu bestimmen nur durch Anwendung der Kategorien, aber Noumena (Gedankendinge jenseits der Erfahrung) wenigstens für den reinen Verstand denkbar. Der Begriff eines reinen Willens enthält schon von selbst den einer Kausalität „mit Freiheit" (causa noumenon).

Das nun folgende zweite Kapitel der Analytik geht von den Grundsätzen zum

d) Gegenstand der relnen praktischen Vernunft (S. 75-92) über. Das Urteil, ob etwas ein Gegenstand der reinen praktischen Vernunft sei oder nicht, hängt mit unserem physischen Vermögen gar nicht zusammen, sondern bezieht sich' nur auf die Frage, ob wir die betreffende Handlung wollen dürfen, mithin auf ihre moralische Möglichkeit. „Die alleinigen Objekte einer praktischen Vernunft sind also die Begriffe des Guten und Bö'sen“ (76). Diese aber sind nicht weiter abzuleiten, sonst kommen wir unvermeidlich zu den rein empirischen Begriffen des Angenehmen und Unangenehmen, Nützlichen und Schädlichen, Wohls oder Ubels, die auf dem Gefühl der Lust (des Vergnügens) oder der Unlust (des Schmerzes) beruhen. Nun kommt auf unser Wohl und Weh zwar "sehr viel", aber doch nicht "alles überhaupt" an. Der Mensch' ist doch nicht "ganz Tier“, wenn seine Vernunft auch" ,einen nicht abzulehnenden Auftrag von seiten der Sinnlichkeit hat, sich um das Interesse derselben zu kümmern" (80). Was an sich (unmittelbar) gut oder böse ist, kann vielmehr allein durch' das Sittengesetz bestimmt werden, das also der Begriffsbestimmung des Guten vorangehen, nicht nachfolgen muß. Die Mißachtung dieser Methode erkläre, meint Kant, „alle Verirrungen der Philosophéen“ bezüglich des Moralprinzips (80). Sie gingen alle, anstatt von dem rein formalen Gesetze, von dem Gegenstande (der Materie) des Wollens aus; daher die Ausbildung der - später in der Dialektik (s. unten) $\mathrm{zu}$ behandelnden - Liehre vom höchsten Gut bei den Alten. Da die Begriffe des Guten und Bösen eine Kausalität der reinen Vernunft voraus- 
setzen, so läßt sich auch eine ethische Kategorientafel, eine ,Tafel der Kategorien der Freiheit" nach Qualität, Quantität, Relation und Modalität, aufstellen (sie findet sich S. 86).

Der sich diesen Ausführungen anschließende kurze Abschnitt Von der Typik der reinen praktischen Urteils. kraft (87-92) soll die konkreten Einzelfälle unseres Handelns unter die praktische Regel der reinen Vernunft bringen. Wie ist das aber, bei dem unübérbrückbar scheinenden Gegensatz der Sinnenwelt und der übersinnlichen Idee des Sittlich-Guten, möglich? Nun, die physische Handlung gehört allerdings unter die Naturbegriffe, deren Schema die transzendentale Einbildungskraft (nach der Kritik der reinen Vernunft) entwirft. Für die Ideo des Guten aber ist das Naturgesetz selbst das Schema, das dem Sittengesetzo als sein ,Typus“ untergelegt werden kann. Wir denken uns den betreffenden Fall als allgemeines Naturgesetz (vgl. S. XXX), indem wir fragen: „Frage dich selbst, ob die Handlung, die du vorhast, wenn sie nach einem Gesetze der Natur, von der du selbst ein Teil wärest, geschehen sollte, du sie wohl als durch deinen Willen möglich ansehen könntest?“ (90). So verhütet die Typik der r. pr. Urteilskraft sowohl den Mystizismus der praktischen Vernunft, der sich auf übersinnliche Anschauungen gründet, als den ihr noch gefährlicheren Empirismus, der die Menschheit degradiert, und bleibt bei oinem gesunden Rationalismus.

zu den

Von dem Gegenstande führt uns Kapitel III

e) Triebfedern der reinen praktischen Vernunft (S. 93-115).

Gingen die vorigen Erörterungen teilweise recht ins Abstrakte, so ist dies Kapitel besonders reich an populären und sittlich erhebenden Betrachtungen, sodaß es in hervorragendem Maße zur Einführung in den Geist der Kantischen Ethik empfohlen werden kann. Wir freilich müssen uns, wio bisher, mit der Skizzierung des Gedankenganges begnügen.

Das Sittengesetz muß den Willen unmittelbar bestimmen. Sonst entsteht Legalität anstatt Moralitat und gilt der Buchstabe anstatt des Geistes. Auf welche 
Art wirkt nun das moralische Gesetz als Triebfeder in uns? Es weist alle Neigungen und sinnlichen Antriebe ab, schlägt den Eigendünkel nieder, läßt nur eine „vernünftige Selbstliebe“ gelten und erweckt vor allem das Gefühl der Achtung: das einzige a priori erkennbare, weil lediglich von der Vernunft bewirkte, und zugleich das einzige wahrhaft moralische Gefühl, dessen eigentümliche Mischung aus Lust und Unlust an mehreren schön gewählten Beispielen illustriert wird. So ist das Sittengesetz zugleich formaler (als Gesetz), materialer (als Gutes und Böses) und subjektiver (als Triebfeder) Bestimmungsgrund (97f.). Die Triebfeder treibt uns zum moralischen Interesse und dieses zur sittlichen Maxime. Aus dem Gefühl der Achtung als dem Bewußtsein einer freien Unterwerfung unter das Gesetz entspringt weiter der Begriff der Pflicht, den der Philosoph nun (104ff.) nach allen Seiten hin, in seinem Gegensatz zur bloß äußerlichen Pflichtmäßigkeit, zur Neigung, zur Schwärmerei and zur Sentimentalität schildert, um mit der berühmten Apostrophe an die Pflicht (111 f.) zu schließen. Deren letzte Wurzel ist der Mensch als Persönlichkeit; woraus dann die weiteren ethischen Begriffe der Menschheit, des Menschen als Selbstzwecks und als Urhebers des moralischen Gesetzes sich von selbst ergeben. Sie alle sind auch dem gemeinen Mann von selbst verständlich, der, wenn es darauf ankommt, sehr wohl die Ehrwürdigkeit der Pflicht von dem bloßen Lebensgenuß zu unterscheiden vermag.

Den Schluß des ersten Buches bildet eine

f) Kritische Beleuchtung der Analytlk (S. 115-137), d. h. nachträglich $\Theta$ erläuternde und rechtfertigende Bemerkungen zu derselben, insbesondere aber ihre Vergleichung mit der Analytik der theoretischen reinen Vernunft. Wie schon die Einleitung bemerkt hatte, mußte der Gang der Untersuchung hier ein umgekehrter sein: zuerst kam die „Logik“, dann folgte die „Ästhetik" der reinen praktischen Vernunft. Die Dreiteilung der Analytik bringt Kant nachträglich in Analogie mit den drei Teilen des Syllogismus (117). Für

Kant, Kritik der prakt. Vernunft. 
die theoretische Erkenntnis bildeten die Wissenschaften den Beleg, für die praktische nur das Faktum des gemeinen praktischen Vernunftgebrauchs. Die wichtigste Aufgabe der Analytik war hier die mathematisch, ja chemisch genaue Untorschoidung der Sitten- von der Glückseligkeitimlehre, die darum übrigens nicht gleich absolute Entgegensetzung beider bedeutet (120). Die einzig mögliche "Deduktion" des obersten Moralprinzips bestand in seinem unzertrennlichen Zusammenhang mit der Freihoit.

Mit Rücksicht auf das immerfort wiederkehrende, aus lediglich psychologischer Auffassung herrührende Mißverstehen des kritischen Freiheitsbegriffs seitens des ,Empirismus in der ganzen BlöBo seiner Seichtigkeit" (121) behandelt dann unser Philosoph an dieser Stelle nochmals das schon in der Kritik der reinen Vernunft, den Prolegomona und der Grundlegung1) erörterte Problem der Vereinbarkeit von Freiheit und Naturnotwendigkeit (S. 121-133). Von besonderem Interesse möchten einige noue Wendungen sein, 80: daß den Dingen ,an sich“ die Dinge „in der Zeit" gegenübergestellt, daß die sogenannte innere oder psychologische Froiheit mit der eines Uhrzeigers oder (noch derber) eines Bratenwenders (125) verglichen und als ein ,elender Behelf" bezeichnet wird, daß ein „anderer Blick" (griechisch: lsźa) uns, selbst wenn wir ,eines Menschen Verhaltion auf die Zukunft mit Gewißheit sowie eine Mond- oder Sonnenfinsternis ausrechnen könnten“, dennoch "dabei bohaupten" lassen würde, daß dor Mensch" frei sei (S. 127 unten). Auch die Tatsachen des anklagenden oder richtenden Gewissens und der Reue, sowie die heute noch unsere Rechtswissenschaft beschäftigenden Problemeder Zurechnungsfähigkeit und des, geborenen“ Verbrechers erfahren ihre Behandlung. Endlich wird auch noch das Verhältnis des neuen, kritischen Freiheitsbegriffes zur Allmacht Gottes untersucht. Gerado die Existenz des letzteren sei, meint Kant, mit

1) Vgl. das Sachregister in moinen Ausgaben dieser Sohriften (Kr. d. r. $\nabla$. bei $O$. Hendel, die boiden anderen Bd. 40 und 41 der Phil. Bibl). 
soiner Lehre von der Idealität der Zeit viel leichter zii vereinen als mit der gegenteiligen Mendelssohns oder Spinozas. - Zum Schluß wirft or dann noch die Frage auf, warum gerade der Freiheitsidee eine so besonders große Fruchtbarkeit eigen sei. Er findet sie zunächst in deren Eigenschaft als dynamischer (nicht mathematischer) Idee, dann aber und vor allem in ihrem unmittelbaren Zusammenhang mit der Sittlichkeit, während derselbe bei der Gottesidee nur ein mittelbarer sei. Besonders aufmerksam macht Kant endlich noch auf die ungesuchte genaue Ubereinstim. mung der wichtigsten Sätze der praktischen mit denen der spekulativen Vernunft. Damit endet das erste Buch: dio Analytik. Es folgt als zweites die

0) Dialektlk der reinen praktischen Vernunft (S. 188-188).

Das kurze erste Kapitel: Von einer Dialektik der reinen praktischen Vernunft iberhaupt (138-141) trägt nur einleitenden Charakter. Ebenso wie bei der theoretischen, treibt uns auch in der praktischen Vernunft der scheinbare Widerspruch zwischen Bedingtem und Unbedingtem, seine Lösung in einer „Dialektik“ zu suchen. Und zwar tritt er hier in dem schon von der antiken Ethik mit Vorliebe behandelten Begriff des höchsten Guts zutage. Das Sittengesetz ist der alleinigo Bestimmungsgrund des reinen Willens, das höchste Gut dessen Gegenstand. Anderseits ist aber in dem letzteren als seine oberste Bedingung das moralische Gesetz mitenthalten. Wie verhalten sich nun beide zueinander? Darauf antwortet

das zweite Kapitel: Von der Dialektik d. r. P. in Bestimmung des Begriffs vom höchsten Gut (142-145). Der Begriff des, "höchisten" enthält sowohl den des "obersten" wie den des „vollendeten" Guts. Das erstere besteht in der Tugend, das zweite aber in der Tugend zusammen mit der ihr entsprechénden Glickseligkeit. Für die Stoiker und Epikureer waren beide Begriffe - obwohl von verschiodenem Standpunkt aus - identisch, während sie einander doch nach der Analytik oft genug widersprechen. Wie also int das a priori notwendige höchsto Gut praktisch mőglich? Das wird nun in noun aufeinanderfolgenden Binzel- 
abschnitten (145-188) des näheren ausgeführt. Zunächst wird

I. die Antinomie der praktischen Vernunft noch einmal deutlich formuliert: die Glückseligkeit darf nicht das Motiv zur Tugend und die Tugend kann nicht a priori Ursache der Glückseligkeit sein (145f.).

II. Die kritische Aufhebung dieser Antinomie ist, wie in der Kritik der reinen Vernunft, durch die Doppeleigenschaft des Menschen als Erscheinung (Naturwesen, Phänomenon) und reine Intelligenz (Vernunftwesen, Noumenon) gegeben. Allerdings kann das bloße Streben nach Glück nio der Grund wahrer Tugend sein, wohl aber kann diese die Glückseligkeit zur Folge haben, vermittelt - durch einen intelligibelen Urheber der Natur. Das Wohlgefallen, das wir an der Bestimmung unseres Willens unmittelbar durch das moralische Gesetz empfinden, ist eine rein intellektuelle Zufriedenheit, die mit sinnlichen Triebfedern bezw. Lustgefühlen nichts zu schaffen hat, vielmehr gerade in der Unabhängigkeit von den - jederzeit von einer gewissen Unzufriedenheit begleiteten - Neigungen besteht (146-153).

III. Damit wäre eigentlich die oben gestellte Hauptfrage (kritische Aufhebung der Antinomie) bereits gelöst. Kant schließt aber in den folgenden Abschnitten noch eine Reihe verwandter Erörterungen an. Zunächst den Gedanken des Primates der reinen praktischen vor der spekulativen Vernunft. Die letztere bleibt ohne die erstere unvollständig, und alles Interesse, selbst das der Erkenntnis, ist in letzter Linie praktisch (moralisch). Verbunden sein aber mitissen beide, weil es im Grunde doch ,eine und dieselbe“ Vernunft ist, die in beiden wirkt (153-156).

IV. Die praktische Vernunft zieht als ihre notwendige Konsequenz drei theoretisch freilich nicht beweisbare Sätze (Postulate) nach sich: 1. die Unsterblichkeit der Seele, weil nur in einem ins Unendliche sich erstreckenden Fortschritt die vom \$ittengesete geforderte völlige Angemessenheit der $\mathrm{Ge}$ sinnung zum moralischen Gesetz zu erreichien ist. Wer sich bewußt ist, mit aller Energie zum Besseren zu streben, darf auf eine ununterbrochene Fortsetzung 
dieses Strebens, auch über das irdische Leben hinaus, hoffen, die ihm der Unendliche ermöglichen wird (156 bis 158). Damit sind wir

V. an dem 2. Postulate, dem Dasein Gottes, angelangt. $\mathrm{Da}$ das Sittengesetz an sich nicht das mindeste mit Naturbedingungen, also auch nicht mit der nur durch solche möglichen Glückseligkeit zu tun hat, anderseits aber die Erreichung des höchsten Guts praktisch notwendig ist: so müssen wir nach Kant ein von der Natur verschiedenes, mit Verstand und Willen begabtes Wesen (Gott) annehmen, das zugleich Urheber der gesamten Natur ist und sa die von unserem sittlichen Bedürfnis geforderte ,genaue Ubereinstimmung der Glückseligkeit mit der Sittlichkeit" (159 unten) herbeizuführen vermag. Eine solche Annahme ist freilich nicht objektiv, wohl aber subjektiv notwendig, nicht Grund unserer moralischen Verbindlichkeit, aber "reiner Vernunftglaube“. Das Christentum steht in diesem Punkte der strengsten sittlich'en Forderung näher als Stoa und Epikureismus. Es verlangt unnachsichtlich strenge moralische Gesinnung ohne eine andere Triebfeder als das Sittengesetz selber [? d. H.] und macht die Glückseligkeit lediglich zum Gegenstand der Hoffnung. Das Sittengesetz aber führt so, durch den Begriff des höchsten Guts als Endzwecks, zur Religion, d. h. „Erkenntnis aller Pflichten als göttlicher Gebote" (165). Indes bemüht sich Kant, um nicht mißverstanden zu werden, immer wieder einzuschärfen, da $\beta$ Pflichterfüllung immer das erste bleibe, daß die Glückwürdigkeit stets der Glückseligkeit vorangehen müsse, daß Gott nicht bloß gütig, sondern auch heilig sei (158-168).

Abschnitt VI gibt eine kurze, jedoch wichtige Zusammenfassung der drei Postulate, unter denen jetzt auch die Freiheit erscheint, und ihres Zusammenhanges mit den drei Ideen der theoretischen Vernunft (168-170). - Einen hier erwähnten Gedanken legt dann Abschnitt VII genauer dar, nămlich, daß durch die Postulate die reine Vernunft zwar erweitert werde, aber nicht "spekulativ“, d. $h$. in bezug auf etwaige neue Erkenntnisse, sondern nur ,in praktischer Absicht“. Neues wird nicht ausgeführt, son- 
dern nur der schon in der Vorrede berührte Gedanke weiter begründet, daß die theoretisch problematischen Ideen: Gott, Freiheit, Unsterblichkeit, durch ihren praktischen Gebrauch objektive Realität, d. h. einen wirklichen Gegenstand, erhalten. Waren sie vorher transzendent und bloß regulativ, so werden sie jetzt immanent und konstitutiv, ohne daß man deshalb in Anthropomorphismus oder Mystik zu verfallon brauchte. Kants Gottesbegriff will ein rein moralischer, nicht physischer oder metaphysischer sein. In naturwissenschaftlichen Erklärungen zur Gottheit seine Zuflucht nehmen, heißt eingestehen, daß man mit seiner Philosophie zu Ende sei (176 unten). Auch die sogenannten Eigenschaften Gottes: seine Allmacht, Allwissenheit usw. sind nur auf moralischem Wege zu begründen. Einschränkung des spekulativen, Frweiterung des praktischen Vernunftgebrauchs: das ist der Weg der Wissenschaft (170-180).

Auch Abschnitt VIII führt einen schon geäußerten Gedanken nur noch weiter aus, nämlich: daß oin Bedürfnis der reinen Vernunft zu den Fostulaten, wie auf theoretischem Gebiete zu - wenn auch unvermeidlichen - Hypothesen, führe. Die Postulate sind auf unsere Pflicht, das höchste Gut zu befördern, gegründet. Die moralische Gesinnung $m u B$ die Möglichkeit des höchsten Gutes voraussetzen, also auch deren physische oder metaphysische Bedingungen. Der Rechtschaffene kann sagen: Ich will, daß ein Gott, daß Freiheit, daß meine Dauer endlos sei, und läßt sich diesen reinen praktischen Vernunftglauben nicht nehmen; denn er beruht auf einem notwendigen $\mathrm{Be}-$ dürfnis der Vernunft, nicht einem zufälligen der Neigung (180-186).

IX. Endlich, das Verhältnis der menschlichen Erkenntnisvermögen zueinander, insbesondere die Unzulänglichkeit der spekulativen Vernunft, ist der praktischen Bestimmung des Menschen weislich angemessen. Ohne das würden auf der einen Seito die Noigungen das große Wort führen, auf der anderen Gott und Ewigkeit in ihrer furchtbaren Majestut uns unabläesig vor Augen stehen, infolgedessen die meisten unsarer Handlungen aus Furcht, wenige ans Hoff- 
nung, keine aus Pflicht geschehen, woran doch ihr ganzer sittlicher Wert hängt. Und so ist, damit schließt die Elementarlehre, „die unerforschlicho Wraisheit, durch die wir existieren, nicht minder verehrungswürdig in dem, was sie uns vorsagte, als in dem, was sie uns zuteil werden lieB" (186-188).

\section{h) Dle Methodenlehre der reinen praktischen Vernunft}

$$
\text { (S. 189-204), }
$$

die den $\mathrm{zw}$ eiten Teil des gesamten Werkes ausmacht, trägt durchaus populären Charakter. Man könnte sie als eine Art Moraldidaktik oder -pädagogik bezeichnen, denn sie will - wenn auoh nur in allgemeinen Umrissen (vgl. den Schluß S. 204) - zieigen, wie man dem Sittengesetze Eingang in bezw. Einfluß auf das menschliche Gemüt verschaffe. Der Kerngedanke (der bereits in der Grundlegung ausgesprochen wurde) ist der, daß das Sittengesetz gerade in seiner Reinheit und Strenge auf den unverdorbenen Menschen stärker wirke als alle Lockungen und Drohungen. Nur bei noch ungebildeten oder verwilderten Gemütern bedürfe es, als Vorbereitung, eines solchen Gängelbandes; sobald es einigermaßen seine Wirkung getan, müsse man das rein moralische Motiv wirken lassen, das allein dem Menschen Charakter, Würde und Seelenstärke verleiht und sich als die mächtigste und einzig wahre Triebfeder zum Guten beweist. Die Empfänglichkeit dafür zeige sich schon in der Neigung zum Aussprechen sittlicher Werturteile (dem „Räsonieren") über Personen, die jedem Menschen auch Geschäftsleuten, Frauenzimmern, ja selbst Kindern - innewohne. Dies sollten sich die Erzieher der Jugend zunutze machen, um an Musterbeispielen aus den Biographien alter und neuer Zeit die moralische Urteilskraft ihrer Zöglinge zu schärfen und in ihnen einen guten sittlichen Grund zu legen. Es sei dabei aber nicht, wie es jetzt so viel geschehe, das Edle, Großmütige, Uberverdienstlich $\theta$ solcher Handlungen zu betonen - das bringe entweder sittlichen Hochmut oder Empfindelei oder Phantasterei hervor -, sondern das Gefühl der einfachen Pflicht und Schuldigkeit; denn nicht auf flitchtige Gefühlsaufwallungen, 
sondern auf feste Grundsätze komme es an. Was aber reine Sittlichkeit sei, das wisse die gemeine Vernunft so gut wie den "Unterschied zwischen der rechten und linken Hand" (196). Kant führt selbst zum Beleg seiner Ansicht ein längeres (196f.) und ein kürzeres (199 f.) Beispiel aus und ein drittes aus Juvenal (200) an. Zuerst muß man den Menschen an die Frage gewöhnen, ob die betreffende Handlung objektiv dem Sittengesetz gemäß sei, dann aber, ob sie auch um des Gesetzes willen geschehe; schließlich wird er dasselbe auch liebgewinnen. Wenn der moralische "Lehrling" erst einmal seines Vermögens der inneren Freiheit sich bewußt geworden ist, dann wird er immer leichter den Sieg über die ihn im Grunde doch nur unzufrieden machenden Neigungen davontragen. Der

\section{1) Sohlub (S. 205-207)}

faßt in schöner und erhebender Sprache noch einmal die beiden großen Gebiete, die den Gegenstand von Kants beiden ersten systematischen Hauptwerken bilden, Natur und Sittlichkeit, zusammen in dem berühmten Worte, das man auf die Marmortafel gegenüber seinem Grabmal geschrieben hat: Der bestirnte Himmel über mir und das moralische Gesetz in mir. Dort die Unendlichkeit der physischen Welt, hier die Unendlichkeit meines unsichtbaren Selbst, der Persönlichkeit. Aber, wie dort, bedarf es auch hier eines Newton, der an die Stelle der bloßen Bewunderung die methodische Forschung setzt und die moralisch urteilende Vernunft zergliedert. Denn allein „Wissenschaft (kritisch' gesucht und mothodisch" eingeleitet) ist die enge Pforte, die zur Weisheitslehre führt" (207).

Kant ist in der Tat der Newton der Ethik geworden. Wie der Verfasser der Philosophiae naturalis principia mathematica der mathematischen Naturwissenschaft, so hat er der Moral diejenige methodische $\mathrm{Be}-$ gründung gegeben, die allein Dauer verspricht und wohl im einzelnen verbesserungsfähig, aber im letzten Grunde weder zu zerstören noch zu ersetzen ist. Das 
hat unsere Zeit in höherem Maße erkannt als selbst Kants Zeitgenossen. Auf diese wirkte vor allem, wie wir schon sahen und durch eine Reihe weiterer Beispiele erhärten könnten ${ }^{1}$ ), die praktische Seite von Kants Ethik, die Reinheit, Strenge und Erhabenheit des von ihm verkündeten neuen Moralprinzips; und diese praktische Wirkung des kategorischen Imperativs, die der Philosoph in seiner Methodenlehre vorausgesagt, ist seitdem nie ganz erloschen, von Friedrich Schiller und den Männern der preußischen Reformzeit (1807 bis 1813) an bis auf den heutigen Tag. Weit weniger dauerhaft erwies sich die philosophische, d. h. methodische Einwirkung. Wohl zählt man eine Reihe Ganzoder Halbkantianer auch in der Ethik ${ }^{2}$ ), jedoch die meisten von ihnen ließen sich durch die glänzenden spekulativen Systeme seiner Nachfolger verlocken, der schlichten kritischen Methode untreu zu werden. Diese Nachfolger aber (Fichte, Schelling, Hegel) sind nicht Fortbildner, sondern Gegner Kants. Und auch als F. A. Lange und andere um die Mitte der 60er Jahre des vorigen Jahrhunderts wieder auf Kant zurückgingen, erklärte man - wenigstens Lange - anfangs „die ganze praktische Philosophie“ für den „wandelbaren und vergänglichen Teil der Kantschen Philosophie“. Erst Hermann Cohen hat durch sein 1877 erschienenes Buch-Kants Begründung der Ethik die kritische Ethik von neuem begründet und diese Begründung zu vertiefen gesucht, indem er die Kant eigentümliche "transzendentale" Methode noch schärfer heraushob, die

1) z. B. durch die briefliche Äußerung Jean Pauls an einen Freund: "Kaufen Sie sich um Himmels willen zwei Bücher, Kants Grundlegung zu einer Metaphysik der Sitten und Kants Kritik der praktischen Vernunft. Kant ist kein Licht der Welt, sondern ein ganzes strahlendes Sonnensystem auf einmal." - Über Kants Wirkung auf Schiller und Go othe vgl. mein Buch: Kant-Schiller-Goethe (Lpz. 1907), das zum ersten Male Kants Einwirkung auf Goethe an der Hand der Quellen ausführlich darlegt und ferner zeigt, daB Schiller Kants "Rigorismus" keineswegs in der hergebrachten Weise bekämpft hat.

2) Vgl. das XVI. Kapitel des 2. Bandes meiner Geschichte der Philosophie: Von Kant zu Fichte (4. Aufl. S. 256 ff.). 
Postulate dagegen und damit die ganze unkritische Verbindung der Ethik mit der Religionsphilosophio als inkonsequent fallen ließ. In seinem seit 1902 im Erscheinen begriffenen eigenen System, dessen zweiton Teil die Ethik des reinen Willens (2. Aufl. 1907) bildet, hat Cohen die Ethik noch weiter in transzendentalem Sinne fortzubilden, nämlich als „Logik der Geisteswissenschaften“, als „Prinzipienlehre der Philosophie von Recht und Staat" zu begründen unternommen. Seit etwa einem Jahrzehnt hat Kants Ethik auch in den sozialphilosophischen Diskussionen eine bedeutsame Rolle gespielt. Wer sich dafür interessiert, sei auf mein diese Dinge eingehend behandelndes Buch: Kant und Marx (Tüb. 1911) verwiesen.

Ein Gesamtbild der Kantischen Ethik oder auch nur eine erschöpfende Charakteristik von deren $\mathrm{Me}-$ thode kann, soweit sie nicht bereits in unserem hier sowie in der Einleitung von Band 41 wiedergegebenen Gedankengang enthalten ist, an dieser Stelle nicht gegeben werden; das ist vielmehr Sache einer Spezialschrift bezw. einer Geschichto der Philosophie. Ich selbst habe Kants ethische Methode in einem Solinger Gymnasialprogramm: Die Kantische Begründung des Moralprinzips (1889), eingehender in meiner Dissertation: Der Formalismus der Kantischen Ethik in seiner Notwendigkeit und Fruchtbarkeit (Marburg 1894) darzustellen gesucht, sie gegen den Vorwurf eines überstrengen "Rigorismus" dort und in Kant-Schiller-Goethe (s. vorige Seite) verteidigt und eine knappe Gesamtschilderung seiner Ethik in Kapitel XIV des 2. Bandes meiner Geschichte der Philosophie (4. Aufl., S. 224-246) geliefert. Das Hauptwerk ist bisher noch immer das obenerwähnte von $H$. Cohen (von 1877, zweite bedeutend erweiterte Auflage 1910) geblieben. Außerdem empfehle ich noch zur Vertiefung in das Systematische von Kants Ethik den ersten, allgemeinen Teil von Paul Natorps Sozialpädagogik (3. Auf́age 1909); für das Vөrhältnis des Transzendentalen zum Psychologischen A. Hegler, Die Psychologie in Kants Ethik, 1891. Eine allgemeinverständliche Einführung in den Inhalt von Kants ethischen Schriften und ihre Hauptprobleme gibt A. Messer, Kants Ethik (Leipzig 1904), eine kürzere 
A. Buchenau, Kants Lehre vom kategorischen Imperativ (Lpz. 1913). Wem Messers bibliographisch Angaben nooh nicht genügen, der findet in Band III des tbberw $\theta$ gschen Grundrisses zu $\S 38$ (11. Aufl. 1914) etwa 150 Schriften, Abhandlungen und Aufsätze über Kants Ethik genannt.

Schließlich noch ein Wort über die Stellung der Kritik der praktischen Vernunft innerhalb von Kants System, d. h. ihr Verhältnis zu seinen übrigen ethischen Schriften. Von den kleineren, Spezialprobleme erörternden Abhandlungen können wir hier absehen. Innerbalb der drei Hauptschriften: Grundlegung (1785), Kritik der praktischen Vernunft (1788) und Metaphysik der Sitten (1797) nimmt die unsere nicht bloß zoitlich, sondern auch sachlich eine Mittelstellung ein, doch in der Weise, daß sie näher an die erstgenannte heranrückt. Die Grundlegung gibt eine umfassende Einführung, die $K r$. d. pr. V. den systematischen Kern, die Metaphysite der.Sitten die Anwendung (in Tugendund Rechtslehre). Inhaltlich bietet unsere Schrift gegenüber der Grundlegung kaum etwas Neues. Die Differenz liegt eigentlich nur in der durch den verschiedenen Zweck bedingten verschiedenen Anordnung des Stoffes, womit natürlich auch der größere Umfang der Hauptschrift zusammenhängt. Die Hauptbegriffe sind bei beiden die gleichen; aber die Grundlegung verfährt im wesentlichen analytisch, die $K r$. $d$. pr. V. synthetisch. ${ }^{1}$ ) Darum treten auch, wie man schon aus einem Blick in unsere beiden Sachregister ersehen kann, in der zweiten Schrift mehr die systematischen Begriffe in den Vordergrund: Gesetz, Grundsätze, Antinomie, Deduktion, theoretische und praktische Erkenntnis; die bloße gesetzgebende Form, der Freiheitsbegriff, das Sittengesetz und (ganz neu): die

1) Ähnlich urteilt auch Natorp in der Einleitung zu seiner Ausgabe: Jeder Leser beider Schriften weiß ja, da $B$ die Grundlegung und die $K r$. d. pr. $V$. sich wirklich dem Hauptinhalt nach decken, daß sie sich fast nur formal und zwar so unterscheiden, daß die Gedankenentwicklung in der Grundlegung mehr einen analytischen, in der $K$. d. pr. $\nabla$. einen synthetischen Gang befolgt". Vgl. auch Meswer a. ฉ. 0 . S. $95 \mathrm{ff}$. 
Kategorien der Freiheit, das Primat, die Typik der Urteilsisraft, die Postulate und die ganzo damit zusammenhängende Lehre vom höchsten Gute. In der Grusdlegung dagegen werden neben den gemeinsamen Grundbegriffen wie: Autonomie, Idee, Interesse, Maxime, Triebfeder usw. nur wenige andere, mehr einführende und populärere in den Vordergrund gestellt wie: der gute Wille, das Reich der Zwecke, der Selbst- oder Endzweck und vor allem - in der bekannten dreifachen Formulierung - der kategorische Imperativ. Im übrigen verweise ich auf das Studium beider Schriften selbst an der Hand meiner Einleitungen und Sachregister.

\section{Textphilologisches.}

\section{A. Dle bisherigen Ausgaben.}

1. Critik der praktischen Vernunft von Immanuel Rant. Riga, bey Johann Friedrich Hartknoch: 1788. 292 Seiten.

2.-5. Dasselbe. Zweyte, vierte, fünfte und sechste Auflage 1792, 1797, 1818 und 1827. Uber die fehlende dritte vgl. oben S. XXIV.

6. Nachdruck, mit dem Beisatz: Neueste, mit einem Register vermehrte Auflage. Grätz 1796. Zwei weiteres. oben S. XXIV.

7. Im 8. Bande der Gesamtausgabe von Rosenkranz und Schubert, Leipzig 1838, S. 103-318.

8. Im 4. Bande der Gesamtausgabe von G. Hartenstein, Leipzig 1838, S. 95-290.

9. Im 5. Bande von G. Hartensteins Gesamtausgabo in chronologischer Reihenfolge. Leipzig 1867, S. 1-169.

10. Als Band 7 (später 38) von J. H. v. Kirchmanns Philosophischer Bibliothel. Berlin 1869. 196 Seiten. 2. Aufl. 1870, 3. Aufl. 1882, 4. Aufl. Lpz. 1897.

11. Als Nr. 1111/1112 in Reclams Universalbibliothek, herausgegeben von Karl Kehrbach. Leipzig, ohne Jahr (Vorredo September 1878). 
12. Herausgegeben mit Einleitung, Lesarten und Sachlichen Erlëuterungen von Paul Natorp in Kants Gesammelte Schriften, herausgegeben von der Kgl. Preußischen Akademie der Wissenschaften. Band V, S. 1-163, bezw. 8. 489-512 (1908, 2. Aufl. 1913).

13. Neuausgabe in der Philos. Bibliothek (5. Aufl.), mit Einleitung und Registern von Karl Vorländer. Leipzig 1906.

14. In Bd. 5 der Ausgabe Immanuel Kants Werke (von $E$. Cassirer), herausg. von B. Kellermann. Berlin 1914. S. 1-176, dazu Lesarten S. 569-581.

\section{B. Textgeschlchtliches.}

\section{Die Originalauflagen.}

Von den 5 bezw. 6 Originalauflagen sind die 5 . und 6. - abgesehen von ganz minimalen Versehen (wio Interpunktionsfehlern) - genaue Wiederabdrücke der vierten, wie letztere ein solcher der ersten Auflage; nur daß in der fünften durch engeren Druck die 292 Seiten der ersten auf 285, in der sechsten gar auf 236 Seiten zusammengedrängt sind. Es kommen mithin für die Textvergleichung nur die erste und zweite Auflage in Betracht. Auch diese sind nicht sehr verschieden voneinander. Die zweite enthält allerdings eine Anzahl offenbarer Verbesserungen, aber auch mehrere Verschlechterungen der ersten Auflage (vgl. unser Verzeichnis aller nicht völlig belanglosen Varianten unter dem Text). Schon daraus ist darauf zu schließen, daß Kant den Druck der 2. Auflage nicht selbst überwacht hat, wie dies auch Hartknochs Brief an Kant vom 29. September 1789 wahrscheinlich macht, wonach nicht Kant, sondern ein gewisser Hertel (Hartknochs Vertreter in Leipzig) ein Exemplar des Werkes dem Drucker (Mauke in Jena) übersandte. Bei der vierten ist es sogar durch Kants Schreiben an Hartknoch vom 28. Januar 1797 (vgl. oben S. XXIV) ausdrücklich bezeugt. Da Kant somit nur an dem Druck der ersten Auflage nachweisbaren Anteil genommen hat - hat doch selbst von den vier Verbesserungen seines Handexemplars nur eine Aufnahme in die 2. Auflage go 
funden -, so haben Kehrbach und Natorp diese mit Recht ihrem Texte zugrunde gelegt; natürlich unter Mitberücksichtigung der Varianten der späteren Auflagen.

\section{Zur Geschichte der Textkritik.}

Das erste „Druckfehlerverzeichnis“ lieferte Grillo (Berlin) im Philosophischen Anzeiger, I. Jahrgang 1795, 41.-48. Stïck, das aber nicht einmal in der Originalauflage von 1797 und noch weniger von den späteren Herausgebern benutzt worden ist; ohne Schaden, da es (nach Natorp) neben vielem Wertlosen nur etwa ein Dutzend wirklicher Berichtigungen enthält, die von den späteren Editoren fast sämtlich ohnedies gefunden worden sind. Rosenkranz, der seinem Texte die zweite Ausgabe zugrunde legte, hat sich, wie auch sonst kaum um dessen Gestaltung gekümmert. Dagegen rühren zahlreiche Verbesserungen auch hier von Hartens tein her, der die 6. Auflage - unter Mitberücksichtigung der zweiten - als Grundlage benutzto. Kirchmanns Ausgabe ist, wie gewöhnlich, ein bloßer Abdruck der Hartensteinschen von 1867. Auch Kehrbac h hat sich fast ganz nach Hartenstein gerichtet; nur drei Lesarten (S. 59, 67, 107 unserer Ausgabe) stammen von ihm selbst her. Die meiste textkritische Arbeit von allen bisherigen Herausgebern hat Natorp geleistet, der darin, wio er in seiner Akademie-Ausgabe mitteilt, von Görland (Hamburg), Nolte (Kassel) und K. Vorländer (Solingen) unterstützt wurde. Auch die Konjekturen von E. Adickes (Kantstudien V $211 \mathrm{ff}$.) und Wille (ebd. VIII $467 \mathrm{ff}$.) konnten von Natorp noch benutzt werden. Es folgten die Bemerkungen von 0. Schondörffer (Altpreuß. Monatsschrift 48, $1 \mathrm{ff}$.), E. von Aster (Kantst. XIV, 468ff.), K. Vorländer (Ztschr. f. Philos. 138, $137 \mathrm{ff}$.) und die 2. Auflage der Akad. Ausg. (1913); endlich 1914 die Ausgabo von B. Kollermann (8. oben 14.), die alle vorigen sorgfältig benutzt hat und selbst einige beachtenswerto Vorschläge bringt.

Unsere eigene Ausgabe beruht auf einer nochmaligen genauen Vergleiohung mit der Akademie-Ausgabe, unter Bertiokwiohtigung aller seitdem hinzugokom- 
Einleitung.

menen Verbesserungsvorschläge. Im folgenden sind die Textänderungen angeführt, die in unserer Ausgabe zum ersten Male in den Text aufgenommen oder als diskutierbar unter demselben verzeichnet worden sind.
C. Textänderungen unserer Ausgabe.

Seite $20^{11}$ ihre statt ihrer.

$n \quad 38$ sie statt es.

n $45^{12}$ welche statt welches.

" $51^{20}$ demselben statt derselben.

n 73 s könnte statt könne.

n 75 ' eines Gegenstandes, Zusatz (Natorp).

n $93^{21}$ jenem statt jedem.

n $98^{26}$ sie statt es.

" $125^{29}$ denen statt den.

" $150^{30}$ durchs statt durch.

"15516 sie Zusatz.

Dazu an Vermutungen:

Seite 12 Erkenntnis statt Elemente?

* $45^{21}$ diese statt dieses?

" $57^{20}$ der Sinnenwelt die Form?

" 59 ? Gesetze statt Gesetzes?

" $68^{10}$ sie Zusatz?

n $96^{12}$ ist statt sei?

n $125^{28}$ in statt an?

" $152^{\circ}$ seiner statt ihrer? 



\title{
Kritik
}

der

\section{praktischen Vernunft}

ron

\author{
Immanuel Kant.
}




\section{Vorrede.}

Warum diese Kritik nicht eine Kritik der reinen praktischen, sondern schlechthin der praktischen Vernunft überhaupt betitelt wird, obgleich der Parallelismus derselben mit der spekulativen das erstere zu erfordern scheint, darüber gibt diese Abhandlung hinreichenden Aufschluß. Sie soll bloß dartun, daß es reine praktische Vernunft gebe, und kritisiert in dieser Absicht ihr ganzes praktischos Vermögen. Wenn es ihr hiermit gelingt, so bedarf sie das 10 reine Vermögen selbst nicht zu kritisieren, um zu sehen, ob sich die Vernunft mit einem solchen als einer bloßen Anmaßung nicht üborsteige (wie es wohl nit der spekulativen geschieht). Denn wenn sie als reine Vernunft wirklich praktisch ist, so beweist sie ihre und ihrer Begriffe Realität durch die Tat, und alles Vernünfteln wider die Möglichkeit, es za sein, ist vergeblich.

Mit diesem Vermögen steht auch die transzendentale Freiheit nunmehr fest, und zwar in derjenigen 20 absoluten Bedeutung genommen, worin die spekulative Vernunft beim Gebrauche des Begriffs der Kausalität sie bedurfte, um sich wider die Antinomie zu retten, darin sie unvermeidlich gerät, wenn sie in der Reihe der Kausalverbindung sich das Unbedingte denken will; welchen Begriff sie aber nur problematisch, als nicht unmöglich zu denken, aufstellen konnte, ohne ihm seine objektive Realität zu sichern, sondern allein, um nicht durch vorgebliche Unmöglichkeit dessen, was sie doch wenigstens als 30 
denkbar gelten lassen muß; in ihrem Wesen angefochten und in einen Abgrund des Skeptizismus gestürzt zu werden.

Der Begriff der Freiheit, sofern dessen Realität durch ein apodiktisches Gesetz der praktischen Vernunft bewiesen ist, macht nun den Schlußstein von dem ganzen Gebäude eines Systems der reinen, selbst [4] der spekulativen Vernunft aus, und alle anderen Begriffe (die von Gott und Unsterblichkeit), welche als

10 bloße Ideen in dieser ohne Haltung bleiben, schließen sich nun an ihn an und bekommen mit ihm und durch ihn Bestand und objektive Realität, d. i. die Möglichkeit derselben wird dadurch bewiesen, daß Freiheit wirklich ist; denn diese Idee offenbart sich durchs moralische Gesetz.

Freiheit ist aber auch die einzige unter allen Ideen der spekulativen Vernunft, wovon wir die Möglichkeit a priori wissen, ohne sie doch einzusehen, weil sie die Bedingung*) des moralischen Gesetzes ist, welches

20 wir wissen. Die Ideen von Gott und Unsterblichkeit sind aber nicht Bedingungen des moralischen Gesetzes, sondern nur Bedingungen des notwendigen Objekts eines durch dieses Gesetz bestimmten Willens, d. i. des bloß praktischen Gebrauchs unserer reinen Vernunft; also können wir von jenen Ideen auch, ich will nicht bloß sagen nicht die Wirklichkeit, sondern auch nicht einmal die Möglichkeit zu erkennen und einzusehen behaupten. Gleichwohl aber sind sie die Bedingungen der Anwendung des moralisch bestimmten

*) Damit man hier nicht Ink on se quenzen anzutreffen wähne, wenn ich jetzt die Freiheit die Bedingung des moralischen Gesetzes nenne and in der Abhandlang nachher behaupte, daß das moralische Gesetz die Bedingung sei, unter der wir uns allererst der Freiheit bew $\mathrm{n}$ Bt werden können, so will ich nur erinnern, daß die Freiheit allerdings die ratio essendi des moralischen Gesetzes, das moralische Gesetz aber die ratio cognoscendi der Freiheit sei. Denn wäre nicht das moralische Gesetz in unserer Vernunft eher deutlich gedacht, so würden wir uns niemals berechtigt halten, so etwas, als Freiheit ist (ob diese gleich sich nicht widerspricht), anzun ehmen. Ware aber keine Freiheit, so wtirde das moralische Gesetz in une gar nicht anzutreffen sein. 
Willens auf sein ihm a priori gegebenes Objekt (das höchste Gut). Folglich kann und muß ihre Möglichkeit in dieser praktischen Beziehung angenommen werden, ohne sie doch theoretisch zu erkennen und einzusehen. Für die letztere Forderung ist in praktischer Absicht genug, daß sie keine innere Unmöglichkeit (Widerspruch) enthalten. Hier ist nun ein in Vergleichung mit der spekulativen Vernunft bloß subjektiver Grund des Fürwahrhaltens, der doch einer ebenso reinen, aber praktischen Vernunft objektiv 10 gültig ist, dadurch den Ideen von Gott und Unsterblichkeit vermittelst des Begriffs der Freiheit objektive Realität und Befugnis, ja subjektive Notwendigkeit (Bedürfnis der reinen Vernunft) sie anzunehmen verschafft wird, ohne daß dadurch doch die Vernunft im theoretischen Erkenntnisse erweitert, sondern nur die Möglichkeit, die vorher nur Problem war, hier Assertion wird, gegeben und so der praktische Gebrauch der Vernunft mit den Elementen des theoretischen verknüpft wird. Und dieses Bedürfnis ist nicht 20 etwa ein hypothetisches einer beliebigen Absicht der Spekulation, daß man etwas annehmen müsse, wenn man zur Vollendung des Vernunftgebrauchs in der Spekulation hinaufsteigen will, sondern ein gesetzliches, etwas anzunehmen, ohne welches nicht geschehen kann, was man sich zur Absicht seines Tuns und Lassens unnachlaßlich setzen soll.

Es wäre allerdings befriedigender für unsere spekulative Vernunft, ohne diesen Umschweif jene Aufgaben für sich aufzulösen und sie als Einsicht zum 30 praktischen Gebrauche aufzubewahren; allein es ist einmal mit unserem Vermögen der Spekulation nicht so gut bestellt. Diejenigen, welche sich solcher hohen Erkenntnisse rühmen, sollten damit nicht zurückhalten, sondern sie öffentlich zar Prüfung und Hochschätzung darstellen. Sie wollen bew oisen; wohlan! so mögen sie denn beweisen, und die Kritik legt ihnen als Siegern ihre ganze Rüstung zu Füßen. Quid statis? Nolunt. Atqui licet esse beatis.a) $\mathrm{Da}$ sie also in der Tat nicht wollen, vermutlich, weil $\mathbf{1 0}$

a) Horaz, Satir. I 1, 19. 
sie nicht können, so müssen wir jene doch nur wiederum zur Hand nehmen, um die Begriffe von Gott, Freiheit und Unsterblichkeit, für welche die Spekulation nicht hinreichende Gowährleistung ihrer Möglichkoit findet, in moralischem Gebrauche der Vernunft zu suchen und auf demselben zu gründen.

Hier erklärt sich auch allererst das Rätsel der Kritik, wie man dem übersinnlichen Gebrauche der

$10 \mathrm{Kategorien} \mathrm{in} \mathrm{der} \mathrm{Spekulation} \mathrm{objektive} \mathrm{Realität}$ absprechen und ihnen ${ }^{2}$ ) doch in Ansehung der $\mathrm{Ob}$ jekte der reinen praktischen Vernunft diese Realität zugestehen könne; denn vorher muß dieses notwendig inkonsequent aussehen, solange man einen solchen praktischen Gebrauch nur dem Namen nach kennt. Wird man aber jetzt durch eine vollständige Zergliederung derb) letzteren inne, daß gedachte Realität hier gar auf keine theoretische Bestimmung der Kategorien und Erweiterung der Erkenntnis 20 zum Übersinnlichen hinausgehe, sondern nur hierdurch gemeint sei, daß. ihnen in dieser Beziehung überall ein Objekt zukomme, weil sie entweder in der notwendigen Willensbestimmung! a priori enthalten oder mit dem Gegenstande derselben unzertrennlich verbunden sind, so verschwindet jene Inkonsequenz, weil man einen anderen Gebrauch von jenen $\mathrm{Be}-$ [6] griffen macht, als spekulative Vernunft bedarf. Dagegen eröffnet sich nun eine vorher kaum zu erwartende und sehr befriedigende Bestätigung der 30 konsequenten Denkungsart der spekulativen Kritik darin, daß, da diese die Gegenstände der Erfahrung als solche und darunter selbst unser eigenes Subjekt nur für Erscheinungen gelten zu lassen, ihnen aber gleichwohl Dinge an sich selbst zum Grunde zu legen, also nicht alles Übersinnliche für Erdichtung und dessen Begriff für leer an Inhalt zu halten einschärfte: praktische Vernunft jetzt für sich selbst, und ohne mit der spekulativen Verabredung getroffen zu haben, einem übersinnlichen Gegenstande der Kate-

a) Erdmann: nihm".

b) Natorp, Adickes: "des". 
gorie der Kausalität, nämlich der Freiheit, Realität verschafft (obgleich als praktischem Begriffe auch nur zum praktischen Gebrauche), also dasjenige, was dort bloß gedacht werden konnte, durch ein Faktum bestätigt. Hierbei erhält nun zugleich die befremdliche, obzwar unstreitige Behauptung der spekulativen Kritik, daß sogar das denkende Subjekt ihm selbst in der inneren Anschauung bloß Er. scheinung sei, in der Kritik der praktischen Vernunft auch ihre volle Bestätigung, so gut, daß man 10 auf sie kommen muß, wenn die erstere diesen Satz auch gar nicht bewiesen hätte.*)

Hierdurch verstehe ich auch, warum die erheblichsten Einwürfe wider die Kritik, die mir bisher noch vorgekommen sind, sich gerade um diese zwei Angeln drehen: nämlich einerseits im theoretischen Erkenntnis geleugnete und im praktischen behauptete objektive Realität der auf Noumenen angewandten Kategorien, andererseits die paradoxe Forderung, sich als Subjekt der Freiheit zum Noumen, zugleich 20 aber auch in Absicht auf die Natur zum Phänomen in seinem eigenen empirischen Bewußtsein zu machen. Denn solange man sich noch keine bestimmten Begriffe von Sittlichkeit und Freiheit machte, konnte man nicht erraten, was man einerseits der vorgeblichen Erscheinung als Noumen zum Grunde legen wolle, und andererseits, ob es überall auch möglich sei, sich noch von ihm einen Begriff zu machen, wenn man vorher alle Begriffe des reinen Verstandes im theoretischen Gebrauche schon ausschließungs- 30 weise den bloßen Erscheinungen gewidmet hätte. Nur eine ausführliche Kritik der praktischen Vernunft kann alle diese Mißdeutung heben und die konse-

*) Die Vereinigung der Kansalität als Freiheit mit ihr als Naturmechanismus, davon die erste durchs Sittengesetz, die $z$ weite durchs Naturgesetz and zwar in einem and demselben Subjekte, dem Menschen, feststeht, ist unmoglich, ohne diesen in Beziehnng auf das erstere als Wesen an sich gelbst, auf das zweite aber als Erscheinung, jenes im roinen, dieses im empirischen Bewu@tsein vorzustellen. Ohne dieses ist der Widerspruch der Vernunft mit sich selbst unvermeidlich. 
quente Denkungsart, welche eben ihren größten Vorzug ausmacht, in ein helles Licht setzen.

Soviel zur Rechtfertigung, warum in diesem Werke die Begriffe und Grundsätze der reinen spekulativen Vernunft, welche doch ihre besondere Kritik schon erlitten haben, hier hin und wieder nochmals der Prüfung unterworfen werden, welches dem systematischen Gange einer zu errichtenden Wissenschaft sonst nicht wohl geziemt (da abgeurteilte Sachen billig nur 10 angeführt und nicht wiederum in Anregung gebracht werden müssen), doch hier erlaubt, ja nötig war: weil die Vernunft mit jenen Begriffen im Ubergange zu einem ganz anderen Gebrauche betrachtet wird, als den sie dort von ihnen machte. Ein solcher Ubergang macht aber eine Vergleichung des älteren mit dem neueren Gebrauche notwendig, um das neue Gleis von dem vorigen wohl $\mathrm{zu}$ unterscheiden und zugleich den Zusammenhang derselben bemerken zu lassen. Man wird also Betrachtungen dieser Art, unter anderen 20 diejenige, welche nochmals auf den Begriff der Freiheit, aber im praktischen Gebrauche der reinen Vernunft gerichtet worden, nicht wie Einschiebsel betrachten, die etwa nur dazu dienen sollen, um Lücken des kritischen Systems der spekulativen Vernunft auszufüllen (denn dieses ist in seiner Absicht vollständig) uma), wie es bei einem übereilten Baue herzugehen pflegt, hintennach noch Stützen und Strebepfeiler anzubringen, sondern als wahre Glieder, die den $\mathrm{Zu}-$ sammenhang des Systems bemerklich machen, um Be80 griffe, die dort nur problematisch vorgestellt werden konnten, jetzt in ihrer realen Darstellung einsehen zu lassen. Diese Erinnerung geht vornehmlich den Begriff der Freiheit an, von dem man mit Befremdung bemerken muß, daß noch so viele ihn ganz wohl einzusehen und die Möglichkeit derselben b) erklären zu können sich rühmen, indem sie ihn bloß in psychologischer Beziehung betrachten, indessen daß, wenn sie ihn vorher in transzendentaler genau erwogen hätten, sie sowohl seine Unentbehrlichkeit

a) Kant: „und"; korr. Hartenstein.

b) 2. Aufl.: "desselben". 
als problematischen Begriffs in vollständigem Gebrauche der spekulativen Vernunft, als auch die völlige Unbegre iflichkeit desselben hätten erkennen und, wenn sie nachher mit ihm zum praktischen Gebrauche gingen, gerade auf die nämliche Bestimmung des letzteren in Ansehung seiner Grundsätze von selbst hätten kommen müssen, $\mathrm{zu}$ welcher sie sich sonst so ungern verstehen wollen. Der Begriff der Freiheit ist der Stein des Anstoßes für alle Empiristen, aber auch der Schlüssel zu den erhabensten prakti- 10 schen Grundsätzen für kritische Moralisten, die da- [8] durch einsehen, daß sie notwendig rational verfahren müssen. Um deswillen ersuche ich den Leser, das, was zum Schlusse der Analytik über diesen Begriff gesagt wird, nicht mit flüchtigem Auge zu übersehen.

$\mathrm{Ob}$ ein solches System, als hier von der reinen praktischen Vernunft aus der Kritik der letzteren entwickelt wird, viel oder wenige Mühe gemacht habe, um vornehmlich den rechten Gesichtspunkt, aus dem das 20 Ganze derselben richtig vorgezeichnet werden kann, nicht $\mathrm{zu}$ verfehlen, muß ich den Kennern einer dergleichen Arbeit $\mathrm{zu}$ beurteilen überlassen. Es setzt zwar die Grundlegung zur Metaphysik der Sitten voraus, aber nur insofern, als diese mit dem Prinzip der Pflicht vorläufige Bekanntschaft macht und eine bestimmte Formel derselben angibt und rechtfertigt*); sonst besteht es durch sich selbst. Daß die Einteilung aller praktischen Wissenschaften zur.

*) Ein Rezensent, der etwas zum Tadel dieser Schrift sagen wollte, hat es besser getroffen, als er wohl selbst gemeint haben mag, indem er sagt: daß darin kein neues Prinzip der Moralität, sondern nur eine nene Formel aufgestellt worden. Wer wollte aber anch einen neuen Grandsatz aller Sittlichkeit einführen und diese gleichsam zuerst erfinden? gleich als ob vor ihm die Welt in dem, was Pflicht sei, unwissend oder in durchgängigem Irrtume gewesen wäre. Wer aber weiB, was dem Mathematiker eine Formel bedentet, die das, was zu tun sei, um eine Anfgabe zu befolgen, ganz genau bestimmt and nicht verfehlen läßt, wird eine Formel, welche dieses in Ansehung aller Ptlicht überhaupt tut, nicht für etwas Unbedentendes und Entbehrliches halten. 
Vollständigkeit nicht mit beigefügt worden, wio es die Kritik der spekulativen Vernunft leistete, dazu ist auch gültiger Grund in der Beschaffenheit dieses praktischen Vernunftvermögens anzutreffen. Denn die besondere Bestimmung der Pflichten als Menschenpflichten, um sie einzuteilen, ist nur möglich, wenn vorher das Subjekt dieser Bestimmung (der Mensch) nach der Beschaffenheit, mit der er wirklich ist, obzwar nur soviel, als in Beziehung auf Pflicht über10 haupt nötig ist, erkannt worden; diese aber gehört nicht in eine Kritik der praktischen Vernunft überhaupt, die nur die Prinzipien ihrer Möglichkeit, ihres Umfangs und Grenzen vollständig ohne besondere Beziehung auf die menschliche Natur angeben soll. Die Einteilung gehört also hier zum System der Wissenschaft, nicht zum System der Kritik.

Ich habe einem gewissen wahrheitliebenden und scharfen, dabei also doch immer achtungswürdigen Rezensenten jener Grundlegung zur Metaphysik 20 der Sitten auf seinen Einwurf: daß der Begriff [9] des Guten dort nicht (wie es seiner Meinung nach nötig gewesen wäre) vor dem moralischen Prinzip festgesetzt worden*), in dem zweiten Hauptstücke

*) Man kơnnte mir noch den Einwurf machen: warum ich nicht auch den Begriff des Begehrungsverm 8 gens oder des Gefühls der Lust vorher erklärt habe; obgleich dieser Vorwarf anbillig sein würde, weil man diese Erklärung, als in der Psychologie gegeben, billig sollte voraussetzen konnen. Es konnte aber freilich die Definition daselbst so eingerichtet sein, daß das Gefühl der Lust der Bestimmung des Begehrungsvermögens zum Grunde gelegt würde (wie es auch wirklich gemeinhin so $\mathrm{zu}$ geschehen pflegt), dadurch aber das oberste Prinzip der praktischen Philosophie notwendig empirisch ansfallen müßte, welches doch allererst anszumachen ist nnd in dieser Kritik gänzlich widerlegt wird. Daher will ich diese Erklärung hier so geben, wie sie sein muß, um diesen streitigen Punkt, wie billig, im Anfange unentschieden zu lassen. - Leben ist das Vermoggen eines Wesens, nach Gesetzen des Begehrungsvermogens zu bandeln. Das Begehrungsvermögen ist das Vermogen desselben, durch seine Vorstellungen Ursache von der Wirklichkeit der Gegenstände dieser Vorstellungen za sein. Lust ist die Vorstellung der Ubereinstimmung dos 
der Analytik, wie ich hoffe, Genüge getan; ebenso auch auf manche andere Einwürfe Rücksicht genommen, die mir von Männern zu Händen gekommen sind, die den Willen blicken lassen, daß die Wahrheit auszumitteln ihnen am Herzen liegt (denn die, so nur ihr altes System vor Augen haben, und bei denen schon vorher beschlossen ist, was gebilligt oder mißbilligt werden soll, verlangen doch keine Erörterung, die ihrer Privatabsicht im Wege sein könnte); und so werde ich es auch fernerhin halten.

Wenn es um die Bestimmung eines besonderen Vermögens der menschlichen Seele nach seinen Quellen, Inhalte und Grenzen zu tun ist, so kann man zwar nach der Natur der menschlichen Erkenntnis nicht ${ }^{2}$ ) anders als von den Teilen derselben, ihrer genauen

Gegenstandes oder der Handlung mit den subjektiven Beding angen des Lobens, d. i. mit dem Vermogen der Kausalitat einer Vorstellung in Ansehang der Wirklichkeit ihres Objekts (oder der Bestimmung der Kräfte des Subjekts zur Handlung, es hervorzubringen). Mehr brauche ich nicht zum Behuf der Kritik von Begriffen, die aus der Psychologie entlehnt werden; das übrige leistet die Kritik selbst. Man wird leicht gewahr, daß die Frage, ob die Lust dem Begehrungsvermogen jederzeit zum Grande gelegt werden müsse, oder ob sie anch unter gevrissen Bedingungen nur auf die Bestimmung desselben folge, durch diese Erklärung unentschieden bleibt; denn sie int aus lauter Merkmalen des reinen Vorstandes, d. i. Kategorien, zusammengesetzt, die nichts Empirisches enthalten. Eino solche Behutsamkeit ist in der ganzen Philosophie sehr empfehlungswürdig und wird dennoch oft verabsăumt, nămlich seinen Urteilen vor der vollst die oft nur sehr spăt erreicht wird, durch gewagt Definition nicht vorzugreifen. Man wird auch durch den ganzen Lauf der Kritik (der theoretischen sowohl als praktischen - Vernunft) bemerken, $\mathrm{da} B$ sich in demselben mannigfaltige Veranlassung vorfinde, manche Măngel im alten dogmatischen Gange der Philosophie zu ergänzen und Fehler abzaändern, die nicht eher bemerkt werden, als wenn man von Begriffen einen Gebranch der Vernunftb) macht, der aufs Ganze derselben geht.

a) 2. Aufl.: "nichts".

b) der Vernunft einen Gebrauch? [Natorp]. 
und (soviel als nach der jetzigen Lage unserer schon erworbenen Elemente ${ }^{a}$ ) derselben möglich ist) vollständigen Darstellung anfangen. Aber es ist noch eine zwoite Aufmerksamkeit, die mehr philosophisch und architektonisch ist: nämlich die Idee des Ganzen richtig zu fassen und aus derselben alle jene Teile in ihrer wechselseitigen Beziehung aufeinander, vermittelst der Ableitung derselben von dem Begriffe jenes Ganzen, in einem reinen Vernunftver10 mögen ins Auge zu fassen. Diese Prüfung und Gewährleistung ist nur durch die innigste Bekanntschaft mit dem System möglich, und die, welche in Ansehung der ersteren Nachforschung verdrossen gewesen, also diese Bekanntschaft zu erwerben nicht der Mühe wert geachtet haben, gelangen nicht zur zweiten Stufe, nämlich der Ubersicht, welche eine synthetische Wiederkehr zu demjenigen ist, was vorher analytisch gegeben worden, und es ist kein Wunder, wenn sie allerwärts Inkonsequenzen finden, ob-

20 gleich die Lücken, die diese vermuten lassen, nicht im System selbst, sondern bloß in ihrem eigenen unzusammenhängenden Gedankengange anzutreffen sind. Ich besorge in Ansehung dieser Abhandlung nichts von dem Vorwurfe, eine neue Sprache einführen zu wollen, weil die Erkenntnisart sich hier von selbst der Popularität nähert. Dieser Vorwurf konnte auch niemanden in Ansehung der ersteren. Kritik beifallen, der sie nicht bloß durchgeblättert, sondern durchgedacht hatte. Neue Worte zu künsteln, wo die

30 Sprache schon so an Ausdrücken für gegebene Begriffe keinen Mangel hat, ist eine kindische $\mathrm{Be}$ mühung, sich unter der Menge, wenn nicht durch neue und wahre Gedanken, doch durch einen neuen Lappen auf dem alten Kleide auszuzeichnen. Wenn daher die Leser jener Schrift populärere Ausdrücke wissen, die doch dem Gedanken ebenso angemessen sind, als mir jene zu sein scheinen, oder etwa die Nichtigkeit dieser Gedanken selbst, mithin zugleich jedes Ausdrucks, der ihn bezeichnet, darzutun sich 40 getrauen: so würden sie mich durch das erstere sehr

a) Erkenntnis? [Vorlănder]. 
verbinden, denn ich will nur verstanden sein, in Ansehung des zweiten aber sich ein Verdienst um die Philosophie erwerben. Solange aber jene Gedanken noch stehen, zweifle ich sehr, daß ihnen angemessene und doch gangbarere Ausdrücke dazu aufgefunden werden dürften.*)

*) Mehr (als jene Unverständlichkeit) besorge ich hier hin and wieder Mißdentung in Ansehung einiger Ausdrücke, die ich mit größter Sorgfalt aussuchte, nm den Begriff nicht verfehlen zu lassen, darauf sio weisen. So hat in der Tafel der Kategorien der praktischen Vernunft, in dem Titel der Modalitat, dasErla ab te nnd Unerlaubte (praktisch-objektiv Mögliche und Unmogliche) mit der nächstfolgenden Kategorie der Pflicht und des Pflicht widrigen im gemeinen Sprachgebrauche beinahe einerlei Sinn; hier aber soll das erstere dasjenige bedenten, was mit einer bloß moglichen praktischen Vorschrift in Einstimmung oder Widerstreit ist (wie etwa die Auflösang aller Probleme der Geometrie und $\mathrm{Me}_{\theta}$ chanik), das zweite, was in solcher Beziehung anf ein in der Vernunft überhaupt wirklich liegendes Gesetz steht; und dieser Unterschied der Bedeutung ist anch dem gemeinen Sprachgebrauche nicht ganz fremd, wenngleich etwas ungewohnlich. So ist es z. B. einem Redner als solchem n norlaubt, nene Worte oder Wortfügungen zu schmieden; dem Dichter ist es in gewissem Maße erlaubt; in keinem von beiden wird hier an Pflicht gedacht. Denn wer sich um den Ruf eines Redners bringen will, dem kann es niemand wehren. Es ist hier nur um den Unterschied der Imperativen unter problematischem, assertorischem nnd ap odiktischem Bestimmungsgrunde zu tun. Ebenso habe ich in derjenigen Note, wo ich die moralischen Ideen praktischer Vollkommenheit in verschiedenen philosophischen Schulen gegeneinander stellte, die Jdee der Weisheit von der der Heiligkeit unterschieden, ob ich sie gleich selbst im Grunde and objektiv für einerlei erklärt habe. Allein ich verstehe an diesem Orte darunter nur diejenige Weisheit, die sich der Mensch (der Stoiker) anmaßt, also s ubjektiv als Eigenschaft dem Menschen angedichtet. (Vielleicht konnte der Ansdruck Tugend, womit der Stoiker anch großen Staat trieb, besser das Charakteristische seiner Schale bezeichnen.) Aber der Ausdruck eines Postulats der reinen praktischen Vernunft konntea) noch am meisten Mißdentung veranlassen, wenn man damit die Bedeutung vermengte,

a) „könnto [Hartenstein]? 
[12] Auf diese Weise wären denn nunmehr die Prinzipien a priori zweier Vermögen des Gemüts, des $\mathrm{Er}$ kenntnis- und Begehrungsvermögens, ausgemittelt und nach den Bedingungen, dem Umfange und Grenzen ihres Gebrauchs bestimmt, hierdurch aber zu einer systematischen, theoretischen sowohl als praktischen, Philosophie als Wissenschaft sicherer Grund gelegt.

Was Schlimmeres könnte aber diesen Bemühungen wohl nicht begegnen, als wenn jemand die unerwartete 10 Entdeckung machte, daß es überall gar keine Erkenntnis a priori gebe, noch geben könne. Allein es hat hiermit keine Not. Es wäre ebensoviel, als ob jemand durch Vernunft beweisen wollte, daß es keine Vernunft gebe. Denn wir sagen nur, daß wir etwas durch Vernunft erkennen, wenn wir uns bewußt sind, daß wir es auch hätten wissen können, wenn es uns auch nicht so in der Erfahrung vorgekommen wäre; mithin ist Vernunfterkenntnis und Erkenntnis a priori einerlei. Aus einem Erfahrungssatze Notwendigkeit

20 (ex pumice aquam a) auspressen wollen, mit dieser auch wahre Allgemeinheit (ohne welche kein Vernunftschluß, mithin auch nicht der Schluß aus der Analogie, welche eine wenigstens präsumierte Allgemeinheit und objektive Notwendigkeit ist und diese also doch immer voraussetzt) einem Urteile verschaffen wollen, ist gerader Widerspruch. Subjektive Notwendigkeit, d. i.

welche die Postulate der reinen Mathematik haben, und welche apodiktische Gewißheit bei sich führen. Aber diese postulieren die Moglichkeit einer Handlung, deren Gegenstand man a priori theoretisch mit volliger Gewißheit als moglich voraus erkannt hat. Jenes aber postaliert die Möglichkeit eines Gegenstandes (Gottes und der Unsterblichkeit der Seele) selbst aus apodiktischen praktischen Gesetzen, also nur zum Behuf einer praktischen Vernunft; da denn diese Gewißheit der postalierten Möglichkoit gar nicht theoretisch, mithin auch nicht apodiktisch, $d$. $i$. in Ansehung des Objekts erkannte Notwendigkeit, sondern in Ansehung des Subjekts zur Befolgung ihrer objektiven, aber praktischen Gesetze notwendige Annehmung, mithin bloB notwendige Hypothesis ist. Ich waßte für diese subjektive, aber doch wahre und unbedingte Vernunftnotwendigkeit keinen besseren Ausdruok auszufinden.

a) = aus Bimstein Wasser (d. i. etwas Unmögliches). Plautus, Persa I 1, 41. 
Gewohnheit, statt der objektiven, die nur in Urteilen a priori stattfindet, unterschieben heißt der Vernunft das Vermögen absprechen, über den Gegenstand zu urteilen, d. i. ihn, und was ihm zukomme, zu erkennen und z. B. von dem, was öfters und immer auf einen gewissen vorhergehenden Zustand folgte, nicht sagen, daß man aus diesem auf jenes schließen könne (denn das würde objektive Notwendigkeit und Begriff von einer Verbindung a priori bedeuten), sondern nur ähnliche Fälle (mit den Tieren auf ähnliche Art) er- 10 warten dürfe, d. i. den Begriff der Ursache im Grunde als falsch und bloßen Gedankenbetrug verwerfen. Diesem Mangel der objektiven und daraus folgenden allgemeinen Gültigkeit dadurch abhelfen wollen, daß man doch keinen Grund sähe, anderen vernünftigen Wesen eine andere Vorstellungsart beizulegen, wenn das einen gültigen Schluß abgäbe, so würde uns unsere Unwissenheit mehr Dienste zu Erweiterung unserer Erkenntnis leisten als alles Nachdenken. Denn bloß deswegen, weil wir andere vernünftige Wesen 20 außer dem Menschen nicht kennen, würden wir ein Recht haben, sie als so beschaffen anzunehmen, wie wir uns erkennen, d. i. wir würden sie wirklich kennen. Ich erwähne hier nicht einmal, daß nicht die Allgemeinheit des Fürwahrhaltens die objektive Gültigkeit eines Urteils (d. i. die Gültigkeit desselben als [13] Erkenntnisses) beweise, sondern, wenn jene auch zufälligerweise zuträfe, dieses doch nicht einen Beweis der Übereinstimmung mit dem Objekt abgeben könne; vielmehr die objektive Gültigkeit allein den Grund 30 einer notwendigen allgemeinen Einstimmung ausmache.

$\operatorname{Hum} \theta$, würde sich bei diesem System des allgemeinen Empirismus in Grundsätzen auch sehr wohl befinden; denn er verlangte, wie bekannt, nichts mehr, als daß statt aller objektiven Bedeutung der Notwendigkeit im Begriffe der Ursache eine bloß subjektive, nämlich Gewohnheit, angenommen werde, nm der Vernunft alles Urteil über Gott, Freiheit und Unsterblichkeit abzusprechen; und er verstand sich gewiß sehr gut darauf, um, wenn man ihm nur die 40 Prinzipien zugestand, Schlüsse mit aller logischen Bündigkeit daraus zu folgern. Aber so allgemein hat 
selbst Hume den Empirismus nicht gemacht, um auch die Mathematik darin einzuschließen. Er hielt ihre Sätze für analytisch, und wenn das seine Richtigkeit hätte, würden sie in der Tat auch apodiktisch sein, gleichwohl aber daraus kein Schluß auf ein Vermögen der Vernunft, auch in der Philosophie apodiktische Urteile, nämlich solche, die synthetisch wären (wie der Satz der Kausalität), zu fällen, gezogen werden können. Nähme man aber den Empirismus der Prinzipien all10 gemein an, so wäre auch Mathematik damit eingeflochtena).

Wenn nun diese mit der Vernunft, die bloß empirische Grundsätze zuläßt, in Widerstreit gerät, wie dieses in der Antinomie, da Mathematik die unendliche Teilbarkeit des Raumes unwidersprechlich beweist, der Empirismus aber sie nicht verstatten kann, unvermeidlich ist: so ist die größte mögliche Evidenz der Demonstration mit den vorgeblichen Schlüssen aus Erfahrungsprinzipien in offenbarem Widerspruch, und 20 nun muß man, wie der Blinde des Cheseldenb), fragen: was betrügt mich, das Gesicht oder Gefühl? (Denn der Empirismus gründet sich auf einer $\mathrm{g} \theta-$ fühlten, der Rationalismus aber auf einer eingesehenen Notwendigkeit.) Und so offenbart sich der allgemeine Empirismus als der echte Skeptizismus, den man dem Hume fälschlich in so unbeschränkter Bedeutung beilegte*), da er wenigstens einen sicheren

*) Namen, welche einen Sektenanhang bezeichnen, haben zu aller Zeit viel Rechtsverdrehung bei sich geführt; ungefähr so, als wenn jemand sagte: N. ist ein Id ealist. Denn ob er gleich durchaus nicht allein einräumt, sondern darauf dringt, da $B$ unseren Vorstellungen äußerer Dinge wirkliche

a) So Hume im 4. Abschnitt seiner Inquiry. Anders in dem älteren Treatise, der Kant mithin nicht oder doch nicht genauer bekannt gewesen zu sein scheint.

b) W. Cheselden ist der Name eines englischen Anatomen, dessen Osteographia in Goethes Morphologie erwähnt wird, und dessen ${ }_{n}$ Anatomie des menschlichen Körpers" (in deutscher Übersetzung) Göttingen 1790 erschien. Kant scheint (nach Natorp) obigen Bericht Kaestners Bearbeitung eines englischen Werks über Optik entnommen zu haben. 
Probierstein der Erfahrung an der Mathematik übrig [14] lie $\beta$, statt da $\beta$ jener schlechterdings keinen Probierstein derselben (der immer nur in Prinzipien a priori angetroffen werden kann) verstattet, obzwar diese doch nicht aus bloßen -Gefühlen, sondern auch aus Urteilen besteht.

Doch da es in diesem philosophischen und kritischen Zeitalter schwerlich mit jenem Empirismus Ernst sein kann, und er vermutlich nur zur Ubung der Urteilskraft und um durch den Kontrast die Not- 10 wendigkeit rationaler Prinzipien a priori in ein helleres Licht zu setzen, aufgestellt wird, so kann man es denen doch Dank wissen, die sich mit dieser sonst eben nicht belehrenden Arbeit bemühen wollen.

Gegenstände äußerer Dinge korrespondieren, so will er doch, daB die Form der Anschanung derselben nicht ihnen, sondern nur dem menschlichen Gemüte anhänge. 


\section{Einleitung.}

Von der Idee einer Kritik der praktischen Vernunft.

Der theoretische Gebrauch der Vernunft beschäftigte sich mit Gegenständen des bloßen Erkenntnisvermögens, und eine Kritik derselben in $\mathrm{Ab}$ sicht auf diesen Gebrauch betraf eigentlich nur das reine Erkenntnisvermögen, weil dieses Verdacht erregte, der sich auch hernach bestätigte, daß es sich leichtlich über seine Grenzen, unter unerreichbare

10 Gegenstände oder gar einander widerstreitende Begriffe verlöre. Mit dem praktischen Gebrauche der Vernunft verhält es sich schon anders. In diesem beschäftigt sich die Vernunft mit Bestimmungsgründen des Willens, welcher ein Vermögen ist, den Vorstellungen entsprechende Gegenstände entweder hervorzubringen oder doch sich selbst zur Bewirkung derselben (das physische Vermögen mag nun hinreichend sein oder nicht), d. i. seine Kausalität $\mathrm{zu}$ bestimmen. Denn da kann wenigstens die Vernunft zur

20 Willensbestimmung zulangen und hat sofern immer objektive Realität, als es nur auf das Wollen ankommt. Hier ist also die erste Frage: ob reine Vernunft zur Bestimmung des Willens für sich allein zulange, oder ob sie nur als empirisch-bedingte ein Bestimmungsgrund desselben ${ }^{a}$ ) sein könne? Nun tritt hier ein durch die Kritik der reinen Vernunft gerechtfertigter, obzwar keiner empirischen Darstellung fähiger Begriff der Kausalität, nämlich der der Freiheit ein;

a) Kant: „derselben“; korr. Hartenstein. 
and wenn wir jetzt Gründe ausfindig machen können zu beweisen, daß diese Eigenschaft dem menschlichen Willen (und so auch dem Willen aller vernünftigen Wesen) in der Tat zukomme, so wird dadurch nicht allein dargetan, daß reine Vernunft praktisch sein könne, sondern, daß sie allein, und nicht die empirisch-beschränkte, unbedingterweise praktisch! sei. Folglich werden wir nicht eine Kritik der reine n praktischen, sondern nur der praktischen Vernunft überhaupt zu bearbeiten haben. Denn reine Ver- 10 [16] nunft, wenn allererst dargetan worden, daß es eine solche gebe, bedarf keiner Kritik. Sie ist es, welche selbst die Richtschnur zur Kritik alles ihres Gebrauchsa) enthält. Die Kritik der praktischen Vernunft überhaupt hat also die Obliegenheit, die empirisch bedingte Vernunft von der Anmaßung abzuhalten, ausschließungsweise den Bestimmungsgrund des Willens allein abgeben zu wollen. Der Gebrauch der reinen Vernunft, wenn, daß es eine solche gebe, ausgemacht ist, ist allein immanent; der empirisch-bedingte, der 20 sich die Alleinherrschaft anmaßt, ist dagegen transzendent und äußert sich in Zumutungen und Geboten, die ganz über ihr Gebiet hinausgehen, welches gerade das umgekehrte Verhältnis von dem ist, was von der reinen Vernunft im spekulativen Gebrauche gesagt werden konnte.

Indessen da es immer noch reine Vernunft ist, deren Erkenntnis hier dem praktischen Gebrauche zum Grunde liegt, so wird doch die Einteilung einer Kritik der praktischen Vernunft, dem allgemeinen Abrisse 30 nach, der der spekulativen gemäß angeordnet werden müssen. Wir werden also eine Elementarlehre und Methodenlehre derselben, in jener als dem ersten Teile eine Analytik als Regel der Wahrheit und eine Dialektik als Darstellung und Auflösung des Scheins in Urteilen der praktischen Vernunft, haben müssen. Allein die Ordnung in der Unterabteilung der Analytik wird wiederum das Umgewandte von der in der Kritik der reinen spekulativen Vernunft sein. Denn in der gegenwärtigen werden wir von Grund-40 sätzen anfangend zo Begriffen und von diesen allererst womöglich zu den Sinnen gehen; da wir hin-

a) Wille: ${ }_{n}$ Richtschnur alles ibres Gebrauchs". 
gegen bei der spekulativen Vernunft von den Sinnen anfingen und bei den Grundsätzen endigen mußten. Hiervon liegt der Grund nun wiederum darin, daß wir es jetzt mit einem Willen zu tun haben und die Vernunft nicht im Verhältnis auf Gegenstände, sondern auf diesen Willen und dessen Kausalität zu erwägen haben, da denn die Grundsätze der empirisch unbedingten Kausalität den Anfang machen müssen, nach welchem der Versuch gemacht werden kann, unsere

10 Begriffe von dem Bestimmungsgrunde eines solchen Willens, ihre ${ }^{\mathrm{a}}$ ) Anwendung auf Gegenstände, zuletzt auf das Subjekt und dessen Sinnlichkeit allererst festzusetzen. Das Gesetz der Kausalität aus Freiheit, d. i. irgend ein reiner praktischer Grundsatz, macht hier unvermeidlich den Anfang und bestimmt die Gegenstände, worauf er allein bezogen werden kann. "nud ihre".

a) Kant: „ihrer66; korr. Vorländer (Adickes). Natorp: 


\section{Der}

\section{Kritik der praktischen Vernunft erster Teil.}

\section{Elementarlehre}

der

reinen praktischen Vernunft. 

Erstes Buch.

\title{
Die Analytik der reinen praktischen Vernunft.
}

\author{
Erstes Hauptstück.
}

Von den

Grundisätzen der reinen praktischen Vernunft.

\author{
$\S 1$. \\ Erklärung.
}

Praktische Grundsätze sind Sätze, welche eine allgemeine Bestimmung des Willens enthalten, die 10 mehrere praktische Regeln unter sich hat. Sie sind subjektiv oder Maximen, wenn die Bedingung nur als für den Willen des Subjekts gültig von ihm angesehen wird; objektiv aber oder praktische Gesetze, wenn jene als objektiv, d. i. für den Willen jedes vernünftigen Wesens gültig erkannt wird.

\section{Anmerkung.}

Wenn man annimmt, da $B$ reine Vernunft einen praktisch, d. i. zur Willensbestimmung hinreichenden Grund in sich enthalten könne, so gibt es praktische 20 Gesetze; wo aber nicht, so werdenalle praktischen Grundsätze bloße Maximen sein. In einem pathologisch affizierten Willen eines vernünftigen Wesens kann ein Widerstreit der Maximen wider die von ihm selbst erkannten praktischen Gesetze angetroffen werden. Z. B. es kann sich jemand zur Maxime machen, keine Beleidigung ungerächt zu erdulden, und doch zugleich 
einsehen, daß dieses kein praktisches Gesetz, sondern nur seine Maxime sei, dagegen als Regel für den Willen eines jeden vernünftigen Wesens in einer und derselben Maxime mit sich selbst nicht zusammenstimmen könne. In der Naturerkenntnis sind die Prinzipien dessen, was geschieht (z. B. das Prinzip der Gleichheit der Wirkung und Gegenwirkung in der Mitteilung der Bewegung) zugleich Gesetze der Natur; [20] denn der Gebrauch der Vernunft ist dort theoretisch 10 und durch die Beschaffenheit des Objekts bestimmt. In der praktischen Erkenntnis, d. i. derjenigen, welche es bloß mit Bestimmungsgründen des Willens zu tun hat, sind Grundsätze, die man sich macht, darum noch nicht Gesetze, darunter man unvermeidlich stehe, weil die Vernunft im Praktischen es mit dem Subjekte zu tun hat, nämlich dem Begehrungsvermögen, nach dessen besonderer Beschaffenheit sich die Regel vielfältig richten kann. - Die praktische Regel ist jederzeit ein Produkt der Vernunft, weil sie Handlung 20 als Mittel zur Wirkung als Absicht vorschreibt. Diese Regel ist aber für ein Wesen, bei dem Vernunft nicht ganz allein Bestimmungsgrund des Willens ist, ein Imperativ, d. i. eine Regel, die durch ein Sollen, welches die objektive Nötigung der Handlung ${ }^{2}$ ) ausdrückt, bezeichnet wird, und bedeutet, da $B$, wenn die Vernunft den Willen gänzlich bestimmte, die Handlung unausbleiblich nach dieser Regel geschehen würde. Die Imperativen gelten also objektiv und sind von Maximen, als subjektiven Grundsätzen, gänzlich unter30 schieden. Jene bestimmen aber entweder die Bedingungen der Kausalität des vernünftigen Wesens als wirkender Ursache bloß in Ansehung der Wirkung und Zulänglichkeit zu derselben, oder sie bestimmen nur den Willen, er mag zur Wirkung hinreichend sein oder nicht. Die ersteren würden hypothetische Imperativen sein und bloße Vorschriften der Geschick- lichkeit enthalten; die zweiten würden dagegen kategorisch und allein praktische Gesetze sein. Maximen sind also zwar Grundsätze, aber nicht Impera40 tiven. Die Imperativen selber aber, wenn sie be-

a) Adickes: „zur Handlung". 
dingt sind, d. i. nicht den Willen schlechthin als Willen, sondern nur in Ansehung einer begehrten Wirkung bestimmen, d. i. hypothetische Imperativen sind, sind zwar praktische Vorschriften, aber keine Gesetze. Die letzteren müssen den Willen als Willen, noch ehe ich frage, ob ich gar das zu einer begehrten Wirkung erforderliche Vermögen habe, oder was mir, um diese hervorzubringen, zu tun sei, hinreichend bestimmen, mithin kategorisch sein, sonst sind es keine Gesetze; weil ihnen die Notwendigkeit fehlt, 10 welche, wenn sie praktisch sein soll, von pathologischen, mithin dem Willen zufällig anklebenden Bedingungen unabhängig sein muß. Saget jemanden z. B., $\mathrm{da} B$ er in der Jugend arbeiten und sparen müsse, um im Alter nicht zu darben, so ist dieses eine richtige und zugleich wichtige praktische Vorschrift des Willens. Man sieht aber gleich, daß der Wille hier auf etwas anderes verwiesen werde, wovon man voraussetzt, daß er es begehre, und dieses Begehren muß man ihm, dem Täter selbst, überlassen, ob er noch andere Hilfsquellen 20 außer seinem selbst erworbenen Vermögen vorhersehe, oder ob er gar nicht hoffe, alt zu werden, oder sich denkt im Falle der Not dereinst schlecht behelfen zu können. Die Vernunft, aus der allein alle Regel, die Notwendigkeit enthalten soll, entspringen kann, legt in diese ihre Vorschrift zwar auch Notwendigkeit (denn ohne das wäre sie kein Imperativ), aber diese ist nur subjektiv bedingt, und man kann sie nicht in allen Subjekten in gleichem Grade voraussetzen. $\mathrm{Zu}$ ihrer Gesetzgebung aber wird erfordert, daß sie bloß sich 30 selbst vorauszusetzen bedürfe, weil die Regel nur [21] alsdann objektiv und allgemein gültig ist, wenn sie ohne zufällige subjektive Bedingungen gilt, die ein vernünftiges Wesen von dem anderen unterscheiden. Nun sagt jemanden, er solle niemals lügenhaft versprechen, so ist dies eine Regel, die bloß seinen Willen betrifft; die Absichten, die der Mensch haben mag, mögen durch denselben erreicht werden können oder nicht; das bloße Wollen ist das, was durch jene Regel völlig a priori bestimmt werden soll. Findet 40 sich nun, daß diese Regel praktisch richtig sei, so ist sie ein Gesetz, weil sie ein kategorischer Imperativ ist. 
Also beziehen sich praktische Gesetze allein auf den Willen unangesehen dessen, was durch die Kausalität desselben ausgerichtet wird, und man kann von der letzteren (als zur Sinnenwelt gehörig) abstrahieren, um sie rein zu haben.

\section{$\S 2$. \\ Lehrsatz I.}

Alle praktischen Prinzipien, die ein Objekt (Materie) des Begehrungsvermōgens als Bestimmungsgrund 10 des Willens voraussetzen, sind insgesamt empirisch und können keine praktischen Gesetze abgeben.

Ich verstehe unter der Materie des Begehrungsvermögens einen Gegenstand, dessen Wirklichkeit begehrt wird. Wenn die Begierde nach diesem Gegenstande nun vor der praktischen Regel vorhergeht und die Bedingung ist, sie sich zum Prinzip zu machen ${ }^{2}$ ), so sage ich (erstlich): dieses Prinzip ist alsdann jederzeit empirisch. Denn der Bestimmungsgrund der Willkür ist alsdann die Vorstellung eines Objekts und das-

20 jenige Verhältnis derselben zum Subjekt, wodurch das Begehrungsvermögen zur Wirklichmachung desselben bestimmt wird. Ein solches Verhältnis aber zum Subjekt heißt die Lust an der Wirklichkeit eines Gegenstandes. Also müßte diese als Bedingung der Möglichkeit der Bestimmung der Willkür vorausgesetzt werden. Es kann aber von keiner Vorstellung irgend eines Gegenstandes, welche sie auch sei, a priori erkannt werden, ob sie mit Lust oder Unlust verbunden oder indifferent sein werde. Also mu in

80 solchem Falle der Bestimmungsgrund der Willkür jederzeit empirisch sein, mithin auch das praktische materiale Prinzip, welches ihn als Bedingung voraussetzte.

Da nun (zweitens) ein Prinzip, das sich nur auf die subjektive Bedingung der Empfänglichkeit einer Lust oder Unlust (die jederzeit nur empirisch erkannt und nicht für alle vernünftige Wesen in gleicher Art gültig sein kann) gründet, zwar wohl für das

a) Kant: „machen“; korr. Grillo. 
Von den Grundsătzen der reinen praktischen Vernunft. 27

Subjekt, das sie besitzt, zu ihrer ${ }^{2}$ ) Maxime, aber auch für diese ${ }^{a}$ ) selbst (weil es ihm an objektiver Notwendigkeit, die a priori erkannt werden muß, [22] mangelt), nicht zum Gesetze dienen kann, so kann ein solches Prinzip niemals ein praktisches Gesetz abgeben.

\section{$\S 3$. \\ Lehrsatz II.}

Alle materialen praktischen Prinzipien sind als solche insgesamt von einer und derselben Art und 10 gehören unter das allgemeine Prinzip der Selbstliebe oder eigenen Glückseligkeit.

Die Lust aus der Vorstellung der Existenz einer Sache, sofern sie ein Bestimmungsgrund des Begehrens dieser Sache sein soll, gründet sich auf der Empfänglichkeit des Subjekts, weil sie von dem Dasein eines Gegenstandes abhängt; mithin gehört sie dem Sinne (Gefühl) und nicht dem Verstande an, der. eine Beziehung der Vorstellung a uf ein Objekt nach Begriffen, aber nicht auf das Subjekt nach Gefühlen 20 ausdrückt. Sie ist also nur sofern praktisch, als die Empfindung der Annehmlichkeit, die das Subjekt von der Wirklichkeit des Gegenstandes erwartet, das Begehrungsvermögen bestimmt. Nun ist aber das Bewußtsein eines vernünftigen Wesens von der Annehmlichkeit des Lebens, die ununterbrochen sein ganzes Dasein begleitet, die Glückseligkeit, und das Prinzip, diese sich zum höchsten Bestimmungsgrunde der Willkür zu machen, das Prinzip der Selbstliebe. Also sind alle materialen Prinzipien, die den $\mathrm{Be}-30$ stimmungsgrund der Willkür in der aus irgend eines Gegenstandes Wirklichkeit $z u$ empfindenden Lust oder Unlust setzen, sofern gänzlich von einerlei Art, da $B$ sio insgesamt zum Prinzip der Selbstliebe oder eigenen Glückseligkeit gehören.

Folgerung.

Alle materialen praktischen Regeln setzen den Bestimmungsgrund des Willens im unteren $\mathrm{Be}$ -

a) "seiner - dieses"? [Wille]. 
gehrungsvermögen, und gäbe es gar keine bloß formalen Gesetze desselben, dia den Willen hinreichend bestimmten, so würde auch kein oberes Begehrungsvermögen eingeräumt werden können.

\section{Anmerkung I.}

Man muß sich wundern, wie sonst scharfsinnige Männer einen Unterschied zwischen dem unteren und oberen Begehrungsvermögen darin zu finden [23] glauben können, ob die Vorstellungen, die mit dem 10 Gefühl der Lust verbunden sind, in den Sinnen oder dem Verstande ihren Ursprung haben. Denn es kommt, wenn man nach den Bestimmungsgründen des Begehrens fragt und sie in einer von irgend etwas erwarteten Annehmlichkeit setzt, gar nicht darauf an, wo die Vorstellung dieses vergnügenden Gegenstandes herkomme, sondern nur, wie sehr sie vergnügt. Wenn eine Vorstellung, sie mag immerhin im Ver stande ihren Sitz und Ursprung haben, die Willkür nur dadurch bestimmen kann, daß sie ein Gefühl einer

so Lust im Subjekte voraussetzt, so ist, daB sie ein Bestimmungsgrund der Willkür sei, gänzlich von der Beschaffenheit des inneren Sinnes abhängig, daß dieser nämlich dadurch mit Annehmlichkeit affiziert werden kann. Die Vorstellungen der Gegenstände mögen noch so ungleichartig, sie mögen Verstandes-, selbst Vernunftvorstellungen im Gegensatze der Vorstellungen der Sinne sein, sa ist doch das Gefühl der Lust, wodurch jene doch eigentlich nur den Bestimmungsgrund des Willens ausmachen (die Annehmlichkeit, das

30 Vergnügen, das man davon erwartet, welches die Tätigkeit zur Hervorbringung des Objekts antreibt) nicht allein sofern von einerlei Art, daB es jederzeit bloß empirisch erkannt werden kann, sondern auch sofern, als es $^{2}$ ) eine und dieselbe Lebenskraft, die sich im Begehrungsvermögen äußert, affiziert und in dieser Beziehung von jodem anderen Bestimmungsgrunde in nichts als dem Grade verschieden sein kann. Wio würde man sonst zwischen zwei der Vorstellungsart nach gänzlich verschiedenen Bestimmungsgründen eine

a) 1. Aafl: ,er". 
Vergleichung der Größe nach anstellen können, um den, der am meisten das Begehrungsvermögen affiziert, vorzuziehen? Ebenderselbe Mensch kann ein ihm lehrreiches Buch, das ihm nur einmal zu Händen kommt, ungelesen zurückgeben, um die Jagd nicht zu versäumen, in der Mitte einer schönen Rede weggehen, nm zur Mahlzeit nicht zu spät zu kommen, eine Unterhaltung durch vernünftige Gespräche, die er sonst sehr schätzt, verlassen, um sich an den Spieltisch zu setzen, sogar einen Armen, dem wohlzutun ihm sonst 10 Freude ist, abweisen, weil er jetzt eben nicht mehr Geld in der Tasche hat, als er braucht, um den Eintritt in die Komödie zu bezahlen. Beruht die Willensbestimmung auf dem Gefühle der Annehmlichkeit oder Unannehmlichkeit, die er aus irgend einer Ursache erwartet, so ist es ihm gänzlich einerlei, durch welche Vorstellungsart er affiziert werde. Nur wie stark, wie lange, wie leicht erworben und oft wiederholt diese Annehmlichkeit sei, daran liegt es ihm, um sich zur Wahl zu entschließen. Sowio demjenigen, der Gold 20 zur Ausgabe braucht, gänzlich einerlei ist, ob die Materie desselben, das Gold, aus dem Gebirge gegraben oder aus dem Sande gewaschen ist, wenn es nur allenthalben für denselben Wert angenommen wird, so fragt kein Mensch. wenn es ihm bloß an der Annehmlichkeit des Lebens gelegen ist, ob Verstandes- oder Sinnesvorstellungen, sondern nur, wie viel und großes Vergnügen sie ihm auf die längste Zeit verschaffen. Nur diejenigen, welche der reinen Vernunft das Vermögen, ohne Vor- 30 aussetzung irgend eines Gefühls den Willen zu bestimmen, gerne abstreiten möchten, können sich so- [24] weit von ihrer eigenen Erklärung verirren, das, was sie selbst vorher auf ein und ebendasselbe Prinzip gebracht haben, dennoch hernach für ganz ungleichartig zu erklären. So findet sich z. B., daß man auch an bloßer Kraftanwendung, an dem Bewußtsein seiner Seelenstärke in Uberwindung der Hindernisse, die sich unserem Vorsatze entgegensetzen, an der Kultur der Geistestalente usw. Vergnügen finden könne, 40 und wir nennen das mit Recht feinere Freuden und Ergötzungen, weil sie mehr. wie andere in unserer 
Gewalt sind, sich nicht abnutzen, das Gefühl zu noch mehrerem Genuß derselben vielmehr stärken und, indem sie ergötzen, zugleich kultivieren. Allein sie darum für eine andere Art, den Willen zu bestimmen als bloß durch den Sinn, auszugeben, da sie doch einmal zur Möglichkeit jener Vergnügen ein darauf in uns angelegtes Gefühl, als erste Bedingung dieses Wohlgefallens, voraussetzen, ist gerade so, als wenn Unwissende, die gerne in der Metaphysik pfuschern

10 möchten, sich die Materie so fein, so überfein, daß sie selbst darüber schwindlig werden möchten, denken und dann glauben, auf diese Art sich ein geistiges und doch ausgedehntes Wesen erdacht $\mathrm{zu}$ haben. Wenn wir es mit dem Epikur bei der Tugend aufs bloße Vergnügen aussetzen, das sie verspricht, um den Willen zu bestimmen, so können wir ihn hernach nicht tadeln,

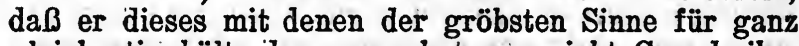
gleichartig hält; denn man hat gar nicht Grund, ihm aufzubürden, da $B$ er die Vorstellungen, wodurch dieses

20 Gefühl in uns erregt würde, bloß den körperlichen Sinnen beigemessen hätte. $\mathrm{Er}$ hat von vielen derselben den Quell, soviel man erraten kann, ebensowohl in dem Gebrauch des höheren Erkenntnisvermögens gesucht; aber das hinderte ihn nicht und konnte ihn auch nicht hindern, nach genanntem Prinzip das Vergnügen selbst, das uns jene allenfalls intellektuellen Vorstellungen gewähren, und wodurch sie allein Bestimmungsgründe des Willens sein können, gänzlich für gleichartig zu halten. Konsequent zu sein, ist die größte 30 Obliegenheit eines Philosophen und wird doch am seltensten angetroffen. Die alten griechischen Schulen geben uns davon mehr Beispiele, als wir in unserem synkretistischen Zeitalter antreffen, wo ein gewisses Koalitionssystem widersprechender Grundsätze voll Unredlichkeit und Seichtigkeit erkünstelt wird, weil es sich einem Publikum besser empfiehlt, das zufrieden ist, von allem etwas und im ganzen nichts zu wissen und dabei in allen Sätteln gerecht zu sein. Das Prinzip der eigenen Glückseligkeit, soviel

40 Verstand und Vernunft bei ihm auch gebraucht werden mag, würde doch für den Willen keine anderen Bestimmungsgründe, als die dem unter en Begehrungs- 
Von den Grundsätzen der reinen praktischen Vernunft. 31

vermögen angemessen sind, in sich fassen, und es gibt also entweder gar kein oberes ${ }^{2}$ ) Begehrungsvermögen, oder reine Vernunft muß für sich allein praktisch sein, d. i. ohne Voraussetzung irgend eines Gefühls, mithin ohne Vorstellungen des Angenehmen oder Unangenehmen, als der Materie des Begehrungsvermögens, die jederzeit eine empirische Bedingung der Prinzipien ist, durch die bloße Form der praktischen Regel den Willen bestimmen können. Alsdann allein ist Vernunft, nur sofern sie für sich selbst 10 den Willen bestimmt (nicht im Dienste der Neigungen ist), ein wahres oberes Begehrungsvermögen, dem das pathologisch bestimmbare untergeordnet ist, und wirklich, ja spezifisch von diesem unterschieden, sodal sogar die mindeste Beimischung von den Antrieben der letzteren ihrer Stärke und Vorzuge Abbruch tut, sowie das mindeste Empirische, als Bedingung in einer mathematischen Demonstration, ihre Würde und Nachdruck herabsetzt und vernichtet. Die Vernunft bestimmt in einem praktischen Gesetze un- 20 mittelbar den Willen, nicht vermittelst eines dazwischenkommenden Gefühls der Lust und Unlust, selbst nicht an diesem Gesetze, und nur, daß sie als reine Vernunft praktisch sein kann, macht es ihr möglich, gesetzgebend zu sein.

\section{Anmerkung II.}

Glücklich zu sein, ist notwendig das Verlangen jedes vernünftigen, aber endlichen Wesens und also ein unvermeidlicher Bestimmungsgrund seines Begehrungsvermögens. Denn die Zufriedenheit mit seinem 30 ganzen Dasein ist nicht etwa ein ursprünglicher Besitz und eine Seligkeit, welche ein Bewußtsein seiner unabhängigen Selbstgenugsamkeit ${ }^{b}$ ) voraussetzen würde, sondern ein durch seine endlich $\theta$ Natur selbst ihm aufgedrungenes Problem, weil es bedürftig ist; und dieses Bedürfnis betrifft die Materie seines Begehrungsvermögens, d. i. etwas, was sich auf ein subjektiv zum Grunde liegendes Gefühl der Lust oder

a) „oberes" in Kants Handexemplar hinzugefügt.

b) 6. Aufl., Hartenstein: "Selbstgenügsamkeit". 
Unlust bezieht, dadurch das, was es zur Zufriedenheit mit seinem Zustande bedarf, bestimmt wird. Aber ebendarum, weil dieser materiale Bestimmungsgrund von dem Subjekte bloß empirisch erkannt werden kann, ist es unmöglich, diese Aufgabo als ein Gesetz zu betrachten, weil dieses als objektiv in allen Fällen und für alle vernünftigen Wesen ebendenselben Bestimmungsgrund des Willens enthalten müßte. Denn obgleich der Begriff der Glückseligkeit der prak-

do tischen Beziehung der Objekte aufs Begehrungsvermögen allerwärts zum Grunde liegt, so ${ }^{2}$ ) ist er er doch nur der allgemeine Titel der subjektiven Bestimmungsgründe und bestimmt nichts spezifisch, darum es doch in dieser praktischen Aufgabe allein zu tun ist, und ohne welche Bestimmung sie gar nicht aufgelöst werden kann. Worin nämlich jeder seine Glückseligkeit $\mathrm{zu}$ setzen habe, kommt auf jedes sein besonderes Gefühl der Lust und Unlust an, und selbst in einemunddemselben Subjekt auf die Verschieden-

20 heit des Bedürfnisses nach den Abänderungen dieses Gefühls, und ein subjektiv notwendiges Gesetz (als Naturgesetz) ist also objektiv ein gar sehr zufälliges praktisches Prinzip, das in verschiedenen Subjekten sehr verschieden sein kann und muß, mithin niemals ein Gesetz abgeben kann; weil es bei der Begierde nach Glückseligkeit nicht auf die Form der Gesetzmäßigkeit, sondern lediglich auf die Materio ankommt, nämlich ob und wieviel Vergnügen ich in der Befolgung des Gesetzes zu erwarten habe. Prin-

30 zipien der Selbstliebe können zwar allgemeine Re[26] geln der Geschicklichkeit (Mittel zu Absichten auszufinden) enthalten; alsdann sind es aber bloß theoretische Prinzipien*), z. B. wio derjenige, der gerne

a) "so" nach der 1. und 2. Anfl. von Natorp wiederhergestellt.

*) Sätze, welche in der Mathematik oder Naturlehre praktisch genannt werden, sollten eigentlich technisch heißen. Denn um die Willensbestimmung ist es diesen Lehren gar nicht za tun; sie zeigen nur das Mannigfaltige der möglichen Handlung an, welches eine gewisse Wirkung hervorzabringen hinreichend ist, and sind also ebenso theo. 
Brot essen möchte, sich eine Mühle auszudenken habe. Aber praktische Vorschriften, die sich auf sie gründen, können niemals allgemein sein, denn der Bestimmungsgrund des Begehrungsvermögens ist auf das Gefühl der Lust und Unlust, das niemals als allgemein auf dieselben Gegenstände gerichtet angenommen werden kann, gegründet.

Aber gesetzt, endliche vernünftige Wesen dächten auch in Ansehung dessen, was sie für Objekte ihrer Gefühle des Vergnügens oder Schmerzes anzunehmen 10 hätten, imgleichen sogar in Ansehung der Mittel, deren sie sich bedienen müssen, um die ersteren zu erreichen, die anderen abzuhalten, durchgehends einerlei: so würde das Prinzip der Selbstliebe dennoch von ihnen durchaus für kein praktisches Gesetz ausgegeben werden können; denn diese Einhelligkeit wäre selbst doch nur zufällig. Der Bestimmungsgrund wäre immer doch nur subjektiv gültig und bloß empirisch und hätte diejenige Notwendigkeit nicht, die in einem jeden Gesetze gedacht wird, nämlich die objektive aus Gründen 20

a priori; man müßte denn diese Notwendigkeit gar nicht für praktisch, sondern für bloß physisch ausgeben, nämlich daß die Handlung durch unsere Neigung uns ebenso unausbleiblich abgenötigt würde als das Gähnen, wenn wir andere gähnen sehen. Man würde eher behaupten können, daß es gar keine praktischen Gesetze gebe, sondern nur Anratungen zum Behuf unserer Begierden, als da $B$ bloß subjektive Prinzipien zum Range praktischer Gesetze erhoben würden, die durchaus objektive und nicht bloß sub- 30 jektive Notwendigkeit haben und durch Vernunft a priori, nicht durch Erfahrung (so empirisch allgemein diese auch sein mag) erkannt sein müssen. Selbst die Regeln einstimmiger Erscheinungen werden nur Naturgesetze (z. B. die mechanischen) genannt, wenn man sie entweder wirklich a priori erkennt oder doch (wie bei den chemischen) annimmt, sie würden a priori aus objektiven Gründen erkannt werden, wenn unsere Ein-

retisch als alle Sătze, welche die Verknüpfung der Ursache mit einer Wirkung aussagen. Wem nun die letztere beliebt, der muß sich auch gefallen lassen, die erstere za sein.

Kant, Kritik der prakt. Vernunft. 
sicht tiefer ginge. Allein bei bloß subjektiven praktischen Prinzipien wird das ausdrücklich zur Bedingung gemacht, daß ihnen nicht óbjektive, sondern subjektive Bedingungen der Willkür zum Grunde liegen müssen; mithin, daß sie jederzeit nur als bloße Maximen, niemals aber als praktische Gesetze vorstellig gemacht werden dürfen. Diese letztere Anmerkung scheint beim ersten Anblicke bloße Wortklauberei zu sein; allein sie ist ${ }^{a}$ ) die Wortbestim10 mung des allerwichtigsten Unterschiedes, der nur in praktischen Untersuchungen in Betrachtung kommen mag.

\section{§4. \\ Lehrsatz III.}

Wenn ein vernünftiges Wesen sich seine Maximen als praktische allgemeine Gesetze denken soll, so kann es sich dieselben nur als solche Prinzipien denken, die nicht der Materie, sondern bloß der Form nach den Bestimmungsgrund des Willens enthalten.

20. Die Materie eines praktischen Prinzips ist der Gegenstand des Willens. Dieser ist entweder der Bestimmungsgrund des letzteren oder nicht. Ist er der Bestimmungsgrund desselben, so würde die Regel des Willens einer empirischen Bedingung (dem Verhältnisse der bestimmenden Vorstellung zum Gefühle der Lust oder Unlust) unterworfen, folglich kein praktisches Gesetz sein. Nun bleibt von einem Gesetze, wenn man alle Materie, d. i. jeden Gegenstand des Willens (als Bestimmungsgrund) davon absondert, 80 nichts übrig àls die bloße Form einer allgemeinen Gesetzgebung. Also kann ein vernünftiges Wesen sich seine subjektiv-praktischen Prinzipien d. i. Maximen entweder gar nicht zugleich als allgemeine Gesetze denken, oder es muß annehmen, daß die bloße Form derselben, nach der jene sich zur allgemeinen Gesetzgebung schicken, sie für sich allein zum praktischen Gesetze mache.

a) Das fehlende ,sie ist" in Kants Handexemplar erganzt; Hartenstein " (Kirchmann): "sie enthält". 
Von den Grundsätzen der reinen praktischen Vernunft.

\section{Anmerkung.}

Welche Form in der Maxime sich zur allgemeinen Gesetzgebung schicke, welche nicht, das kann der gemeinste Verstand ohne Unterweisung unterscheiden. Ich habe z. B. es mir zur Maxime gemacht, mein Vermögen durch alle sicheren Mittel zu vergrößern. Jetzt ist ein Depositum in meinen Händen, dessen Eigentümer verstorben ist und keine Handschrift darüber zurückgelassen hat. Natürlicherweise ist dies der Fall meiner Maxime. Jetzt will ich nur. wissen, ob jene 10 Maxime auch als allgemeines praktisches Gesetz gelten könne. Ich wende jene also auf gegenwärtigen Fall an und frage, ob sie wohl die Form eines Gesetzes annehmen, mithin ich wohl durch meine Maxime zugleich ein solches Gesetz geben könnte: daß jedermann ein Depositum ableugnen dürfe, dessen Niederlegung ihm niemand beweisen kann. Ich worde sofort gewahr, daß ein solches Prinzip als Gesetz sich selbst vernichten würde, weil es machen würde, daß es gar kein Depositum gäbe. Ein praktisches Gesetz, was 20 ich dafür erkenne, muß sich zur allgemeinen Gesetzgebung qualifizieren; dies ist ein identischer Satz und also für sich klar. Sage ich nun: mein Wille steht unter einem praktischen Gesetze, so kann ich nicht meine Neigung (z. B. im gegenwärtigen Falle meine Habsucht) als den zu einem allgemeinen praktischen Gesetzo schicklichen Bestimmungsgrund desselben an- [28] führen; denn diese, weit gefehlt, daß sie zu einer allgemeinen Gesetzgebung tauglich sein sollte, so muß sie vielmehr in der Form eines allgemeinen Gesetzes sich selbst aufreiben.

Es ist daher wunderlich, wie, da die Begierde zur Glückseligkeit, mithin auch die Maxime, dadurch sich jeder diese letztere zum Bestimmungsgrunde seines Willens setzt, allgemein ist, es verständigen Männern habe in den Sinn kommen können, es ${ }^{a}$ ) darum für ein allgemein praktisches Gesetz auszugeben. Denn da sonst ein allgemeines Naturgesetz alles einstimmig macht, so würdo hier, wenn man der Maxime die All-
a) „8ie“? [Adickes]. 
gemeinheit eines Gesetzes geben wollte, gerade das äußerste Widerspiel der Einstimmung, der ärgste Widerstreit und die gänzliche Vernichtung der Maxime selbst und ihrer Absicht erfolgen. Denn der Wille aller hat alsdann nicht einunddasselbe Objekt, sondern ein jeder hat das seinige (sein eigenes Wohlbefinden), welches sich swar zufälligerwoise auch mit anderer ihren Absichten, die sie gleichfalls auf sich selbst richten, vertragen kann, aber lange nicht zum Ge10 setze hinreichend ist, weil die Ausnahmen, die man gelegentlich zu machen befugt ist, endlos sind und gar nicht bestimmt in eine allgemeine Regel befaßt werden kb̈nnen. Es kommt auf diese Art eine Harmonio heraus, die derjenigen ähnlich ist, welche ein gewisses Spottgedicht ouf die Seeleneintracht zweier sich zugrunde richtenden Eheleute schildert: 0 wunderbare Harmonie, was er will, will auch sie usw., oder was von der Anheischigmachung König Franz des Ersten gegen Kaiser Karl den Fünften 20 erzählt wird: Was mein Bruder Karl haben will (Mailand), das will ich auch haben. Empirische Bestimmungsgründe taugen zu keiner allgemeinen äußeren Gesetzgebung, aber auch ebensowenig zur inneren; denn jeder ${ }^{2}$ ) legt sein ${ }^{b}$ ) Subjekt, ein anderer aber ein anderes Subjekt der Neigung zum Grunde, und in jedem Subjekt selber ist bald die bald eine andere im Vorzuge des Einflusses. Ein Gesetz ausfindig zu machen, das sie insgesamt unter dieser Bedingung, nämlich mit allseitiger Einstimmung regierte, ist 80 schlechterdings unmöglich.

\section{$\S 5$. \\ Aufgabe I.}

Vorausgesetzt, daß die bloße gesetzgebende Form der Maximen allein der zureichende Bestimmungsgrund eines Wlllens sei: die Beschaffenheit desjenigen Willens zu finden, der dadurch allein bestimmbar ist.

$\mathrm{Da}$ die bloße Form des Gesetzes lediglich von der Vernunft vorgestellt werden kann und mithin kein

a) Hartenstein:, jener"6.

b) 4.-6. Aufl: „ein“" 
Gegenstand der Sinne ist, folglich auch nicht unter die Erscheinungen gehört, so ist die Vorstellung derselben als Bestimmungsgrund des Willens von allen Bestimmungsgründen der Begebenheiten in der Natur nach dem Gesetze der Kausalität unterschieden, weil bei diesen die bestimmenden Gründe selbst Erschei- [29] nungen sein müssen. Wenn aber auch kein anderer Bestimmungsgrund des Willens für diesen zum Gesetz dienen kann als bloß jene allgemeine gesetzgebende Form, so muß ein solcher Wille als gänzlich unab- 10 hängig von dem Naturgesetz der Erscheinungen, nämlich dem Gesetze der Kausalität, beziehungsweise aufeinander gedacht werden. Eine solche Unabhängigkeit aber heißt Freiheit im strengsten, d. i. transzendentalen Verstande. Also ist ein Wille, dem die bloße gesetzgebende Form der Maxime allein zum Gesetze dienen kann, ein freier Wille.

\section{$\S 6$.}

\section{A ufgabe II.}

Vorausgesetzt da $\beta$ ein Wille frei sei: das Gesetz 20 zu finden, welches ihn allein notwendig zu bestimmen tauglich ist.

$\mathrm{Da}$ die Materie des praktischen Gesetzes, d. i. ein Objekt der Maxime, niemals anders als empirisch gegeben werden kann, der freie Wille aber, als von empirischen (d. i. zur Sinnenwelt gehörigen) Bedingungen unabhängig, dennoch bestimmbar sein muß: so muß ein freier Wille, unabhängig von der Materie des Gesetzes, dennoch einen Bestimmungsgrund in dem Gesetze antreffen. Es ist aber außer der 30 Materie des.Gesetzes nichts weiter in demselben als die gesetzgebende Form enthalten. Also ist die gesetzgebende Form, sofern sie in der Maxime enthalten ist, das einzige, was einen Bestimmungsgrund des Willensa) ausmachen kann.

\section{Anmerkung.}

Freiheit und unbedingtes praktisches Gesetz weisen also wechselsweise aufeinander zurück. Ich frage hier

a) Hartenstein: freien Willens". 
nun nicht, ob sie auch in der Tat verschieden seien, und nicht vielmehr ein unbedingtes Gesetz bloß das Selbstbewußtsein einer reinen praktischen Vernunft, diese aber ganz einerlei mit dem positiven Begriffe der Freiheit sei; sondern wovon unsere Erkenntnis des Unbedingt-Praktischen ànhebe, ob von der Freiheit oder dem praktischen Gesetze. Von der Freiheit kann sio $^{2}$ ) nicht anheben; denn deren können wir uns weder unmittelbar bewußt werden, weil $\mathrm{ihr}^{\mathrm{b}}$ ) 10 erster Begriff negativ ist, noch darauf aus der Erfahrung schließen, denn Erfahrung gibt uns nur das Gesetz der Erscheinungen, mithin den Mechanismus der Natur, das gerade Widerspiel der Freiheit, zu erkennen. Also ist es das moralische Gesetz, dessen wir uns unmittelbar bewußt werden (sobald wir uns Maximen des Willens entwerfen), welches sich uns

[30] zuerst darbietet und, indem die Vernunft jenes als einen durch keine sinnliche Bedingung zu überwiegenden, ja davon gänzlich unabhängigen Bestimmungs20 grund darstellt, gerade auf den Begriff der Freiheit führt. Wie ist aber auch das Bewußtsein jenes moralischen Gesetzes möglich? Wir können uns reiner praktischer Gesetzo bewußt werden, ebenso wie wir uns reiner theoretischer Grundsätze bewußt sind, indem wir auf die Notwendigkeit, womit sie uns die Vernunft vorschreibt, und auf Absonderung aller ompirischen Bedingungen, dazu uns jene hinweist, achthaben. Der Begriff eines reinen Willens entspringt aus den ersteren, wio das Bewaßtsein eines reinen 30 Verstandes aus dem $^{\circ}$ ) letzteren. Daß dieses die wahre Unterordnung unserer Begriffe sei, und Sittlichkeit uns zuerst den Begriff der Freiheit entdecke, mithin praktische Vernunft zuerst der spekulativen das unauflöslichste Problem mit diesem Begriffe aufstelle, um sio duroh denselben in die größte Verlegenheit zu setzen: erhellt schon daraus, da $\Omega$, da aus dem Begriffe der Freiheit in den Erscheinungen nichts erklärt werden kannd), sondern hier immer Naturmecha-
a) Kant: nes"; korr. Vorländer.
b) Kant: "sein ${ }^{\mu}$; korr. Hartenstein.
c) ${ }_{n}$ den $^{4}$ (sc. Gesetzen oder Grundsätzen)? [Natorp].
d) Adickes: ${ }_{n}$ darfu. 
nismus den Leitfaden ausmachen muß, ubèrdem auch die Antinomie der reinen Vernunft, wenn sio zum Unbedingten in der Reihe der Ursachen aufsteigen will, sioh bei einem so sehr wie bei dem anderen in Unbegreiflichkeiten verwickelt, indessen daß doch der letztere (Mechanismus) wenigstens Brauchbarkeit in Erklärung der Erscheinungen hat, man niemals zu dem Wagstücke gekommen sein würde, Freiheit in die Wissenschaft einzuführen, wäre nicht das Sittengesetz und mit ihm praktische Vernunft dazu gekommen 10 und hätte uns diesen Begriff nicht aufgedrungen. Aber auch die Erfahrung bestätigt diese Ordnung der Begriffe in uns. Setzet, daß jemand von seiner wollüstigen Neigung vorgibt, sie sei, wonn ihm der beliebte Gegenstand und die Gelegenheit dazu vorkämen, für ihn ganz unwiderstehlich: ob, wenn ein Galgen vor dem Hause, da er diese Gelegenheit trifft, aufgerichtet wăre, um ihn sogleich nach genossener Wollust daran zu knüpfen, er alsdann nicht seine Neigung bezwingen würde? Man darf nicht lange raten, was er antworten würde. Fragt ihn aber, ob, wenn sein Fürst ihm unter Androhung derselben unverzögerten Todesstrafe zumutete, ein falsches Zeugnis wider einen ehrlichen Mann, den or gerne unter scheinbaren Vorwänden verderben möchte, abzulegen, ob er da, so groß auch seine Liebe zum Leben sein mag, sie wohl zu überwinden für möglich halte? $\mathrm{Ob}$ er es tun würde oder nicht, wird er vielleicht sich nicht getrauen $\mathrm{zu}$ versichern; daß es ihm aber möglich sei, muß er ohne Bedenken einräumen. Er urteilt also, daß er 80 otwas kann, darum weil er sich bewußt ist, daß er as soll, und erkennt in sich die Freiheit, die ihm sonst ohnè das moralisch $\theta$ Gesetz unbekannt geblieben wäre.

\section{$\S 7$}

Grandgesetz der reinen praktischen Vornunft.

Handle so, daß die Maxime deines Willens jederzeit zugleich als Prinzip einer allgemeinen Gesetzgebung gelten konne. 
Die reine Geometrie hat Postulate als praktische Sätze, die aber nichts weiter enthalten als die Voraussetzung, daß man etwas tun könne, wenn etwas gefordert würde, man solle es tun, und diese sind die einzigen Sätze derselben, die ein Dasein betreffen. Es sind also praktische Regeln unter einer problematischen Bedingung des Willens. Hier aber sagt die Regel: man solle schlechthin auf gewisse Weise

10 verfahren. Die praktische Regel ist also unbedingt, mithin als kategorisch praktischer Satz a priori vorgestellt, wodurch der Wille schlechterdings und unmittelbar (durch die praktische Regel selbst, die also hier Gesetz ist), objektiv bestimmt wird. Denn reine, an sich praktische Vernunft ist hier unmittelbar gesetzgebend. Der Wille wird als unabhăngig von empirischen Bedingungen, mithin, als reiner Wille, durch die bloße Form des Gesetzes als bestimmt gedacht und dieser Bestimmungsgrund als die oberste

20 Bedingung aller Maximen angesehen. Die Sache ist befremdlich genug und hat ihresgleichen in der ganzen übrigen praktischen Erkenntnis nicht. Denn der Gedanke a priori von einer möglichen allgemeinen Gesetzgebung, der also bloß problematisch ist, wird, ohne von der Erfahrung oder irgend einem äußeren Willen etwas zu entlehnen, als Gesetz unbedingt geboten. Es ist aber auch nicht eine Vorschrift, nach welcher eine Handlung geschehen soll, dadurch eine begehrte Wirkung möglich ist (denn da wäre die Regel immer

30 physisch bedingt), sondern eine Regel, die bloß den Willen in Ansehung der Form seiner Maximen a priori bestimmt, und da ist ein Gesetz, welches bloß zum Behuf der subjektiven Form der Grundsätze dient, als Bestimmungsgrund durch die objektive Form eines Gesetzes überhaupt, wenigstens zu denken nicht unmöglich. Man kann das Bewußtsein dieses Grundgesetzes ein Faktum der Vernunft nennen, weil man es nicht aus vorhergehenden Datis der Vernunft, z. B. dem Bewußtsein der Freiheit (denn dieses ist uns 40 nicht vorher gegeben) herausvernünfteln kann, sondern weil es sich für sich selbat uns aufdringt als synthe- 
tischer Satz a priori, der auf keiner, weder reinen noch empirischen, Anschauung gegründet ist, ob er gleich analytisch sein würde, wenn man die Freiheit des Willens voraussetzte, wozu aber, als positivem Begriffe, eine intellektuelle Anschauung erfordert werden würde, die man hier gar nicht annehmen darf. Doch muß man, um dieses Gesetz ohne Mißdeutung als ge geben anzusehen, wohl bemerken, daß es kein empirisches, sondern das einzige Faktum der reinen Vernunft sei, die sich dadurch als ursprünglich gesetzgebend (sic 10 volo, sic iubeo a) ankündigt.

\section{Folgerung.}

Reine Vernunft ist für sich allein praktisch und gibt (dem Menschen) ein allgemeines Gesetz, welches wir das Sittengesetz nennen.

\section{Anmerkung.}

Das vorher genannte Faktum ist unleugbar. Man darf nur das Urteil zergliedern, welches die Menschen über die Gesetzmäßigkeit ihrer Handlungen fällen: so wird man jederzeit finden, daß, was auoh die Neigung 20 dazwischen sprechen mag, ihre Vernunft dennoch, unbestechlich und durch sich selbst gezwungen, die Maxime des Willens bei einer Handlung jederzeit an den reinen Willen halte, d. i. an sich selbst, indem sie sich als a priori praktisch betrachtet. Dieses Prinzip der Sittlichkeit nun, eben um der Allgemeinheit der Gesetzgebung willen, die es zum formalen obersten Bestimmungsgrunde des Willens unangesehen aller subjektiven Verschiedenheiten ${ }^{b}$ ) dosselben macht, erklärt die Vernunft zugleich zu einem Gesetze für alle ver- 30 nünftigen Wesen, sofern sie überhaupt einen Willen, d. i. ein Vermögen haben, ihre Kausalität durch die Vorstellung von Regeln zu bestimmen, mithin sofern sie der Handlungen nach Grundsätzen, folglich auch nach praktischen Prinzipien a priori (denn diese haben allein diejenige Notwendigkeit, welche die Vernunft zum Grundsatze fordert), fähig sind. Es schränkt sich also nicht bloß auf Menschen ein, sondern geht auf alle

a) Wohl nach Juvenals bekanntem Wort: Hoc volo, sic iubeo, sit pro ratione voluntas (Sat. VI, 223).

b) 6. Aufl. and Hartenstein: "Verschiedenheitu. 
endlichen Wesen, die Vernunft und Willen haben, ja schließt ogar das unendliche Wesen, als oberste Intelligenz, mit ein. Im ersteren Falle aber hat das Gesetz dio Form eines Imperativs, weil man an jenem zwar als vernünftigem Wesen einen reinen, aber als mit Bedürfnissen und sinnlichen Bewegursachen affiziertem Wesen keinen heiligen Willen, d. i. einen solchen, der keiner dem moralischen Gesetze widerstreitenden Maximen fähig wäre, voraussetzen kann.

10 Das moralische Gesetz ist daher bei jenen ein Imperativ, der kategorisch gebietet, weil das Gesetz unbedingt ist; das Verhältnis eines. solchen Willens zu diesem Gesetze ist Abhängigkeit, unter dem Namen der Verbindlichkeit, welche eine Nötigung, obzwar durch bloße Vernunft und deren ${ }^{2}$ ) objektives Gesetz, zu einer Handlung bedeutet, die darum Pflicht heißt, weil eine pathologisch affizierte (obgleich dadurch nicht bestimmte, mithin auch immer freie) Willkür einen Wunsch bei sich führt, der aus subjek20 tiven Ursachen entspringt, daher auch dem reinen objektiven Bestimmungsgrunde oft entgegen sein kann und also eines Widerstandes der praktischen Vernunft, der ein innerer, aber intellektueller Zwang genannt werden kann, als moralischer Nötigung bedarf. In der allergenugsamsten Intelligenz wird die Willkür als keiner Maxime fähig, diø nicht zugleich objektiv Gesetz sein könnte ${ }^{D}$ ), mit Recht vorgestellt, und der Begriff der Heiligkeit, der ihr um deswillen zukommt, setzt sie zwar nicht über alle praktischen,

80 aber doch über alle praktisch-einschränkenden $\mathrm{Ge}$ setze, mithin Verbindlichkeit und Pflicht weg. Diese Heiligkeit des Willens ist gleichwohl eine praktische Idee, welche notwendig zum Urbilde dienen muß, welchem sich ins Unendliche zu nähern das einzige ist, was allen endlichen vernünftigen Wesen zusteht, und welche das reine Sittengesetz, das darum selbst heilig heißt, ihnen beständig und richtig vor Augen hält, von welchem ins Unendliche gehenden Progressus [33] seiner Maximen und Unwandelbarkeit derselben zum

a) Kant: "dessen ${ }^{\text {; }}$ korr. Hartenstein.

b) Kant: "konnte"; korr. Hartenstein. 
beständigen Fortschreiten sicher zu sein: d. i. Tugend, das Höchste ist, was endliche praktische Vernunft bewirken kann, die selbst wiederum wenigstens als natürlich erworbenes Vermögen nie vollendet sein kann, weil die Sicherheit in solchem Falle niemals apodiktische Gewißheit wird und als Uberredung sehr gefährlich ist.

\section{$\S 8$. \\ Lehrsatz IV.}

Die Autonomie des Willens ist das alleinige 10 Prinzip aller moralischen Gesetze und der ihnen gemäßen Pflichten; alle Heter on o mie der Willkür gründet dagegen nicht allein gar keine Verbindlichkeit, sondern ist vielmehr dem Prinzip derselben und der Sittlichkeit des Willens entgegen. In der Unabhängigkeit nämlich von aller Materie des Gesetzes (nämlich einem begehrten Objekte) und zugleich doch Bestimmung der Willkür durch die bloße allgemeine gesetzgebende Form, deren eine Maxime fähig sein muß, besteht das alleinige Prinzip der Sittlichkeit. Jene Una- 20 - hängigkeit aber ist Freiheit im negativen, diese eigene Gesetzgebung aber der reinen und als solche praktischen Vernunft ist Freiheit im positiven Verstande. Also drückt das moralische Gesetz nichts anderes aus als die Autonomie der reinen praktischen Vernunft, d. i. der $^{a}$ ) Freiheit, und diese ist selbst die formale Bedingung aller Maximen, unter der sie allein mit dem obersten praktischen Gesetze zusammenstimmen können. Wenn daher die Materie des Wollens, welche nichts anderes als das Objekt einer Begierde sein kann, die mit dem Gesetz verbunden wird, in das praktische Gesetz als Bedingung der Möglichkeit desselben hineinkommt, so wird daraus Heteronomis der Willkür, nämlich Abhängigkeit vom Naturgesetze, irgend oinem Antriebe oder Neigung zu folgen, und der Wille gibt sich nicht selbst das Gesetz, sondern nur dio Vorschrift zur vernünftigen Befolgung pathologischer Gesetzo; die Maxime aber, die auf solche

a) "die"? [Natorp]. 
Weise niemals die allgemein-gesetzgebende Form in sich enthalten kann, stiftet auf diese Weise nicht allein keine Verbindlichkeit, sondern ist selbst dem Prinzip einer reinen praktischen Vernunft, hiermit also auch der sittlichen Gesinnung entgegen, wenngleich die Handlung, die daraus entspringt, gesetzmäßig sein sollte.

\section{Anmerkung $I$.}

Zum praktischen Gesetze muß also niemals eine 10 praktische Vorschrift gezählt werden, die eine materiale (mithin empirische) Bedingung bei sich führt. Denn das Gesetz des reinen Willens, der frei ist, setzt diesen in eine ganz andere Sphäre als die empirische, und die Notwendigkeit, die es ausdrückt, da sie keine Naturnotwendigkeit sein soll, kann also blo $B$ in formalen Bedingungen der Möglichkeit eines Gesetzes überhaupt bestehen. Alle Materie praktischer Regeln beruht immer auf subjektiven Bedingungen, die $i r^{2}$ ). keine Allgemeinheit für vernünftige Wesen

20 als lediglich die bedingte (im Falle ich dieses oder jenes begehre, was ich alsdann tun müsse, um es wirklich zu machen) verschaffen, und sie drehen sich insgesamt um das Prinzip der eigenen Glückseligkeit. Nun ist freilich unleugbar, daß alles Wollen auch einen Gegenstand, mithin eine Materie haben müsse; aber diese ist darum nicht eben der $\mathrm{Be}$ stimmungsgrund und Bedingung der Maxime; denn ist sie es, so läßt diese sich nicht in allgemein gesetzgebender Form darstellen, weil die Erwartung der

30 Existenz des Gegenstandes alsdann die bestimmende Ursach $\theta$ der Willkür sẹin würde, und die Abhängigkeit des Begehrungsvermögens von der Existenz irgend einer Sache dem Wollen zum Grunde gelegt werden müßte, welche immer nur in empirischen Bedingungen gesucht werden und daher niemals den Grund zu einer notwendigen und allgemeinen Regel abgeben kann. So wird fremder Wesen Glückseligkeit das Objekt

a) nihnen"? [Natorp]. 
des Willens eines vernünftigen Wesens sein können. Wäre sio aber der Bestimmungsgrund der Maxime, so müßte man voraussetzen, daß wir in dem Wohlsein anderer nicht allein ein natürliches Vergnügen, sondern auch ein Bedürfnis finden, sowie die sympathetische Sinnesart bei Menschen es mit sich bringt. Âber dieses Bedürfnis kann ich nicht bei jedem vernünftigen Wesen (bei Gott gar nicht) voraussetzen. Also kann zwar die Materie der Maxime bleiben; sie muß aber nicht die Bedingung derselben sein, denn sonst würde diese 10 nicht zum Gesetze taugen. Also die bloße Form eines Gesetzes, welch ${ }^{2}$ ) die Materie einschränkt, muß zugleich ein Grund sein, diese Materie zum Willen hinzuzufügen, aber sie nicht vorauszusetzen.b) Die Materie sei z. B. meine eigene Glückseligkeit. Diese, wenn ich sie jedem beilege (wie ich es denn in der Tat bei endlichen Wesen tun darf), kann nur alsdann ein objektives praktisches Gesetz werden, wenn ich anderer ihre in dieselbe mit einschließe. Also entspringt das Gesetz, anderer Glickseligkeit zu beför- 20 dern, nicht von der Voraussetzung, daß diesesc) ein Objekt für jedes seine Willkür sei, sondern bloß daraus, daß die Form der Allgemeinheit, die die Vernunft als Bedingung bedarf, einer Maxime der Selbstliebe die objektive Gültigkeit eines Gesetzes zu geben, der Bestimmungsgrund des Willens wird; und also war das Objekt (anderer Glückseligkeit) nicht der Bestimmungsgrund des reinen Willens, sondern die bloße gesetzliche Form war es allein, dadurch ich meine auf Neigung gegründete Maxime einschränkte, um ihr die 30 Allgemeinheit eines Gesetzes zu verschaffen und sie [35] so. der reinen praktischen Vernunft angemessen zu machen, aus welcher Einschränkung, und nicht dem Zusatz einer äußeren Triebfeder, alsdann der Begriff der Verbindlichkeit, die Maxime meiner Selbstliebo auch auf die Glückseligkeit anderer zu erweitern, allein entspringen konnte.d)

a) Kant: ${ }_{n}$ welches ${ }^{\alpha}$; korr. Vorländer; vgl. unten Zeile 29 f.

b) „voraussetzen"? [Natorp].

c) "diese"? [Vorländer].

d) Kant: „könnte"; korr. Natorp. 


\section{Anmerkung II.}

Das gerade Widerspiel des Prinzips der Sittlichkeit ist: wenn das der eig $\theta n \in n$ Glückseligkeit zum Bestimmungsgrunde des Willens gemacht wird; wozu, wie ich oben gezeigt habe, alles überhaupt gezählt werden muß, was den Bestimmungsgrund, der zum Gesetze dienen soll, irgend worin anders als in der gesetzgebenden Form der Maxime setzt. Dieser Widerstreit ist aber nicht bloß logisch, wie der zwischen

10 empirisch-bedingten Regeln, die man doch zu notwendigen Erkenntnisprinzipien erheben wollte, sondern praktisch, und würde, wäre nicht die Stimme der Vernunft in Beziehung auf den Willen so deutlich, so unüberschreibar, selbst für den gemeinsten Menschen so vernehmlich, die Sittlichkeit gänzlich zugrunde richten; so aber kann sie sich nur noch in den kopfverwirrenden Spekulationen der Schulen erhalten, die dreist genug sind, sich gegen jene himmlische Stimme taub zu machen, um eine Theorie, die kein Kopf20 brechen kostet, aufrecht zu erhalten.

Wenn ein dir sonst beliebter Umgangsfreund sich bei dir wegen eines falschen abgelegten Zeugnisses dadurch $\mathrm{zu}$ rechtfertigen vermeinte, daß er zuerst die seinem Vorgeben nach heilige Pflicht der eigenen Glückseligkeit vorschützte, alsdann die Vorteile-herzählte, die er sich alle dadurch erworben, die Klugheit namhaft machte, die er beobachtet, um wider alle Entdeckung sicher zu sein, selbst wider die von seiten deiner selbst, dem er das Geheimnis darum allein offen-

80 bart, damit er es zu aller Zeit ableugnen könne; dann aber im ganzen Ernst vorgäbe, er habe eine wahre Menschenpflicht ausgeübt: so würdest du ihm entweder gerade ins Gesicht lachen oder mit Abscheu davon zurückbeben, ob du gleich, wenn jemand bloß auf eigene Vorteile seine Grundsätze gesteuert hat, wider diese Maßregel nicht das mindeste einzuwenden hättest. Oder setzet: es empfehle euch jemand einen Mann zum Haushalter, dem ihr alle eure Angelegenheiten blindlings anvertrauen könnet, und, um euch

10 Zutrauen einzuflößen, rühmte er ihn als einen klugen Menschen, der sich auf seinen eigenen Vorteil meister- 
Von den Grandsätzen der reinen praktischen Vernunft. 47

haft verstehe, auch als einen rastlos wirksamen, der keine Gelegenheit dazu ungenutzt vorbeigehen ließe; endlich, damit auch ja nicht Besorgnisse wegen eines pöbelhaften Eigennutzes desselben im Wege stünden, rühmte er, wie er recht fein zu leben verstünde, nicht im Geldsammeln oder brutaler Uppigkeit, sondern in der Erweiterung seiner Kenntnisse, einem wohlgewählten belehrenden Umgange, selbst im Wohltun der Dürftigen sein Vergnügen suchte, übrigens aber wegen der Mittel (die doch ihren Wert oder Unwert nur vom Zwecke entlehnen) nicht bedenklich wäre, und fremdes Geld und Gut ihm hierzu, sobald or nur wisse, daß er [36] es unentdeckt und ungehindert tun könne, so gut wie sein eigenes wäre: so würdet ihr entweder glauben, der Empfehlende habe euch zum besten, oder er habe den Verstand verloren. - So deutlich und scharf sind die Grenzen der Sittlichkeit und der Selbstliebe abgeschnitten, daß selbst das gemeinste Auge den Unterschied, ob etwas zu der einen oder der anderen gehöre, gar nicht verfehlen kann. Folgende wenige Be- 20 merkungen können zwar bei einer so offenbaren Wahrheit überflüssig scheinen, allein sie dienen wenigstens dazu, dem Urteile der gemeinen Menschenvernunft etwas mehr Deutlichkeit zu verschaffen.

Das Prinzip der Glückseligkeit kann zwar Maximen, aber niemals solche abgeben, die zu Gesetzen des Willens tauglich wären, selbst wenn man sich die allgemeine Glückseligkeit zum Objekte machte. Denn weil dieser ihre Erkenntnis auf lauter Erfahrungsdatis beruht, weil jedes Urteil darüber gar sehr $\mathbf{8 0}$ von jedes seiner Meinung, die noch dazu selbst sehr veränderlich ist, abhängt, so kann es wohl generelle, aber niemals universelle Regeln, d. i. solche, die im Durchschnitte am öftesten zutreffen, nicht aber solch $\theta$, die jederzeit und notwendig gültig sein müssen, geben; mithin können keine praktischen Gesetze darauf gegründet werden. Ebendarum, weil hier ein $\mathrm{Ob}$ jekt der Willkür der Regel derselben zum Grunde gelegt ${ }^{a}$ ) und also vor dieser vorhergehen muß, so kann diese nicht worauf anderes als auf das, was man 
empfiehlt ${ }^{a}$ ), und also auf Erfahrung bezogen und darauf gegründet werden, und da muß die Verschiedenheit des Urteils endlos sein. Dieses Prinzip schreibt also nicht allen vernünftigen Wesen ebendieselben praktischen Regeln vor, ob sie zwar unter einem gemeinsamen Titel, nämlich dem der Glückseligkeit, stehen. Das moralische Gesetz wird aber nur darum als objektiv notwendig gedacht, weil es für jedermann gelten soll, der Vernunft und Willen hat.

10 Die Maxime der Selbstliebe (Klugheit) rät bloß an; das Gesetz der Sittlichkeit gebietet. Es ist aber doch ein großer Unterschied zwischen dem, wozu man uns anrätig ist, und dem, wozu wir verbindlich sind.

Was nach dem Prinzip der Autonomie der Willkür zu tun sei, ist für den gemeinsten Verstand ganz leicht und ohne Bedenken einzusehen; was unter Voraussetzung der Heteronomie derselben zu tun sei, schwer und erfordert Weltkenntnis; d. i.: was Pflicht

20 sei, bietet sich jedermann von selbst dar; was aber wahren dauerhaften Vorteil bringe, ist allemal, wenn dieser auf das ganze Dasein erstreckt werden soll, in undurchdringliches Dunkel eingehüllt und erfordert viel Klugheit, um die praktisch darauf gestimmte ${ }^{b}$ ) Regel durch geschickte Ausnahmen auch nur auf erträgliche Art den Zwecken des Lebens anzupassen. Gleichwohl gebietet das sittliche.Gesetz jedermann und zwar die pünktlichste Befolgung. Es muß also zu der ${ }^{c}$ ) Beurteilung dessen, was nach ihm zu tun sei, nicht so 80 schwer sein, daß nicht der gemeinste und ungeübteste Verstand selbst ohne Weltklugheit damit umzugehen wüßte.

Dem kategorischen Gebote der Sittlichkeit Genüge [37] zu leisten, ist in jedes Gewalt zu aller Zeit, der empirisch-bedingten Vorschrift der Glückseligkeit nur selten, und bei weitem nicht, auch nur in Ansehung einer einzigen Absicht, für jedermann möglich. Die Ursache ist, weil es bei dem ersteren nur auf die

a) Hartenstein: "empfindet".

b) 6. Aufl. und Hartenstein: "brstimmte".

c) ${ }^{m} \mathrm{mb}$ also die"? [Natorp]. 
Maxime ankommt, die echt und rein sein muß, bei der letzteren aber auch auf die Kräfte und das physische Vermögen, einen begehrten Gegenstand wirklich zu machen. Ein Gebot, daß jedermann sich glücklich $\mathrm{zu}$ machen suchen sollte, wäre töricht; denn man gebietet niemals jemandem das, was er schon unausbleiblich von selbst will. Man müßte ihm bloß die Maßregeln gebieten oder vielmehr darreichen, weil er nicht alles das kann, was er will. Sittlichkeit aber gebieten unter dem Namen der Pflicht, ist ganz ver- 10 nünftig; denn deren Vorschrift will erstlich eben nicht jedermann gerne gehorchen, wenn sie mit Neigungen im Widerstreite ist, und was die Maßregeln betrifft, wie er dieses Gesetz befolgen könne, so dürfen diese hier nicht gelehrt werden; denn was er in dieser Beziehung willa ${ }^{2}$, das kann er auch.

Der im Spiel verloren hat, kann sich wohl über sich selbst und seine Unklugheit ärgern; aber wenn er sich bewußt ist, im Spiel betrogen (obzwar dadurch gewonnen) $\mathrm{zu}$ haben, so muß er sich selbst 20 verachten, sobald er sich mit dem sittlichen Gesetze vergleicht. Dieses muß also doch wohl etwas anderes als das Prinzip der eigenen Glückseligkeit sein. Denn zu sich selber sagen zu müssen: ich bin ein Nichtswürdiger, ob ich gleich meinen Beutel gefüllt habe, muß doch ein anderes Richtmaß des Urteils haben, als sich selbst Beifall zu geben und zu sagen: ich bin ein kluger Mensch, denn ich habe meine Kasse bereichert.

Endlich ist noch etwas in der Idee unserer prak- 80 tischen Vernunft, welches die Ubertretung eines sittlichen Gesetzes begleitet, nämlich ihre Strafwü rdigkeit. Nun läßt sich mit dem Begriffe einer Strafe als einer solchen doch gar nicht das Teilhaftigwerden der Glückseligkeit verbinden. Denn obgleich der, so da straft, wohl zugleich die gütige Absicht haben kann, diese Strafe auch auf diesen Zweck zu richten, so muß sie doch zuvor als Strafe, d. i. als bloßes Obel für sich selbst gerechtfertigt sein, sodaß der Gestrafte, wenn es dabei bliebe und er auch auf keine sich 40

a) 2. Aufl.: „tun will".

Kant. Kritik der prakt. Vernunft. 
hinter dieser Härte verbergende Gunst hinaussähe, selbst gestehen muß, es sei ihm recht geschehen und sein Los sei seinem Verhalten vollkommen angemessen. In jeder Strafe als solcher muß zuerst Gerechtigkeit sein, und diese macht das Wesentliche dieses Begriffs aus. Mit ihr kann zwar auch Gütigkeit verbunden werden, aber auf diese hat der Strafwürdige nach seiner Aufführung nicht die mindeste Ursache sich Rechnung zu machen. Also ist Strafe ein phy10 sches Utbel, welches, wenn es auch nicht als natürliche Folge mit dem Moralisch-Bösen verbunden wäre, doch als Folge nach Prinzipien einer sittlichen Gesetzgebung verbunden werden müßte. Wenn nun alles Verbrechen, auch ohne auf die physischen Folgen in Ansehung des Täters zu sehen, für sich strafbar ist, d. i. Glückseligkeit (wenigstens zum Teil) verwirkt, so wäre es offenbar ungereimt zu sagen: das Verbrechen habe darin eben bestanden, dah er sich eine Strafe zugezogen hat, indem er seiner eigenen Glück-

[38] 20 seligkeit Abbruch tat (welches nach dem Prinzip der Selbstliebe der eigentliche Begriff alles Verbrechens sein müßte). Die Strafe würde auf diese Art der Grund sein, etwas ein Verbrechen zu nennen, und die Gerechtigkeit müßte vielmehr darin bestehen, alle Bestrafung zu unterlassen und selbst die natürliche $\mathrm{zu}$ verhindern; denn alsdann wäre in der Handlung nichts Böses mehr, weil die Utbel, die sonst darauf folgten, und um deren willen die Handlung allein böse hieß, nunmehr abgehalten wären. Vollends aber alles Strafen

80 und Belohnen nur als das Maschinenwerk in der Hand einer höheren Macht anzusehen, welches vernünftige Wesen dadurch zu ihrer Endabsicht (der Glückseligkeit) in Tätigkeit zu setzen allein dienen sollte, ist gar zu sichtbar ein alle Freiheit aufhebender Mechanismus ihres Willens, als daß es nötig wäre uns hierbei aufzuhalten.

Feiner noch, obgleich ebenso unwahr, ist das Vorgeben derer, die einen gewissen moralischen besondern Sinn annehmen, der und nicht die Vernunft das

40 moralische Gesetz bestimmt, nach welchem das Bewußtsein der Tugend unmittelbar mit Zufriedenheit und Vergnügen, das des Lasters aber mit Seelenunruhe 
und Schmerz verbunden wäre, und so alles doch auf Verlangen nach eigener Glückseligkeit aussetzen. Ohne das hierher zu ziehen, was oben gesagt worden, will ich nur die Täuschung bemerken, die hierbei vorgeht. Um den Lasterhaften als durch das Bewußtsein seiner Vergehungen mit Gemütsunruhe geplagt vorzustellen, müssen sie ihn der vornehmsten Grundlage seines Charakters nach schon zum voraus als, wenigstens in einigem Grade, moralisch gut, sowie den, welchen das Bewußtsein pflichtmäßiger Handlungen 10 ergötzt, vorher schon als tugendhaft vorstellen. Also mußte doch der Begriff der Moralität und Pflicht vor aller Rücksicht auf diese Zufriedenheit vorhergehen und kann von dieser gar nicht abgeleitet werden. Nun muß man doch die Wichtigkeit dessen, was wir Pflicht nennen, das Ansehen des moralischen Gesetzes und den unmittelbaren Wert, den die Befolgung desselben der Person in ihren eigenen Augen gibt, vorher schätzen, um jene Zufriedenheit in dem Bewußtsein seiner Angemessenheit zu demselben ${ }^{2}$ ) und den 20 bitteren Verweis, wenn man sich dessen Ubertretung vorwerfen kann, zu fühlen. Man kann also diese Zufriedenheit oder Seelenunruhe ${ }^{b}$ ) nicht vor der Erkenntnis der Verbindlichkeit fühlen und sie zum Grunde der letzteren machen. Man muß wenigstens auf dem halben Wege schon ein ehrlicher Mann sein, um sich von jenen Empfindungen auch nur eine Vorstellung machen zu können. Daß übrigens, sowie vermöge der Freiheit der menschliche Wille durchs moralische Gesetz unmittelbar bestimmbar ist, auch 30 die öftere Ausübung diesem Bestimmungsgrunde gemäß subjektiv zuletzt ein Gefühl der Zufriedenheit mit sich selbst wirken könne, bin ich gar nicht in $A b$ rede; vielmehr gehört es selbst zur Pflicht, dieses, welches eigentlich allein das moralische Gefühl genannt zu werden verdient, zu gründen und zu kultivieren; aber der Begriff der Pflicht kann davon nicht abgeleitet werden, sonst müßten wir uns ein Gefühl

a) sc. dem Gesetz; Kant: „derselben“; korr. Vorländer.

b) 2.-6. Anfl.: "Seelenruhe". Nach der 1. Anfl. von Natorp wiederhergestellt, vgl. auch vorige Seite, Zeile 42. 
eines Gesetzes als eines solchen denken und das zum [39] Gegenstande der Empfindung machen, was nur durch Vernunft gedacht werden kann; welches, wenn es nicht ein platter Widerspruch werden soll, allen Begriff der Pflicht ganz aufheben und an deren Statt bloß ein mechanisches Spiel feinerer, mit den gröberen bisweilen in Zwist geratender Neigungen setzen würde.

Wenn wir nun unseren for malen obersten Grundsatz der reinen praktischen Vernunft (als einer Auto-

10 nomie des Willens) mit allen bisherigen materialen Prinzipien der Sittlichkeit vergleichen, so können wir in einer Tafel alle übrigen als solche, dadurch wirklich zugleich alle möglichen anderen Fälle außer einem einzigen formalen ${ }^{2}$ ) erschöpft sind, vorstellig machen und so durch den Augenschein beweisen, daß es vergeblich sei, sich nach einem anderen Prinzip als dem jetzt vorgetragenen umzusehen. - Alle möglichen Bestimmungsgründe des Willens sind nämlich entweder bloß subjektiv und also empirisch, oder auch 20 objektiv und rational; beide aber entweder äußere oder innere.

a) „formalen" würde besser hinter "vorgetragenen" (Zeile 16) passen und ist vielleicht nur durch ein Versghen an seine jetzige Stelle gekommen, wie Natorp mit Recht vermutet. 
Von den Grundsätzen der reinen praktischen Vernunft. 53

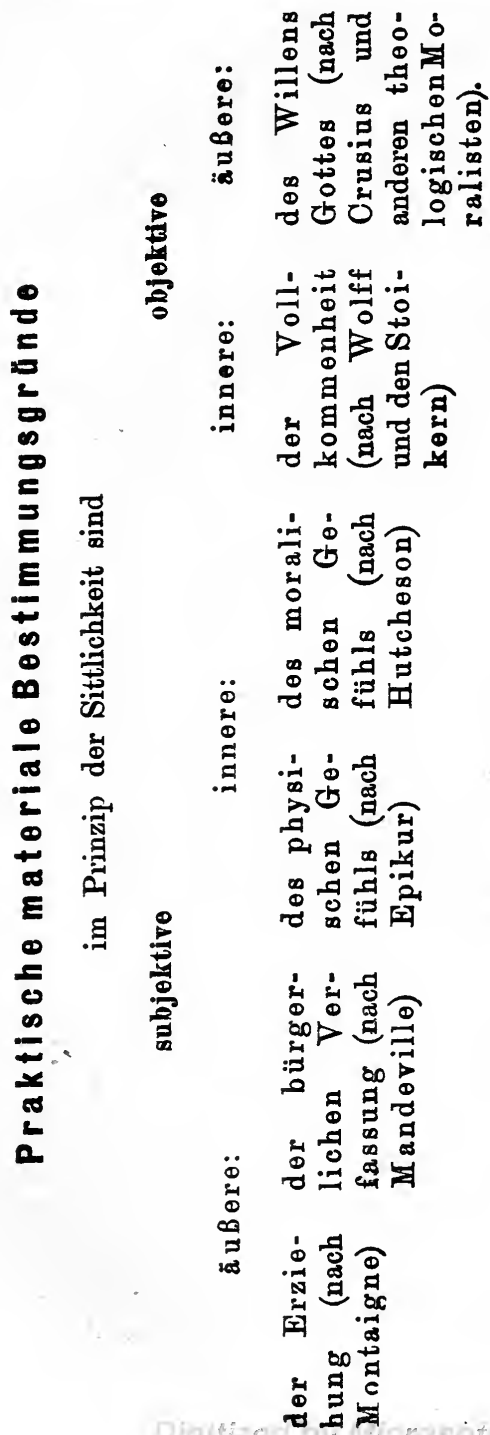


54 Erster Teil, I. Buch, 1. Hauptstück. §8.

[41] Die auf der linken Seite stehenden sind insgesamt empirisch und taugen offenbar gar nicht zum allgemeinen Prinzip der Sittlichkeit. Aber die auf der rechten Seite gründen sich auf die Vernunft (denn Vollkommenheit, als Beschaffenheit der Dinge, und die höchste Vollkommenheit in Substanz vorgestellt, d. i. Gott, sind beide nur durch Vernunftbegriffe zu denken). Allein der erstere Begriff, nämlich der Vollkommenheit, kann entweder in theoretischer Be-

10 deutung genommen werden, und da bedeutet er nichts als Vollständigkeit eines jeden Dinges in seiner Art (transzendentale), oder eines Dinges bloß als Dinges überhaupt (metaphysische), und davon kann hier nicht die Rede sein. Der Begriff der Vollkommenheit in praktischer Bedeutung aber ist die Tauglichkeit oder Zulänglichkeit eines Dinges zu allerlei Zwecken. Diese Vollkommenheit, als Beschaffenheit des Menschen, folglich innerliche, ist nichts anderes als TaIent und, was dieses stärkt oder ergänzt, Geschicklichkeit.

20 Die höchste Vollkommenheit in Substanz, d. i. Gott, folglich äußerliche (in praktischer Absicht betrachtet), ist die Zulänglichkeit dieses Wesens zu allen Zwecken überhaupt. Wenn nun also uns Zwecke vorher gegeben werden müssen, in Beziehung auf welche der Begriff der Vollkommenheit (einer inneren an uns selbst oder einer äußeren an Gott) allein Bestimmungsgrund des Willens werden kann, ein Zweck aber als Objekt, welches vor der Willensbestimmung durch eine praktische Regel vorhergehen und den Grund der Möglich-

80 keit einer solchen enthalten muß, mithin die Materie des Willens, als Bestimmungsgrund desselben genommen, jederzeit empirisch ist, mithin zum Epikurischen Prinzip der Glückseligkeitslehre, niemals aber zum reinen Vernunftprinzip der Sittenlehre und der Pflicht dienen kann (wie denn Talente und ihre Beförderung nur, weil sie zu Vorteilen des Lebens beitragen, oder der Wille Gottes, wenn Einstimmung mit ihm, ohne vorhergehendes von dessen Idee unabhängiges praktisches Prinzip, zum Objekte des Willens

$\$ 0$ genommen worden, nur durch die Glückseligkeit, die wir davon erwarten, Bewegursache desselben werden können), so folgt erstlich: daß alle hier auf- 
gestellten Prinzipien material sind; zweitens: daß sie alle möglichen materialen Prinzipien befassen, und daraus endlich der Schluß: daß, weil materiale Prinzipien zum obersten Sittengesetz ganz untauglich sind (wie bewiesen worden), das formale praktische Prinzip der reinen Vernunft, nach welchem die bloße Form einer durch unsere Maximen möglichen allgemeinen Gesetzgebung den obersten und unmittelbaren Bestimmungsgrund des Willens ausmachen muß, das einzige mögliche sei, welches zu kategorischen Im- 10 perativen, d. i. praktischen Gesetzen (welche Handlungen zur Pflicht machen), und überhaupt zum Prinzip der Sittlichkeit sowohl in der Beurteilung als auch der Anwendung auf den menschlichen Willen in Bestimmung desselben tauglich ist.

I.

Von der Deduktion der Grundsätze der reinen praktischen Vernunft.

Diese Analytik tut dar, daß reine Vernunft praktisch sein, d. i. für sich, unabhängig von allem Em- 20 pirischen den Willen bestimmen könne, - und dieses zwar durch ein Faktum, worin sich reine Vernunft bei uns in der. Tat praktisch beweist, nämlich die Autonomie in dem Grundsatze der Sittlichkeit, wodurch sie den Willen zur Tat bestimmt. - Sie zeigt zugleich, daß dieses Faktum mit dem Bewußtsein der Freiheit des Willens unzertrennlich verbunden, ja mit ihm einerlei sei, wodurch der Wille eines vernünftigen Wesens, das, als zur Sinnenwelt gehörig, sich gleich anderen wirksamen Ursachen notwendig den Gesetzen 30 der Kausalität unterworfen erkennt, im Praktischen doch zugleich sich auf einer anderen Seite, nämlich als Wesen an sich selbst, seines in einer intelligibelen Ordnung der Dinge bestimmbaren Daseins bewußt ist, zwar nicht einer besonderen Anschauung seiner selbst, sondern gewissen dynamischen Gesetzen gemäß, die die Kausalität desselben in der Sinnenwelt bestimmen können; denn daß Freiheit, wenn sie uns beigelegt 
wird, uns in eine intelligibele Ordnung der Dinge versetze, ist anderwärts ${ }^{2}$ ) hinreichend bewiesen worden. Wenn wir nun damit den analytischen Teil der Kritik der reinen spekulativen Vernunft vergleichen, so zeigt sich ein merkwürdiger Kontrast beider gegeneinander. Nicht Grundsätze, sondern reine sinnliche Anschaung (Raum und Zeit) war daselbst das erste Datum, welches Erkenntnis a priori und zwar nur für Gegenstände der Sinne möglich machte. -

10 Synthetische Grundsätze aus bloßen Begriffen ohne Anschauung waren unmöglich, vielmehr konnten diese nur in Beziehung auf jene, welche sinnlich war, mithin auch nur auf Gegenstände möglicher Erfahrung stattfinden, weil die Begriffe des Verstandes, mit dieser Anschauung verbunden, allein diejenige Erkenntnis möglich machen, welche wir Erfahrung nennen. Uber die Erfahrungsgegenstände hinaus, also von Dingen als Noumenen wurde der spekulativen Vernunft alles Positive einer Erkenntnis mit völligem Rechte

20 abgesprochen. - Doch leistete diese soviel, daß sie den Begriff der Noumenen, d. i. die Möglichkeit, ja Notwendigkeit, dergleichen zu denken, in Sicherheit setzte und z. B. die Freiheit, negativ betrachtet, anzunehmen, als ganz verträglich mit jenen Grundsätzen und Einschränkungen der reinen theoretischen Ver-

[43] nunft, wider alle Einwürfe rettete, ohne doch von solchen Gegenständen irgend etwas Bestimmtes und Erweiterndes zu erkennen zu geben, indem sie vielmehr alle Aussicht dahin gänzlich abschnitt.

30 Dagegen gibt das moralische Gesetz, wenngleich keine Aussicht, dennoch ein schlechterdings aus allen Datis der Sinnenwelt und dem ganzen Umfange unseres theoretischen Vernunftgebrauchs unerklärliches Faktum an die Hand, das auf eine reine Verstandeswelt Anzeige gibt, ja diese sogar positiv bestim $m$ t und uns etwas von ihr, nämlich ein Gesetz, erkennen läßt.

Dieses Gesetz soll der Sinnenwelt, als einer sinnlichen Natur (was die vernünftigen Wesen betrifft), die Form einer Verstandeswelt, d. i. einer über10 sinnlichen Natur, verschaffen, ohne doch jener

a) sc. in der Grundlegung (Bd. 41 der $\mathrm{Ph}$. B.). 
ihrem Mechanismus Abbruch zu tun. Nun ist Natur im allgemeinsten Verstande die Existenz der Dinge unter Gesetzen. Die sinnliche Natur vernünftiger Wesen überhaupt ist die Existenz derselben unter empirisch bedingten Gesetzen, mithin für die Vernunft Heter onomie. Die übersinnliche Natur ebenderselben Wesen ist dagegen ihre Existenz nach Gesetzen, die von aller empirischen Bedingung unabhängig sind, mithin zur Autonomie der reinen Vernunft gehören. Und da die Gesetze, nach welchen das Dasein der Dinge von 10 der Erkenntnis abhängt, praktisch sind, so ist die übersinnliche Natur, soweit wir uns einen Begriff von ihr machen können, nichts anderes als eine Natur unter der Autonomie der reinen praktischen Vernunft. Das Gesetz dieser Autonomie aber ist das moralische Gesetz; welches also das Grundgesetz einer übersinnlichen Natur und einer reinen Verstandeswelt ist, deren Gegenbild in der Sinnenwelt, aber doch zugleich ohne Abbruch der Gesetze derselben existieren soll. Man könnte jene die urbildliche (natura arche- 20 typa), die wir bloß in der Vernunft erkennen, diese aber, weil sie die mögliche Wirkung der Idee der ersteren als Bestimmungsgrundes des Willens enthält, die nachgebildete (natura ectypa) nennen. Denn in der Tat versetzt uns das moralische Gesetz der Idee nach in eine Natur, in welcher reine Vernunft, wenn sie mit dem ihr angemessenen physischen Vermögen begleitet wäre, das höchste Gut hervorbringen würde, und bestimmt unseren Willen, die Form der Sinnenwelt ${ }^{2}$ ), als einem Ganzen vernünftiger Wesen, zu erteilen.

$\mathrm{Da}$ diese Idee wirklich unseren Willensbestimmungen gleichsam als Vorzeichnung zum Muster liege, bestätigt die gemeinste Aufmerksamkeit auf sich selbst.

Wenn die Maxime, nach der ich ein Zeugnis abzulegen gesonnen bin, durch die praktische Vernunft geprüft wird, so sehe ich immer danach, wie sie sein würde, wenn sie als allgemeines Naturgesetz gelte. Es ist offenbar, in dieser Art würde es jedermann zur Wahrhaftigkeit nötigen. Denn es kann nicht mit der Allgemeinheit eines Naturgesetzes bestehen, Aussagen

a) Eher verständlich wäre die Stellung: „der Sinnenwelt die Form". 
für beweisend und dennoch als vorsätzlich unwahr gelten zu lassen. Ebenso wird die Maxime, die ich in Ansehung der freien Disposition über mein Leben nehme, sofort bestimmt, wenn ich mich frage, wie sie sein müßte, damit sich eine Natur nach einem Gesetze derselben erhalte. Offenbar würde niemand in einer solchen Natur sein Leben willkürlich endigen können, denn eine solche Verfassung würde keine bleibende Naturordnung sein, und so in allen übrigen

10 Fällen. Nun ist aber in der wirklichen Natur, sowie sie ein Gegenstand der Erfahrung ist, der freie Wille nicht von selbst zu solchen Maximen bestimmt, die für sich selbst eine Natur nach allgemeinen Gesetzen gründen könnten, oder auch in eine solche, die nach ihnen angeordnet wäre, von selbst paßten; vielmehr sind es Privatneigungen, die zwar ein Naturganzes nach pathologischen (physischen) Gesetzen, aber nicht eine Natur, die allein durch unseren Willen nach reinen praktischen Gesetzen möglich wäre, ausmachen. Gleichwohl sind

20 wir uns durch die Vernunft eines Gesetzes bewußt, welchem, als ob durch unseren Willen zugleich eine Naturordnung entspringen müßte, alle unsere Maximen unterworfen sind. Also muß dieses die Idee einer nicht empirisch-gegebenen und dennoch durch Freiheit möglichen, mithin übersinnlichen Natur sein, der wir, wenigstens in praktischer Beziehung, objektive Realität geben, weil wir sie als Objekt unseres Willens als reiner vernünftiger Wesen ansehen.

Der Unterschied also zwischen den Gesetzen einer

80 Natur, welcher der Wille unterw orfen ist, und einer Natur, die einem Willen (in Ansehung dessen, was Beziehung desselben ${ }^{2}$ ) auf seine freien Handlungen hat) unterworfen ist, beruht darauf, daß bei jener die Objekte Ursachen der Vorstellungen sein müssen, die den Willen bestimmen, (bei dieser aber der Wille Ursache von den Objekten sein soll, sodaß die Kausalität derselben ihren Bestimmungsgrund lediglich in reinem Vernunftvermögen liegen hat, welches deshalb auch eine reine praktische Vernunft genannt werden 10 kann.

a) „desselben" zu streichen? [Natorp]. 
Die zwei Aufgaben also: wie reine Vernunft einerseits a priori Objekte erkennen, und wie sie andererseits unmittelbar ein Bestimmungsgrund des Willens, d. i. der Kausalität des vernünftigen Wesens $[45]$ in Ansehung der Wirklichkeit der Objekte (bloß durch den Gedanken der Allgemeingültigkeit ihrer eigenen Maximen als Gesetzes ${ }^{2}$ )) sein könne, sind sehr verschieden.

Die erste, als zur Kritik der reinen spekulativen Vernunft gehörig, erfordert, daß zuvor erklärt werde, 10 wie Anschauungen, ohne welche uns überall kein $\mathrm{Ob}$ jekt gegeben und also auch keines synthetisch erkannt werden kann, a priori möglich sind, und ihre Auflösung fällt dahin aus, daß sie insgesamt nur sinnlich sind, daher auch keine spekulative Erkenntnis möglich werden lassen, die weiter ginge, als mögliche Erfahrung reicht, und da $\beta$ daher alle Grundsätze jener reinen spekulativen ${ }^{D}$ ) Vernunft nichts weiter ausrichten, als Erfahrung entweder von gegebenen Gegenständen oder denen, die ins Unendliche gegeben wer- 20 den mögen, niemals aber vollständig gegeben sind, möglich zu machen.

Die zweite, als zur Kritik der praktischen Vernunft gehörig, fordert keine Erklärung, wie die Objekte des Begehrungsvermögens möglich sind, denn das bleibt als Aufgabe der theoretischen Naturerkenntnis der Kritik der spekulativen Vernunft überlassen, sondern nur, wie Vernunft die Maxime des Willens bestimmen könne, ob es nur vermittelst empirischer Vorstellun$\operatorname{gen}^{\circ}$ ) als Bestimmungsgründe geschehe, oder ob auch 30 reine Vernunft praktisch und ein Gesetz einer möglichen, gar nicht empirisch erkennbaren Naturordnung sein würde. Die Möglichkeit einer solchen übersinnlichen Natur, deren Begriff zugleich der Grund der Wirklichkeit derselben durch unseren freien Willen sein könne, bedarf keiner Anschauung a priori (einer intelligibelen Welt), die in diesem Falle als übersinnlich für uns auch unmöglich sein müBte. Denn es kommt

a) "Gesetze"? [Vorländer].

b) Kant: "praktischen"; korr. Grillo, Kehrbach.

c) Kant: "Vorstellung"; korr. Hartenstein. 
nur auf den Bestimmungsgrund des Wollens in den Maximen desselben an, ob jener empirisch oder ein $\mathrm{Be}-$ griff der reinen Vernunft (von der Gesetzmäßigkeit derselben überhaupt) sei, und wie er letzteres sein könne. Ob die Kausalität des Willens zur Wirklichkeit der Objekte zulange oden nicht, bleibt den theoretischen Prinzipien der Vernunft zu beurteilen überlassen, als Untersuchung der Möglichkeit der Objekte des Wollens, deren Anschauung also in der praktischen Aufgabe

10 gar kein Moment derselben ausmacht. Nur auf die Willensbestimmung und den Bestimmungsgrund der Maxime desselben als eines freien Willens kommt es hier an, nicht auf den Erfolg. Denn wenn der Wille nur für die reine Vernunft gesetzmäßig ist, so mag es mit dem Vermöge $n$ desselben in der Ausführung stehen, wie es wolle; es mag nach diesen Maximen der

[46] Gesetzgebung einer möglichen Natur eine solche wirklich daraus entspringen oder nicht, darum bekümmert sich die Kritik, die da untersucht, ob und wio reine

20 Vernunft praktisch, d. i. unmittelbar willenbestimmend sein könne, gar nicht.

In diesem Geschäft kann sie also ohne Tadel und muß sie von reinen praktischen Gesetzen und deren Wirklichkeit anfangen. Statt der Anschauung aber legt sie denselben den Begriff ihres Daseins in der intelligibelen Welt, nämlich der Freiheit, zum Grunde. Denn dieser bedeutet nichts anderes, und jene $\mathrm{Ge}$ setze sind nur in Beziehung auf Freiheit des Willens möglich, unter Voraussetzung derselben aber not-

80 wendig, oder umgekehrt: diese ist notwendig, weil jene Gesetze als praktische Postulate notwendig sind. Wie nun dieses Bewußtsein der moralischen Gesetze oder, welches einerlei ist, das der Freiheit möglich sei, läßt sich nicht weiter erklären, nur die Zulässigkeit derselben in der theoretischen Kritik gar wohl verteidigen.

Die Exposition des obersten Grundsatzes der praktischen Vernunft ist nun geschehen, d. i. erstlich, was er enthalte, daß er gänzlich a priori und unab40 hängig von empirischen Prinzipien für sich bestehe, und dann, worin er sich von allen anderen praktischen Grundsätzen unterscheide, gezeigt worden. Mit der 
Deduktion, d. i. der Rechtfertigung seiner objektiven und allgemeinen Gültigkeit und der Einsicht der Möglichkeit eines solchen synthetischen Satzes a priori, darf man nicht so gut fortzukommen hoffen, als es mit den Grundsätzen des reinen theoretischen Verstandes anging. Denn diese bezogen sich auf Gegenstände möglicher Erfahrung, nämlich auf Erscheinungen, und man konnte beweisen, da $\beta$ nur dadurch, da $\beta$ diese Erscheinungen nach Maßgabe jener Gesetze unter die Kategorien gebracht werden, diese Erschei- 10 nungen als Gegenstände der Erfahrung erkannt werden können, folglich alle mögliche Eirfahrung diesen Gesetzen angemessen sein müsse. Einen solchen Gang kann ich aber mit der Deduktion des moralischen Gesetzes nicht nehmen. Denn es betrifft nicht die Erkenntnis von der Beschaffenheit der Gegenstände, die der Vernunft irgendwodurch anderwärts gegeben werden mögen, sondern eine Erkenntnis, sofern sie der Grund von der Existenz der Gegenstände selbst werden kann und die Vernunft durch dieselbe Kausalität in 20 einem vernünftigen Wesen hat, d. i. reine Vernunft, die als ein unmittelbar den Willen bestimmendes Vermögen angesehen werden kann.

Nun ist aber alle menschliche Einsicht zu Ende, sobald wir zu Grundkräften oder Grundvermögen gelangt sind; denn deren Möglichkeit kann durch nichts begriffen, darf aber auch ebensowenig beliebig erdichtet und angenommen werden. Daher kann uns im theoretischen Gebrauche der Vernunft nur Erfahrung dazu berechtigen, sie anzunehmen. Dieses Surrogat, statt einer Deduktion aus Erkenntnisquellen a priori empirische Beweise anzuführen, ist uns hier aber in Ansehung des reinen praktischen Vernunftvermögens auch benommen. Denn was den Beweisgrund seiner Wirklichkeit von der Erfahrung herzuholen bedarf, muß den Gründen seiner Möglichkeit nach von Erfahrungsprinzipien abhängig sein, für dergleichen aber reine und doch praktische Vernunft schon ihres Begriffs wegen unmöglich gehalten werden kann. Auch ist das moralische Gesetz gleichsam als ein Faktum der 40 reinen Vernunft, dessen wir uns a priori bewußt sind, und welches apodiktisch gewiß ist, gegeben, gesetzt 
daß man auch in der Erfahrung kein Beispiel, da es genau befolgt wäre, auftreiben könnte. ${ }^{a}$ ) Also kann die objektive Realität des moralischeni Gesetzes durch keine Deduktion, durch keine Anstrengung der theoretischen, spekulativen oder empirisch unterstützten Vernunft bewiesen und also, wenn man auch auf die apodiktische Gewißheit Verzicht tun wollte, durch keine ${ }^{b}$ ) Erfahrung bestätigt und so a posteriori bewiesen werden, und steht dennoch für sich selbst fest.

10 Etwas anderes aber und ganz Widersinnisches tritt an dio Stelle dieser vergeblich gesuchten Deduktion des moralischen Prinzips, nämlich daß es umgekehrt selbst zum Prinzip der Deduktion eines unerforschlichen Vermögens dient, welches keine Erfahrung beweisen $^{c}$ ), die spekulative Vernunft aber (um unter ihren kosmologischen Ideen das Unbedingte seiner Kausalität nach $\mathrm{zu}$ finden, damit sie sich selbst nicht widerspreche) wenigstens als möglich annehmen mußte: nämlich das der Freiheit, von der das moralische Ge-

20 setz, welches selbst keiner rechtfertigenden Gründe bedarf, nicht bloß die Möglichkeit, sondern die Wirklichkeit an Wesen beweist, die dies Gesetz als für sie verbindend erkennen. Das moralische Gesetz ist in der Tat ein Gesetz der Kausalität durch Freiheit und also der Möglichkeit einer übersinnlichen Natur, sowio das metaphysische Gesetz der Begebenheiten in der Sinnenwelt ein Gesetz der Kausalität der sinnlichen Natur war, und jenes bestimmt also das, was spekulative Philosophie unbestimmt lassen mußte, nämlich das

30 Gesetz für eine Kausalität, deren Begriff in der letzteren nur negativ war, und verschafft diesem also zuerst objektive Realität.

[48] Diese Art von Kreditiv des moralischen Gesetzes, da es selbst als ein Prinzip der Deduktion der Freiheit, als einer Kausalität der reinen Vernunft, aufgestellt wird, ist, da die theoretische Vernunft wenigstens die Möglichkeit einer Freiheit an zunehmen genötigt war, zu Ergänzung eines Bedürfnisses derselben statt aller
a) 1. und 4.-6. Anfl.: „konnte".
b) „keine ${ }^{\mu}$, Zusatz Grillos.
c) sc. kann. 
Rechtfertigung a priori völlig hinreichend. Denn das moralische Gesetz beweist seine Realität dadurch auch für die Kritik der spekulativen Vernunft genugtuend, da $\beta$ es einer bloß negativ gedachten Kausalität, deren Möglichkeit jener unbegreiflich und dennoch sie anzunehmen nötig war, positive Bestimmung, nämlich den Begriff einer den Willen unmittelbar (durch die Bedingung einer allgemeinen gesetzlichen Form seiner Maximen) bestimmenden Vernunft hinzufügt und so der Vernunft, die mit ihren Ideen, wenn sie spekulativ verfahren wollte, immer überschwenglich wurde, zum ersten Male objektive, obgleich nur praktische Realität zu geben vermag und ihren transzendenten Gebrauch in einen immanenten (im Felde der Erfahrung durch Ideen selbst wirkende Ursache ${ }^{a}$ ) zu sein) verwandelt.

Die Bestimmung der Kausalität der Wesen in der Sinnenwelt als einer solchen konnte niemals unbedingt sein, und dennoch muß es zu aller Reihe der Bedingungen notwendig etwas Unbedingtes, mithin 20 auch eine sich gänzlich von selbst bestimmende Kausalität geben. Daher war die Idee der Freiheit, als eines Vermögens absoluter Spontaneität, nicht ein Bedürfnis, sondern, was deren Möglichkeit betrifft, ein analytischer Grundsatz der reinen spekulativen Vernunft. Allein da es schlechterdings unmöglich ist, ihr gemä $\beta$ ein Beispiel in irgend einer Erfahrung zu geben, weil unter den Ursachen der Dinge als Erscheinungen keine Bestimmung der Kausalität, die schlechterdings unbedingt wäre, angetroffen werden kann, so konnten wir nur den Gedanken von einer frei handelnden Ursache, wenn wir diesen auf ein Wesen in der Sinnenwelt, sofern es andererseits auch als Noumenon betrachtet wird, anwenden, verteidigen, indem wir zeigten, daß es sich nicht widerspreche, alle seine Handlungen als physisch bedingt, sofern sie Erscheinungen sind, und doch zugleich die Kausalität derselben, sofern das handelnde Wesen ein Verstandeswesen ist, als physisch unbedingt anzusehen und so den Begriff der Freiheit zum regulativen Prinzip 


\section{4} Erster Teil, I. Buch, 1. Hauptatiok. I.

der Vernunft zu machen; wodurch ich zwar den Gegenstand, dem dergleichen Kausalität beigelegt wird, gar nicht erkenne, was er sei, aber doch das Hindernis wegnehme, indem ich einerseits in der Erklärung der Weltbegebenheiten, mithin auch der Handlungen ver[49] nünftiger Wesen dem Mechanismus der Naturnotwendigkeit, vom Bedingten zur Bedingung ins Unendliche zurückzugehen, Gerechtigkeit widerfahren lasse, andererseits aber der spekulativen Vernunft den für

10 sie leeren Platz offen erhalte, nämlich das Intelligibele, um das Unbedingte dahin zu versetzen. Ich konnte aber diesen Gedanken nicht realisieren, d. i. ihn nicht in Erkenntnis eines so handelnden Wesens, auch nur bloß seiner Möglichkeit nach, verwandeln. Diesen leeren Platz füllt nun reine praktische Vernunft durch ein bestimmtes Gesetz der Kausalität in einer intelligibelen Welt (durch Freiheit), nämlich das moralische Gesetz aus. Hierdurch wächst nun zwar der spekulativen Vernunft in Ansehung ihrer Einsicht

90 nichts zu, aber doch in Ansehung der Sicherung ihres problematischen Begriffs der Freiheit, welchem hier objektive und obgleich nur praktische, dennoch unbezweifelte Realität verschafft wird. Selbst den Begriff der Kausalität, dessen Anwendung, mithin auch Bedeutung eigentlich nur in Beziehung auf Erscheinungen, um sie zu Erfahrungen zu verknüpfen, stattfindet (wie die Kritik der reinen Vernunft beweist), erweitert sie nicht so, daß sie seinen Gebrauch über gedachte Grenzen ") ausdehne. Denn wenn sie darauf

80 ausginge, so müßte sie zeigen wollen, wie das logische Verhältnis des Grundes und der Folge bei einer anderen Art von Anschauung, als die sinnliche ist, synthetisch gebraucht werden könne, d. i. wio causa noumenon möglich sei; welches sie gar nicht leisten kann, worauf sie aber auch als praktische Vernunft gar nicht Rücksicht nimmt, indem sie nur den Bestimmungsgrund der Kausalität des Menschen als Sinnenwesens (welche gegeben ist), in der rein en Vernunft (die darum praktisch heißt) setzt, und also den 40 Begriff der Ursache selbst, von dessen Anwendung
a) 2. Aufl.: „Grenze". 
auf Objekte zum Behuf theoretischer Erkenntnisse sie hier gänzlich abstrahieren kann (weil dieser Begriff immer im Verstande, auch unabhängig von aller Anschauung, a priori angetroffen wird), nicht um Gegenstände zu erkennen, sondern die Kausalität in Ansehung derselben überhaupt $\mathrm{zu}$ bestimmen, also in keiner anderen als praktischen Absicht braucht und daher den Bestimmungsgrund des Willens in die intelligibele Ordnung der Dinge verlegen kann, indem sie zugleich gerne gesteht, das, was der Begriff der 10 Ursache zur Erkenntnis dieser Dinge für eine Bestimmung haben möge, gar nicht zu verstehen. Die Kausalität in Ansehung der Handlungen des Willens in der Sinnenwelt muß sie allerdings auf bestimmte Weise erkennen, denn sonst könnte praktische Vernunft wirklich keine Tat hervorbringen. Aber den Begriff, den $\operatorname{sie}^{a}$ ) von ihrer eigenen Kausalität als Noumenon macht, braucht sie nicht theoretisch zum Behuf der Erkenntnis ihrer übersinnlichen Existenz zu bestimmen und also ihm sofern Bedeutung geben zu

können. Denn Bedeutung bekommt er ohnedem, obgleich vur zum praktischen Gebrauche, nämlich durch das moralische Gesetz. Auch theoretisch betrachtet, bleibt er immer ein reiner, a priori gegebener Verstandesbegriff, der auf Gegenstände angewandt werden kann, sie mögen sinnlich oder nicht sinnlich gegeben werden; wiewohl er im letzteren Falle keine bestimmte theoretische Bedeutung und Anwendung hat, sondern bloß ein formaler, aber doch "wesentlicher Gedanke des Verstandes von einem Objekte überhaupt ist. Die 30 Bedeutung, die ihm die Vernunft durchs moralische Gesetz verschafft, ist lediglich praktisch, da nämlich die Idee des Gesetzes einer Kausalität (des Willens) selbst Kausalität hat oder ihr Bestimmungsgrund ist.

a) sc. sich (Natorp). 


\section{II.}

Von dem Befugnisse der reinen Vernunft, im praktischen Gebrauche

su einer Erweiterung, die ihr im spekulativen für sich nicht möglich ist.

An dem moralischen Prinzip haben wir ein Gesetz der Kausalität aufgestellt, welches den Bestimmungsgrund der letzteren über alle Bedingungen der Sinnenwelt wegsetzt, und den Willen, wie er als zu einer

10 intelligibelen Welt gehörig bestimmbar sei, mithin das Subjekt dieses Willens (den Menschen) nicht bloß als zu einer reinen Verstandeswelt gehörig, obgleich in dieser Beziehung als uns unbekannt (wie es nach der Kritik der reinen spekulativen Vernunft geschehen konnte), gedacht ${ }^{2}$ ), sondern ihn auch in Ansehung seiner Kausalität vermittelst eines Gesetzes, welches zu gar keinem Naturgesetze der Sinnenwelt gezählt werden kann, bestimmta), also unsere Erkenntnis über die Grenzen derb) letzteren erweitert ${ }^{a}$ ), welche An-

20 maßung doch die Kritik der reinen Vernunft in aller Spekulation für nichtig erklärte. Wie ist nun hier praktischer Gebrauch der reinen Vernunft mit dem theoretischen ebenderselben in Ansehung der Grenzbestimmung ihres Vermögens zu vereinigen?

David Hume, von dem man sagen kann, daß er alle Anfechtungc) der Rechte einer reinen Vernunft, welche eine gänzliche Untersuchung derselben notwendig machten, eigentlich anfing, schloß so: Der [51] Begriff der Ursache ist ein Begriff, der die Not80 wendigkeit der Verknüpfung der Existenz des Verschiedenen und zwar, sofern es verschieden ist, enthält, soda $\beta$, wenn A gesetzt ist, ich erkenne, da $\beta$ etwas davon ganz verschiedenes, $B$, notwendig auch existieren müsse. Notwendigkeit kann aber auch nur einer Ver-

a) ngedacht ... bestimmt ... erweitert" sind wohl als Part. perf. zu "haben wir" (Zeile 6) anzusehen. ten").

b) Kant: "des"; korr. Hartenstein.

c) besser: "Anfechtungen" (wegen des folgenden "mach- 
knüpfung beigelegt werden, sofern sie a priori erkannt wird; denn die Erfahrung würde von einer Verbindung nur zu erkennen geben, daß sie sei, aber nicht, daß sie so notwendigerweise sei. Nun ist es, sagt er, unmöglich, die Verbindung, die zwischen einem Dinge und einem anderen (oder einer Bestimmung und einer anderen, ganz von ihr verschiedenen a)), wenn sie nicht in der Wahrnehmung gegeben werden, a priori und als notwendig zu erkennen. Also ist der Begriff einer Ursache selbst lügenhaft und betrüg $\theta-10$ risch und ist, am gelindesten davon zu reden, eine sofern noch zu entschuldigende Täuschung, da die Gewohnheit (eine subjektive Notwendigkeit), gewisse Dinge oder ihre Bestimmungen öfters neben- oder nacheinander ihrer Existenz nach als sich beigesellt wahrzunehmen, unvermerkt für eine objektive Notwendigkeit, in den Gegenständen selbst eine solche Verknüpfung zu setzen, genommen, und so der Begriff einer Ursache erschlichen und nicht rechtmäßig erworben ist, ja auch niemals erworben oder be- 20 glaubigt werden kann, weil er eine an sich nichtige, chimärische, von keiner Vernunft haltbare Verknüpfung fordert, der gar kein Objekt jemals korrespondieren kann. - So ward nun zuerst in Ansehung aller Erkenntnis, die die Existenz der Dinge betrifft (die Mathematik blieb also davon noch ausgenommen), der Empirismus als die einzige Quelle der Prinzipien eingeführt, mit ihm aber zugleich der härteste Skeptizismus selbst in Ansehung der ganzen Naturwissenschaft (als Philosophie). Denn wir können nach solchen 80 Grundsätzen niemals aus gegebenen Bestimmungen der Dinge ihrer, Existenz nach auf eine Folge schlieBen (denn dazu würde der Begriff einer Ursache, der die Notwendigkeit einer solchen Verknüpfung enthält, erfordert werden), sondern nur nach der Regel der Einbildungskraft ähnliche Fälle wia sonst erwarten; welche Erwartung aber niemals sicher ist, sie mag auch noch so oft eingetroffen sein. Ja bei keiner $\mathrm{Be}-$ gebenheit könnte man sagen: es müsse etwas vor ihr vorhergegangen sein, worauf sie notwendig folgte, 40

a) sc. besteht (Kehrbach). 
d. i. sie müsse eine Ursache haben, und also, wenn man auch noch so ofttere Fälle kennte, wo dergleichen vorherging, sodaß eine Regel davon abgezogen werden konnte, so könnte man darum es nicht als immer und notwendig sich auf die Art zutragend annehmen, und so müsse man dem blinden Zufalle, bei welchem [52] aller Vernunftgebrauch aufhört, auch sein Recht lassen; welches denn den Skeptizismus in Ansehung der von Wirkungen zu Ursachen aufsteigenden Schlüsse

10 fest gründet und unwiderleglich macht.

Die Mathematik war so lange noch gut weggekommen, weil Hume dafür hielt, daß ihre Sätze alle analytisch wären, d. i. von einer Bestimmung zur anderen um der Identität willen, mithin nach dem Satze des Widerspruchs fortschritten (welches aber falsch ist, indem sie' vielmehr alle synthetisch sind, und, obgleich z. B. die Geometrie es nicht mit der-Existenz der Dinge, sondern nur ihrer Bestimmung a priori in einer möglichen Anschauung zu tun hat $\left.{ }^{2}\right)$, dennoch

20 ebensogut wie durch Kausalbegriffe von einer Bestimmung A zu einer ganz verschiedenen, B, als dennoch mit jener notwendig verknüpft, übergeht). Aber ondlich muß jene wegen ihrer apodiktischen Gewißheit so hochgepriesene Wissenschaft doch dem Empirismus in Grundsätzen aus demselben Grunde, warum Hume an der Stelle der objektiven Notwendigkeit in dem Begriffe der Ursache die Gewohnheit setzte, auch unterliegen und sich unangesehen alles ihres Stolzes gefallen lassen, ihre kühnen, a priori

80 Beistimmung gebietenden Ansprüche herabzustimmen und den Beifall für die Allgemeingültigkeit ihrer Sätze von der Gunst der Beobachter erwarten '), die als Zeugen es doch nicht weigern würden zu gestehen, daß sie das, was der Geometer als Grundsätze vorträgt, jederzeit auch so wahrgenommen hätten, folglich, ob es gleich eben nicht notwendig wär, doch fernerhin es so erwarten zu dürfen erlauben würden. Auf diese Weise führt Hnmes Empirismus in Grundsätzen auch unvermeidlich auf den Skeptizismus, selbst in An-

a) "sie dennoch* (Natorp, Vorländer)?

b) Natorp: „2u erwarten"? 
sehung der Mathematik, folglich in allem wissenschaftlichen theoretischen Gebrauche der Vernunft (denn dieser gehört entweder zur Philosophie oder zur Mathematik). Ob der gemeine Vernunftgebrauch (bei einem so schrecklichen Umsturz, als man den Häuptern der Erkenntnis begegnen sieht) besser durchkommen und nicht vielmehr noch unwiederbringlicher in ebendiese Zerstörung alles Wissens werde verwickelt werden, mithin ein allgemeiner Skeptizismus nicht aus denselben Grundsätzen folgen müsse (der freilich 10 aber nur die Gelehrten treffen würde), das will ich jeden selbst beurteilen lassen.

Was nun meine Bearbeitung in der Kritik der reinen Vernunft betrifft, die zwar durch jene Humesche Zweifellehre veranlaßt ward, doch viel weiter ging und das ganze Feld der reinen theoretischen Vernunft im synthetischen Gebrauche, mithin auch desjenigen, was man Metaphysik überhaupt nennt, befaßte: so verfuhr ich in Ansehung der den Begriff der Kausalität betreffenden Zweifel des schottischen 20 Philosophen auf folgende Art. Daß Hume, wenn er (wie es doch auch fast überall geschieht) die Gegenstände der Erfahrung für Dinge an sich selbst nahm, den Begriff der Ursache für trüglich und falsches Blendwerk erklärte, daran tat er ganz recht; denn von Dingen an sich selbst und deren Bestimmungen als solchen kann nicht eingesehen werden, wie darum, weil etwas A gesetzt wird, etwas anderes B auch notwendig gesetzt werden müsse; und also konnte er eine solche Erkenntnis a priori von Dingen an 80 sich selbst gar nicht einräumen. Einen empirischen Ursprung dieses Begriffs konnte der scharfsinnige Mann noch weniger verstatten, weil dieser geradezu der Notwendigkeit der Verknüpfung widerspricht, welche das Wesentliche des Begriffs der Kausalität ausmacht; mithin ward der Begriff in die Acht erklärt, und in seine Stelle trat die Gewohnheit im Beobachten des Laufs der Wahrnehmungen.

Aus meinen Untersuchungen aber ergab es sich, daß die Gegenstände, mit denen wir es in der Er- 40 fahrung zu tun haben, keineswegs Dinge an sich selbst, sondern bloß Erscheinungen sind, und dab, ob- 
gleich bei Dingen an sich selbst gar nicht abzusehen ist, ja unmöglich ist einzusehen, wie, wenn A gesetzt wird, es widersprechend sein solle, $B$, welches von A ganz verschieden ist, nicht zu setzen (die Notwendigkeit der Verknüpfung zwischen A als Ursache und $B$ als Wirkung): es sich doch ganz wohl denken lasse, daß sie als Erscheinungen in einer Erfahrung auf gewisse Weise (z. B. in Ansehung der Zeitverhälltnisse) notwendig verbunden sein müssen und

10 nicht getrennt werden können, ohne derjenigen Verbindung zu widersprechen, vermittelst deren diese Erfahrung möglich ist, in welcher sie Gegenstände und uns allein erkennbar sind. Und so fand es sich auch in der Tat: soda $B$ ich den Begriff der Ursache nicht allein nach seiner objektiven Realität in Ansehung der Gegenstände der Erfahrung beweisen, sondern ihn auch als Begriff a priori wegen der Notwendigkeit der Verknüpfung, die er bei sich führt, deduzieren, d. i. seine Möglichkeit aus reinem Ver-

20 stande ohne empirische Quellen dartun, und so, nach Wegschaffung des Empirismus seines Ursprungs, die unvermeidliche Folgo desselben, nämlich den Skeptizismus, zuerst in Ansehung der Naturwissenschaft, dann auch, wegen des ganz vollkommen aus denselben Gründen Folgenden, in Ansehung der lifathematik, beider Wissenschaften, die auf Gegenstände möglicher Erfahrung bezogen werden, und hiermit den totalen

[54] Zweifel an allem, was theoretischeVernunft einzusehen behauptet, aus dem Grunde heben konnte.

30 Aber wie wird es mit der Anwendung dieser Kategorie der Kausalität (und so auch aller übrigen, denn ohne sie läßt sich keine Erkenntnis des Existierenden zustande bringen) auf Dinge, die nicht Gegenstände möglicher Erfahrung sind, sondern über dieser ihre Grenze hinaus liegen? Denn ich habe die objektive Realität dieser Begriffe nur in Ansehung der Gegenstände möglicher Erfahrung deduzieren können. Aber ebendieses, da $\beta$ ich sie auch nur in diesem Falle gerettet habe, da $\beta$ ich gewiesen habe, es lassen 40 sich dadurch doch Objekte denken, obgleich nicht a priori bestimmen: dieses ist es, was ihnen einen Platz im reinem Verstande gibt, von dem sie auf 
Objekte überhaupt (sinnliche oder nicht sinnliche) bezogen werden. Wenn etwas noch fehlt, so ist es die Bedingung der Anwendung dieser Kategorien, und namentlich der der Kausalität, auf Gegenstände, nämlich die Anschauung, welche, wo sie nicht gegeben ist, die Anwendung zum Behuf der theoretischen Erkenntnis des Gegenstandes als Noumenon unmöglich macht, die also, wenn es jemand darauf wagt (wie auch in der Kritik der reinen Vernunft geschehen), gänzlich verwehrt wird, indessen daß doch immer die 10 objektive Realität des Begriffs bleibt, auch von Noumenen gebraucht werden kann, aber ohne diesen Begriff theoretisch im mindesten bestimmen und dadurch eine Erkenntnis bewirken zu können. Denn daß dieser Begriff auch in Beziehung auf ein Objekt nichts Unmögliches enthalte, war dadurch bewiesen, daß $\mathrm{ihm}$ sein Sitz im reinen Verstande bei aller Anwendung auf Gegenstände der Sinne gesichert war, und ob er gleich hernach etwa, auf Dinge an sich selbst (die nicht Gegenstände der Erfahrung sein können) be- 20 zogen, keiner Bestimmung zur Vorstellung eines bestimmten Gegenstandes zum Behuf einer theoretischen Erkenntnis fähig ist, so konnte er doch immer noch $\mathrm{zu}$ irgend einem anderen (vielleicht dem praktischen) Behuf einer Bestimmung zur Anwendung desselben fähig sein, welches nicht sein würde, wenn nach Hu $m \theta$ dieser Begriff der Kausalität etwas, das überall zu denken unmöglich ist, enthielte.

Um nun diese Bedingung der Anwendung des gedachten Begriffs auf Noumenen ausfindig zu machen, 30 dürfen wir nur zurücksehen, weswegen wir nicht mit der Anwendung desselben auf Erfahrungsgegenstände zufrieden sind, sondern ihn auch gern von Dingen an sich selbst brauchen möchten. Denn da zeigt sich bald, daß es nicht eine theoretische, sondern praktische Absicht sei, welche uns dieses zur Notwendigkeit macht. Zur Spekulation würden wir, [55] wenn es uns damit auch gelänge, doch keinen wahren Erwerb in Naturkenntnis und überhaupt in Ansehung der Gegenstände, die uns irgend gegeben werden 40 mögen, machen, sondern allenfalls einen weiten Schritt rom Sinnlichbodingten (bei welchem zu bleiben und 
die Kette der Ursachen fleißig durchzuwandern wir so schon genug zu tun haben) zum Ubersinnlichen tun, $u^{2}$ ) unsere Erkenntnis von der Seite der Gründe zu vollenden und zu begrenzen, indessen daß immer eine unendliche Kluft zwischen jener Grenze und dem, was wir kennen, unausgefüllt übrigbliebe, und wir mehr einer eiteln Fragsucht als einer gründlichen Wißbegierde Gehör gegeben hätten.

Außer dem Verhältnisse aber, darin der Ver10 stand zu Gegenständen (in der theoretischen Erkenntnis) steht, hat er auch eines zum Begehrungsvermögen, das darum der Wille heißt, und der reine Wille, sofern der reine Verstand (der in solchem Falle Vernunft heißt) durch die bloße Vorstellung eines Gesetzes praktisch ist. Die objektive Realität eines reinen Willens oder, welches einerlei ist, einer reinen praktischen Vernunft ist im moralischen Gesetze a priori gleichsam durch ein Faktum gegeben; denn so kann man eine Willensbestimmung nennen, die unvermeidlich 20 ist, ob sie gleich nicht auf empirischen Prinzipien beruht. Im Begriffe eines Willens aber ist der Begriff der Kausalität schon enthalten, mithin in dem eines reinen Willens der Begriff einer Kausalität mit Freiheit, d. i. die nicht nach Naturgesetzen bestimmbar, folglich keiner empirischen Anschauung als Beweises seiner $\left.{ }^{b}\right)$ Realität fähig ist, dennoch aber in dem reinen praktischen Gesetze a priori seine objektive Realität, doch (wie leicht einzusehen) nicht zum Behufe des theoretischen, sondern bloß praktischen Gebrauchs

$B 0$ der Vernunft vollkommen rechtfertigt. Nun ist der Begriff eines Wesens, das freien Willen hat, der Begriff einer causa noumenon; und daß sich dieser Begriff nicht selbst widerspreche, davor ist man schon dadurch gesichert, daß der Begriff einer Ursache, als gänzlich vom reinen Verstande entsprungen, zugleich auch seiner objektiven Realität ${ }^{\circ}$ ) in Ansehung der Gegenstände überhaupt durch die Deduktion gesichert, dabei seinem Ursprunge nach von allen sinnlichen
a) 1. und 4.-6. Aufl.: "nnd
b) so. des reinen (freien) Willen.
o) Hartenstein: ${ }_{\text {Realităt nach“. }}$ 
Bedingungen unabhängig, also für sich auf Phänomene nicht eingeschränkt (es sei denn, wo ein theoretischer bestimmter ${ }^{2}$ ) Gebrauch davon gemacht werden wollteb)), auf Dinge als reine Verstandeswesen allerdings angewandt werden könnte $\left.{ }^{c}\right)$. Weil aber dieser Anwendung keine Anschaung, als die jederzeit nur sinnlich sein kann, untergelegt werden kann, so ist causa noumenon in Ansehung des theoretischen Gebrauchs der Vernunft, obgleich ein möglicher, denkbarer, dennoch leerer Begriff. Nun verlange ich aber auch dadurch nicht die 10 Beschaffenheit eines Wesens, sofern es einen reinen Willen hat, theoretisch zu kennen; es ist mir genug, es dadurch nur als ein solches zu bezeichnen, mithin nur den Begriff der Kausalität mit dem der Freiheit (und was davon unzertrennlich ist, mit dem moralischen Gesetze als Bestimmungsgrunde derselben) zu verbinden; welche Befugnis mir vermöge des reinen, nicht empirischen Ursprungs des Begriffs der Ursache allerdings zusteht, indem ich davon keinen anderen Gebrauch als in Beziehung auf das moralische Gesetz, 20 das seine Realität bestimmt, d. i. nur einen praktischen Gebrauch $\mathrm{zu}$ machen mich befugt halte.

Hätte ich mit Hume dem Begriffe der Kausalität die objektive Realität im theoretischend) Gebrauche nicht allein in Ansehung. der Sachen an sich selbst (des Ubersinnlichen), sondern auch in Ansehung der Gegenstände der Sinne genommen, so wäre er aller Bedeutung verlustig und als ein theoretisch unmöglicher Begriff für gänzlich unbrauchbar erklärt worden, und da von nichts sich auch kein Gebrauch machen läßt, der 30 praktische Gebrauch eines theoretisch-nichtigen Begriffs ganz ungereimt gewesen. Nun aber der Begriff einer empirisch unbedingten Kausalität theoretisch zwar leer (ohne darauf sich schickende Anschauung), aber immer doch möglich ist und sich. auf ein unbestimmtes Objekt bezieht, statt dieses aber ihm doch an dem moralischen Gesetze, folglich in praktischer Beziehung. Bedeutung gegeben wird, so

a) Deutlicher wäre: bestimmter theoretischer.

b) "sollte" (Natorp)?

c) Kant: „könne" ; korr. Vorländer.

d) Kant: „praktischen “; korr. Schöndörffer. 
habe ich zwar keine Anschauung, die ihm seine objektive theoretische Realität bestimmte, aber er hat nichtsdestoweniger wirklich $\theta$ Anwendung, die sich in concreto in Gesinnungen oder, Maximen darstellen läßt, d. i. praktische Realität, die angegeben werden kann; welches denn zu seiner Berechtigung selbst in Absicht auf Noumenen hinreichend ist.

Aber diese einmal eingeleitete objektive Realität eines reinen Verstandesbegriffs im Felde des Uber-

10 sinnlichen gibt nunmehr allen übrigen Kategorien, obgleich immer nur, sofern sie mit dem Bestimmungsgrunde des reinen Willens (dem moralischen Gesetze) in notwendiger Verbindung stehen, auch objektive, nur keine andere als bloß praktisch-anwendbare Realität, indessen sie auf theoretische Erkenntnisse dieser Gegenstände, als Einsicht der Natur derselben durch reine Vernunft, nicht den mindesten Einfluß hat, um dieselbe zu erweitern. Wie wir denn auch in der Folge finden werden, daß sie immer nur auf Wesen 20 als Intelligenzen, und an diesen auch nur auf das [67] Verhältnis der Vernunft zum Willen, mithin immer nur aufs Praktische Beziehung haben und weiter hinaus sich keine Erkenntnis derselben anmaßen; was aber mit ihnen in Verbindung noch sonst für Eigenschaften, die zur theoretischen Vorstellungsart solcher übersinnlicher Dinge gehören, herbeigezogen werden möchten, diese insgesamt alsdann gar nicht zum Wissen, sondern nur zur Befugnis (in praktischer $\mathrm{Ab}$ sicht aber gar zur Notwendigkeit) sie anzunehmen und

80 vorauszusetzen gezählt werden, selbst da, wo man übersinnliche Wesen (als Gott) nach einer Analogie, d. i. dem reinen Vernunftverhältnisse, dessen wir in Ansehung der sinnlichen uns praktisch bedienen, annimmt ${ }^{2}$ ), und so der reinen theoretischen Vernunft durch die Anwendung aufs Ubersinnliche, aber nur in praktischer Absicht zum Schwärmen ins Uberschwengliche nicht den mindesten Vorschub gibt.

a) „annimmt", Zusatz Hartensteins. 


\section{Der Analytik der praktischen Vernunft}

Zweites Hauptstück.

\section{Von dem Begriffe eines Gegenstandes der reinen praktischen Vernunft.}

Unter einem Begriffe eines Gegenstandes ${ }^{2}$ ) der praktischen Vernunft verstehe ich die Vorstellung eines Objekts als einer möglichen Wirkung durch Freiheit. Ein Gegenstand der praktischen Erkenntnis als einer solchen zu sein, bedeutet also nur die Beziehung des 10 Willens auf die Handlung, dadurch er oder sein Gegenteil wirklich gemacht würde, und die Beurteilung, ob etwas ein Gegenstand der reinen praktischen Vernunft sei' oder nicht, ist nur die Unterscheidung der Möglichkeit oder Unmöglichkeit, diejenige Handlung $\mathrm{zu}$ wollen, wodurch, wenn wir das Vermögen dazu hätten (worüber die Erfahrung urteilen muß), ein gewisses Objekt wirklich werden würde. Wenn das Objekt als der Bestimmungsgrund unseres Begehrungsvermögens angenommen wird, so muß die physische 20 Möglichkeit desselben durch freien Gebrauch unserer Kräfte vor der Beurteilung, ob es ein Gegenstand der praktischen Vernunft sei oder nicht, vorangehen. Dagegen wenn das Gesetz a priori als der Bestimmungsgrund der Handlung, mithin diese als durch reine praktische Vernunft bestimmt betrachtet werden kann, so ist das. Urteil, ob etwas ein Gegenstand der reinen praktischen Vernunft sei oder nicht, von der Vergleichung mit unserem physischen Vermögen ganz unabhängig, und die Frage ist nur, ob wir eine Handlung, die auf die Existenz eines Objekts gerichtet ist, wollen dürfen, wenn dieses in unserer Gewalt wäre; mithin muß die moralische Möglichkeit der Handlung vorangehen; denn da ist nicht der Gegenstand,

a) „eines Gegenstandes" fehlt bei Kant, ron uns hinzugefügt; v. Aster, Natorp, Schöndörfier wollen: „dem Begriffe eines Gegenstandes". 
sondern das Gesetz des Willens der Bestimmungsgrund derselben.

Die alleinigen Objekte einer praktischen Vernunft sind also die vom Guten und Bösen. Denn durch das erstere versteht man einen notwendigen Gegenstand des Begehrungs-, durch das zweite des Verabscheuungsvermögens, beides aber nach einem Prinzip der Vernunft.

Wenn der Begriff des Guten nicht von einem vor10 hergehenden praktischen Gesetze abgeleitet werden, sondern diesem vielmehr zum Grunde dienen soll: so kann er nur der Begriff von etwas sein, dessen Existenz Lust verheißt und so die Kausalität des Subjekts zur Hervorbringung desselben, d. i. das Begehrungsvermögen bestimmt. Weil es nun unmöglich ist, a priori einzusehen, welche Vorstellung mit Lust, welche hingegen mit Unlust werde begleitet sein, so käme es lediglich auf Erfahrung an, es auszumachen, was unmittelbar gut oder böse sei. Die Eiǵgenschaft

20 des Subjekts, worauf in Beziehung diese Erfahrung allein angestellt werden kann, ist das Gef ühl der Lust und Unlust, als eine dem inneren Sinne angehörige Rezeptivität, und so würde der Begriff von dem, was unmittelbar gut ist, nur auf das gehen, womit die Empfindung des Vergnügens unmittelbar verbunden ist, und der von dem Schlechthin-Bösen auf das, was unmittelbar Schmerz erregt, allein bezogen werden müssen. Weil aber das dem Sprachgebrauche schon zu-। wider ist, der das Angenehme vom Guten, das

80 Unangenehme vom Bösen unterscheidet und verlangt, daß Gutes und Böses jederzeit durch Vernunft, mithin durch Begriffe, die sich allgemein mitteilen lassen, und nicht durch bloße Empfindung, welche sich auf einzelne Subjekte ${ }^{2}$ ) und deren Empfänglichkeit einschränkt, beurteilt werde, gleichwohl aber für sich selbst mit keiner Vorstellung eines Objekts a priori eine Lust oder Unlust unmittelbar verbunden werden kann, so würde der Philosoph, der sich genötigt glaubte, ein Gefühl der Lust seiner praktischen Be40 urteilung zum Grunde zu legen, g ut nennen, was ein

8) Kant: "Objekto"; korr. Natorp. 
Mittel zum Angenehmen, und Böses, was Ursache der Unannehmlichkeit und des Schmerzes ist; denn die Beurteilung des Verhältnisses der Mittel zu Zwecken gehört allerdings zur Vernunft. Obgleich aber. Vernunft allein vermögend ist, die Verknüpfung der Mittel mit ihren Absichten einzusehen (sodaß man auch den Willen durch das Vermögen der Zwecke definieren könnte, indem sie jederzeit Bestimmungsgründe des Begehrungsvermögens nach Prinzipien sind), so würden doch die praktischen Maximen, die aus dem 10 obigen Begriffe des Guten bloß als Mittel folgten, nie etwas für sich selbst, sondern immer nur irgendwozu Gutes zum Gegenstande des Willens enthalten; das Gute würde jederzeit bloß das Nützliche sein, und das, wozu es nützt, müßte allemal außerhalb dem Willen in der Empfindung liegen. Wenn diese nun als angenehme Empfindung vom Begriffe des Guten unterschieden werden müßte, sa würde es überall nichts unmittelbar Gutes geben, sondern das Gute nur in den Mitteln zu etwas anderem, nämlich irgend einer Annehmlichkeit, gesucht werden müssen.

Es ist eine alte Formel der Schulen: nihil appetismus nisi sub ratione boni, nihil aversamur nisi sub ratione mali; und sie hat einen oft richtigen, aber auch der Philosophie oft sehr nachteiligen Gebrauch, weil die Ausdrücke des boni und mali eine Zweideutigkeit enthalten, daran die Einschränkung der Sprache schuld ist, nach welcher sio eines doppelten Sinnes fähig sind, und daher die praktischen Gesetze unvermeidlich auf Schrauben stellen und die Philosophie, die im 30 Gebrauche derselben gar wohl der Verschiedenheit des Begriffs bei demselben Worte inne werden, aber doch keine besonderen Ausdrücke dafür finden kann, zu subtilen Distinktionen nötigen, über die man sich nachher nicht einigen kann, indem der Unterschied durch keinen angemessenen Ausdruck unmittelbar bezeichnet werden konnte.*)

*) Oberdem ist der Ausdruck suo ratione boni auch zweideutig. Denn or kann soviel sagen: wir stellen ans etwas als gut vor, wenn und weil wir es begehren (wollen); aber auch: wir begehren etwas darum, weil wir 
Die deutsche Sprache hat das Glück, die Ausdrücke zu besitzen, welche diese Verschiedenheit nicht übersehen lassen. Für das, was die Lateiner mit einem einzigen Worte bonum benennen, hat sie zwei sehr verschiedene Begriffe und auch ebenso verschiedene Ausdrücke: für bonum das Gute und das Wohl, für malum das Böse und das Ubel (oder Weh); sodaß [60] es zwei ganz verschiedene Beurteilungen sind, ob wir bei einer Handlung das Gute und Böse derselben 10 oder unser Wohl und Weh (Ubel) in Betrachtung ziehen. Hieraus folgt schon, daß obiger psyochologischer Satz wenigstens noch sehr ungewiß sei, wenn er so übersetzt wird: wir begehren nichts als in Rücksicht auf unser Wohl oder Weh; dagegen er, wenn man ihn so gibt: wir wollen nach Anweisung der Vernunft nichts, als nur sofern wir es für gut oder böse halten, ungezweifelt gewiß urd zugleich ganz klar ausgedrückt wird.

Das Wohl oder Obel bedeutet immer nur eine 20 Beziehung auf unseren Zustand der Annehmlichkeit oder Unannehmlichkeit, des Vergnügens und Schmerzens, und wenn wir darum ein Objekt begehren oder verabscheuen, so geschieht es nur, sofern es auf unsere Sinnlichkeit und das Gefühl der Lust und Unlust, das es bewirkt, bezogen wird. Das Gute oder Böse bedeutet aber jederzeit eine Beziehung auf den Willen, sofern dieser durchs Vernunftgesetz bestimmt wird, sich etwas zu seinem Objekte zu machen; wie er denn durch das Objekt und dessen Vorstellung 20 niemals unmittelbar bestimmt wird, sondern ein Vermögen ist, sich eine Regel der Vernunft zur Bewegursache einer Handlung (dadurch ein Objekt wirklich werden kann) zu machen. Das Gute oder Böse wird also eigentlich auf Handlungen, nicht auf den Empfin-

es uns als gut voritellen, sodaß entweder die Begierde der Bestimmangsgrund des Begriffs des Objekts als eines guten, oder der Begriff des Gaten der Bestimmungsgrand des Begehrens (des Willens) sei; da denn das sub ratione boni im ersteren Falle bedenten würde: vir wollen etwas unter der Idee des Guten; im zweiten: zufolge dieser Idee, welche vor dem Wollen als Bestimmangsgrand desselben vorhergehen muß. 
dungszustand der Person bezogen und sollte etwas schlechthin (und in aller Absicht und ohne weitere Bedingung) gut oder böse sein oder dafür gehalten werden, so würde es nur die Handlungsart, die Maxime des Willens und mithin die handelnde Person selbst, als guter oder böser Mensch, nicht aber eine Sache sein, die so genannt werden könnte.

Man mochte also immer den Stoiker auslachen, der in den heftigsten Gichtschmerzen ausrief: Schmerz, du magst mich noch so sehr foltern, ich werde doch nie 10 gestehen, daß du etwas Böses (xaґóv, malum) seist! er hatte doch recht. Ein Obel war es, das fühlte er, und das verriet sein Geschrei; aber daß ihm dadurch ein Böses anhinge, hatte er gar nicht Ursache einzuräumen; denn der Schmerz verringert ${ }^{2}$ ) den Wert seiner Person nicht im mindesten, sondern nur den Wert seines Zustandes. Eine einzige Lüge, deren er sich bewußt gewesen wäre, hätte seinen Mut niederschlagen müssen; aber der Schmerz diente nur zur Veranlassung, ihn zu erheben, wenn er sich bewußt 20

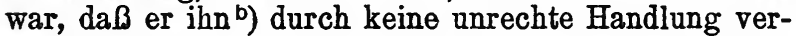
schuldet und sich dadurch strafwürdig gemacht habe.

Was wir gut nennen sollen, muß in jedes vernünftigen Menschen Urteil ein Gegenstand des $\mathrm{Be}$. gehrungsvermögens sein, und das Böse in den Augen von jedermann ein Gegenstand des Abscheues; mithin bedarf es außer dem Sinne zu dieser Beurteilung noch Vernunft. So ist es mit der Wahrhaftigkeit im Gegensatz mit der Lüge, so mit der Gerechtigkeit im Gegensatz der Gewalttätigkeit usw. bewandt. Wir 30 können aber etwas ein Utbel nennen, welches doch jedermann zugleich für gut, bisweilen mittelbar, bisweilen gar unmittelbarc) erklären muß. Der eine chirurgische Operation an sich verrichten läßt, fühlt sie ohne Zweifel als ein Ubel; aber durch Vernunft erklärt er und jedermann sie für gut. Wenn aber jemand, der friedliebende Leute gerne neckt und beunruhigt,

a) "verringerte"? (Natorp).

b) "sie"; korr. Hartenstein.

c) Kant: „für unmittelbar", Hartenstein : „für unmittelbar gut"; korr. Natorp. 
endlich einmal anläuft und mit einer tüchtigen Tracht Schläge abgefertigt wird, so ist dieses allerdings ein Ubel, aber jedermann gibt dazu seinen Beifall und hält es an sich für gut, wenn auch nichts weiter daraus entspränge; ja selbst der, der sie empfängt, muß in seiner Vernunft erkennen, daß ihm recht geschehe, weil er die Proportion zwischen dem Wohlbefinden und Wohlverhalten, welche die Vernunft ihm unvermeidlich vorhält, hier genau in Ausübung gebracht sieht.

Es kommt allerdings auf unser Wohl und Weh in der Beurteilung unserer praktischen Vernunft gar sehr viel und, was unsere Natur als sinnlicher Wesen betrifft, alles auf unsere Glückseligkeit an, wenn diese, wie Vernunft es vorzüglich fordert, nicht nach der vorübergehenden Empfindung, sondern nach dem Einflusse, den diese Zufälligkeit auf unsere ganze Existenz und die Zufriedenheit mit derselben hat, beurteilt wird; aber alles überhaupt kommt darauf doch nicht an. Der Mensch ist ein bedürftiges Wesen,

20 sofern er zur Sinnenwelt gehört, und sofern hat seine Vernunft allerdings einen nicht abzulehnenden Auftrag von seiten der Sinnlichkeit, sich um das Interesse derselben zu bekümmern und sich praktische Maximen auch in Absicht auf die Glückseligkeit dieses und womöglich auch eines zukünftigen Lebens $\mathrm{zu}$ machen. Aber er ist doch nicht so ganz Tier, um gegen alles, was Vernunft für sich selbst sagt, gleichgültig zu sein und diese bloß zum Werkzeuge der Befriedigung seines Bedürfnisses als Sinnenwesens zu gebrauchen. Denn im

30 Werte über die bloße Tierheit erhebt ihn das gar nicht, daß er Vernunft hat, wenn sie ihm nur zum Behuf desjenigen dienen soll, was bei Tieren der Instinkt verrichtet; sie wäre alsdann nur eine besondere Manier, deren sich die Natur bedient hätte, um den Menschen zu demselben Zwecke, dazu sie Tiere bestimmt hat,

[62] auszurüsten, ohne ihn zu einem höheren Zwecke zu bestimmen. Er bedarf also freilich, nach dieser einmal mit ihm getroffenen Naturanstalt, Vernunft, um sein Wohl und Weh jederzeit in Betrachtung zu ziehen, aber

40 er hat sie überdem noch zu einem höheren Beruf, nämlich anch das, wasi an sich gut oder böse ist, und worüber reine, sinnlich gar nicht interessierte Vernunft nur 
allein urteilen kann, nicht allein mit in Uberlegung zu nehmen, sondern diese Beurteilung von jener gänzlich zu unterscheiden und sie zur obersten Bedingung desa) letzteren $\mathrm{zu}$ machen.

In dieser Beurteilung des an sich Guten und Bösen zum Unterschiede von dem, was nur beziehungsweise auf Wohl oder Obel so genannt werden kann, kommt es auf folgende Punkte an. Entweder ein Vernunftprinzip wird schon an sich als der Bestimmungsgrund des Willens gedacht, ohne Rücksicht auf mögliche 10 Objekte des Begehrungsvermögens (also blo $B$ durch die gesetzliche Form der Maxime); alsdann ist jenes Prinzip praktisches Gesetz a priori und reine Vernunft wird für sich praktisch zu sein angenommen. Das Gesetz bestimmt alsdann unmittelbar den Willen, die ihm gemäße Handlung ist an sich selbst gut, ein Wille, dessen Maxime jederzeit diesem Gesetze gemäß ist, ist schlechterdings, in aller Absicht gut und die oberste Bedingung alles Guten. Oder es geht ein Bestimmungsgrund des Begehrungsvermögens vor der 20 Maxime des Willens vorher, der ein Objekt der Lust und Unlust voraussetzt, mithin etwas, das vergnügt oder schmerzt, und die Maxime der Vernunft, jene $\mathrm{zu}$ befördern, diese zu vermeiden, bestimmt die Handlungen, wie sie beziehungsweise auf unsere Neigung, mithin nur mittelbar (in Rücksicht auf einen anderweitigen Zweck, als Mittel zu demselben) gut sind, und diese Maximen können alsdann niemals Gesetze, dennoch aber vernünftige praktische Vorschriften heißen. Der Zweck selbst, das Vergnügen, das wir suchen, ist30 im letzteren Falle nicht ein Gutes, sondern ein Wohl, nicht ein Begriff der Vernunft, sondern ein empirischer Begriff von einem Gegenstande der Empfindung; allein der Gebrauch des Mittels dazu, d. i. die Handlung (weil dazu vernünftige Überlegung erfordert wird), heißt dennoch gut, aber nicht schlechthin, sondern nur in Beziehung auf unsere Sinnlichkeit in Ansehung ihres Gefühls der Lust und Unlust; der Wille aber, dessen Maxime dadurch affiziert wird, ist nicht ein reiner Wille, der nur auf das geht, 40

a) sc. des Guten und Bösen. Nolte, Natorp: „der".

Kant, Kritik der prakt. Vernunft. 
wobei reine Vernunft für sich selbst praktisch sein kann.

Hier ist nun der Ort, das Paradoxon der Methode in einer Kritik der praktischen Vernunft zu erklären: [63] daß nämlich der Begriff des Guten und Bösen nicht vor dem moralischen Gesetze (dem era) dem Anschein nach sogar zum Grunde gelegt werden müßte), sondern nur (wie hier auch geschieht) nach demselben und durch das-

10 selbe bestimmt werden müsse. Wenn wir nämlich auch nicht wüßten, da $\beta$ das Prinzip der Sittlichkeit ein reines, a priori den Willen bestimmendes Gesetz sei, so müßten wir doch, um nicht ganz umsonst (gratis) Grundsätze anzunehmen, es anfänglich wenigstens unausgemacht lassen, ob der Wille bloß empirische oder auch reine Bestimmungsgründe a priori habe; denn es ist wider alle Grundregeln des philosophischen Verfahrens, das, worüber man allererst entscheiden soll, schon zum voraus als entschieden anzunehmen.

20 Gesetzt wir wollten nun vom Begriffe des Guten anfangen, um davon die Gesetze des Willens abzuleiten, so würde dieser Begriff von einem Gegenstande (als einem guten) zugleich diesen als den einzigen Bestimmungsgrund des Willens angeben. Weil nun dieser Begriff kein praktisches Gesetz a priori zu seiner Richtschnur hatte ${ }^{b}$ ), so könnte der Probierstein des Guten oder Bösen in nichts anderem als in der Ubereinstimmung des Gegenstandes mit unserem Gefühle der Lust oder Unlust gesetzt werden, und der Ge-

30 brauch der Vernunft könnte nur darin bestehen, teils diese Lust oder Unlust im ganzen Zusammenhange mit allen Empfindungen meines Daseins, teils die Mittel, mir den Gegenstand derselben zu verschaffen, zu bestimmen. Da nun, was dem Gefühle der Lust gemäß. sei, nur durch Erfahrung ausgemacht werden kann, das praktische Gesetz aber der Angabe nach doch darauf als Bedingung gegründet werden soll, so würde geradezu die Möglichkeit praktischer Gesetze a priori ausgeschlossen; weil man vorher nötig zu finden

a) Kant: „es"; korr. Hartenstein.

b) Hartenstein": „hătto". 
meinte, einen Gegenstand für den Willen auszufinden, davon der Begriff als eines guten den allgemeinen, obzwar empirischen Bestimmungsgrund des Willens ausmachen müsse. Nun aber war doch vorher nötig zu untersuchen, ob es nicht auch einen Bestimmungsgrund des Willens a priori gebe (welcher niemals irgendwo anders als in einem reinen praktischen Gesetze, und zwar sofern dieses die bloße gesetzliche Form ohne Rücksicht auf einen Gegenstand den Maximen vorschreibt, wäre gefunden worden). 10 Weil man aber schon einen Gegenstand nach Begriffen des Guten und Bösen zum Grunde alles praktischen Gesetzes legte, jener aber ohne vorhergehendes Gesetz nur nach empirischen Begriffen gedacht werden konnte, so hatte man sich die Möglichkeit, ein reines praktisches Gesetz auch nur zu denken, schon zum voraus benommen; da man im Gegenteil, wenn man dem letzteren vorher analytisch nachgeforscht hätte, gefun$[64]$ den haben würde, daß nicht der Begriff des Guten als eines Gegenstandes das moralische Gesetz, sondern 20 umgekehrt das moralische Gesetz allererst den Begriff des Guten, sofern es diesen Namen schlechthin verdient, bestimme und möglich mache.

Diese Anmerkung, welche bloß die Methode der obersten moralischen Untersuchungen betrifft, ist von Wichtigkeit. Sie erklärt auf einmal den veranlassenden Grund aller Verirrungen der Philosophen in Ansehung des obersten Prinzips der Moral. Denn sie suchten einen Gegenstand des Willens auf, um ihn zur Materie und dem Grunde eines Gesetzes zu machen (welches 30 alsdann nicht unmittelbar, sondern vermittelst jenes an das Gefühl - der Lust oder Unlust gebrachten Gegenstandes der Bestimmungsgrund des Willens sein sollte), anstatt daß sie zuerst nach einem Gesetze hätten forschen sollen, das a priori und unmittelbar den Willen und diesem gemä $ß$ allererst den Gegenstand bestimmte. Nun mochten sie diesen Gegenstand der Lust, der den obersten Begriff des Guten abgeben sollte, in der Glückseligkeit, in der Vollkommenheit, im moralischen Gefühl ${ }^{a}$ ) oder im Willen Gottes setzen, so war ihr 40

a) Kant: „Gesetze“; korr. Hartenstein. 
Grundsatz allemal Heteronomie, sie mußten unvermeidlich auf empirische Bedingungen $\mathrm{zu}$ einem moralischen Gesetze stoßen: weil sie ihrenGegenstand als unmittelbaren Bestimmungsgrund des Willens nur nach seinem unmittelbaren Verhalten zum Gefühl, welches allemal empirisch ist, gut oder böse nennen konnten. Nur ein formales Gesetz, d. i. ein solches, welches der Vernunft nichts weiter als die Form ihrer allgemeinen Gesetz gebung zur obersten Bedingung der Maximen vor10 schreibt, kann a priori ein Bestimmungsgrund der praktischen Vernunft sein. Die Alten verrieten indessen diesen Fehler dadurch unverhohlen, daß sie ihre moralische Untersuchung gänzlich auf die Bestimmung des Begriffs vom höchsten Gut, mithin eines Gegenstandes setzten, welchen sie nachher zum Bestimmungsgrunde des Willens im moralischen Gesetze zu machen gedachten: ein Objekt, welches weit hinterher, wenn das moralische Gesetz allererst für sich bewährt und als unmittelbarer Bestimmungsgrund des Willens ge20 rechtfertigt ist, dem nunmehr seiner Form nach a priori bestimmten Willen als Gegenstand vorgestellt werden kann, welches wir in der Dialektik der reinen praktischen Vernunft uns unterfangen wollen. Die Neueren, bei denen die Frage über das höchste Gut außer Gebrauch gekommen, zum wenigsten nur Nebensache geworden zu sein scheint, verstecken obigen Fehler (wie in vielen anderen Fällen) hinter unbestimmten [65] Worten, indessen daß man ihn gleichwohl aus ihren Systemen hervorblicken sieht, da er alsdann allent-

30 halben Heteronomie der praktischen Vernunft verrät, daraus nimmermehr ein a priori allgemein gebietendes moralisches Gesetz entspringen kann.

Da nun die Begriffe des Guten und Bösen, als Folgen der Willensbestimmung a priori, auch ein reines praktisches Prinzip, mithin eine Kausalität der reinen Vernunft voraussetzen, so beziehen sie sich ursprünglich nicht (etwa als Bestimmungen der synthetischen Einheit des Mannigfaltigen gegebener Anschauungen in einem Bewußtsein) auf Objekte, wie die reinen Ver40 standesbegriffe oder Kategorien der theoretisch' gebrauchten Vernunft, sio setzen diese vielmehr als gegeben voraus; sondern sie sind insgesamt Modi einer 
einzigen Kategorie, nämlich der der Kausalität, sofern der Bestimmungsgrund derselben in der Vernunftrorstellung eines Gesetzes derselben besteht, welches, als Gesetz der Freiheit, die Vernunft sich selbst gibt und dadurch sich a priori als praktisch beweist. Da indessen die Handlungen einerseits zwar unter einem Gesetze, das kein Naturgesetz, sondern ein Gesetz der Freiheit ist, folglich $\mathrm{zu}_{4}$ dem Verhalten intelligibeler Wesen, andererseits aber doch auch, als Begebenheiten in der Sinnenwelt, zu den Erscheinungen ge- 10 hören, so werden die Bestimmungen einer praktischen Vernunft nur in Beziehung auf die letztere, folglich zwar den Kategorien des Verstandes gemä $B$, aber nicht in der Absicht eines theoretischen Gebrauchs desselben, um das Mannigfaltige der (sinnlichen) Anschauung unter ein Bewußtsein a priori zu bringen, sondern nur um das Mannigfaltige der Begehrungen der Einheit des Bewußtseins einer im moralischen Gesetze gebietenden praktischen Vernunft oder eines reinen Willens a priori zu unterwerfen, statthaben können.

Diese Kategorien der Freiheit, denn so wollen wir sie statt jener theoretischen Begriffe als Kategorien der Natur benennen, haben einen augenscheinlichen Vorzug vor den letzteren, daß, da diese nur Gedankenformen sind, welche nur unbestimmt Objekte überhaupt für jede uns mögliche Anschauung durch allgemeine Begriffe bezeichnen, diese hingegen, da sie auf die Bestimmung einer freien Willkür gehen (der zwar keine Anschauung völlig korrespondierend gegeben werden kann, die aber, welches bei keinen 30 Begriffen des theoretischen Gebrauchs unseres Erkenntnisvermögens stattfindet, ein reines praktisches Gesetz a priori zum Grunde liegen hat), als praktische Elementarbegriffe statt der Form der Anschauung (Raum und Zeit), die nicht in der Vernunft selbst liegt, sondern anderwärts, nämlich von der Sinnlichkeit hergenommen werden muß, die Form eines reinen Willens in ihr, mithin dem Denkungsvermögen selbst, als gegeben zum Grunde liegen haben; dadurch es denn geschieht, da $\Omega$, da es in allen Vorschriften der reinen 40 praktischen Vernunft nur um die Willensbestimmung, nicht um die Naturbedingungen (des prakti- 
schen Vermögens) der Ausführung seiner Absicht zu tun ist, die praktischen Begriffe a priori in Beziehung auf das oberste Prinzip der Freiheit sogleich Erkenntnisse werden und nicht auf Anschauungen warten dürfen, um Bedeutung zu bekommen, und zwar aus diesem merkwürdigen Grunde, weil sie die Wirklichkeit dessen, worauf sie sich beziehen (die Willensgesinnung) selbst hervorbringen, welches gar nicht die Sache theoretischer Begriffe ist. Nur muß man wohl 10 bemerken, daß diese Kategorien nur die praktische Vernunft überhaupt angehen, und so in ihrer Ordnung von den moralisch noch unbestimmten und sinnlichbedingten zu denen, die, sinnlich-unbedingt, bloß durchs moralische Gesetz bestimmt sind, fortgehen.

\section{Tafel der Kategorien der Freiheit}

in Ansehung der Begriffe des Guten und Bősen.

1.

Der Quantität

Subjektiv, nach Maximen (Willensmeinangen des Individuums).

Objektiv, nach Prinzipien (Vorschriften).

A priori objektive sowohl als subjektive Prinzipien der Freiheit (Gesetze).

2.

Der Qualitat

Praktische Regeln des $\mathrm{Be}$ gehens (praeceptivae).

Praktischo Regeln des Unterlassons (prohibitivae).

30 Praktische Regeln der A us nahmon (exceptivae).
3.

Der Relation Anf die Personlichkeit. Auf denZustand derPerson.

Wechselseitig einer Person auf den Zustand der anderen.

4.

Der Modalität

Das Erlaubte and Unerlaubte.

Die Pflicht und das Pflichtwidrige.

Vollkommene and unvollkommene Pflicht. 
Man wird hier bald gewahr, daß in dieser Tafel [67] die Freiheit als eine Art von Kausalität, die aber empirischen Bestimmungsgründen nicht unterworfen ist, in Ansehung der durch sie möglichen Handlungen als Erscheinungen in der Sinnenwelt betrachtet werde, folglich sich auf die Kategorien ihrer Naturmöglichkeit beziehe, indessen daß doch jede Kategorie so allgemein genommen wird; daß der Bestimmungsgrund jener Kausalität auch außer der Sinnenwelt in der Freiheit als Eigenschaft eines intelligibelen Wesens angenom- 10 men werden kann, bis die Kategorien der Modalität den Ubergang von praktischen Prinzipien überhaupt zu denen der Sittlichkeit, aber nur problematisch einleiten, welche nachher durchs moralische Gesetz allererst d o g matisch dargestellt werden können.

Ich füge hier nichts weiter zur Erläuterung gegenwărtiger Tafel bei, weil sie für sich verständlich genug ist. Dergleichen nach Prinzipien abgefaßte Einteilung ist aller Wissenschaft, ihrer Gründlichkeit sowohl als Verständlichkeit halber, sehr zuträglich. So weiß man 20 z. B. aus obiger Tafel und der ersten Nummer derselben sogleich, wovon man in praktischen Erwägungen anfangen müsse: von den Maximen, die jeder auf seine Neigung gründet, den Vorschriften, die für eine Gattung vernünftiger Wesen, sofern sie in gewissen Neigungen übereinkommen, gelten, und endlich dem Gesetze, welches für alle unangesehen ihrer Neigungen gilt usw. Auf diese Weise übersieht man den ganzen Plan von dem, wasj man zu leisten hat, sogar jede Frage der praktischen Philosophie, die zu beantworten, 30 und zugleich die Ordnung, die zu befolgen ist.

\section{Fon der Typik der reinen praktischen Urteilskraft.}

Die Begriffe des Guten und Bösen bestimmen dem Willen zuerst ein Objekt. Sie stehen selbst aber unter einer praktischen Regel der Vernunft, welche, wenn sie reine Vernunft ist, den Willen a priori in Ansehung seines Gegenstandes bestimmt. Ob nun eine 
uns in der Sinnlichkeit mögliche Handlung der Fall sei, der unter der Regel stehe oder nicht, dazu gehört praktische Urteilskraift,. wodurch dasjenige, was in der Regel allgemein (in abstracto) gesagt wurde, auf eine Handlung in concreto angewandt wird. Weil aber eine praktische Regel der reinen Vernunft erstlich, als praktisch, die Existenz eines Objekts betrifft, und zweitens, als praktische Re'gel der reinen Vernunft, Notwendigkeit in Ansehung des Daseins der 10 Handlung bei sich führt, mithin praktisches Gesetz ist, [68] und zwar nicht Naturgesetz durch empirische Bestimmungsgriünde, sondern ein Gesetz der Freiheit, nach welchem der Wille unabhängig von allem Empirischen (bloß durch die Vorstellung eines Gesetzes überhaupt und dessen Form) bestimmbar sein soll, alle vorkommenden Fälle zu möglichen Handlungen aber nur empirisch, d. i. zur Erfahrung und Natur gehörig sein können: so scheint es widersinnisch, in der Sinnenwelt einen Fall antreffen zu wollen, der, da er immer

20 sofern nur unter dem Naturgesetze steht, doch die Anwendung eines Gesetzes der Freiheit auf sich verstatte, und auf welchen die übersinnliche Idee des Sittlichguten, das darin in concreto dargestellt werden soll, angewandt werden könne. Also ist die Urteilskraft der reinen praktischen Vernunft ebendenselben Schwierigkeiten unterworfen als die der reinen theoretischen, welche letztere gleichwohl aus denselben zu kommen ein Mittel zur Hand hatte: nämlich, da es in Ansehung des theoretischen Gebrauchs auf Anschauungen ankam,

30 darauf reine Verstandesbegriffe angewandt werden könnten, dergleichen Anschauungen (obzwar nur von Gegenständen der Sinne) doch a priori, mithin was die Verknüpfung des Mannigfaltigen in denselben betrifft, den reinen Verstandesbegriffen a priori gemäß (als Schemate) gegeben werden können. Hingegen ist das Sittlichgute etwas dem Objekte nach Uber sinnliches, für das also in keiner sinnlichen Anschauung etwas Korrespondierendes gefunden werden kann, und dio Urteilskraft unter Gesetzen der reinen prakti-

40 schen Vernunft scheint daher besonderen Schwierigkeiten unterworfen zu sein, die darauf beruhen, daß ein Gesetz der Freiheit auf Handlungen als Begeben- 
heiten, die in der Sinnenwelt geschehen und also sofern zur Natur gehören, angewandt werden soll.

Allein hier eröffnet sich doch wieder eine günstige Aussicht für die reine praktische Urteilskraft. Es ist bei der Subsumtion einer mir in der Sinnenwelt möglichen Handlung unter einem reinen praktischen Gesetze nicht um die Möglichkeit der Handlung als einer Begebenheit in der Sinnenwelt zu tun; denn die gehört für die Beurteilung des theoretischen Gebrauchs der Vernunft nach dem Gesetze der Kausalität, 10 eines reinen Verstandesbegriffs, für den sie ein Schema in der sinnlichen Anschauung hat. Die physische Kausalität oder die Bedingung, unter der sie stattfindet, gehört unter dio Naturbegriffe, deren Schema transzendentale Einbildungskraft entwirft. Hier aber ist es nicht um das Schema eines Falles nach Gesetzen, sondern um das Schema (wenn dieses Wort hier schicklich ist) eines Gesetzes selbst zu tun; weil die Willensbestimmung (nicht $\mathrm{di}^{\mathrm{a}}$ ) Handlung in $\mathrm{Be}-$ ziehung auf ihren Erfolg) durchs Gesetz allein, ohne 20 einen anderen Bestimmungsgrund, den Begriff der Kausalität an ganz andere Bedingungen bindet, als diejenigen sind, welche die Naturverknüpfung ausmachen.

Dem Naturgesetze als Gesetze, welchem die Gegenstände sinnlicher Anschauung als solche unterworfen sind, muß ein Schema, d. i. ein allgemeines Verfahren der Einbildungskraft (den reinen Verstandesbegriff, den das Gesetz bestimmt, den Sinnen a priori darzustellen) korrespondieren. Aber dem Gesetze der Freiheit (als einer gar nicht sinnlich bedingten Kausalität), mithin auch dem Begriffe des Unbedingt-Guten kann keine Ansehauung, mithin kein Schema zum Behuf seiner Anwendung in concreto untergelegt werden. Folglich hat das Sittengesetz kein anderes die Anwendung desselben auf Gegenstände der Natur vermittelndes Erkenntnisvermögen als den Verstand (nicht die Einbildungskraft), welcher einer Idee der Vernunft nicht ein Schema der Sinnlichkeit, sondern ein Gesetz, aber doch ein solches, das an Gegenständen der Sinne in concreto dargestellt werden kann, mithin ein Natur- 40

a) Kant: „der"; korr. Hartenstein. 
gesetz, aber nur seiner Form nach, als Gesetz zum Behuf der Urteilskraft unterlegen, kann, und dieses können wir daher den Typus des Sittengesetzes nennen.

Die Regel der Urteilskraft uniter Gesetzen der reinen praktischen Vernunft ist diese: Frage dich selbst, ob die Handlung, die du vorhast, wenn sie nach einem Gesetze der Natur, von der du selbst ein Teil wärest, geschehen sollte, sie $\mathrm{du}^{2}$ ) wohl als durch deinen Willen möglich ansehen könntest? Nach dieser Regel

10 beurteilt in der Tat jedermann Handlungen, ob sie sittlich gut oder böse sind. So sagt man: Wie, wenn ein jeder, wo er seinen Vorteil zu schaffen glaubt, sich erlaubte zu betrügen, oder b'efugt hielte, sich das Leben abzukürzen, sobald ihn ein völliger tberdruß desselben befällt, oder anderer Not mit völliger Gleichgültigkeit ansehe, und du gehörtest mit zu einer solchen Ordnung der Dinge, würdest du darin wohl mit Einstimmung deines Willens sein? Nun wөiß ein joder wohl, daß, wenn er sich insgeheim Betrug erlaubt, darum eben

20 nicht jedermann es auch tue, oder wenn er unbemerkt lieblos ist, nicht sofort jedermann anch gegen ihn es sein würde; daher ist diese Vergleichung der Maxime seiner Handlungen mit einem allgemeinen Naturgesetze auch nicht der Bestimmungsgrund seines Willens. Aber das letztere ist doch ein Typus der Beurteilung der ersteren nach sittlichen Prinzipien. Wenn die Maxime der Handlung nicht so beschaffen ist, daß sie an der

[70] Form eines Naturgesetzes überhaupt die Probe hält, so ist sie sittlich unmöglich. So urteilt selbst der

80 gemeinste 'Verstand; denn das Naturgesetz liegt allen seinen gewöhnlichsten, selbst den Erfahrungsurteilen immer zum Grunde. Fr hat es also jederzeit bei der Hand, nur daß er in Fällen, wo die Kausalität aus Freiheit beurteilt werden soll, jenes Naturgesetz bloß zum Typus eines Gesetzes der Freiheit macht, weil er, ohne etwas, was er zum Beispiele im Erfahrungsfalle machen könnte, bei Hand zu haben, dom Gesetze einer reinen praktischen Vernunft nicht den Gebrauch in der Anwendung ver40 schaffen könnte.

a) „du sie" [Grillo]? 
Es ist also auch erlaubt, die Natur der Sinnenwelt als Typus einer intelligibelen Natur zu brauchen, solange ich nur nicht die Anschauungen, und was davon abhängig ist, auf diese übertrage, sondern bloß die Form der Gesetzmäßigkeit überhaupt (deren Begriff auch im gemeinstena) Vernunftgebrauche stattfindet, aber in keiner anderen Absicht, als bloß zum reinen praktischen Gebrauche der Vernunft a priori bestimmt erkannt werden kann) darauf beziehe. Denn Gesetze als solche sind sofern einerlei, 10 sie mögen ihre Bestimmungsgründe hernehmen, woher sie wollen.

Ubrigens, da von allem Intelligibelen schlechterdings nichts als (vermittelst des moralischen Gesetzes) die Freiheit, und auch diese nur, sofern sie eine von jenem unzertrennliche Voraussetzung ist, und ferner alle intelligibelen Gegenstände, auf welche uns die Vernunft nach Anleitung jenes Gesetzes etwa noch führen möchte, wiederum für uns keine Realität weiter haben als zum Behuf desselben Gesetzes und des Gebrauches 20 der reinen praktischen Vernunft, diese aber zum Typus der Urteilskraft die Natur (der reinen Verstandesform derselben nach) $\mathrm{zu}$ gebrauchen berechtigt und auch benötigt ist: so dient die gegenwärtige Anmerkung dazu, um zu verhüten, da, , was bloß zur Typik der Begriffe gehört, nicht zu den Begriffen selbst gezählt werde. Diese also, als Typik der Urteilskraft, bewahrt vor dem Empiris mu s der praktischen Vernunft, der die praktischen Begriffe des Guten und Bösen bloß in Erfahrungsfolgen (der sogenannten Glückseligkeit) 30 setzt, obzwar diese und die unendlichen nützlichen Folgen eines durch Selbsthilfe bestimmten Willens, wenn dieser sich selbst zugleich zum allgemeinen Naturgesetze machte, allerdings zum ganz angemessenen Typus für das Sittlichgute dienen kann, aber mit diesem doch nicht einerlei ist. Ebendieselbe Typik bewahrt auch vor dem Mystizismus der praktischen Vernunft, welcher ${ }^{b}$ ) das, was nur zum Sy mbol diente, zum Schema macht, d. i. wirkliche und doch nicht [71]

a) Kant: „reinsten"; korr. Hartenstein.

b) Kant: "welcbe"; korr. Hartenstein. 
sinnliche Anschauungen (eines unsichtbaren Reichs Gottes) der Anwendung der moralischen Begriffe unterlegt und ins Uberschwengliche hinausschweift. Dem Gebrauche der moralischen Begriffe ist bloß der Rationalismus der Urteilskraft angemessen, der von der sinnlichen Natur nichts weiter nimmt, als was auch reine Vernunft für sich denken kann, d. i. die Gesetz mäßigkeit, und in die übersinnliche nichts hineinträgt, als was umgekehrt sich durch Handlungen in der

10 Sinnenwelt nach der formalen Regel eines Naturgesetzes überhaupt wirklich darstellen läßt. Indessen ist die Verwahrung vor dem Empirismus der praktischen Vernunft viel wichtiger und anratungswürdiger, weil ${ }^{2}$ ). der Mystizismus sich doch noch mit der Reinigkeit und Erhabenheit des moralischen Gesetzes zusammen verträgt, und außerdem es nicht eben natürlich und der gemeinen Denkungsart angemessen ist, seine Einbildungskraft bis zu übersinnlichen Anschauungen anzuspannen, mithin auf dieser Seite die Gefahr nicht so

20 allgemein ist; dahingegen der Empirismus die Sittlichkeit in Gesinnungen (worin doch und nicht bloß in Handlungen der hohe Wert besteht, den sich die Menschheit durch sie verschaffen kann und soll) mit der Wurzel ausrottet und ihr ganz etwas anderes, nämlich ein empirisches Interesse, womit die Neigungen überhaupt unter sich Verkehr treiben, statt der Pflicht unterschiebt, überdem auch ebendarum mit allen Neigungen, die (sie mögen einen Zuschnitt bekommen, welchen sie wollen), wenn sie zur Würde eines obersten

30 praktischen Prinzips erhoben werden, die Menschheit degradieren, und da $\operatorname{sie}^{b}$ ) gleichwohl der Sinnesart aller so günstig sind, aus der Ursache weit gefährlicher isto) als alle Schwärmerei, die niemals einen dauernden Zustand vieler Menschen ausmachen kann.

a) Kant: „womit"; korr. Hartenstein.

b) Adickes will "da sie" streichen; Natorp würde statt nda sie" lieber ,die" schreiben.

c) sc. der Empirismus. 
Von den Triebfedern der reinen prakt. Vernunft.

Drittes Hauptstück.

\section{Von den Triebfedern der reinen praktischen Vernunft.}

Das Wesentliche alles sittlichen Werts der Handlungen kommt darauf an, da $\mathrm{\rho}$ das moralische Gesetz unmittelbar den Willen bestimme. Geschieht die Willensbestimmung zwar gemäß dem moralischen Gesetze, aber nur vermittelst eines Gefühls, welcher Art es auch sei, das vorausgesetzt werden muß, damit jenes ein hinreichender Bestimmungs- 10 grund des Willens werde, mithin nicht um des Gesetzes willen, so wird die Handlung zwar Legalität, aber nicht Moralität enthalten. Wenn nun unter Triebfeder (elater animi) der subjektive Bestimmungsgrund des Willens eines Wesens verstanden wird, dessen Vernunft nicht schon vermöge seiner Natur dem objektiven Gesetze notwendig gemäß ist, so wird erstlich daraus folgen: daß man dem göttlichen Willen gar keine Triebfedern beilegen könne, die Triebfeder des menschlichen Willens aber (und des von je- 20 $n^{n} m^{2}$ ) erschaffenen vernünftigen Wesens) niemals etwas anderes als das moralische Gesetz sein könne ${ }^{b}$ ), mithin der objektive Bestimmungsgrund jederzeit und ganz allein zugleich der subjektiv hinreichende Bestimmungsgrund der Handlung sein müsse, wenn diese nicht bloß den Buchstaben des Gesetzes, ohne den Geist*) desselben $\mathrm{zu}$ enthalten, erfüllen soll.

Da man also zum Behuf des moralischen Gesetzes, und um ihm Einfluß auf den Willen zu verschaffen, keine anderweitige Triebfeder, dabei die des morali- 30 schen Gesetzes entbehrt werden könnte, suchen muß, weil das alles lauter Gleisnerei ohne Bestand bewirken

*) Man kann von jeder gesetzmäßigen Handlung, die doch nicht um des Gesetzes willen geschehen ist, sagen: sie sei blob dem Buchstaben, aber nicht dem Geiste (der Gesinnung) nach moralisch gut.

a) Kant: ,jedem"; korr. Vorländer.

b) Adickes: „dürfe". 
würde, und sogar es bedenklich ist, auch nur neben dem moralischen Gesetze noch einige andere Triebfedern (als die des Vorteils) mitwirken zo lassen: so bleibt nichts übrig, als bloß sorgfältig zu bestimmen, auf welche Art das moralisch $\theta$ Gesetz Triebfeder werde, und was, indem sie es ist, mit dem menschlichen Begehrungsvermögen, als Wirkung jenes Bestimmungsgrundes auf dasselbe, vorgehe. Denn wie ein Gesetz für sich und unmittelbar Bestimmungsgrund des Wil-

10 lens sein könne (welches doch das Wesentliche aller Moralität ist), das ist ein für die menschliche Vernunft unauflösliches Problem und mit dem einerlei: wio ein freier Wille möglich sei. Also werden wir nicht den Grund, woher das moralische Gesetz in sich eine Triebfeder abgebe, sondern was, sofern es eine solche ist, sie im Gemüte wirkt (besser zu sagen, wirken maß), a priori anzuzeigen haben.

Das Wesentliche aller Bestimmung des Willens durchs sittliche Gesetz ist: daß er als freier Wille, 20 mithin nicht bloß ohne Mitwirkung sinnlicher Antriebe, sondern selbst mit Abweisung aller derselben und mit Abbruch aller Neigungen, sofern sie jenem Gesetze zuwider sein könnten, bloß durchs Gesetz bestimmt werde. Soweit ist also die Wirkung des moralischen Gesetzes als Triebfeder nur negativ, und als solch $\theta$ kann diese Triebfeder a priori erkannt werden. Denn [73] alle Neigung und jeder sinnliche Antrieb ist auf Gefühl gegründet, und die negative Wirkung aufs Gefühl (durch den Abbruch, der den Neigungen geschieht) 30 ist selbst Gefühl. Folglich können wir a priori einsehen, da $\beta$ das moralische Gesetz als Bestimmungsgrund des Willens, dadurch daß es allen unseren Neigungen Eintrag tut, ein Gefühl bewirken müsse, welches Schmerz genannt werden kann, und hier haben wir nun den ersten, vielleicht auch einzigen Fall, da wir aus Begriffen a priori das Verhältnis einer Erkenntnis (hier ist es einer reinen praktischen Vernunft) zum Gefühl der Lust oder Unlust bestimmen konnten. Allo Neigungen zusammen (die auch wohl in ein erträg-

40 liches System gebracht werden können, und deren Befriedigung alsdann eigene Glückseligkeit heißt) machen die Selbstsucht (solipsismus) aus. Diese ist entweder 
die der Selbstliebe, eines über alles gehenden Wohlwollens gegen sich selbst (philautia), oder die des Wohlgefallens an sich selbst (arrogantia). Jene heißt besonders Eigenliebe, diese Eigendünkel. Die reine praktische Vernunft tut der Eigenliebe bloß Abbruch, indem sie solche, als natürlich und noch vor dem moralischen Gesetze in uns rege, nur auf die Bedingung der Einstimmung mit diesem Gesetze einschränkt; da sie alsdann vernünftige Selbstliebe genannt wird. Aber den Eigendünkel schlägt sie gar 10 nieder, indem alle Ansprüche der Selbstschätzung, die vor der Ubereinstimmung mit dem sittlichen Gesetze vorhergehen, nichtig! und ohne alle Befugnis sind, indem eben die Gewißheit einer Gesinnung, die mit diesem Gesetze übereinstimmt, die erste Bedingung alles Wertes der Person ist (wie wir bald deutlicher machen werden), und alle Anmaßung vor derselben falsch und gesetzwidrig ist. Nun gehört der Hang zur Selbstschätzung mit zu den Neigungen, denen das moralische Gesetz Abbruch tut, sofern jene blob auf 20 der Sinnlichkeit ${ }^{a}$ ) beruht. Also schlägt das moralische Gesetz den Eigendünkel nieder. Da dieses Gesetz aber doch etwas an sich Positives ist, nämlich die Form einer intellektuellen Kausalität, d. i. der Freiheit, so ist es, indem es im Gegensatze mit dem subjektiven Widerspiele, nämlich den Neigungen in uns, den Eigendünkel schwächt, zugleich ein Gegenstand der Achtung, und indem es ihn sogar niederschlägt, d. i. demütigt, ein Gegenstand der größten Achtung, mithin auch der Grund eines positiven Gefühls, das nicht 30 empirischen Ursprungs ist und a priori erkannt wird. Also ist Achtung fürs moralische Gesetz ein Gefühl, welches durch einen intellektuellen Grund gewirkt wird, und dieses Gefühl ist das einzige, welches wir völlig a priori erkennen, und dessen Notwendigkeit wir einsehen können.

Wir haben im vorigen Hauptstück gesehen, daß [74] alles, was sich als Objekt des Willens vor dem moralischen Gesetze darbietet, von den Bestimmungsgründen Wille.

a) Kant: „Sittlichkeit"; korr. Adicken, Gorland, Nolte, 
des Willens, unter dem Namen des Unbedingt-Guten, durch dieses Gesetz selbst als die oberste Bedingung der praktischen Vernunft ausgeschlossen werde, und daß die bloße praktische Form, die in der Tauglichkeit der Maximen zur allgemeinen Gesetzgebung besteht, zuerst das, was an sich und schlechterdings gut ist, bestimme und die Maxime eines reinen Willens gründe, der allein in aller Absicht gut ist. Nun finden wir aber unsere Natur als sinnlicher Wesen so be10 schaffen, daß die Materio des Begehrungsvermögens (Gegenstände der Neigung, sei der Hoffnung oder Furcht) sich zuerst aufdringt und unser pathologisch bestimmbares Selbst, ob es gleich durch seine Maximen zur allgemeinen Gesetzgebung ganz nntauglich ist, dennoch, gleich als ob es unser ganzes Selbst ansmachte, seine Ansprüche vorher und als die ersten und ursprünglichen geltend zu machen bestrebt sei. ${ }^{2}$ ) Man kann diesen Hang, sich selbst nach den subjektiven Bestimmungsgründen seiner Willkür zum objektiven

20 Bestimmnngsgrunde des Willens überhaupt zu machen, die Selbstliobe nennen, welche, wenn sie sich gesetzgebend and zum unbedingten praktischen Prinzip macht, Eigendünkel heißen kann. Nun schließt das moralische Gesetz, welches allein wahrhaftig (nämlich in aller Absicht) objektiv ist, den Einfluß der Selbstliebe auf das oberste praktische Prinzip gänzlich aus und tut dem Eigendünkel, der die subjektiven Bedingungen der $^{\text {b) }}$ ersteren als Gesetze vorschreibt, unendlichen Abbruch. Was nun unserem Eigendünkel in 80 unserem eigenen Urteil Abbruch tut, das demütigt. Also demütigt das moralische Gesetz unvermeidlich jeden Menschen, indem dieser mit demselben den sinnlichen Hang seiner Natur vergleicht. Dasjenige, dessen Vorstellung als Bestimmungsgrund unseres Willens, uns in unserem SelbstbewuBtsein demütigt, erweckt, sofern als es positiv und Bestimmungsgrund ist, für sich Achtung. Also ist das moralische Gesetz auch subjektiv ein Grund der Achtung. Da nun alles, was in der Selbstliebe angetroffen wird, zur Neigung

a) ,ist"? (Vorländer).

b) Kant: „des"; korr. Adickes, Wille. 
Von den Triebfedern der reinen prakt. Vernunft. 97

gehört, alle Neigung aber auf Gefühlen beruht, mithin, was allen Neigungen insgesamt in der Selbstliebe $\mathrm{Ab}$ bruch tut, ebendadurch notwendig auf das Gefühl Einfluß hat, so begreifen wir, wie es möglich ist, a priori einzusehen, daß das moralische Gesetz, indem es die Neigungen und den Hang, sie zur obersten praktischen Bedingung zu machen, d. i. die Selbstliebe, von allem Beitritte zur obersten Gesetzgebung ausschließt, eine Wirkung aufs Gefühl ausüben könne, welche einerseits bloß negativ ist, andererseits und zwar in Ansehung des einschränkenden Grundes der reinen praktischen Vernunft positiv ist, und wozu gar keine besondere Art von Gefühl, unter dem Namen eines praktischen oder moralischen, als vor dem moralischen Gesetze vorhergehend und ihm zum Grunde liegend angenommen werden darf.

Die negative Wirkung aufs ${ }^{a}$ ) Gefühl (der Unannehmlichkeit) ist, sowie aller Einfluß auf dasselbe und wio jedes Gefühl überhaupt, pathologisch. Als Wirkung aber vom BewuBtsein des moralischen Gesetzes, 20 folglich in Beziehung auf eine intelligibele Ursache, nämlich das Subjekt der reinen praktischen Vernunft als obersten Gesetzgeberin, heißt dieses Gefühl eines vernünftigen von Neigungen affizierten Subjekts zwar Demütigung (intellektuelle Verachtung), aber in $\mathrm{Be}$ ziehung auf den positiven Grund derselben ${ }^{b}$ ), das Gesetz, zugleich Achtung für dasselbe; für welches Gesetz gar kein Gefühl stattfindet, sondern im Urteile der Vernunft, indem es den Widerstand aus dem Wege schafft, die Wegräumung eines Hindernisses einer posi- 80 tiven Beförderung der Kausalität gleichgeschätzt wird. Darum kann dieses Gefühl nun auch ein Gefühl der Achtung fürs moralische Gesetz, aus beiden Gründen zusammen aber ein moralisches Gefühl genannt werden.

Das moralische Gesetz also, sowie es formaler Bestimmungsgrund der Handlung ist durch praktische reine Vernunft, sowio es zwar auch materialer, aber

a) Kant: „auf".

b) Das Komma hinter "derselben" warde von Hartonotein zuerst hinzugefugt. 
nur objektiver Bestimmungsgrund der Gegenstände der Handlung unter dem Namen des Guten und Bösen ist, so ist es auch subjektiver Bestimmungsgrund d. $i$. Triebfeder zu dieser Handlung, indem es auf die Sinnlichkeit ${ }^{2}$ ) des Subjekts Einfluß hat und ein Gefühl bewirkt, welches dem Einflusse des Gesetzes auf den Willen beförderlich ist. Hier geht kein Gefühl im Subjekt vorher, das auf Moralität gestimmt wäre. Denn das ist unmöglich, weil alles Gefühl sinnlich ist;

10 die Triebfeder der sittlichen Gesinnung aber muß von aller sinnlichen Bedingung frei sein. Vielmehr ist das sinnliche Gefühl, was allen unseren Neigungen zum Grunde liegt, zwar die Bedingung derjenigen Empfindung, die wir Achtung nennen, aber die Ursache der Bestimmung desselben liegt in der reinen praktischen Vernunft, und diese Empfindung kann daher ihres Ursprunges wegen nicht pathologisch, sondern muß praktisch gewirkt heißen; indem dadurch, daß die Vorstellung des moralischen Gesetzes der Selbstliebe

20 den Einfluß und dem Eigendünkel den Wahn benimmt, das Hindernis der reinen praktischen Vernunft ver-

[76] mindert und die Vorstellung des Vorzuges ihres objektiven Gesetzes vor den Antrieben der Sinnlichkeit, mithin das Gewicht des ersteren relativ (in Ansehung eines durch die letztere affizierten Willens) durch die Wegschaffung des Gegengewichts im Urteile der Vernunft hervorgebracht wird. Und so ist die Achtung fürs Gesetz nicht Triebfeder zur Sittlichkeit, sondern sie ist die Sittlichkeit selbst, subjektiv als Triebfeder

30 betrachtet, indem die reine praktische Vernunft, dar durch daß sie der Selbstliebe im Gegensatze mit ihr alle Ansprüche abschlägt, dem Gesetze, das jetzt allein Einfluß hat, Ansehen verschafft. Hierbei ist nun zu bemerken, daß, sowie die Achtung eine Wirkung aufs Gefühl, mithin auf die Sinnlichkeit eines vernünftigen Wesens ist, sieb) diese Sinnlichkeit, mithin auch die Endlichkeit solcher Wesen, denen das moralische Gesetz Achtung auferlegt, voraussetze, und daß einem Zeile 35f.).

a) Kant: "Sittlichkeit"; korr. Nolte, Wille (vgl. unten

b) Kant: „e8"; korr. Vorländer. 
Von den Triebfedern der reinen prakt. Vernunft. 99

höchsten oder auch einem von aller Sinnlichkeit freien Wesen, welchem diese also auch kein Hindernis der praktischen Vernunft sein kann, Achtung fürs Gesetz nicht beigelegt werden könne.

Dieses Gefühl (unter dem Namen des moralischen) ist also lediglich durch Vernunft bewirkt. Es dient nicht zur Beurteilung der Handlungen oder wohl gar zur Gründung des objektiven, Sittengesetzes selbst, sondern bloB zur Triebfeder, um dieses in sich zur Maxime zu machen. Mit welchem Namen aber könnte man dieses sonderbare Gefühl, welches mit keinem pathologischen in Vergleichung gezogen werden kann, schicklicher belegen? Es ist so eigentümlicher Art, $\mathrm{da} B$ es lediglich der Vernunft und zwar der praktischen reinen Vernunft zu Gebote zu stehen scheint.

Achtung geht jederzeit nur auf Personen, niemals auf Sachen. Die letzteren können Neigung und, wenn es Tiere sind (z. B. Pferde, Hunde usw.) sogar Liebe, oder auch Furcht, wie das Meer, ein Vulkan, ein Raubtier, niemals aber Achtung in uns erwecken. 20 Etwas, was diesem Gefühl schon nähher tritt, ist $\mathrm{Be}$ wunderung, und diese als Affekt, das Erstaunen, kann auch auf Sachen gehen, z. B. himmelhohe Berge, die Größe, Menge und Weite der Weltkörper, die Stärke und Geschwindigkeit mancher Tiere usw. Aber alles dieses ist nicht Achtung. Ein Mensch kann mir auch ein Gegenstand der Liebe, der Furcht oder der Bewunderung, sogar bis zum Erstaunen und doch darum kein Gegenstand der Achtung sein. Seine scherzhafte Laune, sein Mut und Stärke, seine Macht durch seinen 80 Rang, den er unter anderen hat, können mir dergleichen Empfindungen einflößen, es fehlt aber immer noch an innerer Achtung gegen ihn. Fontenelle ${ }^{2}$ ) sagt: Vor einem Vornehmen bücke ich mich, aber mein Geist bückt sich nicht. Ich kann hinzusetzen: Vor einem niedrigen, bürgerlich-gemeinen - Mann, an dem ich eine Rechtschaffenheit des Charakters in einem gewissen Maße, als ich mir von mir selbst

a) Bernard lo Bovier de Fonten elle (1657-1757), seinerzeit vielgelesener franzosischer Popularphilosoph and eatirischer Sohriftsteller. 
nicht bewuBt bin, wahrnehme, bückt sich mein Geist, ich mag wollen oder nicht und den Kopf noch so hoch tragen, um ihn meinen Vorrang nicht übersehen zu lassen. Warum das? Sein Beispiel hält mir ein Gesetz vor, das meinen Eigendünkel niederschlägt, wenn ich es mit meinem Verhalten vergleiche, und dessen Befolgung, mithin die Tunlichkeit desselben ich durch die Tat bewiesen vor mir sehe. Nun mag ich mir sogar eines gleichen Grades der Rechtschaffenheit 10 bewußt sein, und die Achtung bleibt doch. Denn da beim Menschen immer alles Gute mangelhaft ist, so schlägt das Gesetz, durch ein Beispiel anschaulich gemacht, doch immer meinen Stolz nieder, wozu der Mann, den ich vor mir sehe, dessen Unlauterkeit, die ihm immer noch anhängen mag, mir nicht so wie mir die meinige bekannt ist, der $\mathrm{mir}$ also in reinerem Lichte erscheint, einen Maßstab abgibt. Achtung ist ein Tribut, den wir dem Verdienste nicht verweigern können, wir mögen wollen oder nicht; wir mögen allen20 falls äußerlich damit qurückhalten, so können wir doch nicht verhüten, sie innerlich 20 empfinden.

Die Achtung ist so wenig ein Gefühl der Lust, daß man sich ihr in Ansehung eines Menschen nur ungern überläßt. Man sucht etwas ausfindig zu machen, was uns die Last derselben erleichtern könne, irgend einen Tadel, um uns wegen der Demütigung, die uns durch ein solches Beispiel widerfährt, schadlos zu halten. Selbst Verstorbene sind, vornehmlich wenn ihr Beispiel unnachahmlich scheint, vor dieser Kritik nicht

80 immer gesichert. Sogar das moralische Gesetz selbst in seiner feierlichen Majestät ist diesem Bestreben, sich der Achtung dagegen zu erwehren, ausgesetzt. Meint man wohl, daß es einer anderen. Ursache zuzuschreiben sei, weswegen man es gern zu unserer vertraulichen Neigung herabwürdigen möchte, und sich aus anderen Ursachen alles so bemühe, um es zur beliebten Vorschrift unseres eigenen wohlverstandenen Vorteils zu machen, als da $\beta$ man der abschreckenden Achtung, die uns unsere eigene Unwürdigkeit so 40 strenge vorhält, loswerden möge? Gleichwohl ist darin doch auch wiederum so wenig Unlust, daß, wenn man einmal den Eigendünkel abgelegt und jener Ach- 
Von den Triebfedern der reinen prakt. Vernunft. 101

tung praktischen Einflu. verstattet hat, man sich wiederum an der Herrlichkeit dieses Gesetzes nicht sattsehen kann, und die Seele sich in dem Maße selbst zu erheben glaubt, als sie jas heilige Gesetz über sich und ihre gebrechliche Natur erhaben sieht. Zwar können große Talente und eine ihnen proportionierte Tätigkeit auch Achtung oder ein mit derselben analogisches Gefühl bewirken, es ist auch ganz anständig, es ihnen zu widmen, und da scheint es, als ob Bewunderung mit jener Empfindung einerlei sei. Allein, 10 wenn man näher zusieht, so wird man bemerken, daß, da es immer ungewiß bleibt, wieviel das angeborene Talent und wieviel Kultur durch eigenen Fleiß an der Geschicklichkeit teil habe, so stellt uns die Vernunft die letztere mutmaßlich als Frucht der Kultur, mithin als Verdienst vor, welches unseren Eigendünkel merklich herabstimmt und uns darüber entweder Vorwürfe macht oder uns die Befolgung eines solchen Beispiels in der Art, wie es uns angemessen ist, auferlegt. Sie ist also nicht bloße Bewunderung, diese Achtung, die 20 wir einer solchen Person (eigentlich dem Gesetze, was uns sein ${ }^{a}$ Beispiel vorhält) beweisen; welches sich auch dadurch bestätigt, daß der gemeine Haufe der Liebhabër, wenn er das Schlechte des Charakters eines solchen Mannes (wie etwa Voltaire) sonstwoher erkundigt zu haben glaubt, alle Achtung gegen ihn aufgibt, der wahre Gelehrte aber sie noch immer wenigstens im Gesichtspunkte seiner Talente fühlt, weil er selbst in einem Geschäfte und Berufe verwickelt ist, welches die Nachahmung desselben ihm gewissermaßen zum Gesetze macht.

Achtung fürs moralische Gesetz ist also die einzige und zugleich unbezweifelte moralische Triebfeder, sowie dieses Gefühl auch auf kein Objekt anders als lediglich aus diesem Grunde gerichtet ist. Zuerst bestimmt das moralische Gesetz objektiv und unmittelbar den Willen im Urteile der Vernunft; Freiheit, deren Kausalität bloß durchs Gesetz bestimmbar ist, besteht aber eben darin, da $B$ sie alle Neigungen, mithin die Schätzung der Person selbst auf die Bedingung der 10

a) Hartenstein: „ihr". 
Befolgung ihres reinen Gesetzes einschränkt. Diese Einschränkung tut nun eine Wirkung aufs Gefühl und bringt Empfindung der Unlust hervor, die aus dem moralischen Gesetze a priori erkannt werden kann. $\mathrm{Da}$ sie aber bloß sofern eine negative Wirkung ist, die, als aus dem Einflusse einer reinen praktischen Vernunft entsprungen, vornehmlich der Tätigkeit des Subjekts, sofern Neigungen die Bestimmungsgründe desselben sind, mithin der Meinung seines persönlichen

10 Werts Abbruch tut (der ohne Einstimmung mit dem moralischen Gesetze auf nichts herabgesetzt wird), so ist die Wirkung dieses Gesetzes aufs Gefühl bloß Demütigung, welche wir also zwar a priori einsehen, aber an ihr nicht die Kraft des reinen praktischen Gesetzes als Triebfeder, sondern nur den Widerstand

[79] gegen Triebfedern der Sinnlichkeit erkennen können. Weil aber dasselbe Gesetz doch objektiv, d. i. in der Vorstellung der reinen Vernunft ein unmittelbarer Bestimmungsgrund des Willens ist, folglich diese De20 mütigung nur relativ auf die Reinigkeit des Gesetzes stattfindet, so ist die Herabsetzung der Ansprtiche der moralischen Selbstschätzung, d. i. die Demütigung auf der sinnlichen Seite eine Erhebung der moralischen, d. i. der praktischen Schätzung des Gesetzes selbst auf der intellektuellen, mit einem. Worte Achtung fürs Gesetz also auch ein seiner intellektuellen Ursache nach positives Gefühl, das a priori erkannt wird. Denn eine jede Verminderung der Hindernisse einer Tätigkeit ist Beförderung dieser Tätigkeit selbst. Die Anerkennung

30 des moralischen Gesetzes aber ist das Bewußtsein einer Tätigkeit der praktischen Vernunft aus objektiven Gründen, die bloß darum nicht ihre Wirkung in Handlungen äußert, weil subjektive Ursachen (pathologische) sie hindern. Also muß die Achtung fürs moralische Gesetz auch als positive, aber indirekte Wirkung desselben aufs Gefühl, sofern jenes den hindernden Einfluß der Neigungen durch Demütigung des Eigendünkels schwächt, mithin als subjektiver Grund der Tätigkeit, d. i. als Triebfeder zur Be-

10 folgung desselben und als Grund zu Maximen eines ihm gemäßen Lebenswandels angesehen werden. Aus dem Begriffe einer Triebfeder entspringt der eines Inter- 
Von den Triebfedern der reinen prakt. Vernunft. 103

esse, welches niemals einem Wesen, als was Vernunft hat, beigelegt wird und eine Triebfeder des Willens bedeutet, sofern sie durch Vernunft vorgestellt wird. Da das Gesetz selbst in einem moralisch guten Willen die Triebfeder sein muß, so ist das moralischo In teress $\theta$ ein reines sinnenfreies Interesse der bloßen praktischen Vernunft. Auf dem: Begriffe eines Interesse gründet sich auch der einer Maxime. Diese ist also nur alsdann moralisch echt, wenn sie auf dem bloßen Interesse, das man an der Befolgung des Gesetzes 10 nimmt, beruht. Alle drei Begriffe aber, der einer Triebfeder, eines Interesse und einer Maxime, können nur auf endliche Wesen angewandt werden. Denn sie setzen insgesamt eine Eingeschränktheit der Natur eines Wesens voraus, da dio subjektive Beschaffenheit seiner Willkür mit dem objektiven Gesetze einer praktischen Vernunft nicht von selbst übereinstimmt; ein Bedürfnis, irgendwodurch zur Tätigkeit angetrieben $\mathrm{zu}$ werden, weil ein inneres Hindernis derselben entgegensteht. Auf den göttlichen Willen 20 können sie also nicht angewandt werden.

Es liegt so etwas Besonderes in der grenzenlosen Hochschätzung des reinen, von allem Vorteil entblößten moralischen Gesetzes, sowie es praktische Vernunft uns zur Befolgung vorstellt, deren Stimme auch den kühnsten Frevler zittern macht und ihn nötigt, sich vor seinem Anblicke zu verbergen, da $\$$ man sich nicht wundern darf, diesen Einfluß einer bloß intellektuellen Idee aufs Gefühl für spekulative Vernunft unergründlich $\mathrm{zu}$ finden und sich damit begnügen $\mathrm{zu} 30$ müssen, daß man a priori doch noch soviel einsehen kann: ein solches Gefühl sei unzertrennlich mit der Vorstellung des moralischen Gesetzes in jedem endlichen vernünftigen Wesen verbunden. Wäre dieses Gefühl der Achtung pathologisch und also ein auf dem inneren Sinne gegründetes Gefühl der Lust, so würde es vergeblich sein, eine Verbindung desselben ${ }^{2}$ ) mit irgend einer Idee a priori zu entdecken. Nun aber ist, esb) ein Gefühl, was bloß aufs Praktische geht und

a) Kant: „derselben“; korr. Hartenstein.

b) „es" Zusatz Hartensteins. 
zwar der Vorstellung eines Gesetzes lediglich' seiner Form nach, nicht irgend eines Objekts desselben wegen anhängt, mithin weder zum Vergnügen noch zum Schmerze gerechnet werden kann und dennoch ein Interesse an der Befolgung desselben hervorbringt, welches wir das moralische nennen; wie denn auch die Fähigkeit, ein solches Interesse am Gesetze zu nehmen (oder die Achtung fürs moralische Gesetz selbst), eigentlich das moralische Gefühl ist.

Das Bewußtsein einer freien Unterwerfung des Willens unter das Gesetz, doch als mit einem unvermeidlichen Zwange, der allen Neigungen, aber nur durch eigene Vernunft angetan wird, verbunden, ist nun die Achtung fürs Gesetz. Das Gesetz, was diese Achtung fordert und auch einflößt, ist, wie man sieht, kein anderes als das moralische (denn kein anderes schließt alle Neigungen von der Unmittelbarkeit ihres Einflusses auf den Willen aus). Die Handlung, die nach diesem Gesetze, mit Ausschließung aller Be20 stimmungsgründe aus Neigung, objektiv praktisch ist, heißt Pflicht, welche um dieser Ausschließung willen in ihrem Begriffe praktische Nötigung, d. i. Bestimmung zu Handlungen; so ungerne wie sie auch geschehen mögen, enthält. Das Gefühl, das aus dem Bewußtsein dieser Nötigung entspringt, ist nicht pathologisch, als ein solches, was von einem Gegenstande der Sinne gewirkt würde, sondern allein praktisch, d. i. durch eine vorhergehende (objektive) Willensbestimmung und Kausalität der Vernunft möglich. Es 30 enthält also, als Unterwerfung unter ein Gesetz, d. i. als Gebot (welches für das sinnlich affizierte Subjekt Zwang ankündigt), keine Lust, sondern sofern vielmehr Unlust an der Handlung in sich. Dagegen aber, da dieser Zwang bloß durch Gesetzgebung der eigenen Vernunft ausgeübt wird, enthält es auch

[81] Erhebung, und die subjektive Wirkung aufs Gefühl, sofern davon reine praktische ,Vernunft die alleinige Ursache ist, kann also bloß Selbstbilligung in Ansehung der letzteren heißen, indem man sich dazu 40 ohne alles Interesse, bloß durchs Gesetz bestimmt erkennt, und sich nunmehr eines ganz anderen, dadurch subjektiv hervorgebrachten Interesse, welches rein 
Vou den Triebfedurn der reinen prakt. Vormunft. 105

praktisch und frei ist, bewußt wird, welches an einer pflichtmäßigen Handlung zu nehmen nicht etwa eine Neigung anrätig ist, sondern die Vernunft durchs praktische Gesetz schlechthin gebietet und auch wirklich hervorbringt, darum aber einen ganz eigentümlichen Namen, nämlich den der Achtung, führt.

Der Begriff der Pflicht fordert also an der Handlung objektiv Übereinstimmung mit dem Gesetze, an der Maxime derselben aber subjektiv Achtung fürs Gesetz, als die alleinige Bestimmungsart des Wil- 10 lens durch dasselbe. Und darauf beruht der Unterschied zwischen dem Bewußtsein, pflichtmäßig und a us Pflicht, d. i. aus Achtung fürs Gesetz, gehandelt zu haben, davon das erstere (die Legalität) auch möglich ist, wenn Neigungen bloß die Bestimmungsgründe des Willens gewesen wären, das zweite aber (die Moralität), der moralische Wert, lediglich darin gesetzt werden muß, daß die Handlung aus Pflicht, d. i. bloß um des Gesetzes willen geschehe.*)

Es ist von der größten Wichtigkeit in allen mora- 20 lischen Beurteilungen, auf das subjektive Prinzip aller Maximen mit der äußersten Genauigkeit acht zu haben, damit alle Moralität der Handlungen in der Notwendigkeit derselben aus Pflicht und aus Achtung fürs Gesetz, nicht aus Liebe und Zuneigung zu dem, was die Handlungen hervorbringen sollen, gesetzt werde. Für Menschen und alle erschaffenen: vernünftigen Wesen ist die moralische Notwendigkeit Nötigung, d. i. Verbindlichkeit, und jede darauf gegründete Handlung als Pflicht, nicht aber als eine von uns selbst schon 80 beliebte oder beliebt werden könnende Verfahrungs-

*) Wenn man den Begriff der Achtung für Personen, so wie or vorher dargelegt worden, genau erwägt, so wird man gewahr, daß sie immer auf dem Bewußtsein einer Pflicht beruhe, die uns ein Beispiel vorhalt, and daß also Achtung niemals einen anderen als moralischen Grund haben kőnne, und es sehr gut, sogar in psychologischer Absicht zur Menschenkenntnis sehr nützlich sei, allerwärts, wo wir diesen Ausdruck braachen, auf die geheime und wandernswürdige, dabei aber oft vorkommende Rücksicht, die der Nensch in seinen Beurteilungen aufs moralische Gesetz nimmt, acht za haben. 
art vorzustellen. Gleich als ob wir es dahin jemals [82] bringen könnten, daß ohne Achtung fürs Gesetz, welche mit Furcht oder wenigstens Besorgnis vor Ubertretung verbunden ist, wir wie die über alle Abhängigkeit erhabene Gottheit von selbst, gleichsam durch eine uns zur Natur gewordene, niemals zu verrückende Ubereinstimmung des Willens mit dem reinen Sittengesetze (welches also, da wir niemals versucht werden könnten ${ }^{2}$, ihm untreu zu werden, wohl endlich gar

10 aufhören könnte, für uns Gebot zu sein) jemals in den Besitz einer Heiligkeit des Willens kommen könnten.

Das moralische Gesetz ist nämlich für den Willen eines allervollkommensten Wesens ein Gesetz der Heiligkeit, für den Willen jedes endlichen vernünftigen Wesens aber ein Gesetz der Pflicht, der moralischen Nötigung und der Bestimmung der Handlungen desselben durch Achtung für das Gesetz und aus Ehrfurcht für seine Pflicht. Fin anderes subjek20 tives Prinzip muß zur Triebfeder nicht angenommen werden; denn sonst kann zwar die Handlung, wie das Gesetz sie vorschreibt, ausfallen, aber, da sie zwar pflichtmäßig ist, aber nicht aus Pflicht geschieht, so ist die Gesinnung dazu nicht moralisch, auf die es doch in dieser Gesetzgebung eigentlich ankömmt.

Es ist sehr schön, aus Liebe zu Menschen und teilnehmendem Wohlwollen ihnen Gutes zu tun oder aus Liebe zur Ordnung gerecht $\mathrm{zu}$ sein, aber das ist noch nicht die echte moralische Maxime unseres Ver-

30 haltens, die unserem Standpunkte unter vernünftigen Wesen als Menschen angemessen ist, wenn wir uns anmaßen, gleichsam als Volontäre, uns mit stolzer Einbildung über den Gedanken von Pflicht wegzusetzen und ${ }^{b}$ ), als vom Gebote unabhängig, bloß aus eigener Lust das tun zu wollen, woztu für uns kein Gebot nötig wäre. Wir stehen unter einer Disziplin der Vernunft und müssen in allen unseren Maximen der Unterwürfigkeit unter derselben nicht vergessen, ihr nichts $\mathrm{zu}$ entziehen, oder dem Ansehen des Gesetzes (ob es gleich

a) Kant: „kőnnen“"; korr. Nolte.

b) Kant: ",nd uns"; korr. Rosenkranz, Hartenstein. 
unsere eigene Vernunft gibt) durch eigenliebigen Wahn dadurch etwas abkürzena), da $\beta$ wir den Bestimmungsgrund unseres Willens, wenngleich dem Gesetze gemäb, doch wiorin anders als im Gesetze selbst und in der Achtung für dieses Gesetz setzten. Pflicht und Schuldigkeit sind die Benennungen, die wir allein unserem Verhältnisse zum moralischen Gesetze geben' müssen. Wir sind zwar gesetzgebende Glieder eines durch Freiheit möglichen, durch praktische Vernunft uns zur Achtung vorgestellten Reichs der Sitten, aber doch zugleich 10 Untertanen, nicht das Oberhaupt desselben, und die Verkennung unserer niederen Stufe als Geschöpfe und Weigerung des Eigendünkels gegen das Ansehen des heiligen Gesetzes ist schon eine Abtrünnigkeit von [83] demselben dem Geiste nach, wenngleich der Buchstabe desselben erfüllt würde.

Hiermit stimmt aber die Möglichkeit eines solchen Gebots als: Liebe Gott über alles und deinen Nächsten als dich selbst*), ganz wohl zusammen. Denn es fordert doch als Gebot Achtung für ein Ge- 20 setz, das Liebe befiehlt, und überläßt es nicht der beliebigen Wahl, sich diese zum Prinzip zu machen. Aber Liebe zu Gott als Neigung (pathologische Liebe) ist unmöglich; denn er ist kein Gegenstand der Sinne. Ebendieselbe gegen Menschen ist zwar möglich, kann aber nicht geboten werden; denn es steht in keines Menschen Vermögen, jemanden bloß auf Befehl zu lieben. Also ist es bloß die praktische Liebe, die in jenem Kern aller Gesetze verstanden wird. Gott lieben heißt in dieser Bedeutung: seine Gebote gerne tun; 30 den Nächsten lieben heißt: alle Pflicht gegen ihn gerne ausüben. Das Gebot aber, das dieses zur Regel macht, kann auch nicht diese Gesinnung in pflichtmäßigen Handlungen zu haben, sondern bloß danach

*) Mit diesem Gesetze macht das Prinzip der eigenen Glückseligkeit, welches einige zum obersten Grundsatze der Sittlichkeit machen wollen, einen seltsamen Kontrast. Dieses würde so lanten: Liebe dich selbst übor alles, Gott bor und deinen Nachsten nm dein selbot willen.

s) Kehrbach, Natorp: nabzukürzen $^{4}$. 
zu streben gebieten. Denn ein Gebot, daß man etwas gerne tun soll, ist in sich widersprechend, weil, wenn wir, was uns zu tun obliege, schon von selbst wisser, wenn wir uns überdem auch bewußt wären, es gerne zu tun, ein Gebot darüber ganz unnötig, und, tun wir es zwar, aber eben nicht gerne, sondern nur aus Achtung fürs Gesetz, ein Gebot, welches diese Achtung eben zur Triebfeder der Maxime macht, gerade der gebotenen Gesinnung zuwider wirken würde. Jenes

10 Gesetz aller Gesetze stellt also, wie alle moralische Vorschrift des Evangelii, die sittliche Gesinnung in ihrer ganzen Vollkommenheit dar, sowio sie als ein Ideal der Heiligkeit von keinem Geschöpfe erreichbar, dennoch ein Urbild ist, welchem wir uns zu nähern und in einem ununterbrochenen, aber unendlichen Progressus gleich zu werden streben sollen. Könnte nämlich ein vernünftig Geschöpf jemals dahin kommen, alle moralischen Gesetze völlig gerne zu tun, so würde das soviel bedeuten als: es fände sich in ihm

80 auch nicht einmal die Möglichkeit einer Begierde, die $\left.i_{n}{ }^{a}\right)$ zur Abweichung von ihnen reizte; denn die Uberwindung einer solchen kostet dem Subjekt immer Aufopferung, bedarf also Selbstzwang, d. i. innere Nöti-

[84] gung zu dem, was man nicht ganz gern tut. Zu dieser Stufe der moralischen Gesinnung aber kann es ein Geschöpf niemals bringen. Denn da es ein Geschöpf, mithin in Ansehung dessen, was es zur gänzlichen Zufriedenheit mit seinem Zustande fordert, immer abhängig ist, so kann $\mathrm{es}^{\mathrm{b}}$ ) niemals von Begierden und Eo Neigungen ganz frei sein, die, weil sie auf physischen Ursachen beruhen, mit dem moralischen Gesetze, das ganz andere Quellen hat, nicht vion selbst stimmen, mithin es jederzeit notwendig machen, in Rücksicht auf dieselben die Gesinnung seiner Maximen auf mora- lische Nötigung, nicht auf bereitwillige Ergebenheit, sondern auf Achtung, welche die Befolgung des Gesetzes, obgleich sie ungerne geschähe, fordert, nicht auf Liebe, die keine innere Weigerung des Willens gegen das Gesetz besorgt, zu gründen, gleichwohl

a) Hartenstein: „es".

b) Kant: „er"; korr. Grillo. 
Von den Triebfedern der reinen prakt. Vernunft. 109

aber diese letztere, nämlich die bloße Liebe zum $\mathrm{Ge}$ setze (da es alsdann aufhören würde, Gebot zu sein, und Moralität, die nun subjektiv in Heiligkeit überginge, aufhören würde, Tug end zu sein) sich zum beständigen, obgleich unerreichbaren Ziele seiner Bestrebung $\mathrm{zu}$ machen. Denn an dem, was wir hochschätzen, aber doch (wegen des Bewußtseins unserer Schwächen) scheuen, verwandelt sich durch die mehrere Leichtigkeit, ihm Genüge zu tun, die ehrfurchtsvolle Scheu in Zuneigung und Achtung in Liebe; wenigstens 10 würde es die Vollendung einer dem Gesetze gewidmeten Gesinnung sein, wenn es jemals einem Geschöpfe möglich wäre, sie zu erreichen.

Diese Betrachtung ist hier nicht sowohl dahin abgezweckt, das angeführte evangelische Gebot auf deutliche Begriffe zu bringen, um der Religionsschwärmerei in Ansehung der Liebe Gottes, sondern die sittliche Gesinnung auch unmittelbar in Ansehung der Pflichten gegen Menschen genau zu bestimmen, und $^{2}$ ) einer bloß moralischen Schwärmerei, welche 20 viel Köpfe ansteckt, zu steuern oder womöglich vorzubeugen. Die sittliche Stufe, worauf der Mensch (aller unserer Einsicht nach auch jedes vernünftige $\mathrm{Ge}-$ schöpf) steht, ist Achtung fürs moralische Gesetz. Die Gesinnung, die ihm dieses zu befolgen obliegt, ist: es aus Pflicht, nicht aus freiwilliger Zuneigung und auch allenfalls unbefohlener, von selbst gern unternommener Bestrebung zu befolgen, und sein moralischer Zustand, darin er jedesmal sein kann, ist Tugend, d. i. moralische Gesinnung im $\mathrm{Kampfe}$, und 30 nicht Heiligkeit im vermeinten Besitze einer völligen Reinigkeit der Gesinnungen des Willens. Es ist lauter moralische Schwärmerei und Steigerung des Eigendünkels, wozu man die Gemüter durch Aufmunterung zu Handlungen als edler, erhabener und großmütiger stimmt, dadurch man sie in den Wahn versetzt, als wäre es nicht Pflicht, d. i. Achtung fürs Gesetz, [85] dessen Joch (das gleichwohl, weil es uns Vernunft selbst auferlegt, sanft ist) sie, wenngleich ungern, tragen müßten, was den Bestimmungsgrund ihrer Hand-
a) "am"? (Natorp). 
lungen ausmachte, und welches sie immer noch demütigt, indem sie es befolgen (ihm gehorchon); sondern als ob jene Handlungen nicht aus Pflicht, sondern als barer Verdienst von ihnen erwartet würden. ${ }^{a}$ ) Denn nicht allein, daß sie durch Nachahmung solcher Taten, nämlich aus solchem Prinzip, nicht im mindesten dem Geiste des Gesetzes ein Genüge getan hätten, welcher in der dem Gesetze sich unterwerfenden Gesinnung, nicht in der Gesetzmäßigkeit der Handlung 10 (das Prinzip möge sein, welches es ${ }^{b}$ ) auch wolle) besteht, und die Triebfeder pathologisch (in der Sympathie oder auch Philautie), nicht moralisch (im Gesetze) setzen: so bringen sie auf diese Art eine windige, überfliegende, phantas`ische Denkungsart hervor, sich mit einer freiwilligen Gutartigkeit ihres Gemüts, das weder Sporns noch Zügel bedürfe, für welches gar nicht einmal ein Gebot nötig, sei, zu schmeicheln, und darüber ihrer Schuldigkeit, an welche sie doch' eher denken sollten als an Verdienst, zu vergessen. Es 20 lassen sich wohl Handlungen anderer, die mit großer Aufopferung und zwar bloß um der Pflicht willen geschehen sind, unter dem Namen edler und erhabener Taten preisen, und doch auch nur sofern Spuren da sind, welche vermuten lassen, daß sio ganz aus Achtung für seine Pflicht, nicht aus Herzensaufwallungen geschehen sind. Will man jemandem aber sie als Beispiele der Nachfolge vorstellen, so muß durchaus die Achtung für Pflicht (als das einzige echte moralische Gefühl) zur Triebfeder gebraucht 80 werden: diese $^{c}$ ) ernste, heilige Vorschrift, die es nicht unserer eiteln Selbstliebe überläßt, mit pathologischen Antrieben (sofern sie der Moralität analogisch sind) zu tändeln und uns auf verdienstlichen Wert was zugute zu tun. Wenn wir nur wohl nachsuchen, so werden wir zu allen Handlungen, die anpreisungswürdig sind, schon ein Gesetz der Pflicht finden, welches gebietet und nicht auf unser Belieben ankommen läßt, was unserem Hange gefällig sein möchte.

a) Kant: ,würde"; korr. Hartenstein.

b) "өs", Zusatz von Rosenkranz und Hartenstein.

c) 8. and spätere Auflagen: „die“" 
Von den Triebfedern der reinen prakt. Vernunft. 111

Das ist die einzige Darstellungsart, welche die Seele moralisch bildet, weil sie allein fester, und genau bostimmter Grundsätze fähig ist.

Wenn Schwärmerei in der allgemeinsten Bedeutung eine nach Grundsätzen unternommene Uberschreitung der Grenzen der menschlichen Vernunft ist, so ist moralische Schwärmerei diese Utberschreitung der Grenzen, die die praktische reine Vernunft der Menschheit setzt, dadurch sie verbietet, den sub- [86] jektiven Bestimmungsgrund pflichtmäßiger Handlun- 10 gen, d. i. die moralisch $\theta$ Triebfeder derselben irgend worin anders als im Gesetze selbst, und die Gesinnung, die dadurch in die Maximen gebracht wird, irgend anderwärts als in der Achtung für dies Gesetz zu setzen, mithin den alle Arroganz sowohl als eitle Philautie niederschlagenden Gedanken von Pflicht zum obersten Lebensprinzip aller Moralität im Menschen $\mathrm{zu}$ machen gebietet.

Wenn dem also ist, so haben nicht allein Romanschreiber oder empfindelnde Erzieher (ob sie gleich 20 noch so sehr wider Empfindelei eifern), sondern bisweilen selbst Philosophen, ja die strengsten unter allen, die Stoiker, moralische Schwärmerei statt nüchterner, aber weiser Disziplin der Sitten eingeführt, wenngleich die Schwärmerei der letzteren mehr horoisch, der ersteren von schaler und schmelzender Beschaffenheit war; und man kann es, ohne zu heucheln, der moralischen Lehre des Evangelii mit aller Wahrheit nachsagen: daß es zuerst durch die Reinigkeit des moralischen Prinzips, zugleich aber durch die An- 30 gemessenheit desselben mit den Schranken endlicher Wesen alles Wohlverhalten des Menschen der Zucht einer ihnen vor Augen gelegten Pflicht, die sie nicht unter moralischen geträumten Vollkommenheiten schwärmen läßt, unterworfen und dem. Eigendünkel sowohl als der Eigenliebe, die beide gerne ihre Grenzen verkennen, Schranken der Demut (d. i. der Selbsterkenntnis) gesetzt habe.

Pflicht! du erhabener großer Name, der du nichts Beliebtes, was Einschmeichelung bei sich führt, in dir $\mathbf{4 0}$ fassest, sondern Unterwerfung verlangst, doch auch nichts drohest, was natürlich $\theta$ Abneigung im Gemüte 
erregte und schreckte, um den.Willen zu bewegen, sondern bloß èn Gesetz aufstellst, welches von selbsta) im Gemüte Eingang findet und doch sich selbst wider Willen Verehrung (wenngleich nicht immer Befolgung) erwirbt, vor dem alle Neigungen verstummen, wenn sie gleich insgeheim ihm entgegenwirken: welches ist der deiner würdige Ursprung, und wo findet man die Wurzel deiner edeln Abkunft, welche alle Verwandtschaft mit Neigungen stolz ausschlägt, und von welcher 10 Wurzel abzustammen die unnachläßlich $\theta$ Bedingung desjenigen, Werts ist, den sich Menschen allein selbst geben können?

Es kann nichts minderes sein, als was den Menschen über sich selbst (als einen Teil der Sinnenwelt) erhebt, was ihn an eine Ordnung der Dinge knüpft, die nur der Verstand denken kann, und die zugleich die ganze Sinnenwelt, mit ihr das empirisch bestimm[87] bare Dasein des Menschen in der Zeit und das Ganze aller Zwecke (welches allein solchen unbedingten prak20 tischen Gesetzen als das moralische angemessen ist) unter sich hat. Es ist nichts anderes als die Persönlichkeit, d. i. die Freiheit und Unabhängigkeit von dem Mechanismus der ganzen Natur, doch zugleich als ein Vermögen eines Wesens betrachtet, welches eigentümlichen, nämlich von seiner eigenen Vernunft gegebenen reinen praktischen Gesetzen, die Person also als zur Sinnenwelt gehörig ihrer eigenen Persönlichkeit unterworfen ist, sofern sie zugleich zur intelligibelen Welt gehört; da es denn nicht zu verwundern

30 ist, wenn der Mensch, als zu beiden Welten gehörig, sein eigenes Wesen in Beziehung auf seine zweite und höchste Bestimmung nicht anders als mit Verehrung und die Gesetze derselben mitder höchsten Achtung betrachten muß. Auf diesen Ursprung gründen sich nun manch $\theta$ Ausdrücke, welche den Wert der Gegenstände nach moralischen Ideen bezeichnen. Das moralische Gesetz ist heilig (unverletzlich). Der Mensch ist zwar unheilig genug, aber die Menschheit in seiner Person muß ihm heilig sein. In der ganzen. Schöpfung kann 40 alles, was man will, und worüber man etwas vermsg, auch bloß als Mittel gebraucht werden; nur der

a) Romundts Vorschlag (Kantst. XIII 313f.): „nicht von selbst" schwerlich Kants Sinn entsproshend. 
Mensch, und mit ihm jedes vernünftige Geschöpf, ist Zweck an sich selbst. Er ist nämlich das Subjekt des moralischen Gesetzes, welches heilig ist, vermöge der Autonomie seiner Freiheit. Eben um dieser willen ist jeder Wille, selbst jeder Person ihr eigener, auf sie selbst gerichteter Wille auf die Bedingung der Einstimmung mit der Autonomie des vernünftigen Wesens eingeschränkt, es nämlich keiner Absicht zu unterwerfen, die nicht nach einem Gesetze, welches aus dem Willen des leidenden Subjekts selbst ent- 10 springen könnte, möglich ist; also dieses niemals bloß als Mittel, sondern zugleich selbst als Zweck zu gebrauchen. Diese Bedingung legen wir mit Recht sogar dem göttlichen Willen in Ansehung der vernünftigen Wesen in der Welt als seiner Geschöpfe bei, indem sie auf der Persönlichkeit derselben beruht, dadurch allein sie Zwecke an sich selbst sind.

Diese Achtung erweckende Idee der Persönlichkeit, welche uns die Erhabenheit unserer Natur (ihrer Bestimmung nach) vor Augen stellt, indem sie uns zu- 20 gleich den Mangel der Angemessenheit unseres Verhaltens in Ansehung derselben bemerken läßt und dadurch den Eigendünkel niederschlägt, ist selbst der gemeinsten Menschenvernunft natürlich und leicht bemerklich. Hat nicht jeder auch nur mittelmäßig ehrliche Mann bisweilen gefunden, daß er eine sonst unschädliche Lüge, dadurch er sich entweder selbst aus einem verdrießlichen Handel ziehen oder wohl gar $[88]$ einem geliebten und verdienstvollen Freunde Nutzen schaffen konnte, bloß darum unterließ, um sich ins- 30 geheim in seinen eigenen Augen nicht verachten zu dürfen? Hält nicht einen rechtschaffenen Mann im größten Unglücke des Lebens, das er vermeiden konnte, wenn er sich nur hätte über die Pflicht wegsetzen können, noch das Bewußtsein aufrecht, daß er die Menschheit in seiner Person doch in ihrer Würde erhalten und geehrt habe, daß er sich nicht vor sich selbst zu schämen und den inneren Anblick der Selbstprüfung zu scheuen Ursache habe? Dieser Trost ist nicht Glückseligkeit, auch nicht der mindeste Teil der- 40 selben. Denn niemand wird sich die Gelegenheit dazu, auch vielleicht nicht einmal ein Leben in solchen

Kant, Kritik der prakt. Vernunft. 


\section{Erster Teil, I. Buch, 8. Hauptstáck.}

Umständen wünschen. Aber er lebt und kann es nicht erdulden, in seinen eigenen Augen des Lebens unwürdig zu sein. Diese innere Beruhigung ist also bloß negativ in Ansehung alles dessen, was das Leben angenehm machen mag; nämlich sie ist die Abhaltung der Gefahr, im persönlichen Werte zu sinken, nachdem der seines Zustandes von ihm schon gänzlich aufgegeben worden. Sie ist die Wirkung von einer Achtung für etwas ganz anderes als das Leben, womit in Vergleichung

10 und Entgegensetzung das Leben vielmehr mit aller seiner Annehmlichkeit gar keinen Wert hat. Er lebt nur noch aus Pflicht, nicht, weil er am Leben den mindesten Geschmack findet.

So ist die echte Triebfeder der reinen praktischen Vernunft beschaffen; sie ist keine andere als das reine moralische Gesetz selber, sofern es uns die Erhabenheit unserer eigenen übersinnlichen Existenz spüren läßt und subjektiv in Menschen, die sich zugleich ihres sinnlichen Daseins und der damit verbundenen $\mathrm{Ab}$ -

20 hängigkeit von ihrer sofern sehr pathologisch affizierten Natur bewußt sind, Achtung für ihre höhere Bestimmung wirkt. Nun lassen sich mit dieser Triebfeder gar wohl so viele Reize und Annehmlichkeiten des Lebens verbinden, daß auch um dieser willen allein schon die klügste Wahl eines vernünftigen und über das größte Wohl' des Lebens nachdenkenden Epikureers sich für das sittliche Wohlverhalten erklären würde, und es kann auch ratsam sein, diese Aussicht auf einen fröhlichen Genuß des Lebens mit jener

30 obersten und schon für sich allein hinlänglich bestimmenden Bewegursache zu verbinden; aber nur um den Anlockungen, die das Laster auf der Gegenseite vorzuspiegeln nicht ermangelt, das Gegengewicht zu halten, nicht um hierin die eigentliche bewegende Kraft, auch nicht dem mindesten Teile nach, zu setzen, wenn von Pflicht die Rede ist. Denn das würde so-

[89] viel sein, als die moralische Gesinnung in ihrer Quelle verunreinigen wollen. Die Ehrwürdigkeit der Pflicht hat nichts mit Lebensgenuß zu schaffen; sie hat ihr 40 eigentümliches Gesetz, auch ihr eigentümliches Gericht, und wenn man auch beide noch so sehr zusammenschütteln wollte, um sie vermischt gleichsam 
als Arzneimittel der kranken Seele zuzureichen, so scheiden sie sich doch alsbald von selbst, und tun sie es nicht, so wirkt das erste gar nicht; wenn aber auch das physische Leben hierbei einige Kraft gewönne, so würde doch das moralische ohne Rettung dahinschwinden.

\section{Kritische Beleuchtung der Analytik der reinen praktischen Vernunft.}

Ich verstehe unter der kritischen Beleuchtung einer Wissenschaft oder eines Abschnitts derselben, der für sich ein System ausmacht, die Untersuchung und Rechtfertigung, warum sie gerade diese und keine andere systematische Form haben müsse, wenn man sie mit einem anderen System vergleicht, das ein ähnliches Erkenntnisvermögen zum Grunde hat. Nun hat praktische Vernunft -mit der spekulativen sofern einerlei Erkenntnisvermögen zum Grunde, als beide reine Vernunft sind. Also wird der Unterschied der systematischen Form der einen von der anderen durch Vergleichung beider bestimmt und Grund davon 20 angegeben werden müssen.

Die Analytik der reinen theoretischen Vernunft hat es mit der Erkenntnis der Gegenstände, die dem Verstande gegeben werden mögen, zu tun und mußte also von der Anschauung, mithin (weil diese jederzeit sinnlich ist) von der Sinnlichkeit anfangen, von da aber allererst $z u$ Begriffen (der Gegenstände dieser Anschauung) fortschreiten und durfte nur nach beider Voranschickung mit Grundsätzen endigen. Dagegen, weil praktische Vernunft es nicht mit Gegen- 80 ständen, sie zu erkennen, sondern mit ihrem eigenen Vermögen, jene (der Erkenntnis derselben gemäß) wirklich zu machen, d. i. es mit einem Willen zu tun hat, welcher eine Kausalität ist, sofern Vernunft den Bestimmungsgrund derselben enthält, da siefolglich kein Objekt der Anschauung, sondern (weil der Begriff der Kausalität jederzeit die Beziehung auf ein Gesetz enthält, welches die Existenz des Mannigfaltigen im Verhältnisse zueinander bestimmt) als praktische 
116 Erster Teil, I. Bach, 3. Hauptstück.

Vernunft, nur ein Gesetz derselben anzugeben hat: so muß eine Kritik der Analytik derselben, sofern sie eine praktische Vernunft sein soll (welches die eigentliche Aufgabe ist ${ }^{2}$ ), von der Möglichkeit

[90] praktischer Grundsätze a priori anfangen. Von da konnte sie allein zu Begriffen der Gegenstände einer praktischen Vernunft, nämlich denen des schlechthin Guten und Bösen, fortgehen, um sie jenen Grundsätzen gemäß allererst zu geben (denn diese sind vor

10 jenen Prinzipien als Gutes und Böses durch gar kein Erkenntnisvermögen zu geben möglich), und nur alsdann konnte allererst das letzte Hauptstück, nämlich das von dem Verhältnisse der reinen praktischen Vernunft zur Sinnlichkeit und von ihrem notwendigen, a priori zu erkennenden Einflusse auf dieselbe, d. i. vom moralischen Gefühle, den Teil beschließen. So teilte denn die Analytik der praktischen reinen Vernunft ganz analogisch mit der theoretischen den ganzen Umfang aller Bedingungen ihres Gebrauchs,

20 aber in umgekehrter Ordnung. Die Analytik der theoretischen reinen. Vernunft wurde in transzendentale Ästhetik und transzendentale Logik eingeteilt, die der praktischen umgekehrt in Logik und Ästhetik der reinen praktischen Vernunft (wenn es mir erlaubt ist, diese sonst gar nicht angemessenen Benennungen blo der Analogie wegen hier zu gebrauchen), die Logik wiederum dort in die Analytik der Begriffe und die der Grundsätze, hier in die der Grundsätze und Begriffe. Die Asthetik hatte dort noch zwei Teile, wegen 80 der doppelten Art einer sinnlichen Anschauung; hier wird die Sinnlichkeit gar nicht als Anschauungsfähigkeit, sondern bloß als Gefühl (das ein subjektiver Grund des Begehrens sein kann) betrachtet, und in Ansehung dessen verstattet die reine praktische Vernunft keine weitere Einteilung.

Auch daß diese Einteilung in zwei Teile mit deren Unterabteilung nicht wirklich (sowie man wohl im Anfange durch das Beispiel der ersteren verleitet wer-

a) Natorp vermutet: „Kritik derselben ... (welches die eigentliche Aufgabe der Analytik ist)"; Nolte schlägt vor „Kritik der" zu streiohon. 
den konnte zu versuchen) hier vorgenommen wurde, davon läßt sich auch der Grund gar wohl einsehen. Denn weil es reine Vernunft ist, die hier in ihrem praktischen Gebrauche, mithin von Grundsätzen a priori und nicht von empirischen Bestimmungsgründen ausgehend, betrachtet wird: so wird die Einteilung der Analytik der reinen praktischen Vernunft der eines Vernunftschlusses ähnlich ausfallen müssen, nämlich vom Allgemeinen im Obersatze (dem moralischen Prinzip) durch eine im Un'tersatze vorgenommene 10 Subsumtion möglicher Handlungen (als guter und böser) unter jenen zu dem Schlußsatze, nämlich der subjektiven Willensbestimmung (einem Interesse an dem praktisch möglichen Guten und der darauf gegründeten Maxime) fortgehend. Demjenigen, der sich von den in der Analytik vorkommenden Sätzen hat [91] überzeugen können, werden solche Vergleichungen Vergnügen machen; denn sie veranlassen mit Recht die Erwartung, es vielleicht dereinst bis zur Einsicht der Einheit des ganzen reinen Vernunftvermögens (des 20 theoretischen sowohl als praktischen) bringen und alles aus einem Prinzip ableiten zu können; welches das unvermeidliche Bedürfnis der menschlichen Vernunft ist, die nur in einer vollständig systematischen Einheit ihrer Erkenntnisse völlige Zufriedenheit findet.

Betrachten wir nun aber auch den Inhalt der Erkenntnis, die wir von einer reinen praktischen Vernunft und durch dieselbe haben können, wie ihn die Analytik derselben darlegt, so finden sich, bei einer merkwürdigen Analogie zwischen ihr und der theore- 80 tischen, nicht weniger merkwürdige Unterschiede. In Ansehung der theoretischen konnte ${ }^{a}$ ) das Vermögen einer reinen Vernunfterkenntnis a priori durch Beispiele aus Wissenschaften (bei denen man, da sie ihre Prinzipien auf so mancherlei Art durch methodischen Gebrauch auf die Probe stellen, nicht so leicht wie in der gemeinen Erkenntnis geheime Beimischung empirischer Erkenntnisgründe zu besorgen hat) ganz leicht und evident bewiesen werden. Aber daß reine Vernunft, ohne Beimischung irgend eines empirischen 40

a) Kant: „kס̋nte“; korr. Grillo. 
Bestimmungsgrundes, für sich allein auch praktisch sei: das mußte man aus dem gemeinsten praktischen Vernunftgebrauche dartun können, indem man den obersten praktischen Grundsatz als einen solchen, den jede natürliche Menschenvernunft als völlig a priori, von keinen sinnlichen Datis abhängend, für das oberste Gesetz seines Willens erkennt, beglaubigte. Man mußte ihn zuerst, der Reinigkeit seines Ursprungs nach, selbst im Urteile dieser gemeinen

10 Vernunft bewähren und rechtfertigen, ehe ihn noch die Wissenschaft in die Hände nehmen konnte, um Gebrauch von ihm zu machen, gleichsam als ein Faktum, das vor allem Vernünfteln über seine Möglichkeit und allen Folgerungen, die daraus zu ziehen sein möchten, vorhergeht. Aber dieser Umstand läßt sich auch aus dem kurz vorher Angeführten gar wohl erklären; weil praktische reine Vernunft notwendig von Grundsätzen anfangen muß, die also aller Wissenschaft als erste Data zum Grunde gelegt werden müssen und nicht 20 allererst aus ihr entspringen können. Diese Rechtfertigung der moralischen Prinzipien als Grundsätze einer reinen Vernunft konnte aber auch darum gar wohl und mit genugsamer Sicherheit durch bloße Berufung auf das Urteil des gemeinen Menschenverstandes geführt werden, weil sich alles Empirische, was sich als Bestimmungsgrund des Willens in unsere

[92] Maximen einschleichen möchte, durch das Gefühl des Vergnügens oder Schmerzens, das ihm, sofern als es Begierde erregt, notwendig anhängt, sofort kenntlich $30 \mathrm{macht}$, diesem aber jene reine praktische Vernunft geradezu widersteht, es in ihr Prinzip als Bedingung aufzunehmen. Die Ungleichartigkeit der Bestimmungsgründe (der empirischen und rationalen) wird durch diese Widerstrebung einer praktisch gesetzgebenden Vernunft wider alle sich einmengende Neigung durch eine eigentümliche Art von Empfind ung, welche aber nicht vor der Gesetzgebung der praktischen Vernunft vorhergeht, sondern vielmehr durch dieselbe allein und zwar als ein Zwang gewirkt wird, nämlich durch 40 das Gefühl einer Achtung, dergleichen kein Mensch für Neigungen hat, sie mögen sein welcher Art sie wollen, wohl aber für das Gesetz, so kenntlich gemacht und 
so gehoben und hervorstechend, daß keiner, auch der gemeinste Menschenverstand, in einem vorgelegten Beispiele nicht den Augenblick inne werden sollte, daß durch empirische Gründe des Wollens ihm zwar ihren Anreizen zu folgen geraten, niemals aber einem anderen als lediglich dem reinen praktischen Vernunftgesetze zu gehorchen zugemutet werden könne.

Die Unterscheidung der Glückseligkeitslehre von der Sittenlehre, in deren ersterer empirische Prinzipien das ganze Fundament, von der zweiten aber 10 auch nicht den mindesten Beisatz derselben ausmachen, ist nun in der Analytik der reinen praktischen Vernunft die erste und wichtigste ihr obliegende Beschäftigung, in der sie so pünktlich, ja wenn es auch hieße, peinlich verfahren muB, als je der Geometer in seinem Geschäfte. Es kommt aber dem Philosophen, der hier (wie jederzeit in der Vernunfterkenntnis durch bloße Begriffe, ohne Konstruktion derselben) mit größerer Schwierigkeit zu kämpfen hat, weil er keine Anschauung (reinema) Noumen) zum Grunde legen 20 kann, doch auch zustatten, daß er, beinahe wie der Chemist, zu aller Zeit ein Experiment mit jedes Menschen praktischer Vernunft anstellen kann, um den moralischen (reinen) Bestimmungsgrund vom empirischen zu unterscheiden; wenn er nämlich zu dem empirisch affizierten Willen (z. B. desjenigen, der gerne lügen möchte, weil er sich dadurch was erwerben kann) das moralische Gesetz (als Bestimmungsgrund) zusetzt. Es ist, als ob der Scheidekünstler der Solution der Kalkerde in ${ }^{b}$ ) Salzgeist Alkali zusetzt; der Salzgeist 30 verläßt sofort den Kalk, vereinigt sich mit dem Alkali, und jener wird zu Boden gestürzt. Ebenso haltet dem, der sonst ein ehrlicher Mann ist (oder sich doch diesmal nur in Gedanken in die Stelle eines ehrlichen Mannes versetzt), das moralische Gesetz vor, an dem er die Nichtswürdigkeit eines Lügners erkennt, - sofort verläßt seine praktische Vernunft (im Urteil über das, was von ihm geschehen sollte) den Vorteil, ver-

a) Natorp vermutet: ${ }_{n}$ seinem ${ }^{4}$; Adickes: ${ }_{n}$ von einem"; Kellermann (wohl am richtigsten): ${ }_{n}$ einem reinen ${ }^{\mu}$.

b) 2. Aufl.: ${ }_{n}$ im". 
einigt sich mit dem, was ihm die Achtung für seine eigene Person erhält (der Wahrhaftigkeit), und der Vorteil wird nun von jedermann, nachdem er von allem Anhängsel der Vernunft (welche nur gänzlich auf der Seito der Pflicht ist) abgesondert und gewaschen worden, gewogen, um mit der Vernunft noch wohl in anderen Fällen in Verbindung zu treten, nur nicht, wo er dem moralischen Gesetze, welches die Vernunft niemals verläßt, sondern sich innigst damit vereinigt, zuwider 10 sein könnte.

Aber diese Unterscheidung des Glückseligkeitsprinzips von dem der Sittlichkeit ist darum nicht sofort Entgegensetzung beider, und die reine praktische Vernunft will nicht, man solle die Ansprüche auf Glückseligkeit aufgeben, sondern nur, sobald von Pflicht die Rede ist, darauf gar nicht Rücksicht nehmen. Es kann sogar in gewissem Betracht Pflicht sein, für seine Glückseligkeit zu sorgen; teils weil sie (wozu Geschicklichkeit, Gesundheit, Reichtum gehört) Mittel

20 zur Erfüllung seiner Pflicht enthält, teils weil der Mangel derselben (z. B. Armut) Versuchungen enthält, seine Pflicht zu übertreten. Nur seine Glückseligkeit zu befördern, kann unmittelbar niemals Pflicht, noch weniger ein Prinzip aller Pflicht sein. Da nun alle Bestimmungsgründe des Willens, außer dem einigen reinen praktischen Vernunftgesetze (dem moralischen), insgesamt empirisch sind, als solche also zum Glückseligkeitsprinzip gehören, so müssen sie insgesamt vom obersten sittlichen Grundsatz abgesondert und ihm nie als $\mathrm{Be}-$ 30 dingung einverleibt werden, weil dieses ebensosehr allen sittlichen Wert, als empirische Beimischung zu geometrischen Grundsätzen alle mathematische Evidenz, das Vortrefflichste, was (nach Platos Urteile) die Mathematik an sich hat, und das selbst allem Nutzen derselben vorgeht, aufheben würde.

Statt der Deduktion des obersten Prinzips der reinen praktischen Vernunft, d. i. der Erklärung der Möglichkeit einer dergleichen Erkenntnis a priori, konnte aber ${ }^{2}$ ) nichts weiter angeführt werden, als daß, 40 wenn man dio Möglichkeit der Freiheit einer wirkenden

8) "oben" (Natorp)? 
Ursache einsähe, man auch nicht etwa bloß die Möglichkeit, sondern gar die Notwendigkeit des moralischen Gesetzes als obersten praktischen Gesetzes vernünftiger Wesen, denen man Freiheit der Kausalität ihres Willens beilegt, einsehen würde; weil beide Begriffe so unzertrennlich verbunden sind, daß man praktische Freiheit auch durch Unabhängigkeit des Willens von jedem anderen außer allein dem moralischen $\mathrm{Ge}-$ setze definieren könnte. Allein die Freiheit einer wirkenden Ursache, vornehmlich in der Sinnenwelt, kann ihrer Möglichkeit nach keineswegs eingesehen werden; glücklich! wenn wir nur, daß kein Beweis ihrer Unmöglichkeit stattfindet, hinreichend versichert werden können, und nun, durchs moralische Gesetz, welches dieselbe postuliert, genötigt, ebendadurch auch berechtigt werden, sie anzunehmen. Weil es indessen noch viele gibt, welche diese Freiheit noch immer glauben nach empirischen Prinzipien wie jedes andere Naturvermögen erklären zu können, und sie als psychologische Eigenschaft, deren Erklärung lediglich auf 20 einer genaueren Untersuchung der Natur der Seele und der Triebfeder des Willens ankäme, nicht als transzendentales Prädikat: der Kausalität eines Wesens, das zur Sinnenwelt gehört (wie es doch hierauf allein wirklich ankommt), betrachten und so die herrlich $\Theta$ Eröffnung, die uns durch reine praktische Vernunft vermittelst des moralischen Gesetzes widerfährt, nämlich die Eröffnung einer intelligibelen Welt durch Realisierung des sonst transzendenten Begriffs der Freiheit und hiermit das moralische Gesetz selbst, 30 welches durchaus keinen empirischen Bestimmungsgrund annimmt, aufheben: so wird es nötig sein, hier noch etwas zur Verwahrung wider dieses Blendwerk und der Darstellung des Empirismus in der ganzen Blöße seiner Seichtigkeit anzuführen.

Der Begriff der Kausalität als Naturnotwendig keit zum Unterschiede derselben als Freiheit betrifft nur die Existenz der Dinge, sofern sie in der Zeit bestimmbar ist, folglich als Erscheinungen im Gegensatze ihrer Kausalität als Dinge an sich selbst. 40 Nimmt man nun die Bestimmungen der Existenz der Dinge in der Zeit für Bestimmungen der Dinge an sich 
selbst (welches die gewöhnlichste Vorstellungsart ist), so läßt sich die Notwendigkeit $\mathrm{im}^{\mathrm{a}}$ ) Kausalverhältnisse mit der Freiheit auf keinerlei Weise vereinigen; sondern sie sind einander kontradiktorisch entgegengesetzt. Denn aus der ersteren folgt, daß eine jede Begebenheit, folglich auch jede Handlung, die in einem Zeitpunkte vorgeht, unter der Bedingung dessen, was in der vorhergehenden Zeit war, notwendig sei. Da nun die vergangene Zeit nicht mehr in meiner Gewalt

10 ist, so muß jede Handlung, die ich ausübe, durch bestimmende Gründe, die nicht in meiner Gewalt sind, notwendig sein, d. i. ich bin in dem Zeitpunkte, darin ich handle, niemals frei. Ja, wenn ich gleich mein ganzes Dasein als unabhängig von irgend einer [95] fremden Ursache (etwa von Gott) annähme, sodaß die Bestimmungsgründe meiner Kausalität, sogar meiner ganzen Existenz gar nicht außer mir wären, so würde dieses jene Naturnotwendigkeit doch nicht im mindesten in Freiheit verwandeln. Denn in jedem Zeitpunkte

20 stehe ich doch immer unter der Notwendigkeit, durch das zum Handeln bestimmt zu sein, was nicht in meiner Ge walt ist, und die a parte priori unendliche Reihe der Begebenheiten, die ich immer nur nach einer schon vorherbestimmten Ordnung fortsetzen, nirgend von selbst anfangen' würde, wäre eine stetige Naturkette, meine Kausalität also niemals Freiheit.

Will man also einem Wesen, dessen Dasein in der Zeit bestimmt ist, Freiheit beilegen, so kann man es sofern wenigstens rom Gesetze der Naturnotwendig-

30 keit aller Begebenheiten in seiner Existenz, mithin auch seiner Handlungen nicht ausnehmen; denn das wäre soviel, als es dem blinden Ungefähr übergeben. $\mathrm{Da}$ dieses Gesetz aber unvermeidlich alle Kausalität der Dinge, sofern ihr Dasein in der Zeit bestimmbar ist, betrifft, so würde, wenn dieses die Art wäre, wonach man sich auch das Dasein dieser Dinge an sich selbst vorzustellen hätte, die Freiheit als ein nichtiger und unmöglicher Begriff verworfen werden müssen. Folglich, wenn man sie noch retten will, so 40 bleibt kein Weg übrig, als das Dasein eines Dinges,

a) Kant: „in“; korr. Rosenkranz, Hartenstein. 
sofern es in der Zeit bestimmbar ist, folglich auch die Kausalität nach dem Gesetze der Naturnotwendigkeit bloß der Erscheinung, die Freiheit aber ebendemselben Wesen als Dinge an sich selbst beizulegen. So ist es allerdings unvermeidlich, wenn man beide einander widerwärtigen Begriffe zugleich erhalten will; allein in der Anwendung, wenn man sie als in einer und derselben Handlung vereinigt und also diese Vereinigung selbst erklären will, tun sich doch große Schwierigkeiten hervor, die eine solche 10 Vereinigung untunlich $\mathrm{zu}$ machen scheinen.

Wenn ich von einem Menschen, der einen Diebstahl verübt, sage: diese Tat sei nach dem Naturgesetze der Kausalität aus den Bestimmungsgründen der vorhergehenden Zeit ein notwendiger Erfolg, so war es unmöglich, daß sie hat unterbleiben können; wie kann dann die Beurteilung nach dem moralischen Gesetze hierin eine Änderung machen und voraussetzen, daß sie doch habe unterlassen werden können, weil das Gesetz sagt, sie hätte unterlassen werden sollen, d. i. 20 wie kann derjenige in demselben Zeitpunkte in Absicht auf dieselbe Handlung ganz frei heißen, in welchem und in derselben Absicht er doch unter einer unvermeidlichen Naturnotwendigkeit steht? Eine Ausflucht [96] darin suchen, daß man bloß die Art der Bestimmungsgründe seiner Kausalität nach dem Naturgesetze einem komparativen Begriffe von Freiheit anpaßt (nach welchem das bisweilen freie Wirkung heißt, davon der bestimmende Naturgrund innerlich im wirkenden Wesen liegt, z. B. das, was ein geworfener Körper 30 verrichtet, wenn er in freier Bewegung ist, da man das Wort Freiheit braucht, weil er, während daß er im Fluge ist, nicht von außen wodurch getrieben wird, oder wie wir die Bewegung einer Uhr auch eine freie Bewegung nennen, weil sie ihren Zeiger selbst treibt, der also nicht äußerlich geschoben werden darf, ebenso die Handlungen des Menschen, ob sie gleich durch ihre Bestimmungsgründe, die in der Zeit vorhergehen, notwendig sind, dennoch frei nennen, weil es doch innere, durch unsere eigenen Kräfte hervorge- 40 brachte Vorstellungen, dadurch nach veranlassenden Umiständen erzeugte Begierden und mithin nach un- 
124 Erster Teil, 1. Buch, B. Hanptstück.

serem eigenen Belieben bewirkte Handlungen sind), ist ein elender Behelf, womit sich noch immer einige hinhalten lassen und so jenes schwere Problem mit einer kleinen Wortklauberei aufgelöst zu haben meinen, an dessen Auflösung Jahrtausende vergeblich gearbeitet haben, die daher wohl schwerlich so ganz auf der Oberfläche gefunden werden dürfte. Es kommt nämlich bei der Frage nach derjenigen Freiheit, die allen moralischen Gesetzen und der ihnen gemäßen $\mathrm{Zu}$ -

10 rechnung zum Grunde gelegt werden muß, darauf gar nicht an, ob die nach einem Naturgesetze bestimmte Kausalität durch Bestimmungsgründe, die im Subjekte oder a u Ber ihm liegen, und im ersteren Fall, ob sie durch Instinkt oder mit Vernunft gedachte Bestimmungsgründe notwendig sei; wenn diese bestimmenden Vorstellungen nach dem Geständnisse eben dieser Männer selbst den Grund ihrer Existenz doch in der Zeit und zwar dem vorigen Zustand $\theta$ haben, dieser aber wieder in einem vorhergehenden usw., so mögen 20 sie, diese Bestimmungen, immer innerlich sein, sie mögen psychologische und nicht mechanische Kausalität haben, d. i. durch Vorstellungen und nicht durch körperliche Bewegung Handlung hervorbringen: so sind es immer Beśstimmungsgründe der Kausalität eines Wesens, sofern sein Dasein in der Zeit bestimmbar ist, mithin unter notwendig machenden Bedingungen der vergangenen Zeit, die also, wenn das Subjekt handeln soll, nicht mehr in seiner Gewalt sind, die also zwar psychologische Freiheit (wenn man ja dieses 30 Wort von einer bloß inneren Verkettung der Vorstellungen der Seele brauchen will), aber doch Natur[97] notwendigkeit bei sich führen, mithin keine transzendentale Freiheit übrig lassen, welche als Unabhängigkeit von allem Empirischen und also von der Natur überhaupt gedacht werden muß, sie mag nun als $\left.{ }^{\mathrm{a}}\right)$ Gegenstand des inneren Sinnes bloB in der Zeit, oder auch der ${ }^{b}$ ) äußeren Sinne im Raume und der Zeit zugleich betrachtet werden, ohne welche Freiheit (in der letzteren eigentlichen Bedeutung), die allein

a) "als" fehlt bei Kant.

b) „der" Zusatz Hartenstein.. 
a priori praktisch ist, kein moralisches Gesetz, keine Zurechnung nach demselben möglich ist. Eben um deswillen kann man auch alle Notwendigkeit der Begebenheiten in der Zeit nach dem Naturgesetze der Kausalität den Mechanismus der Natur nennen, ob man gleich darunter nicht versteht, da $\$$ Dinge, die ihm unterworfen sind, wirklich materielle Maschinen sein müßten. Hier wird nur auf die Notwendigkeit der Verknüpfung der Begebenheiten in einer Zeitreihe, sowie sie sich nach dem Naturgesetze entwickelt, gesehen, man mag nun das Subjekt, in welchem dieser Ablauf geschieht, Automaton materiale, da das Maschinenwesen durch Materie, oder mit Leibniz spirituale, da es durch Vorstellungen betrieben wird, nennen, und wenn die Freiheit unseres Willens keine andere als die letztere (etwa die psychologische und komparative, nicht transzendentale, d. i. absolute, zugleich) wäre, so würde sie im Grunde nichts besser als die Freiheit eines Bratenwenders sein, der auch, wenn er einmal aufgezogen worden, von selbst seine Bewegungen verrichtet. 20

Um nun den scheinbaren Widerspruch zwischen Naturmechanismus und Freiheit in einundderselben Handlung $a^{2}$ ) dem vorgelegten Falle aufzuheben, muß man sich an das erinnern, was in der Kritik der reinen Vernunft gesagt war oder daraus folgt: daß die Naturnotwendigkeit, welche mit der Freiheit des Subjekts nicht zusammen bestehen kann, bloß den Bestimmungen desjenigen Dinges anhängt, das unter Zeitbedingungen steht, folglich nur denen ${ }^{b}$ ) des handelnden Subjekts als Erscheinung, daß also sofern die Bestimmungsgründe 80 einer jeden Handlung desselben in demjenigen liegen, was zur vergangenen Zeit gehört und nicht $\mathrm{mehr}$ in seiner Gewalt ist (wozu auch seine schon begangenen Taten und der ihm dadurch bestimmbare Charakter in seinen eigenen Augen, als Phänomens, gezählt werden müssen). Aber ebendasselbe Subjekt, das sich anderseits auch seiner als Dinges an sich selbst bewußt ist, betrachtet auch sein Dasein, sofern es nicht unter Zeitbedingungen steht, sich selbst

a) ,in"? [Vorländer].

b) Kant: „den“; korr. Vorländer (auch Akad.-Ausg.). 


\section{Erster Teil, I. Buch, 3. Hauptstück.}

aber nur als bestimmbar durch Gesetze, die es sich durch Vernunft selbst gibt, und in diesem seinem Dasein ist ihm nichts vorhergehend vor seiner Willensbestim-

[98] mung, sondern jede Handlung und überhaupt jede dem inneren Sinne gemä $\beta$ wechselnde Bestimmung seines Daseins, selbst die ganze Reihenfolge seiner Existenz als Sinnenwesen, ist im Bewußtsein seiner intelligibelen Existenz nichts als Folge, niemals aber als Bestimmungsgrund seiner Kausalität als Noumens, anzu-

10 sehen. In diesem Betracht nun kann das vernünftige Wesen von einer jeden gesetzwidrigen Handlung, die es verübt, ob sie gleich als Erscheinung in dem Vergangenen hinreichend bestimmt und sofern unausbleiblich nottwendig ist, mit Recht sagen, $\mathrm{da} ß \mathrm{er}^{\mathrm{a}}$ ) sie hätte unterlassen kö̉nnen; denn sie mit allem Vergangenen, das sie bestimmt, gehört zu einem einzigen Phänomen seines Charakters, den er ${ }^{2}$ ) sich selbst verschafft, und nach welchem $\mathrm{er}^{a}$ ) sich, als einer von aller Sinnlichkeit unabhängigen Ursache, die Kausalität-jener Er-

20 scheinungen selbst zurechnet.

Hiermit stimmen auch die Richteraussprüche desjenigen wundersamen Vermögens in uns, welches wir Gewissen nennen, vollkommen überein. Ein Mensch mag künsteln, soviel als er will, um ein gesetzwidriges Betragen, dessen er sich erinnert, sich als unvorsätzliches Versehen, als bloße Unbehutsamkeit, die man niemals gänzlich vermeiden kann, folglich als etwas, worin er vom Strom der Naturnotwendigkeit fortgerissen wäre, vorzumalen und sich darüber für.

30 schuldfrei $\mathrm{zu}$ erklären: sa findet er doch, daß der Advokat, der zu seinem Vorteil spricht, den Ankläger in ihm keineswegs zum Verstummen bringen könne, wenn er sich bewußt ist, daß er zu der Zeit, als er das Unrecht verübte, nur bei Sinnen, d. i. im Gebrauche seiner Freiheit war, und gleichwohl erklärt er sich sein Vergehen aus gewisser übler, durch allmähliche Vernachlässigung der Achtsamkeit auf sich selbst zugezogener Gewohnheit bis auf den Grad, daß er es als eine natürliche Folge derselben ansehen kann, 40 ohne daß dieses ihn gleichwohl wider den Selbsttadel

a) eigentlich: „es" (sc. das vernünftige Wesen). 
und den Verweis sichern kann, den er sich selbst macht. Darauf gründet sich denn auch die Reue über eine längst begangene Tat bei jeder Erinnerung derselben; eine schmerzhafte, durch moralische Gesinnung gewirkte Empfindung, die sofern praktisch leer ist, als sie nicht dazu dienen kann, das Geschehene ungeschehen zu machen und sogar ungereimt sein würde (wie Priestley als ein echter, konsequent verfahrender Fatalist sie auch dafür erklärt, und in Ansehung welcher Offenherzigkeit er mehr Beifall ver- 10 dient als diejenigen, welche, indem sie den Mechanismus des Willens in der Tat, die Freiheit desselben aber mit Worten behaupten, noch immer dafür gehalten sein wollen, daß sie jene, ohne doch die Möglichkeit einer solchen Zurechnung begreiflich zu machen, in [99] ihrem synkretistischen System mit einschließen), aber als Schmerz doch ganz rechtmäßig ist, weil die Vernunft, wenn es auf das Gesetz unserer intelligibelen Existenz (das moralische) ankommt, keinen Zeitunterschied anerkennt und nur fragt, ob die Begebenheit 20 mir als Tat angehöre, alsdann aber immer dieselbe Empfindung damit moralisch verknüpft, sie mag jetzt geschehen oder vorlängst geschehen sein. Denn das Sinnenleben hat in Ansehung des intelligibelen Bewußtseins seines Daseins (der Freiheit) absolute Einheit eines Phänomens, welches, sofern es bloß Erscheinungen von der Gesinnung, die das moralische Gesetz angeht, (von dem Charakter) enthält, nicht nach der Naturnotwendigkeit, die ihm als Erscheinung zukommt, sondern nach der absoluten Spontaneität der $\mathbf{8 0}$ Freiheit beurteilt werden muB. Man kann also einräumen, daß; wenn es für uns möglich wäre, in eines Menschen Denkungsart, sowie sie sich durch innere sowohl als äußere Handlungen zeigt, so tiefe Einsicht zu haben, daß jede, auch die mindeste Triebfeder dazu uns bekannt würde, imgleichen alle auf diese wirkenden äußeren Veranlassungen, man eines Menschen Verhalten auf die Zukunft mit Gewißheit sowie eine Mond- oder Sonnenfinsternis, ausrechnen könnte, und dennoch dabei behaupten, daß der Mensch frei sei. Wenn wir nämlich' noch eines anderen Blicks (der uns aber freilich gar nicht verliehen ist, son- 
dern an dessen Statt wir nur den Vernunftbegriff haben), nämlich einer intellektuellen Anschauung desselben Subjekts fähig wären, so würden wir doch inne werden, daß diese ganze Kette von Erscheinungen in Ansehung dessen, was nur immer das moralische Gesetz angehen kann, von der Spontaneität des Subjekts als Dinges an sich selbst abhängt, von deren Bestimmung sich gar keine physische Erklärung geben läßt. In Ermangelung dieser Anschauung versichert uns

10 das moralische Gesetz diesen Unterschied der Beziehung unserer Handlungen als Erscheinungen auf das Sinnenwesen unseres Subjekts, von derjenigen, dadurch dieses Sinnenwesen selbst auf das intelligibele Substrat in uns bezogen wird. - In dieser Rücksicht, die unserer Vernunft natürlich, obgleich unerklärlich ist, lassen sich auch Beurteilungen rechtfertigen, die, mit aller Gewissenhaftigkeit gefällt, dennoch dem ersten Anscheine nach aller Billigkeit ganz $\mathrm{zu}$ widerstreiten scheinen. Es gibt Fälle, wo Menschen von Kindheit

20 auf, selbst unter einer Erziehung, die mit der ihrigen zugleich anderen ersprießlich war, dennoch so frühe Bosheit zeigen und so bis in ihre Mannesjahre zu steigern fortfahren, daß man sie für geborene Bösewichter und gänzlich, was die Denkungsart betrifft,

[100] für unbesserlich hält, gleichwohl aber sie wegen ihres Tuns und Lassens ebenso richtet, ihnen ihre Verbrechen ebenso als Schuld verweist, ja sie (die Kinder) selbst diese Verweise so ganz gegründet finden, als ob sie, ungeachtet der ihnen beigemessenen hoffnungslosen

30 Naturbeschaffenheit ihres Gemüts, ebenso verantwortlich blieben als jeder andere Mensch. Dieses würde nicht geschehen können, wenn wir nicht voraussetzten, da $\beta$ alles, was aus seiner Willkür entspringt (wie ohne Zweifel jede vorsätzlich verübte Handlung), eine freie Kausalität zum Grunde habe, welche von der frühen Jugend an ihren Charakter in ihren Erscheinungen (den Handlungen) ausdrückt, die wegen der Gleichförmigkeit des Verhaltens einen Naturzusammenhang kenntlich machen, der aber nicht die arge

40 Beschaffenheit des Willens notwendig macht, sondern vielmehr die Folge der freiwillig angenommenen bösen und unwandelbaren Grundsätze ist, welche ihn 
nur noch um desto verwerflicher und strafwürdiger machen.

Aber noch steht eine Schwierigkeit der Freiheit bevor, sofern sie mit dem Naturmechanismus in einem Wesen, das zur Sinnenwelt gehört, vereinigt werden soll: eine Schwierigkeit, die, selbst nachdem alles bisherige eingewilligt worden, der Freiheit dennoch mit ihrem gänzlichen Untergange droht. Aber bei dieser Gefahr gibt ein Umstand doch zugleich Hoffnung zu einem für die Behauptung der Freiheit noch glück- 10 lichen Ausgange, nämlich daß dieselbe Schwierigkeit viel stärker (in der Tat, wie wir bald sehen werden, allein) das System drückt, in welchem die in Zeit und Raum bestimmbare Existenz für die Existenz der Ding $\Theta$ an sich selbst gehalten wird, sie uns also nicht nötigt, unsere vornehmste Voraussetzung von der Idealität der Zeit als bloßer Form sinnlicher Anschauung, folglich als bloßer Vorstellungsart, die dem Subjekte als zur Sinnenwelt gehörig eigen ist, aufzugeben ${ }^{2}$ ) und also nur erfordert, sie mit dieser Idee zu vereinigen. 20

Wenn man uns nämlich auch einräumt, daß das intelligibele Subjekt in Ansehung einer gegebenen Handlung noch frei sein kann, obgleich es als Subjekt, das auch zur Sinnenwelt gehörig, in Ansehung derselben mechanisch bedingt ist, so scheint es doch', man müsse, sobald man annimmt, Gott als allgemeines Urwesen sei die Ursache auch der Existenz der Substanz (ein Satz, der niemals aufgegeben werden darf, ohne den Begriff von Gott als Wesen aller Wesen und hiermit seine Allgenugsamkeit, auf die alles in der 30 Theologie ankommt, zugleich mit aufzugeben), auch ${ }^{\text {b) }}$ einräumen: die Handlungen des Menschen haben in demjenigen ihren bestimmenden Grund, was gänzlich a ußer ihrer Gewalt ist, nämlich in der Kausalität eines von ihm unterschiedenen höchsten Wesens, von welchem das Dasein des ersteren und die ganze Bestimmung seiner Kausalität ganz und gar abhängt. In der Tat: wären die Handlungen des Menschen, sowie

a) Kant: „abzugehen"; korr. Hartenstein; oder „von anserer ... abzugehen" (Natorp)?

b) "auch" fehlt in der 2. Auflage.

Kant, Kritik der prakt. Vernunft. 
sie zu seinen Bestimmungen in der Zeit gehören, nicht bloße Bestimmungen desselben als Erscheinung, sondern als Dinges an sich selbst, so würde die Freiheit nicht zu retten sein. Der Mensch wäre Marionette oder ein Vaucansonsches ${ }^{a}$ ) Automat, gezimmert und aufgezogen von dem obersten Meister aller Kunstwerke, und das Selbstbewußtsein würde es zwar zu einem denkenden Automate machen, in welchem aber das Bewußtsein seiner Spontaneität, wenn sie für Freiheit 10 gehalten wird, bloße Täuschung wäre, indem sie nur komparativ so genannt zu werden verdient, weil die nächsten bestimmenden Ursachen seiner Bewegung und eine lange Reihe derselben zu ihren bestimmenden Ursachen hinauf zwar innerlich sind, die letzte und höchste aber doch gänzlich in einer fremden Hand angetroffen wird. Daher sehe ich nicht ab, wie diejenigen, welche noch immer dabei beharren, Zeit und Raum für zum Dasein der Dinge an sich selbst gehörige Bestimmungen anzusehen, hier die Fatalität der

20 Handlungen vermeiden wollen; oder, wenn sie so geradezu (wie der sonst scharfsinnige Mendelssohnb) tat) beide nur als zur Existenz endlicher und abgeleiteter Wesen, aber nicht zu der des unendlichen Urwesens notwendig gehörende Bedingungen einräumen, sich rechtfertigen wollen, woher sie diese Befugnis nehmen, einen solchen Unterschied zu machen; sogar wie sie auch nur dem Widerspruche ausweichen wollen, den sie begehen, wenn sie das Dasein in der Zeit als den endlichen Dingen an sich notwendig an30 hängende Bestimmung ansehen, da Gott die Ursache dieses Daseins ist, er aber doch nicht die Ursache der Zeit (oder des Raums) selbst sein kann (weil diese als notwendige Bedingung a priori dem Dasein der Dinge vorausgesetzt sein muß), seine Kausalität folglich in Ansehung der Existenz dieser Dinge selbst der Zeit nach bedingt sein muß, wobei nun alle die Widersprüche gegen die Begriffe seiner Unendlichkeit und Unabhängigkeit unvermeidlich eintreten müssen. Hin-

a) A. von Vaucanson aus Grenoble zeigte 1738 zuerst in Paris automatische Figuren: einen Flötenspieler, einen Klarinettenbläser und eine fressende Ente.

b) In seinen Morgenstunden oder über das Dasein Gottes (1785). 
gegen ist es uns ganz leicht, die Bestimmung der göttlichen Existenz als unabhängig von allen Zeitbedingungen, zum Unterschiede von der eines Wesens der Sinnenwelt, als die Existenz eines Wesens an sich selbst von der eines Dinges in der Erscheinung zu unterscheiden. Daher, wenn man jene Idealität der Zeit und des Raums nicht annimmt, nur allein der Spinozismus übrig bleibt, in welchem Raum und Zeit wesentliche Bestimmungen des Urwesens selbst sind, die von ihm abhängigen Dinge aber (also 10 auch wir selbst) nicht Substanzen, sondern bloß ihm inhärierende Akzidenzen sind; weil, wenn diese Dinge bloß als seine Wirkungen in der Zeit existieren, welche die Bedingung ihrer Existenz an sich wäre, auch die Handlungen dieser Wesen bloß seine Handlungen sein müßten, die er irgendwo und irgendwann ausübte. Daher schließt der Spinozismus, unerachtet der Ungereimtheit seiner Grundidee, doch weit bündiger, als es nach der Schöpfungstheorie geschehen kann, wenn die für Substanzen angenommenen und an 20 sich in der Zeit existierenden Wesen als ${ }^{2}$ ) Wirkungen einer obersten Ursache und doch nicht zugleich $\mathrm{zu} \mathrm{ihm}$ und seiner Handlung gehörigb), sondern für sich als Substanzen angesehen werden.

Die Auflösung obgedachter Schwierigkeit geschieht kurz und einleuchtend auf folgende Art. Wenn die Existenz in der Zeit eine bloß sinnliche Vorstellungsart der denkenden Wesen in der Welt ist, folglich sie als Dinge an sich selbst nicht angeht: so ist die Schöpfung dieser Wesen eine Schöpfung der 30 Dinge an sich selbst, weil der Begriff einer Schöpfung nicht zu der sinnlichen Vorstellungsart der Existenz und zur Kausalität gehört, sondern nur auf Noumenen bezogen werden kann. Folglich, wenn ich von Wesen in der Sinnenwelt sage: sie sind erschaffen, so betrachte ich sie sofern als Noumenen. Sowie es also ein Widerspruch wäre, zu sagen, Gott sei ein Schöpfer von Erscheinungen, so ist ès auch ein Widerspruch, zu sagen, er sei als Schöpfer Ursache der Handlungen in der

a) „als" Zusatz Hartensteins.

b) "gehörig" Zusatz Hartensteins. 
Sinnenwelt, mithin als Erscheinungen, wenn er gleich Ursache des Daseins der handelnden Wesen (als Noumenen) ist. Ist es nun möglich (wenn wir nur das Dasein in der Zeit für etwas, was bloß von Erscheinungen, nicht von Dingen an sich selbst gilt, annehmen), die Freiheit unbeschadet dem Naturmechanismus der Handlungen als Erscheinungen zu behaupten, so kann, daß die handelnden Wesen Geschöpfe sind, nicht die mindeste Änderung hierin machen, weil die

10 Schöpfung ihre intelligibele, aber nicht sensibele Existenz betrifft, und also nicht als Bestimmungsgrund der Erscheinungen angesehen werden kann; welches aber ganz anders ausfallen würde, wenn die Weltwesen als Dinge an sich selbst in der Zeit existierten, da der Schöpfer der Substanz zugleich der Urheber des ganzen Maschinenwesens an dieser Substanz sein würde.

Von so großer Wichtigkeit ist die in der Kritik

[103] der reinen spekulativen Vernunft verrichtete Absonderung der Zeit (sowie des Raums) von der Existenz 20 der Dinge an sich selbst.

Die hier vorgetragene Auflösung der Schwierigkeit hat aber, wird man sagen, doch viel Schweres in sich und ist einer hellen Darstellung kaum empfänglich. Allein ist denn jede andere, die man versucht hat oder versuchen mag, leichter und faßlicher? Eher möchte man sagen, die dogmatischen Lehrer der Metaphysik hätten mehr ihre Verschmitztheit als Aufrichtigkeit darin bewiesen, daß sie diesen schwierigen Punkt soweit wie möglich aus den Augen brachten,

30 in der Hoffnung, daß, wenn sie davon gar nicht sprächen, auch wohl niemand leichtlich an ihn denken würde. Wenn einer Wissenschaft geholfen werden soll, so müssen alle Schwierigkeiten aufgedeckt und sogar diejenigen aufgesucht werden, die ihr noch so ingeheim im Wege liegen; denn jede derselben ruft ein Hilfsmittel auf, welches, ohne der Wissenschaft einen Zuwachs, es sei an Umfang oder an Bestimmtheit, zu verschaffen, nicht gefunden werden kann, wodurch also selbst die Hindernisse Beförderungsmittel

40 der Gründlichkeit der Wissenschaft werden. Dagegen, werden die Schwierigkeiten absichtlich verdeckt oder bloß durch Palliativmittel gehoben, so brechen sie 
über kurz oder lang in unheilbare Ubel aus, welche die Wissenschaft in einem gänzlichen Skeptizismus zugrunde richten.

$\mathrm{Da}$ es eigentlich der Begriff der Freiheit ist, der unter allen Ideen der reinen spekulativen Vernunft allein so große Erweiterung im Felde des Ubersinnlichen, wenngleich nur in Ansehung der praktischen Erkenntnis, verschafft, so frage ich mich: woher denn ihm ausschliebungsweise eine so grobe Fruchtbarkeit zuteil geworden sei, indessen die 10 übrigen zwar die leere Stelle für reine mögliche Verstandeswesen bezeichnen, den Begriff von ihnen aber durch nichts bestimmen können. Ich begreife bald, daß, da ich nichts ohne Kategorie denken kann, diese auch in der Idee der Vernunft von der Freiheit, mit der ich mich beschäftige, zuerst müsse aufgesucht werden, welche hier die Kategorie der Kausalität ist, und $d a \beta^{a}$ ), wenngleich dem Vernunftbegriffe der Freiheit als überschwenglichem Begriffe keine korrespondierende Anschauung untergelegt werden 20 kann, dennoch dem Verstandesbegriffe (der Kausalität), für dessen Synthesis jener das Unbedingte fordert, zuvor eine sinnliche Anschauung gegeben werden müsse, dadurch ihm zuerst die objektive Realität gesichert wird. Nun sind alle Kategorien in zwei Klassen, die mathematischen, welche bloß auf die Einheit der Synthesis in der Vorstellung der Objekte, und die dynamischen, welche auf die in der Vorstellung der Existenz der Objekte gehen, eingeteilt. Die ersteren (die der Größe und der Qualität) ent- 30 halten jederzeit eine Synthesis des Gleichartigen, in welcher das Unbedingte zu dem in der sinnlichen Anschauung gegebenen Bedingten in Raum und Zeit, da es selbst wiederum zum Raume und der Zeit gehören und also immer wiederum bedingt ${ }^{b}$ ) sein müßte ${ }^{\circ}$ ), gar nicht kann gefunden werden; daher auch in der Dia-

a) Kant: „daß ich"; korr. Rosenkranz, Hartenstein.

b) Kant: ",wieder unbedingt"; korr. Natorp.

c) Kant: „mußte“; korr. Hartenstein", Natorp. 
lektik der reinen theoretischen Vernunft die einander entgegengesetzten Arten, das Unbedingte und die Totalität der Bedingungen für sie zu finden, beide falsch waren. Die Kategorien der zweiten Klasse (die der Kausalität und der Notwendigkeit eines Dinges) erforderten diese Gleichartigkeit (des Bedingten und der Bedingung in der Synthesis) gar nicht, weil hier nicht die Anschauung, wie sie aus einem Mannigfaltigen in ihr zusammengesetzt, sondern nur wie die Existenz $10 \mathrm{des} \mathrm{ihr}$ korrespondierenden bedingten Gegenstandes zu der Existenz der Bedingung (im Verstande als damit verknüpft) hinzukomme, vorgestellt werden sollte $\left.{ }^{a}\right)$; und da war es erlaubt, zu dem durchgängig Bedingten in der Sinnenwelt (sowohl in Ansehung der Kausalität als des zufälligen Daseins der Dinge selbst) das Unbedingte, obzwar übrigens unbestimmt, in der intelligibelen Welt zu setzen und die Synthesis transzendent zu machen; daher denn auch in der Dialektik der reinen spekulativen Vernunft sich fand, daß beide dem

20 Scheine nach einander entgegengesetzte Arten, das Unbedingte zum Bedingten zu finden, z. B. in der Synthesis der Kausalität zum Bedingten in der Reihe der Ursachen und Wirkungen der Sinnenwelt die Kausalität, die weiter nicht sinnlich bedingt ist, zu denken, sich in der Tat nicht widerspreche, und daß dieselbe Handlung, die als zur Sinnenwelt gehörig jederzeit sinnlich bedingt, d. i. mechanisch notwendig ist, doch zugleich auch, als zur Kausalität des handelnden Wesens, sofern es zur intelligibelen Welt gehörig istb), 30 eine sinnlich unbedingte Kausalität zum Grunde haben, mithin als frei gedacht werden könne. Nun kam es bloß darauf an, daß dieses Können in ein Sein verwandelt würde, d. i. daß man in einem wirklichen Falle gleichsam durch ein Faktum beweisen könne, daß gewisse Handlungen eine solche Kausalität (die intellektuelle, sinnlich unbedingte) voraussetzen, sie mögen nun wirklich oder auch nur geboten, d. i. objektiv praktisch notwendig sein. An wirklich in der Erfahrung gegebenen Handlungen, als Begebenheiten

a) Kant: „soll“; korr. Hartenstein.

b) Hinter "gehorig ist" hinzuzudenken: „gehorig". 
der Sinnenwelt, konnten wir diese Verknüpfung nicht [105] anzutreffen hoffen, weil die Kausalität durch Freiheit immer außer der Sinnenwelt im Intelligibelen gesucht werden muß. Andere Dinge außer den Sinnenwesen sind uns aber zur Wahrnehmung und Beobachtung nicht gegeben. Also blieb. nichts übrig, als daß etwa ein unwidersprechlicher und zwar objektiver Grundsatz der Kausalität, welcher alle sinnliche Bedingung von ihrer Bestimmung ausschließt, d. i. ein Grundsatz, in welchem die Vernunft sich nicht weiter auf etwas an- 10 deres als Bestimmungsgrund in Ansehung der Kausalität beruft, sondern den sie durch jenen Grundsatz schon selbst enthält, und wo sie also als reine Vernunft selbst praktisch ist, gefunden werde. Dieser Grundsatz aber bedarf keines Suchens und keiner Erfindung; er ist längst in aller Menschen Vernunft gewesen und ihrem Wesen einverleibt und ist der Grundsatz der Sittlichkeit. Also ist jene unbedingte Kausalität und das Vermögen derselben, die Freiheit, mit dieser aber ein Wesen (ich selber), welches zur Sinnen- 20 welt gehört, doch zugleich als zur intelligibelen gehörig nicht bloß unbestimmt und problematisch gedacht (welches schon die spekulative Vernunft als tunlich ausmitteln konnte), sondern sogar in Ansehung des Gesetzes ihrer Kausalität bestimmt und assertorisch erkannt, und so uns die Wirklichkeit der intelligibelen Welt und zwar in praktischer Rücksicht bestimmt gegeben worden, und diese Bestimmung, die in theoretischer Absicht transzendent (überschwenglich) sein würde, ist in praktischer 80 immanent. Dergleichen Schritt aber konnten wir in Ansehung der zweiten dynamischen Idee, nämlich der eines notwendigen Wesens, nicht tun. Wir konnten $\mathrm{zu}$ ihm aus der Sinnenwelt ohne Vermittelung der ersteren dynamischen Idee nicht hinaufkommen. Denn wollten wir es versuchen, so müßten wir den Sprung gewagt haben, alles das, was uns gegeben ist, zu verlassen und uns zu dem hinzuschwingen, wovon uns auch nichts gegeben ist, wodurch w:= die Verknüpfung eines solchen intelligibelen Wesens mit der 40 Sinnenwelt vermitteln könnten (weil das notwendige Wesen als außer uns gegeben erkannt werden sollte); 
welches dagegen in Ansehung unseres eigenen Subjekts, sofern es sich durch das moralische Gesetz einerseits als intelligibeles Wesen (vermöge der Freiheit) bestimmt, andererseits als nach dieser $\mathrm{Be}-$ stimmung in der Sinnenwelt tätig selbst erkennt, wie jetzt der Augenschein dartut, ganz wohl möglich ist. Der einzige Begriff der Freiheit verstattet es, daß wir nicht außer uns hinausgehen dürfen, um das Unbedingte und Intelligibele zu dem Bedingten und Sinnlichen zu

[106] 10 finden. Denn es ist unsere Vernunft selber, die sich durchs höchste und unbedingte praktisch $\theta$ Gesetz und das Wesen, das sich dieses Gesetzes bewußt ist (unsere eigene Person), als zur reinen Verstandeswelt gehörig und zwar sogar mit Bestimmung der Art, wie es als ein solches tätig sein könne, erkennt. So läßt sich begreifen, warum in dem ganzen Vernunftvermögen nur das Praktische dasjenige sein könne, welches uns über die Sinnenwelt hinaushilft und Erkenntnisse von einer übersinnlichen Ordnung und Ver-

20 knüpfung verschaffe, die aber ebendarum freilich nur so weit, als es gerade für die reine praktische $\mathrm{Ab}$ sicht nötig ist, ausgedehnt werden können.

Nur auf eines sei es mir erlaubt bei dieser Gelegenheit noch aufmerksam zu machen, nämlich daß jeder Schritt, den man mit der reinen Vernunft tut, sogar im praktischen Felde, wo man auf subtile Spekulation gar nicht Rücksicht nimmt, dennoch sich so genan und zwar von selbst an alle Momente der Kritik der theoretischen Vernunft anschließe, als ob jeder

30 mit überlegter Vorsicht, bloß um dieser Bestätigung zu verschaffen, ausgedacht wäre. Eine solche auf keinerlei Weise gesuchte, sondern (wie man sich selbst davon überzeugen kann, wenn man nur die moralischen Nachforschungen bis zu ihren Prinzipien fortsetzen will) sich von selbst findende genaue Eintreffung der wichtigsten Sätze der praktischen Vernunft mit den oft zu subtil und unnötig scheinenden Bemerkungen der Kritik der spekulativen überrascht und setzt in Verwunderung, und bestärkt die schon von anderen

40 erkannte und gepriesene Maxime, in jeder wissenschaftlichen Untersuchung mit aller möglichen Genauigkeit und Offenheit seinen Gang ungestört fortzusetzen, ohne 
sich an das $z u$ kehren, wowider sie außer ihrem Felde etwa verstoßen möchte, sondern sie für sich allein, soviel man kann, wahr und vollständig zu vollführen. Oftere Beobachtung hat mich überzeugt, daß, wenn man dieses ${ }^{2}$ ) Geschäfte $z u$ Ende gebracht hat, das, was in der Hälfte desselben in Betracht anderer Lehren außerhalb mir bisweilen sehr bedenklich schien, wenn ich diese Bedenklichkeit nur so lange aus den Augen lie $\beta$ und bloß auf mein Geschäft acht hatte, bis es vollendet sei, endlich auf unerwartete Weise mit 10 demjenigen vollkommen zusammenstimmte, was sich ohne die mindeste Rücksicht auf jene Lehren, ohne Parteilichkeit und Vorliebe für dieselben von selbst gefunden hatte. Schriftsteller würden sich manche Irrtümer, manche verlorene Mühe (weil sie auf Blendwerk gestellt war) ersparen, wenn sie sich nur entschließen könnten, mit etwas mehr Offenheit zu Werke zu gehen.

8) Kant: „diese“; korr. Grillo. 


\section{Dialektik der reinen praktischen Vernunft.}

Erstes Hauptstück.

\section{Von einer Dialektik der reinen praktischen Vernunft überhaupt.}

Die reine Vernunft hat jederzeit ihre Dialektik, man mag sie in ihrem spekulativen oder praktischen Gebrauche betrachten; denn sie verlangt die absolute

10 Totalität der Bedingungen zu einem gegebenen Bedingten, und diese kann schlechterdings nur in Dingen an sich selbst angetroffen werden. Da aber alle Begriffe der Dinge auf Anschauungen bezogen werden müssen, welche bei uns Menschen niemals anders als sinnlich sein können. mithin die Gegenstände nicht als Dinge an sich selbst, sondern bloß als Erscheinungen erkennen lassen, in deren Reihe des Bedingten und der Bedingungen das Unbedingte niemals angetroffen werden kann: so entspringt ein unvermeidlicher Schein

20 aus der Anwendung dieser Vernunftidee der Totalität der Bedingungen (mithin des Unbedingten) auf Erscheinungen, als wären sie Sachen an sich selbst (denn dafür werden sie in Ermangelung einer warnenden Kritik jederzeit gehalten), der aber niemals als trüglich bemerkt werden würde, wenn er sich nicht durch einen Widerstreit der Vernunft mit sich selbst in der Anwendung ihres Grundsatzes, das Unbedingte zu allem Bedingten vorauszusetzen, auf Erscheinungen selbst verriete. $\left.{ }^{a}\right)$ Hierdurch wird aber die Vernunft genötigt,

a) Kant: „verrieten"; korr. Rosenkranz, Hartenstein. 
diesem Scheine nachzuspüren, woraus er entspringe und wio er gehoben werden könne, welches nicht anders als durch eine vollständige Kritik des ganzen reinen Vernunftvermögens geschehen kann, sodaß die Antinomie der reinen Vernunft, die in ihrer Dialektik offenbar wird, in der Tat die wohltätigste Verirrung ist, in die die menschliche Vernunft je hat geraten können, indem sie uns zuletzt antreibt, den Schlüssel zu suchen, aus diesem Labyrinthe herauszukommen, der, wenn er gefunden worden, noch das entdeckt, was man nicht 10 suchte und doch bedarf, nämlich eine Aussicht in eine höhere, unveränderliche Ordnung der Dinge, in der wir schon jetzt sind, und in der unser Dasein der höchsten Vernunftbestimmung gemä $\beta$ fortzusetzen $[108]$ wir durch bestimmte Vorschriften nunmehr angewiesen werden können.

Wie im spekulativen Gebrauche der reinen Vernunft jene natürliche Dialektik aufzulösen und der Irrtum aus einem übrigens natürlichen Scheine zu verhüten sei, kann man in der Kritik jenes Vermögens ausführlich antreffen. Aber der Vernunft in ihrem praktischen Gebrauche geht es um nichts besser. Sie sucht als reine praktische Vernunft zu dem PraktischBedingten (was auf Neigungen und Naturbedürfnis beruht) ebenfalls das Unbedingte, und zwar nicht als Bestimmungsgrund des Willens, sondern, wenn dieser auch (im moralischen Gesetze) gegeben worden, die unbedingte Totalität des Gegenstandes der reinen praktischen Vernunft, unter dem Namen des höchsten Guts.

Diese Idee praktisch, d. i. für die Maxime unseres vernünftigen Verhaltens hinreichend $z u$ bestimmen, ist die Weisheitslehre, und diese wiederum als Wissenschaft ist Philosophie in der Bedeutung, wie die Alten das Wort verstanden, bei denen sie eine Anweisung $\mathrm{zu}$ dem Begriffe war, worin das höchste Gut zu setzen, und zum Verhalten, durch welches es zu erwerben sei. Es wäre gut, wenn wir dieses Wort bei seiner alten Bedeutung ließen, als eine Lehre vom höchsten Gut, sofern die Vernunft bestrebt ist, es darin zur Wissenschaft zu bringen. Denn einesteils würde die angehängte einschränkende Be- 
dingung dem griechischen Ausdrucke (welcher Liebe zur Weish eit bedeutet) angemessen und doch zugleich hinreichend sein, die Liebe zur Wissenschaft, mithin aller spekulativen Erkenntnis der Vernunft, sofern sie ihr sowohl zu jenem Begriffe als auch dem praktischen Bestimmungsgrunde dienlich ist, unter dem Namen der Philosophie mitzubefassen, und doch den Hauptzweck, um dessen willen sie allein Weisheitslehre genannt werden kann, nicht aus den Augen verlieren lassen.

10 Andererseits würde es auch nicht übel sein, den Eigendünkel desjenigen, der es wagte, sich des Titels eines Philosophen selbst anzumaßen, abzuschrecken, wenn man ihm schon durch die Definition den Maßstab der Selbstschätzung vorhielte, der seine Ansprüche sehr herabstimmen wird; denn ein Weisheitslehrer zu sein, möchte wohl etwas mehr als einen Schüler bedeuten, der noch immer nicht weit genug gekommen ist, um sich selbst, viel weniger um andere mit sicherer Erwartung eines so hohen Zwecks zu leiten; es würde

20 einen Meister in Kenntnis der Weisheit bedeuten, welches mehr sagen will, als ein bescheidener Mann sich selber anmaßen wird, und Philosophie würde,

[109] sowie die Weisheit selbst noch immer ein Ideal bleiben, welches objektiv in der Vernunft allein vollständig vorgestellt wird, subjektiv aber, für die Person, nur das Ziel seiner unaufhörlichen Bestrebung ist, und in dessen Besitz unter dem angemaßten Namen eines Philosophen zu sein, nur der vorzugeben berechtigt ist, der auch die unfehlbare Wirkung derselben (in

30 Beherrschung seiner selbst und dem ungezweifelton Interesse, das er vorzüglich am allgemeinen Guten nimmt) an seiner Person als Beispiele aufstellen kann, welches die Alten auch forderten, um jenen Ehrennamen verdienen zu können.

In Ansehung der Dialektik der reinen praktischen Vernunft im Punkte der Bestimmung des Begriffs $\nabla 0 \mathrm{~m}$ höchsten Gute (welche, wenn ihre Auflösung gelingt, ebensowohl als die der theoretischen die wohltätigste Wirkung erwarten läßt, dadurch daß die auf10 richtig angestellten und nicht verhehlten Widerspriuehe der reinen praktischen Vernunft mit ihr selbst zor vollstïndigen Kritik ihres eigenen Vermögens 
Von einer Dialektik d. r. prakt. Vernunft überbaupt. 141

nötigen) haben wir nur noch eine Erinnerung voranzuschicken.

Das moralische Gesetz ist der alleinige Bestimmungsgrund des reinen Willens. Da dieses aber bloß formal ist (nämlich allein die Form der Maxime als allgemein gesetzgebend fordert), so abstrahiert es als Bestimmungsgrund von aller Materie, mithin von allem Objekte des Wollens. Mithin mag das höchste Gut immer der ganze Gegenstand einer reinen praktischen Vernunft, d. i. eines reinen Willens sein, so ist 10 es darum doch nicht für den Bestimmungsgrund desselben $\mathrm{zu}$ halten, und das moralische Gesetz muß allein als der Grund angesehen werden, jenes und dessen Bewirkung oder Beförderung sich zum Objekte zu machen. Diese Erinnerung ist in einem sa delikaten Falle, als die Bestimmung sittlicher Prinzipien ist, wo auch die kleinste Mißdeutung Gesinnungen verfälscht, von Erheblichkeit. Denn man wird aus der Analytik ersehen haben, daß, wenn man vor dem moralischen Gesetze irgend ein Objekt unter dem Namen eines Guten als Bestimmungsgrund des Willens annimmt und von ihm dann das oberste praktische Prinzip ableitet, dieses alsdann jederzeit Heteronomie herbeibringen und das moralische Prinzip verdrängen würde.

Es versteht sich aber von selbst, daß, wenn im Begriffe des höchsten Guts das moralische Gesetz als oberste Bedingung schon mit eingeschlossen ist, alsdann das höchste Gut nicht bloß Objekt, sondern auch sein Begriff und die Vorstellung der durch unsere praktische Vernunft möglichen Existenz desselben zugleich der Bestimmungsgrund des reinen Willens sei; weil alsdann in der Tat das in diesem Begriffe schon eingeschlossene und mitgedachte moralische Gesetz und kein anderer Gegenstand nach dem Prinzip der Autonomie den Willen bestimmt. Diese Ordnung der Begriffe von der Willensbestimmung darf nicht aus den Augen gelassen werden; weil man sonst sich selbst mißversteht und sich zu widersprechen glaubt, wo doch alles in der vollkommensten Harmonie 40 nebeneinander steht. 


\section{Von der Dialektik der reinen Vernunft in Bestimmung des Begriffs vom höchsten Gut.}

Der Begriff des Höchsten enthält schon eine Zweideutigkeit, die, wenn man darauf nicht acht hat, unnötige Streitigkeiten veranlassen kann. Das Höchste kann das Oberste (supremum) oder auch das Vollendete (consummatum) bedeuten. Das erstere ist diejenige Bedingung, die selbst unbedingt, d. i. keiner anderen

10 untergeordnet ist (originarium); das zweite dasjenige Ganze, das kein Teil eines noch größeren Ganzen von derselben Art ist (perfectissimum). Daß Tugend (als die Würdigkeit, glücklich zu sein) die oberste Bedingung alles dessen, was uns nur wünschenswert scheinen mag, mithin auch aller unserer Bewerbung um Glückseligkeit, mithin das oberste Gut sei, ist in der Analytik bewiesen worden. Darum ist sie aber noch nicht das ganze und vollendete Gut, als Gegenstand des Begehrungsvermögens vernünftiger end-

20 licher Wesen; denn um das zu sein, wird auch Glückseligkeit dazu erfordert, und zwar nicht bloß in den parteiischen Augen der Person, die sich selbst zum Zwecke macht, sondern selbst im Urteile einer unparteiischen Vernunft, die jene überhaupt in der Welt als Zweck an sich betrachtet. Denn der Glückseligkeit bedürftig, ihrer auch würdig, dennoch aber derselben nicht teilhaftig zu sein, kann mit dem vollkommenen Wollen eines vernünftigen Wesens, welches zugleich alle Gewalt hätte, wenn wir uns auch nur ein

30 solches zum Versuche denken, gar nicht zusammen bestehen. Sofern nun Tugend und Glückseligkeit zusammen den Besitz des höchsten Guts in einer Person, hierbei aber auch Glückseligkeit, ganz genau in Proportion der Sittlichkeit (als Wert der Person und deren Würdigkeit, glücklich zu sein) ausgeteilt, das hö chste Gut einer möglichen Welt ausmachen: so bedeutet [111] dieses das Ganze, das vollendete Gute, worin doch Tugend immer als Bedingung das oberste Gut ist, weil es weiter keine Bedingung über sich hat, Glückseligkeit 
immer etwas, was dem, der sie besitzt, zwar angenehm, aber nicht für sich allein schlechterdings und in aller Rücksicht gut ist, sondern jederzeit das moralische gesetzmäßige Verhalten als Bedingung voraussetzt.

Zwei in einem Begriffe notwendig verbundene Bestimmungen müssen als Grund und Folge verknüpft sein, und zwar entweder so, daß diese Einheit als analytisch (logische Verknüpfung) oder als synthetisch (reale Verbindung), jene nach dem Gesetze der Identität, diese der Kausalität betrachtet wird. Die 10 Verknüpfung der Tugend mit der Glückseligkeit kann also entweder so verstanden werden, daß die Bestrebung, tugendhaft zu sein, und die vernünftige Bewerbung um Glückseligkeit nicht zwei verschiedene, sondern ganz identische Handlungen wären, da dann der ersteren keine andere Maxime als zu der letzterena) zum Grunde gelegt zu werden brauchte; oder jene Verknüpfung wird darauf ausgesetzt, daß Tugend die Glückseligkeit als etwas von dem Bewußtsein der ersteren Unterschiedenes, wie die Ursache eine Wir- 20 kung, hervorbringe.

Von den alten griechischen Schulen waren eigentlich nur zwei, die in Bestimmung des Begriffs vom höchsten Gute sofern zwar einerlei Methode befolgten, daß sie Tugend und Glückseligkeit nicht als zwei verschiedene Elemente des höchsten Guts gelten ließen, mithin die Einheit des Prinzips nach der Regel der Identität suchten; aber darin schieden sie sich wiederum, daß sie unter beiden den Grundbegriff verschiedentlich wählten. Der Epikureer sagte: sich 30 seiner auf Glückseligkeit führenden Maxime bewußt sein, das ist Tugend; der Stoiker: sich seiner Tugend bewußt sein, ist Glückseligkeit.' Dem ersteren war Klugheit soviel als Sittlichkeit; dem zweiten, der eine höhere Benennung für die Tugend wählte, war Sittlichkeit allein wahre Weisheit.

Man muß bedauern, daß die Scharfsinnigkeit dieser Männer (die man doch zugleich darüber bewundern muß, daß sie in so frühen Zeiten schon alle erdenklichen Wege philosophischer Eroberungen versuchten) 40 unglücklich angewandt war, zwischen äußerst ungleichartigen Begriffen, dem der Glückseligkeit und dem der

a) Kellermann: als der letzteren“. 


\section{Erster Teil, II. Bach, 2. Hauptstück.}

- Tugend, Identität zu ergrübeln. Allein es war dem dialektischen Geiste ihrer Zeiten angemessen, was auch jetzt bisweilen subtile Köpfe verleitet, wesentliche und nie zu vereinigende Unterschiede in Prinzipien dadurch aufzuheben, daß man sie in Wortstreit zu verwandeln sucht und so dem Scheine nach Einheit des Begriffs

[112] bloß unter verschiedenen Benennungen erkünstelt; und dieses trifft gemeiniglich solche Fälle, wo die Vereinigung ungleichartiger Gründe so tief oder hoch

10 liegt, oder eine so gänzliche Umänderung der sonst im philosophischen System angenommenen Lehren erfordern würde, daß man Scheu trägt, sich in den realen Unterschied tief einzulassen, und ihn lieber als Uneinigkeit in bloßen Formalien behandelt.

Indem beide Schulen Einerleiheit der praktischen Prinzipien der Tugend und Glückseligkeit zu ergrübeln suchten, so waren sie darum nicht unter sich einhellig, wie sié diese Identität herauszwingen wollten, sondern schieden sich in unendliche Weiten von ein-

20 ander, indem die eine ihr Prinzip auf der ästhetischen, die andere auf der logischen Seite, jene im Bewußtsein des sinnlichen Bedürfnisses, die andere in der Unabhängigkeit der praktischen Vernunft von allen sinnlichen Bestimmungsgründen setzte. Der Begriff der Tugend lag nach dem Epikureer schon in der Maxime, seine eigene Glückseligkeit zu befördern; das Gefühl der Glückseligkeit war dagegen nach dem Stoiker schon im Bewußtsein seiner Tugend enthalten. Was aber in einem anderen Begriffe ent80 halten ist, ist zwar mit einem Teile des Enthaltenden, aber nicht mit dem Ganzen einerlei, und zwei Ganze können überdem spezifisch voneinander unterschieden sein, ob sie zwar aus eben demselben Stoffe bestehen, wenn nämlich die Teile in beiden auf ganz verschiedene Art zu einem Ganzen verbunden werden. Der Stoiker behauptete, Tugend sei das ganze höchste Gut, und Glückseligkeit nur das Bewußtsein des Besitzes derselben als zum Zustand des Subjekts gehörig. Der Epikureer behauptete, Glückseligkeit sei das ganze

40 höchste Gut, und Tugend nur die Form der Maxime, sich um sie zu bewerben, nämlich im vernünftigen Gebrauche der Mittel zu derselben. 
Nun ist aber aus der Analytik klar, daß die Maximen der Tugend und die der eigenen Glückseligkeit in Ansehung ihres obersten praktischen Prinzips ganz ungleichartig sind, und weit gefehlt, einbellig zu sein, ob sie gleich zu einem höchsten Guten gehören, um das letztere möglich zu machen, einander in demselben Subjekte gar sehr einschränken und Abbruch tun. Also bleibt die Frage: wie ist das höchste Gut praktisch möglich? noch immer unerachtet aller bisherigen Koalitionsversuche eine unauf- 10 gelöste Aufgabe. Das aber, was sie zu einer schwer zu lösenden Aufgabe macht, ist in der Analytik gegeben, nämlich daß Glückseligkeit und Sittlichkeit zwei spezifisch ganz verschiedene Elemente des höchsten Guts sind und ihre Verbindung also nicht analytisch erkannt werden könne (daß etwa der, so seine Glückseligkeit sucht, in diesem seinem Verhalten sich durch bloße Auflösung seiner Begriffe tugendhaft oder der, so der Tugend folgt, sich im Bewußtsein eines solchen Verhaltens schon ipso facto glücklich 20 finden werde), sondern eine Synthesis der Begriffe sei. Weil aber diese Verbindung als a priori, mithin praktisch notwendig, folglich nicht als aus der $\mathrm{Er}$ fahrung abgeleitet erkannt wird, und die Möglichkeit des höchsten Guts also auf keinen empirischen Prinzipien beruht, so wird die Deduktion dieses Begriffs transzendental sein müssen. Es ist a priori (moralisch) notwendig, das höchste Gut durch Freiheit des Willens hervorzubringen; es muß also auch die Bedingung der Möglichkeit desselben ledig- 30 lich auf Erkenntnisgründen a priori beruhen.

\section{I.}

Die Antinomie der praktischen Vernunft.

In dem höchsten für uns praktischen, d. i. durch unseren Willen wirklich zu machenden Gute werden Tugend und Glückseligkeit als notwendig verbunden gedacht, soda $\mathrm{B}$ das eine durch eine praktische Vernunft nicht angenommen werden kann, ohne daß das andere auch zu ihm gehöre. Nun ist diese Verbindung (wio eine jede überhaupt) entweder analytisch oder 40

Kant, Kritik der prakt. Vernunft. 
synthetisch. Da' diese gegebene aber nicht analytisch sein kann, wie nur eben vorher gezeigt worden, so muß sie synthetisch und zwar als Verknüpfung der Ursache mit der Wirkung gedacht werden; weil sie ein praktisches Gut, d. i. was durch Handlung möglich ist, betrifft. Es muß also entweder die Begierde nach Glückseligkeit die Bewegursache zu Maximen der Tugend, oder die Maxime der Tugend muß die wirkende Ursache der Glückseligkeit sein. Das erste 10 ist schlechterdings unmöglich; weil (wie in der Analytik bewiesen worden) Maximen, die den Bestimmungsgrund des Willens in dem Verlangen nach seiner Glückseligkeit setzen, gar nicht moralisch sind und keine Tugend gründen können. Das zweite ist aber auch unmöglich, weil alle praktische Verknüpfung der Ursachen und der Wirkungen in der Welt, als Erfolg der Willensbestimmung, sich nicht nach moralischen Gesinnungen des Willens, sondern der Kenntnis der Naturgesetze und dem physischen Vermögen, sie

$20 \mathrm{zu}$ seinen Absichten zu gebrauchen, richtet, folglich keine notwendige und zum höchsten Gut zureichende Verknüpfung der Glückseligkeit mit der Tugend in der

[114] Welt durch die pünktlichste Beobachtung der moralischen Gesetze erwartet werden kann. Da nun die Beförderung des höchsten Guts, welches diese Verknüpfung in seinem Begriffe enthält, ein a priori notwendiges Objekt unseres Willens ist und mit dem moralischen Gesetze unzertrennlich zusammenhängt, so muß die Unmöglichkeit des ersteren auch die Falsch-

30 heit des zweiten beweisen. Ist also das höchste Gut nach praktischen Regeln unmöglich, so muß auch das moralische Gesetz, welches gebietet, dasselbe zu befördern, phantastisch und auf leere eingebildete Zwecke gestellt, mithin an sich falsch sein.

\section{II.}

\section{Kritische Aufhebung der Antinomie der praktisehen Vernunft.}

In der Antinomie der reinen spekulativen Vernunft findet sich ein ähnlicher Widerstreit zwischen Natur40 notwendigkeit und Freiheit in der Kausalität der Be- 
gcbenheiten in der Welt. Er wurde dadurch gehoben, daß bewiesen wurde, es sei kein wahrer Widerstreit, wenn man die Begebenheiten und selbst die Welt, darin sie sich ereignen, (wie man auch soll) nur als Erscheinungen betrachtet; da einunddasselbe handelnde Wesen als Erscheinung (selbst vor seinem eigenen inneren Sinne) eine Kausalität in der Sinnenwelt hat, die jederzeit dem Naturmechanismus gemä $\beta$ ist, in Ansehung derselben Begebenheit aber, sofern sich die handelnde Person zugleich als Noumenon betrachtet 10 (als reine Intelligenz in seinem nicht der Zeit nach bestimmbaren Dasein), einen Bestimmungsgrund jener Kausalität nach Naturgesetzen, der selbst von allem Naturgesetze frei ist, enthalten könne.

Mit der vorliegenden Antinomie der reinen praktischen Vernunft ist es nun ebenso bewandt. Der erste von den zwei Sătzen, daß das Bestreben nach Glückseligkeit einen Grund tugendhafter Gesinnung hervorbringe, ist schlechterdings falsch; der zweite aber, daß Tugendgesinnung notwendig Glück- 20 seligkeit hervorbringe, ist nicht schlechterdings, sondern nur, sofern sie als die Form der Kausalität in der Sinnenwelt betrachtet wird, und mithin, wenn ich das Dasein in derselben für die einzige Art der Existenz des vernünftigen Wesens annehme, also nur bedingterweise falsch. Da ich aber nicht allein befugt bin, mein Dasein auch als Noumenon in einer Verstandeswelt zu denken, sondern sogar am moralischen Gesetze einen rein intellektuellen Bestimmungsgrund meiner Kausalität (in der Sinnenwelt) habe, so 30 ist es nicht unmöglich, daß die Sittlichkeit der Gesinnung einen wo nicht unmittelbaren, so doch mittelbaren (vermittelst eines intelligibelen Urhebers der Natur) und zwar notwendigen Zusammenhang als Ursache mit der Glückseligkeit als Wirkung in der Sinnenwelt habe, welche Verbindung in einer Natur, die bloß Objekt der Sinne ist, niemals anders als zufällig stattfinden und zum höchsten Gute nicht zulangen kann. Also ist, unerachtet dieses scheinbaren Widerstreits einer praktischen Vernunft mit sich selbst, 40 das höchste Gut, der notwendige höchste Zweck eines moralisch bestimmten Willens, eln wahres Objekt der- 
selben; denn es ist praktisch möglich, und die Maximen des letzteren, die sich darauf ihrer Materie nach beziehen, haben objektive Realität, welche anfänglich durch jene Antinomie in Verbindung der Sittlichkeit mit Glückseligkeit nach einem allgemeinen Gesetze getroffen wurde, aber aus bloßem Mißverstande, weil man das Verhältnis zwischen Erscheinungen für ein Verhältnis der Dinge an sich selbst zu diesen Erscheinungen hielt.

10 Wenn wir uns genötigt sehen, die Möglichkeit des höchsten Guts, dieses durch die Vernunft allen vernünftigen Wesen ausgesteckten Ziels aller ihrer moralischen Wünsche, in solcher Weite, nämlich in der Verknüpfung mit einer intelligibelen Welt zu suchen, so muß es befremden, daß gleichwohl die Philosophen alter sowohl als neuer Zeiten die Glückseligkeit mit der Tugend in ganz geziemender Proportion schon in diesem Leben (in der Sinnenwelt) haben finden oder sich ihrer bewußt zu sein haben überreden können.

20 Denn Epikur sowohl als die Stoiker erhoben die Glückseligkeit, die aus dem Bewußtsein der Tugend im Leben entspringe, über alles, und der erstere war in seinen praktischen Vorschriften nicht so niedrig gesinnt, als man aus den Prinzipien seiner Theorie, die er zum Erklären, nicht zum Handeln brauchte, schließen möchte, oder wie sie viele, durch den Ausdruck Wollust für Zufriedenheit verleitet, ausdeuteten; sondern rechnete die uneigennützigste Ausübung des Guten mit zu den Genußarten der innigsten Freude,

30 und die Genügsamkeit und Bändigung der Neigungen, sowie sie immer der strengste Moralphilosoph fordern mag, gehörte mit zu seinem Plane eines Vergnügens (er verstand darunter das stets fröhliche Herz); wobei er von den Stoikern vornehmlich nur darin abwich, daß er in diesem Vergnügen den Bewegungsgrund setzte, welches die letzteren und zwar mit Recht ver-

[116] weigerten. Denn einesteils fiel der tugendhafte Epikur, sowie noch jetzt viele moralisch wohlgesinnte, obgleich über ihre Prinzipien nicht tief genug nach-

40 denkende Männer, in den Fehler, die tugendhafte $\mathrm{G}_{\theta}-$ sinnung in den Personen schon vorauszusetzen, für die er die Triebfeder zur Tugend zuerst angeben wollte 
(und in der Tat kann der Rechtschaffene sich nicht glücklich finden, wenn er sich nicht zuvor seiner Rechtschaffenheit bewußt ist; weil bei jener Gesinnung die Verweise, die er bei Ubertretungen sich selbst zu machen durch seine eigene Denkungsart genötigt sein würde, und die moralische Selbstverdammung ihn alles Genusses der Annehmlichkeit, die sonst sein Zustand enthalten mag, berauben würden). Allein die Frage ist: wodurch wird eine solche Gesinnung und Denkungsart, den Wert seines Daseins zu schätzen, 10 zuerst möglich? da vor derselben noch gar kein Gefühl für einen moralischen Wert überhaupt im Subjekte angetroffen werden würde. Der Mensch wird, wenn er tugendhaft ist, freilich, ohne sich in jeder Handlung seiner Rechtschaffenheit bewußt zu sein, des Lebens nicht froh werden, so günstig ihm auch das Glück im physischen Zustande desselben sein mag; aber um ihn allererst tugendhaft $\mathrm{zu}$ machen, mithin ehe er noch den moralischen Wert seiner Existenz so hoch anschlägt, kann man ihm da wohl die Seelenruhe an- 20 preisen, die aus dem Bewußtsein einer Rechtschaffenheit entspringen werde, für die er doch keinen Sinn hat?

Andererseits aber liegt hier immer der Grund zu einem Fehler des Erschleichens (vitium subreptionis) und gleichsam einer optischen Illusion in dem Selbstbewußtsein dessen, was man tut, zum Unterschiede dessen, was man empfindet, die auch der Versuchteste nicht völlig vermeiden kann. Die moralische Gesinnung ist mit einem Bewußtsein der Bestimmung 30 des Willens unmittelbar durchs Gesetz notwendig verbunden. Nun ist das Bewußtsein einer Bestimmung des Begehrungsvermögens immer der Grund eines Wohlgefallens an der Handlung, die dadurch hervorgebracht wird; aber diese Lust, dieses Wohlgefallen an sich selbst, ist nicht der Bestimmungsgrund der Handlung, sondern die Bestimmung des Willens unmittelbar bloß durch die Vernunft ist der Grund des Gefühls der Lust, und jene bleibt eine reine praktische, nicht ästhetische Bestimmung des Begehrungsvermö- 40 gens. Da diese Bestimmung nun innerlich gerade dieselbe Wirkung eines Antriebes zur Tätigkeit tut, als 
ein Gefühl der Annehmlichkeit, die aus der begehrten Handlung erwartet wird, würde getan haben, so sehen wir das, was wir selbst tun, leichtlich für etwas an, [117] was wir bloß leidentlich fühlen, und nehmen die moralische Triebfeder für sinnlichen Antrieb, wie das allemal in der sogenannten Täuschung der Sinne (hier des inneren) zu geschehen pflegt. Es ist etwas sehr Erhabenes in der menschlichen Natur, unmittelbar durch ein reines Vernunftgesetz zu Handlungen be-

10 stimmt zu werden, und sogar die Täuschung, das Subjektive dieser intellektuellen Bestimmbarkeit des Willens für etwas Ästhetisches und Wirkung eines besonderen sinnlichen Gefühls (denn ein intellektuelles wäre ein Widerspruch) zu halten. Es ist auch von großer Wichtigkeit, auf diese Eigenschaft unserer Persönlichkeit aufmerksam zu machen und die Wirkung der Vernunft auf dieses Gefühl bestmöglichst zu kultivieren. Aber man muß sich auch in acht nehmen, durch unechte Hochpreisungen dieses moralischen Be-

20 stimmungsgrundes als Triebfeder, indem man ihm Gefühle besonderer Freuden als Gründe (die doch nur Folgen sind) unterlegt, die eigentliche echte Triebfeder, das Gesetz selbst, gleichsam wie durch eine falsche Folie herabzusetzen und $\mathrm{zu}$ verunstalten, Achtung und nicht Vergnügen oder Genuß der Glückseligkeit ist also etwas; wofür kein der Vernunft zum Grunde gelegtes vorhergehendes Gefühl (weil dieses jederzeit ästhetisch und pathologisch sein würde) möglich ist, als ${ }^{2}$ ) Bewußtsein der unmittelbaren Nöti-

30 gung des Willens durchs ${ }^{b}$ ) Gesetz ist kaum eina) Analogon des Gefühls der Lust, indem es im Verhältnisse zum Begehrungsvermögen gerade ebendasselbe, aber aus anderen Quellen tut; durch diese Vorstellungsart aber kann man allein erreichen, was man sucht, nämlich daß Handlungen nicht bloß pflichtmäßig (angenehmen Gefühlen zufolge), sondern aus Pflicht geschehen, welches der wahre Zweck aller moralischen Bildung sein muß.

Hat man aber nicht ein Wort, welches nicht einen

a) nalso" (Natorp)? Hartenstein, Kehrbach: ${ }_{n}$ und", Kellermann: "ist als ... kaum ein A."

b) Kant: „durch"; korr. Vorländer. 
Genuß, wie das der Glückseligkeit, bezeichnete, aber doch ein Wohlgefallen an seiner Existenz, ein Analogon der Glückseligkeit, welche das Bewußtsein der Tugend notwendig begleiten muß, anzeigte? Ja! dieses Wort ist Selbstzufriedenheit, welches in seiner eigentlichen Bedeutung jederzeit nur ein negatives Wohlgefallen an seiner Existenz andeutet, in welchem man nichts $\mathrm{zu}$ bedürfen sich bewußt ist. Freiheit und das Bewußtsein derselben als eines Vermögens, mit überwiegender Gesinnung das moralische Gesetz 10 zu befolgen, ist Unabhängigkeit von Neigungen, wenigstens als bestimmenden (wenngleich nicht als affizierenden) Bewegursachen unseres Begehrens und, sofern als ich mir derselben in der Befolgung meiner moralischen Maximen bewußt bin, der einzige Quell einer notwendig damit verbundenen, auf keinem besonderen Gefühle beruhenden, unveränderlichen $\mathrm{Zu}-$ friedenheit, und diese kann intellektuell heißen. Die ästhetische (die uneigentlich so genannt wird), welche auf der Befriedigung der Neigungen, so fein sie auch 20 immer ausgeklügelt werden mögen, beruht, kann niemals dem, was man sich darüber denkt, adäquat sein. Denn die Neigungen wechseln, wachsen mit der Begünstigung, die man ihnen widerfahren läßt, und lassen immer ein noch größeres Leeres übrig, als man auszufüllen gedacht hat. Daher sind sie einem vernünftigen Wesen jederzeit lästig, und wenn es sie gleich nicht abzulegen vermag, so nötigen sie ihm doch den Wunsch $a b$, ihrer entledigt zu sein. Selbst eine Neigung zum Pflichtmäßigen (z. B. zur Wohltätigkeit) 30 kann zwar die Wirksamkeit der moralischen Maximen sehr erleichtern, aber keine hervorbringen. Denn alles muß in dieser auf die Vorstellung des Gesetzes als Bestimmungsgrund angelegt sein, wenn die Handlung nicht bloß Legalität, sondern auch Moralität enthalten soll. Neigung ist blind und knechtisch, sie mag nun gutartig sein oder nicht, und die Vernunft, wo es auf Sittlichkeit ankommt, muß nicht bloß den Vormund derselben vorstellen, sondern, ohne auf sie Rücksicht zu nehmen, als reine praktische Vernunft ihr $\mathbf{4 0}$ eigenes Interesse ganz allein besorgen. Selbst dies Gefühl des Mitleids und der weichherzigen Teilneh- 
mung, wenn es vor der Uberlegung, was Pflicht sel, vorhergeht und Bestimmungsgrund wird, ist wohldenkenden Personen selbst lästig, bringt ihre überlegten Maximen in Verwirrung und bewirkt den Wunsch, ihrer ${ }^{2}$ ) entledigt und allein der gesetzgebenden Vernunft unterworfen zu sein.

Hieraus läßt sich verstehen: wie das Bewußtsein dieses Vermögens einer reinen praktischen Vernunft durch Tat (die Tugend) ein Bewußtsein der Obermacht

10 über seine Neigungen, hiermit also der Unabhängigkeit von denselben, folglich auch der Unzufriedenheit, die diese immer begleitet, und also ein negatives Wohlgefallen mit seinem Zustande, d. i. Zufriedenheit hervorbringen könne, welche in ihrer Quelle Zufriedenheit mit seiner Person ist. Die Freiheit selbst wird auf solch ${ }^{-W e i s e ~(n a ̈ m l i c h ~ i n d i r e k t) ~ e i n e s ~ G e-~}$ nusses fähig, welcher nicht Glückseligkeit heißen kann, weil or nicht vom positiven Beitritt eines Gefühls abhängt, auch genau zu reden nicht Seligkeit, weil

20 er nicht gänzlich $\Theta$ Unabhängigkeit von Neigungen und Bedürfnissen enthält, der aber doch der letzteren ähnlich ist, sofern nämlich wenigstens seine Willensbestimmung sich von ihrem Einflusse frei halten kann, und also wenigstens seinem Ursprunge nach der Selbstgenugsamkeit analogisch ist, die man nur dem höchsten Wesen beilegen kann.

[119] Aus dieser Auflösung der Antinomie der praktischen reinen Vernunft folgt, daß sich in praktischen Grundsätzen eine natürliche und notwendige Ver-

30 bindung zwischen dem BowuBtsein der Sittlichkeit und der Erwartung einer ihr proportionierten Glückseligkeit als Folge derselben wenigstens als möglich denken (darum aber freilich noch eben nicht erkennen und einsehen) lasse; dagegen, daß Grundsätze der Bewerbung um Glückseligkeit unmöglich Sittlichkeit hervorbringen können: daß also das oberste Gut (als die erste Bedingung des höchsten Guts) Sittlichkeit, Glückseligkeit dagegen zwar das zweite Element desselben ausmache, doch so, daß diese nur die moralisch 40 bedingte, aber doch notwendige Folge der ersteren sei.

a) „seiner" (Vorländer)? 
In dieser Unterordnung allein ist das $\mathrm{h} \delta \mathrm{chste}$ Gut das ganze Objekt der reinen praktischen Vernunft, die es sich notwendig als möglich vorstellen muß, weil es ein Gebot derselben ist, zu dessen Hervorbringung alles mögliche beizutragen. Weil aber die Möglichkeit einer solchen Verbindung des Bedingten mit seiner Bedingung gänzlich zum übersinnlichen Verhältnisse der Dinge gehört und nach Gesetzen der Sinnenwelt gar nicht gegeben werden kann, obzwar die praktische Folge dieser Idee, nämlich die Handlungen, die darauf 10 abzielen, das höchste Gut wirklich zu machen, zur Sinnenwelt gehören: so werden wir die Gründe jener Möglichkeit erstlich in Ansehung dessen, was urmittelbar in unserer Gewalt ist, und dann zweitens in dem, was uns Vernunft als Ergänzung unseres Unvermögens zur Möglichkeit des höchsten Guts (nach praktischen Prinzipien notwendig) darbietet und nicht in unserer Gewalt ist, darzustellen suchen.

\section{III.}

Von dem Primat der reinen praktischen Vernunft

in threr Verbindung mit der spekulativen.

Unter dem Primate zwischen zweien oder mehreren durch Vernunft verbundenen Dingen verstehe ich den Vorzug des einen, der erste Bestimmungsgrund der Verbindung mit allen übrigen $\mathrm{zu}$ sein. In engerer praktischer Bedeutung bedeutet es den Vorzug des Interesses des einen, sofern ihm (welches keinem anderen nachgesetzt werden kann) das Interesse der anderen untergeordnet ist. Einem jeden Vermögen des Gemüts kann man ein Interesse beilegen, d. i. ein 30 Prinzip, welches die Bedingung enthält, unter welcher allein die Ausübung desselben befördert wird. Die Vernunft, als das Vermögen der Prinzipien, bestimmt das Interesse aller Gemütskräfte, das ihrige aber sich selbst. Das Interesse ihres spekulativen Gebrauchs besteht in der Erkenntnis des Objekts bis zu den höchsten Prinzipien a priori, das des praktischen Gebrauchs in der Bestimmung des Willens in Ansehung des letzten und vollständigen Zwecks. Das, was zur M8g- 
lichkeit eines Vernunftgebrauchs überhaupt erforderlich ist, nämlich daß die Prinzipien und Behauptungen derselben einander nicht widersprechen müssen, macht keinen Teil ihres Interesses aus, sondern ist die Bedingung, überhaupt Vernunft zu haben; nur die Erweiterung, nicht die bloße Zusammenstimmung mit sich selbst wird zum Interesse derselben gezählt.

Wenn praktische Vernunft nichts weiter annehmen und als gegeben denken darf, als was speku10 lative Vernunft für sich ihr aus ihrer Einsicht darreichen konnte, so führt diese das Primat. Gesetzt aber, sie hätte für sich ursprüngliche Prinzipien a priori, mit denen gewisse theoretische Positionen unzertrennlich verbunden wären, die sich gleichwohl aller möglichen Einsicht der spekulativen Vernunft entzögen (ob sie zwar derselben auch nicht widersprechen müßten), so ist die Frage, welches Interesse das oberste sei (nicht, welches weichen müßte, denn eines widerstreitet dem anderen nicht notwendig): ob spekulative

20 Vernunft, die nichts ${ }^{a}$ ) von allem dem weiß, was praktische ihr anzunehmen darbietet, diese Sätze aufnehmen und sie, ob sie gleich für sie überschwenglich sind, mit ihren Begriffen als einen fremden, auf sie übertragenen Besitz zu vereinigen suchen müsse; oder ob sie berechtigt sei, ihrem eigenen abgesonderten Interesse hartnäckig zu folgen und nach der Kanonik des Epikur alles als leere Vernünftelei auszuschlagen, was seine objektive Realität nicht durch augenscheinliche, in der Erfahrung aufzustellende Beispiele be30 glaubigen kann, wenn es gleich noch so sehr mit dem Interesse des praktischen (reinen) Gebrauchs verwebt, an sich auch der theoretischen nicht widersprechend wäre, bloß weil es wirklich sofern dem Interesse der spekulativen Vernunft Abbruch tut, daß es die Grenzen, die diese sich selbst gesetzt, aufhebt und sie allem Unsinn oder Wahnsinn der Einbildungskraft preisgibt.

In der Tat, sofern praktische Vernunft als pathologisch bedingt, d. i. das Interesse der Neigungen unter dem sinnlichen Prinzip der Glückseligkeit bloß 40 verwaltend zum Grunde gelegt würde, so ließe sich

a) 1. and 4.-6. Anfl., Hartonatoin: "nicht", 
diese Zumutung an die spekulative Vernunft gar nicht tun. Mahomets Paradies oder der Theosophen und Mystiker schmelzende Vereinigung mit der Gottheit, sowie jedem sein Sinn steht, würden der Vernunft ihre Ungeheuer aufdringen, und es wäre ebensogut, gar keine $\mathrm{zu}$ haben, als sie auf solche Weise allen [121] Träumereien preiszugeben. Allein wenn reine Vernunft für sich praktisch sein kann und es wirklich ist, wie das Bewußtsein des moralischen Gesetzes es ausweist, so ist es doch immer nur einunddieselbe Vernunft, die, es sei in theoretischer oder praktischer Absicht, nach Prinzipien a priori urteilt, und da ist es klar, daß, wenn ibr Vermögen in der ersteren gleich nicht zulangt, gewisse Sätze behauptend festzusetzen, indessen daß sie ihr auch eben nicht widersprechen, sie $^{a}$ ) eben diese Sätze, sobald sie unabtrennlich zum praktischen Interesse der reinen Vernunft gehören, zwar als ein ihr fremdes Angebot, das nicht auf ihrem Boden erwachsen, aber doch hinreichend beglaubigt ist, annehmen und sie mit allem, was sie als 20 spekulative Vernunft in ihrer Macht hat, zu vergleichen und $\mathrm{zu}$ verknüpfen suchen müsse; doch sich bescheidend, daß dieses nicht ihre Einsichten, aber doch Erweiterungen ihres Gebrauchs in irgend einer anderen, nämlich praktischen Absicht sind, welches ihrem Interesse, das in der Einschränkung des spekulativen Frevels Desteht, ganz und gar nicht zuwider ist.

In der Verbindung also der reinen spekulativen mit der reinen praktischen Vernunft zu einer Erkenntnis führt die letztere das Primat, vorausgesetzt 30 nämlich, daß diese Verbindung nicht etwa zufällig und beliebig, sondern a priori auf der Vernunft selbst gegründet, mithin notwendig sei. Denn es würde ohne diese Unterordnung ein Widerstreit der Vernunft mit ihr selbst entstehen; weil, wenn sie einander bloß beigeordnet (koordiniert) wären, die erstere für sich ihre Grenze enge verschließen und nichts von der letzteren in ihr Gebiet aufnehmen, diese aber ihro Grenzen dennoch über alles ausdehnen und, wo es ihr Bedürfnis erheischt, jene innerhalb der ihrigen mit- 10

a) sie $^{\alpha}$, ergänzt durch den Herausgeber; Kellermann will statt dessen Zeile 20 setzen: "sie annehmen und ${ }^{4}$. 
156 Erster Teil, II. Buch, 8. Hauptstack. IV.

zubefassen suchen würde. Der spekulativen Vernunft aber untergeordnet zu sein und also die Ordnung umzukehren, kann man der reinen praktischen gar nicht zumuten, weil alles Interesse zuletzt praktisch ist und selbst das der spekulativen Vernunft nur bedingt und im praktischen Gebrauche allein vollständig ist.

Die Unsterblichkelt der Seele als eln Postulat der reinen praktischen Vernunft.

10 Die Bewirkung des höchsten Guts in der Welt ist das notwendige Objekt eines durchs moralische Gesetz bestimmbaren Willens. In diesem aber ist die völlige Angemessenheit der Gesinnungen zum moralischen Gesetze die oberste Bedingung des höchsten Guts. Sie muß also ebensowohl möglich sein als ihr Objekt, weil sie in demselben Gebote dieses zu befördern enthalten ist. Die völlige Angemessenheit des Willens aber zum moralischen Gesetze ist Heiligkeit, eine Vollkommenheit, deren kein vernünftiges

20 Wesen der Sinnenwelt in keinem Zeitpunkte seines Daseins fähig ist. $\mathrm{Da}$ sie indessen gleichwohl als praktisch notwendig gefordert wird, so kann sie nur in einem ins Unendliche gehenden Progressus zu jener völligen Angemessenheit angetroffen werden, und es ist nach Prinzipien der reinen praktischen Vernunft notwendig, eine solche praktische Fortschreitung als das reale Objekt unseres Willens anzunehmen.

Dieser unendliche Progressus ist aber nur unter Voraussetzung einer ins Unendliche fortdauernden

30 Existenz und Persönlichkeit desselben vernünftigen Wesens (welche man die Unsterblichkeit der Seele nennt) möglich. Also ist das höchste Gut praktisch nur unter der Voraussetzung der Unsterblichkeit der Seele möglich; mithin diese, als unzertrennlich mit dem moralischen Gesetz verbunden, ein Postulat der reinen praktischen Vernunft (worunter ich einen theoretischen, als solchen aber nicht erweislichen Satz verstehe, sofern er einem a priori unbedingt geltenden praktischen Gesetze unzertrennlich anhangt). 
Der Satz von der moralischen Bestimmung unserer Natur, nur allein in einem ins Unendliche gehenden Fortschritte zur völligen Angemessenheit mit dem Sittengesetze gelangen zu können, ist von dem größten Nutzen, nicht bloß in Rücksicht auf die gegenwärtige Ergänzung des Unvermögens der spekulativen Vernunft, sondern auch in Ansehung der Religion. In Ermangelung desselben wird entweder das moralische Gesetz von seiner Heiligkeit gänzlich abgewürdigt, indem man es sich als nachsichtig (indulgent) und so unserer Behaglichkeit angemessen verkünstelt, oder auch seinen Beruf und zugleich Erwartung zu einer unerreichbaren Bestimmung, nämlich einem verhofften völligen Erwerb der Heiligkeit des Willens, spannt und sich in schwärmende, der Selbsterkenntnis ganz widersprechende theosophische Träume verliert, durch welches beides das unaufhörliche Streben zur pünktlichen und durchgängigen Befolgung eines strengen, unnachsichtlichen, dennoch aber nicht idealischen, sondern wahren Vernunftgebots nur verhindert wird. 20 Einem vernünftigen, aber endlichen Wesen ist nur der Progressus ins Unendliche, von niederen zu den höheren Stufen der moralischen Vollkommenheit möglich. Der Unendliche, dem die Zeitbedingung nichts ist, sieht in dieser für uns endlosen Reihe das Ganze der Angemessenheit mit dem moralischen Gesetze, und die Heiligkeit, die sein Gebot unnachlaßlich fordert, um seiner Gerechtigkeit in dem Anteil, den er jedem am höchsten Gute bestimmt, gemä $\beta$ zu sein, ist in einer einzigen intellektuellen Anschauung des Daseins 30 vernünftiger Wesen ganz anzutreffen. Was dem Geschöpfe allein in Ansehung der Hoffnung dieses Anteils zukommen kann, wäre das Bewußtsein seiner erprüften Gesinnung, um aus seinem bisherigen Fortschritte vom Schlechteren zum Moralisch-Besseren und dem dadurch ihm bekannt gewordenen unwandelbaren Vorsatze eine fernere ununterbrochene Fortsetzung desselben, wieweit seine Existenz auch immer reichen mag, selbst über dieses Leben hinaus zu hoffen*), und

*) Die Uberzengung von der Unwandelbarkeit seiner [123] Gesinnang im Fortschritte zum Gaten scheint gleichwohl 
so zwar niemals hier oder in irgend einem absehlichen künftigen Zeitpunkte seines Daseins, sondern [124] nur in der (Gott allein übersehbaren) Unendlichkeit seiner Fortdauer dem Willen desselben (ohne Nachsicht oder Erlassung, welche sich mit der Gerechtigkeit nicht zusammenreimt) völlig adäquat $\mathrm{zu}$ sein.

V.

\section{Das Dasein Gottes als ein Postulat der reinen praktischen Vernunft.}

Das moralische Gesetz führte in der vorhergehenden Zergliederung zur praktischen Aufgabe, welche ohne allen Beitritt sinnlicher Triebfedern bloß durch reine Vernunft vorgeschrieben wird, nämlich der notwendigen Vollständigkeit des ersten und vornehmsten Teils des höchsten Guts, der Sittlichkeit, und, da diese nur in einer Ewigkeit völlig aufgelöst werden kann, zum Postulat der Unsterblichkeit. Ebendieses Ge-

auch einem Geschöpfe für sich unmöglich zu sein. Um deswillen labt dio christliche Religionslehre sie nach von demselben Geiste, der die Heiligung, d. i. diesen festen Vorsatz nnd mit ihm das Bewußtsein der Beharrlichkeit im moralischen Progressus wirkt, allein abstammen. Aber auch natürlicherweise darf derjenige, der sich bewaßt ist, einen langen Teil seines Lebens bis zu Ende desselben im Fortschritte zum Besseren, and zwar ans echten moralischen $\mathrm{Be}$ wegungsgründen angehalten zu haben, sich wohl die tröstende Hoffnung, wenngleich nicht Gewißheit machen, daß or auch in einer über dieses Leben hinaus fortgesetzten Existenz bei diesen Grundsätzen beharren werde und, wiewohl er in seinen eigenen Augen hier nie gerechtfertigt ist, noch bei dem verhofften künftigen Anwach seiner Naturvollkommenheit, mit ihr aber anch seiner Pflichten en jemals hoffen darf, dennooh in diesem Fortschritte, der, ob er zwar ein ins Unendliche hinausgerücktes Ziel betrifft, dennoch für Gott als Besitz gilt, eine Aussicht in eine selige Zuknnft haben; denn dieses ist der Ausdruck, dessen sich die Vernunft bedient, um oin von allen zufalligen Ursachen der Welt unabhängiges vollständiges Wohl zu bezeichnen, welches ebenso wie Heiligkeit eine Idee ist, welche nur in einem unendlichen Progressas und dessen Totalität enthalten sein kann, mithin vom Genohopfo niemale vollig erreicht wird. 
setz muß auch zur Möglichkeit des zweiten Elements des höchsten Guts, nämlich der jener Sittlichkeit angemessenen Glückseligkeit, ebenso uneigennützig wie vorher aus bloßer unpartelischer Vernunft, nämlich auf die Voraussetzung des Daseins einer dieser Wirkung adäquaten Ursache führen, d. i. die Existenz Gottes als zur Möglichkeit des höchsten Guts (welches Objekt unseres Willens mit der moralischen Gesetzgebung der reinen Vernunft notwendig verbunden ist) notwendig gehörig postulieren. Wir wollen 10 diesen Zusammenhang überzeugend darstellen.

Glückseligkeit ist der Zustand eines vernünftigen Wesens in der Welt, dem es im. Ganzen seiner Existenz alles nach Wunsch und Willen geht, und beruht also auf der Ubereinstimmung der Natur zu seinem ganzen Zwecke, imgleichen zum wesentlichen Bestimmungsgrunde seines Willens. Nun gebietet das moralische Gesetz als ein Gesetz der Freiheit durch Bestimmungsgründe, die von der Natur und der Ubereinstimmung derselben $z u$ unserem Be- 20 gehrungsvermögen (als Triebfedern) ganz unabhängig sein sollen; das handelnde vernünftige Wesen in der Welt aber ist doch nicht zugleich Ursache der Welt und der Natur selbst. Also ist in dem moralischen Gesetze nicht der mindeste Grund zu einem notwendigen Zusammenhang zwischen Sittlichkeit und der ihr proportionierten Glückseligkeit eines zur Welt als Teil gehörigen und daher von ihr abhängigen Wesens, welches ebendarum durch seinen Willen nicht Ursache dieser Natur sein und sie, was seine Glückseligkeit 30 betrifft, mit seinen praktischen Grundsätzen aus eigenen Kräften nicht durchgängig einstimmig machen kann. Gleichwohl wird in der praktischen Aufgabe [125] der reinen Vernunft, d. i. der notwendigen Bearbeitung zum höchsten Gute, ein solcher Zusammenhang als notwendig postuliert: wir sollen das höchste Gut (welches also doch möglich sein muß) zu befördern suchen. Also wird auch das Dasein einer von der Natur unterschiedenen Ursache der gesamten Natur, welche den Grund dieses Zusammenhanges, nämlich der genauen 40 Ubereinstimmung der Glückseligkeit mit der Sittlichkeit enthalte, postuliert. Diese oberste Ursache aber soll 
160 Erster Teil, II. Buch, 2. Hauptstück. V.

den Grund der Ubereinstimmung der Natur nicht bloß mit einem Gesetze des Willens der vernünftigen Wesen, sondern mit der Vorstellung dieses Gesetzes, sofern diese es sich zum obersten Bestimmungsgrunde des Willens setzen, also nicht bloß mit den Sitten der Form nach, sondern auch ihrer Sittlichkeit als dem Bewegungsgrunde derselben, d. i. mit ihrer moralischen Gesinnung enthalten. Also ist das höchste Gut in der Welt nur möglich, sofern eine oberste Ur-

10 sache $^{a}$ ) der Natur angenommen wird, die eine der moralischen Gesinnung gemäße Kausalität hat. Nun ist ein Wesen, das der Handlungen nach der Vorstellung von Gesetzen fähig ist, eine Intelligenz (vernünftig. Wesen), und die Kausalität eines solchen Wesens nach dieser Vorstellung der Gesetze ein Wille desselben. Also ist die oberste Ursache der Natur, sofern sie zum höchsten Gute vorausgesetzt werden muß, ein Wesen, das durch Verstand und Willen die Ursache (folglich der Urheber) der Natur ist, d. i. Gott.

20 Folglich ist das Postulat der Möglichkeit des höchsten abgeleiteten Guts (der besten Welt) zugleich das Postulat der Wirklichkeit eines höchsten ursprünglichen Guts, nämlich der Existenz Gottes. Nun war es Pflicht für uns, das höchste Gut zu befördern, mithin nicht allein Befugnis, sondern auch mit der Pflicht als Bedürfnis verbundene Notwendigkeit, die Möglichkeit dieses höchsten Guts vorauszusetzen; welches, da es nur unter der Bedingung des Daseins Gottes stattfindet, die Voraussetzung desselben

30 mit der Pflicht unzertrennlich verbindet, d. i. es ist moralisch notwendig, das Dasein Gottes anzunehmen.

Hier ist nun wohl zu merken, daß diese moralische Notwendigkeit subjektiv, d. i. Bedürfnis, und nicht objektiv, d. i. selbst Pflicht sei; denn es kann gar keine Pflicht geben, die Existenz eines Dinges anzunehmen (weil dieses bloß den theoretischen Gebrauch der Vernunft angeht). Auch wird hierunter nicht verstanden, daß die Annehmung des Daseins Gottes als eines Grundes aller Verbindlichkeit über40 haupt notwendig sei (denn dieser beruht, wie hin-

a) „Ursache" Zusatz Grillos. 
reichend bewiesen worden, lediglich auf der Autonomie der Vernunft selbst). Zur Pflicht gehört hier nur die Bearbeitung zu Hervorbringung und Beförderung des höchsten Guts in der Welt, dessen Möglichkeit also postuliert werden kann, die aber unsere Vernunft nicht anders denkbar findet als unter Voraussetzung einer höchsten Intelligenz, deren Dasein anzunehmen also mit dem Bewußtsein unserer Pflicht verbunden ist, obzwar diese Annehmung selbst für die theoretische Vernunft gehört, in Ansehung deren allein sie als Er- 10 klärungsgrund betrachtet Hypothes $\theta$, in Beziehung aber auf die Verständlichkeit eines uns doch durchs moralische Gesetz aufgegebenen Objekts (des höchsten Guts), mithin eines Bedürfnisses in praktischer Absicht Glaube und zwar reiner Vernunftglaube heißen kann, weil bloß reine Vernunft (sowohl ihrem theoretischen als praktischen Gebrauche nach) die Quelle ist, daraus er entspringt.

Aus dieser Deduktion wird es nunmehr begreiflich, warum die griechischen Schulen zur Auflösung so ihres Problems von der praktischen Möglichkeit des höchsten Guts niemals gelangen konnten: weil sie nur immer die Regel des Gebrauchs, den der Wille des Menschen von seiner Freiheit macht, zum einzigen und für sich allein zureichenden Grunde derselben machten, ohne ihrem Bedünken nach das Dasein Gottes dazu zu bedürfen. Zwar taten sie daran recht, daß sie das Prinzip der Sitten unabhängig von diesem Postulat für sich selbst aus dem Verhältnis der Vernunft allein zum Willen festsetzten, und es mithin zur obersten 30 praktischen Bedingung des höchsten Guts machten; es war darum aber nicht die ganze Bedingung der Möglichkeit desselben. Die Epikureer hatten nun zwar ein ganz falsches Prinzip der Sitten zum obersten angenommen, nämlich das der Glückseligkeit, und eine Maxime der beliebigen Wahl nach jedes seiner Neigung für ein Gesetz untergeschoben; aber darin verfuhren sie doch konsequent genug, daß sie ihr höchstes Gut ebenso, nämlich der Niedrigkeit ihres Grundsatzes proportionierlich, abwürdigten und keine 40 größere Glückseligkeit erwarteten, als die sich durch menschliche Klugheit (wozu auch Enthaltsamkeit und 
Mäßigung der Neigungen gehört) erwerben läßt, die, wie man weiß, kümmerlich genug und nach Umständen sehr verschiedentlich ausfallen muß; die Ausnahmen, welche ihre Maximen unaufhörlich einräumen mußten und die sie zu Gesetzen untauglich machen, nicht einmal gerechnet. Die Stoiker hatten dagegen ihr oberstes praktisches Prinzip, nämlich die Tugend, als $\mathrm{Be}-$ dingung des höchsten Guts ganz richtig gewählt, aber,

[127] indem sie den Grad derselben, der für das reine Gesetz

10 derselben erforderlich ist, als in diesem Leben völlig erreichbar vorstellten, nicht allein das moralische Vermögen des Menschen unter dem Namen eines Weisen über alle Schranken seiner Natur hoch gespannt und etwas, das aller Menschenkenntnis widerspricht, angenommen, sondern auch vornehmlich das zweite zum höchsten Gute gehörige Bestandstück, nämlich die Glückseligkeit, gar nicht für einen besonderen Gegenstand des menschlichen Begehrungsvermögens wollen gelten lassen, sondern ihren Weisen gleich einer Gott-

20 heit im Bewußtsein der Vortrefflichkeit seiner Person von der Natur (in Absicht auf seine Zufriedenheit) ganz unabhängig gemacht, indem sie ihn zwar Ubeln des Lebens aussetzten, aber nicht unterwarfen (zugleich auch als frei vom Bösen darstellten), und so wirklich das zweite Element des höchsten Guts, eigene Glückseligkeit, wegließen, indem sie es bloß im Handeln und der Zufriedenheit mit seinem persönlichen Werte setzten und also im Bewußtsein der sittlichen Denkungsart mit einschlossen, worin sie aber durch die

80 Stimme ihrer eigenen Natur hinreichend hätten widerlegt werden können.

Die Lehre des Christentums*), wenn man sie auch

*) Man hält gemeiniglich dafür, die christliche Vorschrift der Sitten habe in Ansehnng ihrer Reinigkeit vor dem moralischen Begriffe der Stoiker nichts voraus; allein der Unterschied beider ist doch sehr sichtbar. Das stoische System machte das Bewaßtsein der Seelenstärke zum Angel, um den sich alle sittliche Gesinnungen wenden sollten, und ob die Anhänger desselben zwar von Pflichten redeten, auch sie ganz wohl bestimmten, so setzten sio doch dio Triebfeder and den eigentlichen Bestimmungegrund de Willens in einer Erhebang der Denknngsart über die niedrigen. 
noch nicht als Religionslehre betrachtet, gibt in diesem Stücke einen Begriff des höchsten Guts (des Reichs

and nur durch Seelenschwăche machthabenden Triebfedern der Sinne. Tugend war also bei ihnen ein gewisser Heroismus des über die a) tierische Natur des Menschen sich erhebenden $\mathrm{W}$ eisen, der ihm selbst genug ist, anderen zwar Pflichten vorträgt, selbst aber über sie erhaben ${ }^{b}$ ) und keiner Versuchnng zu Obertretung des sittlichen Gesetzes unterworfen ist. Dieses alles aber konnten sie nicht tun, wenn sie sich dieses Gesetz in der Reinigkeit und Strenge, als es die Vorschrift des Evangelii tut, vorgestellt hätten. Wenn ich unter einer Idee eine Vollkommenheit verstehe, der nichts in der Erfahrung adäquat gegeben werden kann, so sind die moralischen Ideen darum nichts Oberschwengliches, d. i. dergleichen, wovon wir auch nicht einmsl den Begriff hinreichend bestimmen konnten, oder von dem es ungewiß ist, ob ihm überall ein Gegenstand korrespondiere, wie die Ideen der spekulativen Vernunft, sondern dienen, als Urbilder der praktischen Vollkommenheit, zar anentbehrlichen Richtschnur des sittlichen Verhaltens und zugleich zum Ma Bstabe der Vergleichung. Wenn ich nun die christliche Moral von ihrer philosophischen Seite betrachte, so würde sie, mit den Ideen der griechischen Schulen verglichen, so erscheinen: die Ideen der Cyniker, der Epiknreer, der Stoiker und derc) Christen sind: die Natureinfalt, die Klugheit, die Weisheit and die Heiligkeit. In Ansehung des Weges, dazu zu gelangen, nnterschieden sich die griechischen Philosophen so voneinander, daß die Cyniker daza den gemeinen Menschenverstand, die anderen nur den Weg der Wissenschaft, beide also doch bloßen Gebrauch der natürlichen Kräfte dazu hinreichend fanden. Die christliche Moral, weil sie ihre Vorschrift (wie es auch sein muß) so rein und unnachsichtlich einrichtet, benimmt dem Menschen das Zutrauen, wenigstens hier im Leben ihr vollig adäquat zn sein, richtet esd) aber doch anch dadurch wiederum auf, daß, wenn wir so gut handeln, als in unserem Verm $\varnothing \mathrm{g} \theta \mathrm{n}$ ist, wir hoffen konnen, daß, was nicht in unserem Vermögen ist, uns anderweitig werde zu Statten kommen, wir mögen nun wissen, auf welche Art, oder nicht. Aristoteles und Plato anterschieden sich nar in Ansehung des Ursprungs nnserer sittlichen Begriffe.

a) "die" Zusatz Hartensteins.

b) 1. und 4.-6. Anfl.: "erhoben".

c) 1. und 4.-6. Aufl.: "des".

d) „ihn“ (Natorp)? 
164 Erster Teil, II. Buch, 2. Hauptstück. V.

Gottes), der allein der strengsten Forderung der praktischen Vernunft ein Genüge tut. Das moralische Gesetz ist heilig (unnachsichtlich) und fordert Heiligkeit der Sitten, obgleich alle moralische Vollkommenheit, zu welcher der Mensch gelangen kann, immer nur Tugend ist, d. i. gesetzmäßige Gesinnung aus Achtung fürs Gesetz, folglich Bewußtsein eines kontinuierlichen Hanges zur Ubertretung, wenigstens Unlauterkeit, d. i. Beimischung vieler unechter (nicht mora10 lischer) Bewegungsgründe zur Befolgung des Gesetzes, folglich eine mit Demut verbundene Selbstschätzung, und also in der Ansehung der Heiligkeit, welche das christliche Gesetz fordert, nichts als Fortschritt ins Unendliche dem Geschöpfe übrig läßt, ebendaher aber auch dasselbe zur Hoffnung seiner ins Unendliche gehenden Fortdauer berechtigt. Der Wert einer dem moralischen Gesetze völlig angemessenen Gesinnung ist unendlich: weil alle mögliche Glückseligkeit im Urteile eines weisen und alles vermögenden Austeilers

20 derselben keine andere Einschränkung hat als den Mangel der Angemessenheit vernünftiger Wesen an ihrer Pflicht. Aber das moralische Gesetz für sich verheißt doch keine Glückseligkeit; denn diese ist, nach Begriffen von einer Naturordnung überhaupt, mit der Befolgung desselben nicht notwendig verbunden. Die christliche Sittenlehre ergänzt nun diesen Mangel (des zweiten unentbehrlichen Bestandstücks des höchsten Guts) durch die Darstellung der Welt, darin vernünftige Wesen sich dem sittlichen Gesetze von ganzer Seele 30 weihen, als eines Reichs Gottes, in welchem Natur und Sitten in eine jeder von beiden für sich selbst fremde Harmonie durch einen heiligen Urheber kommen, der das abgeleitete höchste Gut möglich macht. Die Heiligkeit der Sitten wird ihnen in diesem Leben

[129] schon zur Richtschnur angewiesen, das dieser proportionierte Wohl aber, die Seligkeit, nur als in einer Ewigkeit erreichbar vorgestellt; weil jene immer das Urbild ihres Verhaltens in jedem Stande sein muß, und das Fortschreiten $\mathrm{zu}$ ihr schon in diesem Leben mög40 lich und notwendig ist, diese aber in dieser Welt, unter dem Namen der Glückseligkeit, gar nicht erreicht werden kann (soviel auf unser Vermögen ankommt) 
und daher lediglich zum Gegenstande der Hoffnung gemacht wird. Diesem ungeachtet ist das christlicho Prinzip der Moral selbst doch nicht theologisch (mithin Heteronomie), sondern Autonomie der reinen praktischen Vernunft für sich selbst, weil sie die Erkenntnis Gottes und seines Willens nicht zum Grunde dieser Gesetze, sondern nur der Gelangung zum höchsten Gute unter der Bedingung der Befolgung derselben macht and selbst die eigentliche Triebfeder zu Befolgung der ersteren nicht in den gewünschten Folgen der- 10 selben, sondern in der Vorstellung der Pflicht allein setzt, als in deren treuer Beobachtung die Würdigkeit des Erwerbs der letzteren allein besteht.

Auf solche Weise führt das moralische Gesetz durch den Begriff des höchsten Guts, als das Objekt und den Endzweck der reinen praktischen Vernunft, zur Religion, d. i. zur Erkenntnis aller Pflichten als göttlicher Gebote, nicht als Sanktionen, d. i. willkürlichera), für sich selbst zufälliger ${ }^{2}$ ) Verordnungen eines fremden Wil- 20 lens, sondern als wesentlicher Gesetze eines jeden freien Willens für sich selbst, die aber dennoch als Gebote des höchsten Wesens angesehen werden müssen, weil wir nur von einem moralisch vollkommenen (heiligen und gütigen), zugleich auch allgewaltigen Willen das höchste Gut, welches zum Gegenstande unserer Bestrebung zu setzen uns das moralische Gesetz zur Pflicht macht, und also durch Ubereinstimmung mit diesem Willen dazu zu gelangen b) hoffen können. Auch hier bleibt daher alles uneigennützig und bloß auf 30 Pflicht gegründet; ohne daß Furcht oder Hoffnung als Triebfedern zum Grunde gelegt werden dürften, die, wenn sie zu Prinzipien werden, den ganzen moralischen Wert der Handlungen vernichten. Das moralische Gesetz gebietet, das höchste mögliche Gut in einer Welt mir zum letzten Gegenstande alles Verhaltens zu machen. Dieses aber kann ich nicht zu bewirken hoffen, als nur durch die Ubereinstimmung meines Willens mit dem eines heiligen und gütigen Welturhebers; und obgleich in dem Begriffe des höchsten Guts als dem 40

a) Kant: „willkürliche ... zufällige"; korr. Hartenstein.

b) Keltermann: „dazu, zu erlangen". 
166 Erster Teil, II. Buch, 2. Hauptstäck. V.

eines Ganzen, worin die größte Glückseligkeit mit dem größten $\mathrm{Maße}$ sittlicher (in Geschöpfen möglicher) Vollkommenheit als in der genauesten Proportion ver[130] bunden vorgestellt wird, meine eigene Glückseligkeit mitenthalten ist: so ist doch nicht sie, sondern das moralische Gesetz (welches vielmehr mein unbegrenztes Verlangen danach auf Bedingungen strenge einschränkt) der Bestimmungsgrund des Willens, der zur Beförderung des höchsten Guts angewiesen wird.

10 Daher ist auch die Moral nicht eigentlich die Lehre, wie wir uns glücklich machen, sondern wie wir der Glückseligkeit wür dig werden sollen. Nur dann, wenn Religion dazu kommt, tritt auch die Hoffnung ein, der Glückseligkeit dereinst in dem Maße teilhaftig zu werden, als wir darauf bedacht gewesen, ihrer nicht unwürdig zu sein.

Würdig ist jemand des Besitzes einer Sache oder eines Zustandes, wenn, da $\beta$ er in diesem Besitze sei, mit dem höchsten Gute zusammenstimmt. Man kann

20 jetzt leicht einsehen, daß alle Würdigkeit auf das sittliche Verhalten ankomme, weil dieses im Begriffe des höchsten Guts die Bedingung des übrigen (was zum Zustande gehört), nämlich des Anteils an Glückseligkeit, ausmacht. Nun folgt hieraus: daß man die Moral an sich niemals als Glückseligkeitslehre behandeln müsse, d. i. als eine Anweisung, der Glückseligkeit teilhaftig zu werden; denn sie hat es lediglich mit der Vernunftbedingung (conditio sine qua non) der letzteren, nicht mit einem Erwerbmittel derselben zu 30 tun. Wenn sie aber (die bloß Pflichten auferlegt, nicht eigennützigen Wünschen Maßregeln an die Hand gibt) vollständig vorgetragen worden: alsdann allererst kann, nachdem der sich auf ein Gesetz gründende moralische Wunsch, das höchste Gut zu befördern (das Reich Gottes zu uns zu bringen), der vorher keiner eigennützigen Seele aufsteigen konnte, erweckt und ihm zu Behuf der Schritt zur Religion geschehen ist, diese Sittenlehre auch Glückseligkeitslehre genannt werden, weil die Hoffnung dazu nur mit der Religion 40 allererst anhebt.

Auch kann man hieraus ersehen: daß, wenn man nach dem letzten Zwecke Gottes in Schöpfung der 
Welt fragt, man nicht die Glückseligkeit der vernünftigen Wesen in ihr, sondern das höchste Gut nennen müsse, welches jenem Wunsche dieser Wesen noch eine Bedingung, nämlich die, der Glückseligkeit würdig zu sein, d. i. die Sittlichkeit ebenderselben vernünftigen Wesen hinzufügt, die allein den Maßstab enthält, nach welchem sie allein der ersteren durch die Hand eines weisen Urhebers teilhaftig zu werden hoffen können. Denn da Weisheit, theoretisch betrachtet, die Erkenntnis des höchsten Guts und praktisch die Angemessenheit des Willens zum höchsten Gute bedeutet, so kann man einer höchsten selbständigen Weisheit nicht einen Zweck beilegen, der bloß auf $G$ ütigkeit gegründet wäre. Denn dieser ihre Wirkung (in Ansehung der Glückseligkeit der vernünftigen Wesen) kann man nur unter den einschränkenden Bedingungen der Ubereinstimmung mit der Heiligkeit*) seines Willens als dem höchsten ursprünglichen Gute angemessen denken. Daher diejenigen, welche den Zweck der Schöpfung in die Ehre 20 Gottes (vorausgesetzt da $\beta$ man diese nicht anthropomorphistisch als Neigung, gepriesen zu werden, denkt) setzten, wohl den besten Ausdruck getroffen haben. Denn nichts ehrt Gott mehr als das, was das

*) Hierbei und um das Eigentïmliche dieser Begriffe kenntlich zu machen, merke ich nur noch an: daß, da man Gott verschiedene Eigenschaften beilegt, deren Qualität man auch den Geschöpfen angemessen findet, nar daß sie dort zam höchsten Grade erhoben werden, z. B. Macht, Wissenschaft, Gegenwart, Güte nsw. unter den Benennungen der Allmacht, der Allwissenheit, der Allgegenwart, der Allgütigkeit usw., es doch drei gibt, die ausschließangsweise und doch ohne Beisatz von Große Gott beigelegt werden, und die insgesamt moralisch sind: or ist der allein $\mathrm{Hei}$ lige, der allein Selige, der allein Weise; weil diese Begriffe schon die Uneingeschränktheit bei sich führen. Nach der Ordnung derselben ist er denn also anch der heilige Gesetzgeber (und Schopfer), der gütige Regierer (nnd Erhalter) und der gèrechte Richter: drei Eigenschaften, die alles in sich enthalten, wodurch Gott der -Gegenstand der Religion wird, and denen angemessen die metaphysischen Vollkommonheiten sich von selbst in der Vernunft hinzufügen. 
Schätzbarste in der Welt ist, die Achtung für sein Gebot, die Beobachtung der heiligen Pflicht, die uns sein Gesetz auferlegt, wenn seine herrliche Anstalt dazu kommt, eine solche schöne Ordnung mit angemessener Glückseligkeit zu krönen. Wenn ihn das letztere (auf menschliche Art zu reden) liebenswürdig macht, so ist er durch das erstere ein Gegenstand der Anbetung (Adoration). Selbst Menschen können sich durch Wohltun zwar Liebe, aber dadurch allein nie-

10 mals Achtung erwerben, sodaß die größte Wohltätigkeit ihnen nur dadurch Ehre macht, daß sie nach Würdigkeit ausgeübt wird.

$\mathrm{DaB}$ in der Ordnung der Zwecke der Mensch (mit ihm jedes vernünftige Wesen) $Z$ weck an sich selbst sei, d. i. niemals bloß als Mittel von jemanden (selbst nicht von Gott), ohne zugleich hierbei selbst Zweck zu sein, könne gebraucht werden, daß also die Menschheit in unserer Person uns selbst heilig sein müsse, folgt nunmehr von selbst, weil er das

20 Subjekt des moralischen Gesetzes, mithin dessen [132] ist, was an sich heilig ist, um dessen willen und in Einstimmung mit welchem auch überhaupt nur etwas heilig genannt werden kann. Denn dieses moralische Gesetz gründet sich auf der Autonomie seines Willens als eines freien Willens, der nach seinen allgemeinen Gesetzen notwendig zu demjenigen zugleich muß einstimmen können, welchem er sich unterwerfen soll.

\section{VI.}

30

\section{Utber die Postulate der reinen praktischen}

Vernunft überhaupt.

Sie gehen alle vom Grundsatze der Moralität aus, der kein Postulat, sondern ein Gesetz ist, durch welches Vernunft unmittelbar ${ }^{a}$ ) den Willen bestimmt, welcher Wille, ebendadurch da $B$ er so bestimmt ist, als reiner Wille, diese notwendigen Bedingungen der Befolgung seiner Vorschrift fordert. Diese Postulate sind nicht theoretische Dogmata, sondern Voraussetzungen in notwendig prăktischer Rücksicht, erweitern also zwar

a) Kant: „mittelbar"; korr. Hartenstein. 
Die Postalate d. reinen prakt. Vernunft überhaupt. 169

nichta) die spekulative Erkenntnis, geben aber den Ideen der spekulativen Vernunft im allgemeinen (vermittelst ihrer Beziehung auf das Praktische) objektive Realität und berechtigen sie zu Begriffen, deren Möglichkeit auch nur zu behaupten sie sich sonst nicht anmaßen könnte.

Diese Postulate sind die der Unsterblichkeit, der Freiheit, positiv betrachtet (als der Kausalität eines Wesens, sofern es zur intelligibelen Welt gehört), und des Daseins Gottes. Das erste fließt aus 10 der praktisch notwendigen Bedingung der Angemessenheit der Dauer zur Vollständigkeit der Erfüllung des moralischen Gesetzes; das zweite aus der notwendigen Voraussetzung der Unabhängigkeit von der Sinnenwelt und des Vermögens der Bestimmung seines Willens nach dem Gesetze einer intelligibelen Welt, d. i. der Freiheit; das dritte aus der Notwendigkeit der Bedingung $\mathrm{zu}$ einer solchen intelligibelen Welt, um das höchste Gut zu sein, durch die Voraussetzung des höchsten selbständigen Guts, d. i. des Daseins 20 Gottes.

Die durch die Achtung fürs moralisché Gesetz notwendige Absicht auf das höchste Gut und daraus flieBende Voraussetzung der objektiven Realität desselben führt also durch Postulate der praktischen Vernunft zu Begriffen, welche die spekulative Vernunft zwar als Aufgaben vortragen, sie aber nicht auflösen konnte. Also 1) zu derjenigen, in deren Auflösung die letztere nichts als Paralogismen begehen konnte (nämlich der Unsterblichkeit), weil es hier am Merkmale der Beharr- 30 lichkeit fehlte, um den psychologischen Begriff eines letzten Subjekts, welcher der Seele im Selbstbewußtsein notwendig beigelegt wird, zur realen Vorstellung einer Substanz zu ergänzen, welches die praktische Vernunft durch das Postulat einer zur Angemessenheit mit dem moralischen Gesetze im höchsten Gute als dem ganzen Zwecke der praktischen Vernunft erforderlichen Dauer ausrichtet. 2) Führt sie zu dem, wovon die spekulative Vernunft nichts als Antinomie ent- 
hielt, deren Auflösung sie nur auf einem problematisch zwar denkbaren, aber seiner objektiven Realität nach für sie nicht erweislichen und bestimmbaren Begriffe gründen konnte, nämlich die kosmologische Idee einer intelligibelen Welt und das Bewußtsein unseres Daseins in derselben, vermittelst des Postulats der Freiheit (deren Realität sie durch das moralische Gesetz darlegt und mit ihm zugleich das Gesetz einer intelligibelen Welt, worauf die spekulative nur hinweisen, 10 ihren Begriff aber nicht bestimmen konnte). 3) Verschafft sie dem, was spekulative Vernunft zwar denken, aber als bloßes transzendentales Ideal unbestimmt lassen mußte, dem theologischen Begriffe des Urwesens, Bedeutung (in praktischer Absicht, d. i. als einer Bedingung der Möglichkeit des Objektes eines durch jenes Gesetz bestimmten Willens), als dem obersten Prinzip des höchsten Guts in einer intelligibelen Welt durch gewalthabende moralische Gesetzgebung in derselben.

20 Wird nun aber unsere Erkenntnis auf solche Art durch reine praktische Vernunft wirklich erweitert, und ist das, was für die spekulative transzendent war, in der praktischen immanent? Allerdings, aber nur in praktischer Absicht. Denn wir erkennen zwar dadurch weder unserer Seele Natur noch die intelligibele Welt noch das höchste Wesen nach dem, was sie an sich selbst sind, sondern haben nur die Begriffe von ihnen im praktischen Begriffe des höchsten Guts vereinigt, als dem Objekte unseres Willens, 30 und völlig a priori durch reine Vernunft, aber nur vermittelst des moralischen Gesetzes und auch bloß in Beziehung auf dasselbe in Ansehung des Objekts, das es gebietet. Wie aber auch nur die Freiheit möglich sei, und wie man sich diese Art von Kausalität theoretisch und positiv vorzustellen habe, wird dadurch nicht eingesehen, sondern nur, daß eine solche sei, durch das moralische Gesetz und zu dessen Behuf postuliert. So ist es auch mit den übrigen Ideen bewandt, die nach ihrer Möglichkeit kein menschlicher Verstand jemals

[134] 40 ergründen, aber auch, daß sie nicht wahre Begriffe sind, keine Sophisterei der Utberzeugung selbst des gemeinsten Menschen jemals entreißen wird. 
Wio eine Erweiterung der reinen Vernunft usw.

VII.

Wie eine Erweiterung der reinon Vernunft in praktischer Absicht, ohne damit ihre Erkenntnis als spekulativ zugleich zu erweitern, zu denken moglich sei?

Wir wollen diese Frage, um nicht zu abstrakt zu werden, sofort in Anwendung auf den vorliegenden Fall beantworten. - Um eine reine Erkenntnis praktisch zu erweitern, muß eine Absicht a priori gegeben sein, d. i. ein Zweck als Objekt (des Willens), 10 welches unabhängig von allen theoretischen ${ }^{2}$ ) Grundsätzen, durch einen den Willen unmittelbar bestimmenden (kategorischen) Imperativ, als praktisch notwendig vorgestellt wird; und das ist hier das höchste Gut. Dieses ist aber nicht möglich, ohne drei theoretische Begriffe (für die sich, weil sie bloße reine Vernunftbegriffe sind, keine korrespondierende Anschauung, mithin auf dem theoretischen Wege keine objektive Realität finden läßt) vorauszusetzen: nämlich Freiheit, Unsterblichkeit und Gott. Also wird durchs prak-20 tische Gesetz, welches die Existenz des höchsten in einer Welt möglichen Guts gebietet, die Möglichkeit jener Objekte der reinen spekulativen Vernunft, die objektive Realität, welche diese ihnen nicht sichern konnte, postuliert; wodurch denn die theoretische Erkenntnis der reinen Vernunft allerdings einen Zuwachs bekommt, der aber bloß darin besteht, daß jene für sie sonst problematischen (bloß denkbaren) Begriffe jetzt assertorisch für solche erklärt werden, denen wirklich Objekte zukommen, weil praktische Vernunft 30 die Existenz derselben zur Möglichkeit ihres und zwar praktisch schlechthin notwendigen Objekts des höchsten Guts, unvermeidlich bedarf, und die theoretische dadurch berechtigt wird, sie vorauszusetzen. Diese Erweiterung der theoretischen Vernunft ist aber keine Erweiterung der Spekulation, d. i. um in theoretischer Absicht nunmehr einen positiven Gebrauch davon

a) Kant: „theologischen", korr. Hartenstein; Grillo: "teleologischen". 
zu machen. Denn da nichts weiter durch praktische Vernunft hierbei geleistet worden, als daß jene $\mathrm{Be}-$ griffe real sind und wirklich ihre (möglichen) Objekte haben, dabei aber uns nichts von Anschauungen derselben gegeben wird (welches auch nicht gefordert werden kann), so ist kein synthetischer Satz durch diese eingeräumte Realität derselben möglich. Folglich hilft uns diese Eröffnung nicht im mindesten in speku[135] lativer Absicht, wohl aber in Ansehung des prak-

10 tischen Gebrauchs der reinen Vernunft zur Erweiterung dieser unserer Erkenntnis. Die obigen drei Ideen der spekulativen Vernunft sind an sich noch keine Erkenntnisse; doch sind es (transzendente) Gedanken, in denen nichts Unmögliches ist. Nun bekommen sie durch ein apodiktisches praktisches Gesetz als notwendige Bedingungen der Möglichkeit dessen, was dieses sich zum Objekte zu machen gebietet, objektive Realität, d. i. wir werden durch jenes angewiesen, da $B$ sie Objekte haben, ohne doch, wie sich

$20 \mathrm{ihr}$ Begriff auf ein Objekt bezieht, anzeigen zu können, und das ist auch noch nicht Erkenntnis dieser $\mathrm{Ob}$ jekte; denn man kann dadurch gar nichts über sie synthetisch urteilen noch die Anwendung derselben theoretisch bestimmen, mithin von ihnen gar keinen theoretischen Gebrauch der Vernunft machen, als worin eigentlich alle spekulative Erkenntnis derselben besteht. Aber dennoch ward die theoretische Erkenntnis zwar nicht dieser Objekte, aber der Vernunft überhaupt dadurch sofern erweitert, daß durch die

so praktischen Postulate jenen Ideen doch Objekte gegeben wurden, indem ein bloß problematischer Gedanke dadurch allererst objektive Realität bekam. Also war es keine Erweiterung der Erkenntnis von gegebenen übersinnlichen Gegenständen, aber doch eine Erweiterung der theoretischen Vernunft und der Erkenntnis derselben in Ansehung des Ubersinnlichen überhaupt, sofern als sie genötigt wurde, da $B$ es solche Gegenstände gebe, einzuräumen, ohne sie doch näher bestimmen, mithin diese Erkenntnis von

40 den Objekten (die ihr nunmehr aus praktischem Grunde und auch nur zum praktischen Gebrauche gegeben worden) selbst erweitern zu können, welchen Zuwachs 
also die reine theoretische Vernunft, für die alle jene Ideen transzendent und ohne Objekt sind, lediglich ihrem reinen praktischen Vermögen zu verdanken hat. Hier werden sie immanent und konstitutiv, indem sie Gründe der Möglichkeit sind, das ${ }^{2}$ ) notwe ndige Objekt der reinen praktischen Vernunft (das höchste Gut) wirklich zu machen, da sie ohne dies transzendent und bloß regulative Prinzipien der spekulativen Vernunft sind, die $\mathrm{ihr}$ nicht ein neues Objekt über die Erfahrung hinaus anzunehmen, sondern nur 10 ihren Gebrauch in der Erfahrung der Vollständigkeit zu nähern auferlegen. Ist aber die Vernunft einmal im Besitze dieses Zuwachses, so wird sie als spekulative Vernunft (eigentlich nur zur Sicherung ihres praktischen Gebrauchs) negativ, d. i. nicht erweiternd, sondern läuternd mit jenen Ideen zu Werke gehen, um einerseits den Anthropomorphismus als den Quell der Superstition oder scheinbare Erweiterung jener Begriffe durch vermeinte Erfahrung, andererseits den $[136]$ Fanatizismus, der sie $^{b}$ ) durch übersinnliche An- 20 schauung oder dergleichen Gefühle verspricht, abzuhalten; welches alles Hindernisse des praktischen Gebrauchs der reinen Vernunft sind, deren Abwehrung also zu der Erweiterung unserer Erkenntnis in praktischer Absicht allerdings gehört, ohne ${ }^{c}$ ) daß es dieser widerspricht, zugleich zu gestehen, daß die Vernunft in spekulativer Absicht dadurch im mindesten nichts gewonnen habe.

$\mathrm{Zu}$ jedem Gebrauch der Vernunft in Ansehung eines Gegenstandes werden reine Verstandesbegriffe 30 (Kategorien) erfordert, ohne die kein Gegenstand gedacht werden kann. Diese können zum theoretischen Gebrauche der Vernunft, d. i. zu dergleichen Erkenntnis nur angewandt werden, sofern ihnen zugleich Anschauung (die jederzeit sinnlich ist) untergelegt wird, und also bloß, um durch sio ein Objekt möglicher Erfahrung vorzustellen. Nun sind hier aber Ideen der Vernunft, die in gar keiner Erfahrung gegeben

a) Original: „sind. Das".

b) sc. die Erweiterang.

c) Kant: „oder“; korr. Hartenstein. 
174 Erster Teil, II. Buch, 2. Hauptstück. VII.

werden können, das, was ich durch Kategorien denken müßte, um es $\mathrm{zu}$ erkennen. Allein es ist hier auch nicht um die theoretische Erkenntnis der Objekte dieser Ideen, sondern nur darum, daß sie überhaupt Objekte haben, zu tun. Diese Realität verschafft reine praktisch $\theta$ Vernunft, und hierbei hat die theoretische Vernunft nichts weiter zu tun, als jene Objekte durch Kategorien bloß zu denken, welches, wie wir sonst deutlich gewiesen haben, ganz wohl, ohne Anschauung

10 (weder sinnliche noch übersinnliche) $\mathrm{zu}$ bedürfen, angeht, weil die Kategorien im reinen Verstande unabhängig und vor aller Anschauung, lediglich als dem Vermögen zu denken, ihren Sitz und Ursprung haben, und sie immer nur ein Objekt überhaupt bedeuten, a uf welche Art es uns auch immer gegeben werden mag. Nun ist den Kategorien, sofern sie auf jene Ideen angewandt werden sollen, zwar kein Objekt in der Anschauung zu geben möglich; es ist ihnen aber doch, daß ein solches wirklich sei, mithin

20 die Kategorie als eine bloße Gedankenform hier nicht leer sei, sondern Bedeutung habe, durch eîn Objekt, welches die praktische Vernunft im Begriff des höchsten Guts ungezweifelt darbietet, die Realität der Begriffe, die zum Behuf der Möglichkeit des höchisten Guts gehören, hinreichend gesichert, ohne gleichwohl durch diesen Zuwachs die mindeste Erweiterung der Erkenntnis nach theoretischen Grundsätzen zu bewirken.

[137] Wenn nächstdem diese Ideen von Gott, einer in30 telligibelen Welt (dem Reiche Gottes) und der Unsterblichkeit durch Prädikate bestimmt werden, die von unserer eigenen Natur hergenommen sind, so darf man diese Bestimmung weder als Versinnlichung jener reinen Vernunftideen (Anthropomorphismen), noch als überschwengliche Erkenntnis übersinnlicher Gegenstände ansehen; denn diese Prädikate sind keine anderen als Verstand und Wille, und zwar so im Verhältnisse gegeneinander betrachtet, als sie im moralischen Gesetze gedacht werden müssen,

40 also nur, soweit von ihnen ein reiner praktischer Gebrauch gemacht wird. Von allem übrigen, was dieson 
Wie eine Erweiterung der reinen Vernanft usw. 175

Begriffen psychologisch anhängt, d. i. sofern wir diese unsere Vermögen in ihrer Ausübung empirisch beobachten (z. B. daß der Verstand des Menschen diskursiv ist, seine Vorstellungen also Gedanken, nicht Anschauungen sind, daß diese in der Zeit aufeinander folgen, daß sein Wille immer mit einer Abhängigkeit der Zufriedenheit von der Existenz seines Gegenstandes behaftet ist usw., welches im höchsten Wesen so nicht sein kann), wird alsdann abstrahiert; und so bleibt von den Begriffen, durch die wir uns ein reines Verstandeswesen denken, nichts mehr übrig, als gerade zur Möglichkeit erforderlich ist, sich ein moralisch Gesetz zu denken, mithin zwar eine Erkenntnis Gottes, aber nur in praktischer Beziehung; wodurch, wenn wir den Versuch machen, sie $\mathrm{zu}$ einer theoretischen $\mathrm{zu}$ erweitern, wir einen Verstand desselben bekommen, der nicht denkt, sondern anschaut, einen Willen, der auf Gegenstände gerichtet ist, von deren Existenz seine Zufriedenheit nicht im mindesten abhängt (ich will nicht einmal der transzendentalen Prädikate erwähnen, als 20 z. B. eine Größe der Existenz, d. i. Dauer, die aber nicht in der Zeit, als dem einzigen uns möglichen Mittel, uns Dasein als Größe vorzustellen, stattfindet): lauter Eigenschaften, von denen wir uns gar keinen Begriff, zur Erkenntnis des Gegenstandes tauglich, machen können, und dadurch belehrt werden, daß sie niemals zu einer Theorie von übersinnlichen Wesen gebraucht werden können und also auf dieser Seite eine spekulative Erkenntnis zu gründen gar nicht vermögen, sondern ihren Gebrauch lediglich auf die Ausübung 30 des moralischen Gesetzes einschränken.

Dieses letztere ist so augenscheinlich und kann so klar durch die Tat bewiesen werden, daß man getrost alle vermeinten natürlichen Gottesgelehrten (ein wunderlicher Name)*) auffordern kann, auch nur eine

*) Gelehrsamkeit ist eigentlich nur ein Inbegriff historischer Wissenschaften. Folglich kann nur der Lehrer der geoffenbarten Theologie ein Gotteagelehrter heißen. Wollte man aber auch den, der im Besitze von Vernunftwissenschaften (Mathematik and Philosophie) ist, einen Gelehrten nennen, obgleich dieses schon der Wort- 
[138] diesen ihren Gegenstand (über die bloß ontologischen Prädikate hinaus) bestimmende Eigenschaft, etwa des Verstandes oder des Willens zu nennen, an der man nicht unwidersprechlich dartun könnte, daß, wenn man alles Anthropomorphistische davon absondert, uns nur das bloße Wort übrig bleibe, ohne damit den mindesten Begriff verbinden zu können, dadurch eine Erweiterung der theoretischen Erkenntnis gehofft werden dürfte. In Ansehung des Praktischen aber bleibt uns

10 von den Eigenschaften eines Verstandes und Willens doch noch der Begriff eines Verhältnisses übrig, welchem das praktische Gesetz (das gerade dieses Verhältnis des Verstandes zum Willen a priori bestimmt) objektive Realität verschafft. Ist dieses nun einmal geschehen, so wird dem Begriffe des Objekts eines moralisch bestimmten Willens (dem des höchsten Guts) und mit ihm den Bedingungen seiner Möglichkeit, den Ideen von Gott, Freiheit und Unsterblichkeit, auch Realität, aber immer nur in Beziehung auf die Ausübung des

20 moralischen Gesetzes (zu keinem spekulativen Behuf) gegeben.

Nach diesen Erinnerungen ist nun auch die Beantwortung der wichtigen Frage leicht $z \mathfrak{a}$ finden: ob der Begriff von Gott oin zur Physik (mithin auch zur Metaphysik, als die nur die reinen Prinzipien a priori der ersteren in allgemeiner Bedeutung enthält), oder ein zur Moral gehöriger Begriff sei? Natureinrichtungen oder deren Veränderung zu erklären, wenn man da zu Gott als dem Urheber aller Dinge

80 seine Zuflucht nimmt, ist wenigstens keine physische Erklärung und überall ein Geständnis, man sei mit seiner Philosophie zu Ende: weil man genötigt ist, etwas, wovon man sonst für sich keinen Begriff hat, anzunehmen, um sich von der Möglichkeit dessen, was

bedeutung (als die jederzeit nur dasjenige, welches darchaus gelehrt werden mab, and was man also nicht von selbst durch Vernunft erfinden kann, zur Gelehrsamkeit zählt) widerstreiten wärde: so möchte wohl der Philosoph mit seiner Erkentnis Gottes als positiver Wissenschaft eine zu schlechte Figur machen, am sich deshalb einen Gelehrten nenner. za lassen. 
Wie eine Erweiterung der reinen Vernunft usw. 177

man vor Augen sieht, einen Begriff machen zu können. Durch Metaphysik aber von der Erkenntnis dieser Welt zum Begriffe von Gott und dem Beweise seiner Existenz durch sichere Schlüsse zu gelangen, ist darum unmöglich, weil wir diese Welt als das vollkommenste mögliche Ganze, mithin zu diesem Behuf alle mögliche Welten (um sie mit dieser vergleichen zu können) erkennen, mithin allwissend sein müßten, um zu sagen, daß sie nur durch einen Gott (wie wir uns diesen Begriff denken müssen) möglich war. 10 Vollends aber die Existenz dieses Wesens aus bloßen Begriffen zu erkennen, ist schlechterdings unmöglich, weil ein jeder Existentialsatz, d. i. der, so von einem Wesen, von dem ich mir einen Begriff mache, sagt, daß es existiere, ein synthetischer Satz ist, d. i. ein solcher, dadurch ich über jenen Begriff hinausgehe und mehr von ihm sage, als im Begriffe gedacht war: nämlich daß diesem Begriffe im Verstande noch ein Gegenstand außer dem Verstande korrespondierend gesetzt sei, welches offenbar unmöglich ist durch 20 irgend einen Schluß herauszubringen. Also bleibt nur ein einziges Verfahren für die Vernunft übrig, zu dieser Erkenntnis zu gelangen, da sie nämlich als reine Vernunft von dem obersten Prinzip ihres reinen praktischen Gebrauchs ausgehend (indem dieser ohnedem bloß auf die Existenz von Etwas als Folge der Vernunft gerichtet ist) ihr Objekt bestimmt. Und da zeigt sich nicht allein in ihrer unvermeidlichen Aufgabe, nämlich der notwendigen Richtung des Willens auf das höchste Gut, die Notwendigkeit, ein solches Urwesen in Be- 80 ziehung auf die Möglichkeit dieses Guten in der Welt anzunehmen, sondern, was das Merkwürdigste ist, etwas, was dem Fortgange der Vernunft auf dem Naturwege ganz mangelte, nämlich ein genau bestimmter Begriff dieses Urwesens. Da wir diese Welt nur zu einem kleinen Teile kennen, noch weniger: sie mit allen möglichen Welten vergleichen können, so können wir von ihrer Ordnung, ZweckmäBigkeit und Größe wohl auf einen weisen, gütigen, mächtigen usw. Urheber derselben schließen, aber nicht 40 auf seine Allwissenheit, Allgütigkeit, Allmacht usw. Man kann auch gar wohl einräumen,

Kant, Kritik der prakt. Vernunft. 
daß man diesen unvermeidlichen Mangel durch eine erlaubte, ganz vernünftige Hypothese zu ergânzen wohl befugt sei: daß nämlich, wenn in soviel Stücken, als sich unserer näheren Kenntnis darbieten, Weisheit, Gütigkeit usw. hervorleuchtet, in allen übrigen es ebenso sein werde und es also vernünftig sei, dem Welturheber alle mögliche Vollkommenheit beizulegen; aber das sind keine Schlüsse, wodurch wir uns auf unsere Einsicht etwas dünken: sondern nur Befugnisse,

10 die man uns nachsehen kann, und doch noch einer anderweitigen Empfehlung bedürfen, um davon Gebrauch zu machen. Der Begriff von Gott bleibt also auf dem empirischen Wege (der Physik) immer ein nicht genau bestimmter Begriff von der Vollkommenheit des ersten Wesens, um ihn dem Begriffo einer Gottheit für angemessen zu halten (mit der Metaphysik aber in ihrem transzendentalen Teile ist gar nichts auszurichten).

[140] Ich versuche nun diesen Begriff an das Objekt der.

20 praktischen Vernunft zu halten, und da finde ich, daß der moralische Grundsatz ihn ${ }^{2}$ ) nur als möglich unter Voraussetzung eines Welturhebers von höchster Vollkommenheit zulasse. Er muß allwissend sein, um mein Verhalten bis zum Innersten meiner Gesinnung in allen möglichen Fällen und in alle Zukunft zu erkennen; allmächtig, um ihm die angemessenen Folgen zu erteilen; ebenso allgegenwärtig, ewig usw. Mithin bestimmt das moralische Gesetz durch den Begriff des höchsten Guts, als Gegenstandes

30 einer reinen praktischen Vernunft, den Begriff des Urwesens als höchsten Wesens, welches der physische (und höher fortgesetzt der metaphysische), mithin der ganze spekulative Gang der Vernunft nicht bewirken konnte. Also ist der Begriff von Gott ein ursprünglich nicht zur Physik, d. i. für die spekulative Vernunft, sondern zur Moral gehöriger Begriff, und ebendas kann man auch von den übrigen Vernunftbegriffen sagen, von denen wir als Postulaten derselben in ihrem praktischen Gebrauche oben gehandelt haben. 40 Wenn man in der Geschichte der griechischen

a) „es" [Natorp]? 
Wie eine Erweiterang der reinen Vernunft usw. 179

Philosophie über den Anaxagoras hinaus keine deutlichen Spuren einer reinen Vernunfttheologie antrifft, so ist der Grund nicht darin gelegen, daß es den älteren Philosophen an Verstand und Einsicht fehlte, um durch den Weg der Spekulation, wenigstens mit Beihilfe einer ganz vernünftigen Hypothese, sich dahin zu erheben; was konnte leichter, was natürlicher sein, als der sich von selbst jedermann darbietende Godanke, statt unbestimmter Grade der Vollkommenheit verschiedener Weltursachen eine einzige vernünftige 10 anzunehmen, die alle Vollkommenheit hat? Aber die Utbel in der Welt schienen ihnen viel zu wichtige Einwürfe zu sein, um zu einer solchen Hypothese sich für berechtigt zu halten. Mithin zeigten sie darin eben Verstand und Einsicht, daß sie sich jene nicht erlaubten und vielmehr in den Naturursachen herumsuchten, ob: sie unter ihnen nicht die $\mathrm{zu}^{\mathrm{a}}$ ) Urwesen erforderliche Beschaffenheit und Vermögen antreffen möchten. Aber nachdem dieses scharfsinnige Volk soweit in Nachforschungen fortgerückt war, selbst sittliche Gegen- 20 stände, darüber andere Völker niemals mehr als geschwatzt haben, philosophisch zu behandeln: da fanden sie allererst ein neues Bedürfnis, nämlich ein praktisches, welches nicht ermangelte, ihnen den Begriff des Urwesens bestimmt anzugeben, wobei die spekulative Vernunft das Zusehen hatte, höchstens noch das Verdienst, einen Begriff, der nicht auf ihrem Boden erwachsen war, auszuschmückẻn und mit einem Gefolge von Bestätigungen aus der Naturbetrachtung, die nun allererst hervortraten, wohl nicht das Ansehen des- 30 selben (welches schon gegründet war), sondern vielmehr nur das Gepränge mit vermeinter theoretischer Vernunfteinsicht zu befördern.

Aus diesen Erinnerungen wird der Leser der Kritik der reinen spekulativen Vernunft sich vollkommen überzeugen, wie höchst nötig, wie ersprießlich für Theologie und Moral jene mühsame Deduktion der Kategorien war. Denn dadurch allein kann verhütet werden, sie, wenn man sie im reinen Verstande setzt,

a) „zum" [Hartenstein]? 
mit Plato für angeboren zu halten und darauf überschwengliche Anmaßungen mit Theorien des Ubersinnlichen, wovon man kein Ende absieht, zu gründen, dadurch aber die Theologie zur Zauberlaterne von Hirngespenstern zu machen; wenn man sie aber für erworben hält, zu verhüten, daß man nicht mit Epikur allen und jeden Gebrauch derselben, selbst den in praktischer Absicht, bloß auf Gegenstände und Bestimmungsgründe der Sinne einschränke. Nun aber,

10 nachdem die Kritik in jener Deduktion erstlich bewies, daß sie nicht empirischen Ursprungs sind, sondern a priori im reinen Verstande ihren Sitz und Quelle haben; zw eitens auch, daß, da sie a uf Gegenst ände überhaupt unabhängig von ihrer Anschauung bezogen werden, sie zwar nur in Anwendung auf empirische Gegenstände theoretische Erkenntnis zustande bringen, aber doch auch, auf einen durch reine praktische Vernunft gegebenen Gegenstand angewandt, zum bestimmten Denken des Ubersinnlichen die-

20 nen, jedoch nur, sofern dieses bloß durch solche Prädikate bestimmt wird, die notwendig zur reinen, a priori gegebenen praktischen Absicht und deren Möglíchkeit gehören. Spekulative Einschränkung der reinen Vernunft und praktische Erweiterung derselben bringen dieselbe allererst in dasjenige Verhältnis der Gleichheit, worin Vernunft überhaupt zweckmäßig gebraucht werden kann, und dieses Beispiel beweist besser als sonst eines, daß der Weg zur Weisheit, wenn er gesichert und nicht ungangbar oder

80 irreleitend werden soll, bei uns Menschen unvermeidlich durch die Wissenschaft durchgehen müsse, wovon man aber, daß diese zu jenem Ziele führe, nur nach Vollendung derselben überzeugt werden kann.

\section{VIII.}

Vom Fürwahrhalten ans einem Bedürfnisse der reinen Vernunft.

Ein Bedürfnis der reinen Vernunft in ihrem spekulativen Gebrauche führt nur auf Hypothesen, das der reinen praktischen Vernunft aber zu Postulaten; 40 denn im ersteren Fallo steige ich vom Abgeleiteten 
Vom Fürwahrhalten aus e. Bedürfnisse d. r. Vernunft. 181

so hoch hinauf in der Reihe der Gründe, wie ich will, und bedarf eines Urgrundesa), nicht um jenem Abgeleiteten (z. B. der Kausalverbindung der Dinge und Veränderungen in der Welt) objektive Realität zu geben, sondern nur um meine forschende Vernunft in Ansehung desselben vollständig zu befriedigen. So sehe ich Ordnung und Zweckmäßigkeit in der Natur vor mir und bedarf nicht, um mich von deren Wirklichkeit zu versichern, zur Spekulation zu schreiten, sondern nur, um sie zu erklären, eine Gottheit als 10 deren Ursache vorauszusetzen, da denn, weil von einer Wirkung der Schluß auf eine bestimmte, vornehmlich so genau und so vollständig bestimmte Ursache, als wir an Gott zu denken haben, immer unsicher und mißlich ist, eine solche Voraussetzung nicht weiter gebracht werden kann, als zu dem Grade der für uns Menschen allervernünftigsten Meinung.*) Dagegen ist ein Bedürfnis der reinen praktischen Vernunft auf einer Pflicht gegründet, etwas (das höchste Gut) zum Gegenstande meines Willens zu machen, um es nach allen meinen Kräften zu befördern; wobei ich aber die Möglichkeit desselben, mithin auch die Bedingungen dazu, nämlich Gott, Freiheit und Unsterblichkeit, voraussetzen muß, weil ich diese durch meine spekulative Vernunft nicht beweisen, obgleich auch nicht widerlegen kann. Diese Pflicht gründet sich auf einem freilich von diesen letzteren Voraussetzungen ganz

*) Aber selbst anch hier würden wir nicht ein Bedürfnis der Vernunft vorschützen können, läge nicht ein problematischer, aber doch unvermeidlicher Begriff der Vernunft vor Angen, nämlich der eines schlechterdings notwendigen Wesens. Dieser Begriff will nun bestimmt sein, und das ist, wenn der Trieb zur Erweiterung dazu kommt, der objektive Grund eines Bedürfnisses der spekulativen Vernunft, nämlich den Begriff eines notwendigen Wesens, welches anderen zum Urgrunde dienen soll, näher zu bestimmen, und dieses letzte also wodurch kenntlich za machen. Ohne solche vorausgehende notwendige Probleme gibt es keine Bedürfnisse, wenigstens nicht der reinen Vernunft; die übrigen sind Bedürfnisse der Neigung.

a) 1. und 4.-6. Anfl.: "Ungrundee". 


\section{Erster Teil, II. Buch, 2. Hauptetũck. VIII.}

unabhängigen, für sich selbst apodiktisch gewissen, nämlich dem moralischen Gesetze und ist sofern keiner

[143] anderweitigen Unterstützung durch theoretische Meinung von der inneren Beschaffenheit der Dinge, der geheimen Abzweckung der Weltordnung oder eines ihr vorstehenden Regierers bedürftig, um uns auf das Vollkommenste $\mathrm{zu}$ unbedingt gesetzmäßigen Handlungen zu verbinden. Aber der subjektive Effekt dieses Gesetzes, nämlich die ihm angemessene und durch das-

10 selbe auch notwendige Gesinnung, das praktisch mögliche höchste Gut zu befördern, setzt doch' wenigstens voraus, daß das letzter $\theta$ möglich sei, widrigenfalls es praktisch unmöglich wäre, dem Objekte eines Begriffes nachzustreben, welcher im Grunde leer und ohne Objekt wäre. Nun betreffen obige Postulate nur die physischen oder metaphysischen, mit einem Worte in der Natur der Dinge liegenden Bedingungen der Möglichkeit des höchsten Guts, aber nicht zum Behuf einer beliebigen spekulativen Absicht, sondern eines

20 praktisch notwendigen Zwecks des reinen Vernunftwillens, der hier nicht wählt, sondern einem unnachlaßlichen Vernunftgebote gehorcht, welches seinen Grund objektiv in der Beschaffenheit der Dinge hat, sowie sie durch reine Vernunft allgemein beurteilt werden müssen, und gründet sich nicht etwa auf $\mathrm{Nei}$ gung, die zum Behuf dessen, was wir aus bloß subjektiven Gründen wünschen, sofort die Mittel dazu als möglich oder den Gegenstand wohl gar als wirklich anzunehmen keineswegs berechtigt ist. Also ist dieses

80 ein Bedürfnis in schlechterdings notwendiger Absicht und rechtfertigt seine Voraussetzung nicht bloß als erlaubte Hypothese, sondern als Postulat in praktischer Absicht; und zugestanden, daß das reine moralische Gesetz jedermann als Gebot (nicht als Klugheitsregel) unnachlaßlich verbinde, darf der Rechtschaffene wohl sagen: ich will, daß ein Gott, daß mein Dasein in dieser Welt auch außer der Naturverknüpfung noch ein Dasein in einer reinen Verstandeswelt, endlich auch, daß meine Dauer endlos sei, ich

10 beharre darauf und lasse mir diesen Glauben nicht nehmen; denn dieses ist das einzige, wo mein Interesse, weil ich von demselben nichts nachlassen darf, moin 
Urteil unvermeidlich bestimmt, ohne auf Vernūnfteleien zu achten, so wenig ich auch darauf zu antworten oder ihnen scheinbarere entgegenzustellen imstande sein möchte.*)

Um bei dem Gebrauche eines noch so ungewohnten Begriffs, als der eines reinen praktischen Vernunftglaubens ist, Mißdeutungen zu verhüten, sei mir erlaubt, noch eine Anmerkung hinzuzufügen. - Es sollte fast scheinen, als ob dieser Vernunftglaube hier selbst als Gebot angekündigt werde, nämlich das 10

*) Im dentschen Museum, Februar 1787, findet sich eine Abhandlung von einem sehr feinen und hellen Kopfe, dem sel. Wizenmanna), dessen früher Tod za bedanern ist, darin er die Befugnis, ans einem Bedürnisse auf die objektive Realităt des Gegenstandes desselben zu schließen, bestreitet and seinen Gegenstand durch das Beispiel eines Verliebten erläntert, der, indem er sich in eine Idee von Schönheit, welche bloß sein Hirngespinst ist, vernarrt hătte, schließen wollte, daß ein solches Objekt wirklich wo existiere. Ich gebe ihm hierin vollkommen recht in allen Fällen, wo das Bedürfnis auf $\mathrm{N}$ eign ng gegründet ist, die nicht einmal notwendig für den, der damit angefochten ist, die Existenz ihres Objekts postulieren kann, viel weniger eine für jedermann gültige Forderung enthält und daher ein bloß subjektiver Grund der Wünsche ist. Hier ist aber ein Vernunftbedürfnis aus einem objektiven Bestimmangsgrande des Willens, nämlich dem moralischen Gesetze entspringend, welches jedes vernünftige Wesen notwendig verbindet, also zur Voraussetzung der ihm angemessenen Bedingungen in der Natur a priori berechtigt und die letzteren von dem vollständigen praktischen Gebranche der Vernunft anzertrennlich macht. Es ist Pflicht, das höchste Gut nach unserem größten Vermögen wirklich zu machen; daher muß es doch auch moglich sein: mithin ist es für jedes vernünftige Wesen in der Welt auch unvermeidlich, dasjenige vorauszusetzen, was zu dessen objektiver Möglichkeit notwendig ist. Die Voraussetzung ist so notwendig als das moralische Gesetz, in Beziehung auf welches sio auch nur gültig ist.

a) Ober Wizenmann vglo meine Einleitang $z a \mathrm{Ph}$. Bibl., Bd. 46 b, S. XXVIII, XXX, XXXV. 
184 Irster Teil, II. Buch, 2. Hauptstüek. VIII.

höohste Gut für möglich anzunehmen. Ein Glaube aber, der geboten wird ist ein Unding. Man erinnere sich aber-der obigen Auseinandersetzung dessen, was im Begriffe des höchsten Guts anzunehmen verlangt wird, und man wird ${ }^{2}$ ) inne werden, daß diese Möglichkeit anzunehmen gar nicht geboten werden dürfe und keine praktischen Gesinnungen fordere, sie einzuräumen, sondern daß spekulative Vernunft sie ohne Gesuch zugeben müsse; denn daß eine dem moralischen

10 Gesetze angemessene Würdigkeit der vernünftigen Wesen in der Welt, glücklich zu sein, mit einem dieser proportionierten Besitze dieser Glückseligkeit in Verbindung an sich unmöglich sei, kann doch niemand behaupten wollen. Nun gibt uns in Ansehung des ersten Stücks des höchsten Guts, nämlich was dio Sittlichkeit betrifft, das moralische Gesetz bloß ein Gebot, und die Möglichkeit jenes Bestandstücks zu bezweifeln, wäre ebensoviel, als das moralische Gesetz selbst in Zweifel zu ziehen. Was aber das zweite Stück

30 jenes Objekts, nämlich die jener Würdigkeit durchgängig angemessen $\theta$ Glückseligkeit betrifft, so ist zwar die Möglichkeit derselben überhaupt einzuräumen gar nicht eines Gebots bedürftig, denn die theoretische Vernunft hat selbst nichts dawider; nur die Art, wie wir uns eine solche Harmonie der Naturgesetze mit

[145] denen der Freiheit denken sollen, hat etwas an sich, in Ansehung dessen uns eine Wahl zukommt, weil theoretische Vernunft hierüber nichts mit apodiktischer Gewißheit entscheidet, und in Ansehung dieser kann 30 es ein moralisches Interesse geben, das den Ausschlag gibt.

Oben hatte ich gesagt, daß nach einem bloßen Naturgange in der Welt die genau dem sittlichen Werte angemessene Glückseligkeit nicht za erwarten und für unmöglich zu halten sei, und daß also die Möglichkeit des höchsten Guts von dieser Seite nur unter Voraussetzung eines moralischen Welturhebers könne eingeräumt werden. Ich hielt mit Vorbedacht mit der Einschränkung dieses Urteils auf die subjektiven to Bedingungen unserer Vernunft zurück, um nur dann

a) Kant: „wird man"; korr. Rosenkranz, Hartenstein. 
allererst, wenn die Art ihres Fürwahrhaltens näher bestimmt werden sollte, davon Gebrauch zu machen. In der Tat ist die genannte Unmöglichkeit blo B subjektiv, d. i. unsere Vernunft findet es ihr unmöglich, sich einen so genau angemessenen und durchgängig zweckmäßigen Zusammenhang zwischen zwei nach so verschiedenen Gesetzen sich ereignenden Weltbegebenheiten nach einem bloßen Naturlaufe begreiflich zu machen; ob sie zwar, wie bei allem, was sonst in der Natur Zweckmäßiges ist, die Unmöglichkeit desselben nach allgemeinen Naturgesetzen doch auch nicht beweisen, d. i. aus objektiven Gründen hinreichend dartun kann.

Allein jetzt kommt ein Entscheidungsgrund von anderer Art ins Spiel, um im Schwanken der spekulativen Vernunft den Ausschlag zu geben. Das Gebot, das höchste Gut zu befördern, ist objektiv (in der praktischen Vernunft), die Möglichkeit desselben überhaupt gleichfalls objektiv (in der theoretischen Vernunft, die nichts dawider hat) gegründet. Allein die 20 Art, wie wir uns diese Möglichkeit vorstellen sollen, ob nach allgemeinen Naturgesetzen ohne einen der Natur vorstehenden weisen Urheber, oder nur unter dessen Voraussetzung, das kann die Vernunft objektiv nicht entscheiden. Hier tritt nun eine subjektive Bedingung der Vernunft ein: die einzige ihr theoretisch mögliche, zugleich der Moralität (die unter einem objektiven Gesetze der Vernunft steht) allein zuträgliche Art, sich die genaue Zusammenstimmung des Reichs der Natur mit dem Reiche der Sitten als Be- 30 dingung der Möglichkeit des höchsten Guts zu denken. Da nun die Beförderung desselben und also die Voraussetzung seiner Möglichkeit objektiv (aber nur der praktischen Vernunft zufolge) notwendig ist, zugleich aber die Art, auf welche Weise wir es uns als möglich denken wollen, in unserer Wahl steht, in welcher aber ein freies Interesse der reinen praktischen Vernunft für die Annehmung eines weisen Welturhebers $[146]$ entscheidet: so ist das Prinzip, was unser Urteil hierin bestimmt, zwar subjektiv als Bedürfnis, aber auch 40 zugleich als Beförderungsmittel dessen, was objektiv (praktisch) notwendig ist, der Grund einer Maxime 
des Fürwahrhaltens in moralischer Absicht, d. i. ein reiner praktischer Vernunftglaube. Dieser ist also nicht geboten, sondern als freiwillig zur moralischen (gebotenen) Absicht zuträgliche, überdem noch mit dem theoretischen Bedürfnisse der Vernunft einstimmige Bestimmung unseres Urteils, jene Existenz anzunehmen und dem Vernunftgebrauch ferner zum Grunde zu legen, selbst aus der moralischen Gesinnung entsprungen; kann also öfters selbst bei Wohlgesinnten

10 bisweilen in Schwanken, niemals aber in Unglauben geraten.

\section{IX.}

\section{Von der der praktischen Bestimmung}

des Menschen weislich angemessenen Proportion seiner Erkenntnisvermögen.

Wenn die menschliche Natur zum höchsten Gute zu streben bestimmt ist, so muß auch das Maß ihrer Erkenntnisvermögen, vornehmlich ihr Verhältnis untereinander, als zu diesem Zwecke schicklich angenommen

20 werden. Nun beweist aber die Kritik der reinen spekulativen Vernunft die größte Unzulänglichkeit derselben, um die wichtigsten Aufgaben, die ihr vorgelegt werden, dem Zwecke angemessen aufzulösen, ob sie zwar die natürlichen und nicht zu übersehenden Winke ebenderselben Vernunft, ingleichen die großen Schritte, die sie tun kann, nicht verkennt, um sich diesem großen Ziele, das ihr ausgesteckt ist, zu nähern, aber doch ohne es jemals für sich selbst sogar mit Beihilfe der größten Naturkenntnis zu erreichen. Also scheint

80 die Natur uns hier nur stiefmütterlich mit einem zu unserem Zwecke benötigten Vermögen versorgt zu haben.

Gesetzt nun, sie wäre hierin unserem Wunsche willfährig gewesen und hätte uns diejenige Einsichtsfähigkeit oder Erleuchtung erteilt, die wir gern besitzen möchten oder in deren Besitz einige wohl gar wähnen sich wirklich $\mathrm{zu}$ befinden, was würde allem Ansehen nach wohl die Folge hiervon sein? Wofern nicht zugleich unsere ganze Natur umgeändert wäre, so wür40 den die Neigungen, die doch allemal das erste Wort 
Von der der prakt. Bestimmang des Menschen uow. 187

haben, zuerat ihre Befriedigung und, mit vernünftiger Oberlegung verbunden, ihre größtmögliche und [147] dauernde Befriedigung unter dem Namen der Glückseligkeit verlangen; das moralische Gesetz würde nachher sprechen, um jene in ihren geziemenden Schranken zu halten und sogar sie alle insgesamt einem höheren, auf keine Neigung Rücksicht nehmenden Zwecke zu unterwerfen. Aber statt des Streits, den jetzt die moralische Gesinnung mit den Neigungen zu führen hat, in welchem nach einigen Niederlagen 10 doch allmählich moralische Stärke der Seele zu erwerben ist, würden Gott und Ewigkeit mit ihrer furchtbaren Majestät uns unablässig vor Augen liegen (denn was wir vollkommen beweisen können, gilt in Ansehung der Gewißheit uns soviel, als wovon wir uns durch den Augenschein versichern). Die Ubertretung des Gesetzes würde freilich vermieden, das Gebotene getan werden; weil aber die Gesinnung, aus welcher Handlungen geschehen sollen, durch kein Gebot mit eingeflößt werden kann, der Stachel der 20 Tätigkeit hier aber sogleich bei Hand und äußerlich ist, die Vernunft also sich nicht allererst emporarbeiten darf, um Kraft zum Widerstande gegen Neigungen durch lebendige Vorstellung der Würde des Gesetzes zu sammeln, so würden die mehrsten gesetzmäßigen Handlungen aus Furcht, nur wenige aus Hoffnung und gar keine aus Pflicht geschehen, ein moralischer Wert der Handlungen aber, worauf doch allein der Wert der Person und selbst der der Welt in den Augen der höchsten Weisheit ankommt, würde gar nicht existie- $\mathbf{3 0}$ ren. Das Verhalten der Menschen, solange ihre Natur, wie sie jetzt ist, bliebe, würde also in einen bloßen Mechanismus verwandelt werden, wo wie im Marionettenspiel alles gut gestikulieren, aber in den Figuren doch kein Leben anzutreffen sein würde. Nun, da es mit uns ganz anders beschaffen ist, da wir mit aller Anstrengung unserer Vernunft nur eine sehr dunkle und zweideutige Aussicht in die Zukunft haben, der Weltregierer uns sein Dasein und seine Herrlichkeit nur mutmaßen, nicht erblicken oder klar beweisen 10 läßt, dagegen das moralische Gesetz in uns, ohne uns etwas mit Sicherheit zu verheißen oder zu drohen, 
188 Erster Teil, II. Bach, 2. Hauptstück. IX.

von uns uneigennützige Achtung fordert, übrigens aber, wenn diese Achtung tätig und herrschend geworden, allererst alsdann und nur dadurch Aussichten ins Reich des Ubersinnlichen, aber auch nur mit schwachen Blicken erlaubt: so kann wahrhafte sittliche, dem Gesetze unmittelbar geweihte Gesinnung stattfinden und das vernünftige Geschöpf des Anteils am höchsten Gute würdig werden, das dem moralischen Werte seiner Person und nicht bloß seinen Handlungen an-

[148] 10 gemessen ist. Also möchte es auch hier wohl damit seine Richtigkeit haben, was uns das Studium der Natur und des Menschen sonst hinreichend lehrt, daß die unerforschliche Weisheit, durch die wir existieren, nicht minder verehrungswürdig ist in dem, was sie uns versagte, als in dem, was sie uns zuteil werden ließ. 
Der

[149]

\title{
Kritik der praktischen Vernunft
}

\author{
zweiter Teil.
}

\section{Methodenlehre}

der

reinen praktischen Vernunft. 
4

Digitized by Microsoft ${ }^{\circledR}$ 
Unter der Methodenlehre der reinen prakti- [151] schen Vernunft kann man nicht die Art (sowohl im Nachdenken als im Vortrage), mit reinen praktischen Grundsätzen in Absicht auf eine wissenschaftliche Erkenntnis derselben zu verfahren, verstehen, welches man sonst in der theoretischen eigentlich allein Methode nennt (denn populäre Erkenntnis bedarf einer Manier, Wissenschaft aber einer Methode, d. i. eines Verfahrens nach Prinzipien der Vernunft, wodurch das Mannigfaltige einer Erkenntnis allein ein 10 System werden kann). Vielmehr wird unter dieser Methodenlehre die Art verstanden, wie man den Gesetzen der reinen praktischen Vernunft Eingang in das menschliche Gemüt, Einfluß auf die Maxımen desselben verschaffen, d. i. die objektiv praktische Vernunft auch subjektiv praktisch machen könne.

Nun ist zwar klar, daß diejenigen Bestimmungsgründe des Willens, welche allein die Maximen eigentlich moralisch machen und ihnen einen sittlichen Wert geben, die unmittelbare Vorstellung des Gesetzes und 20 die objektiv notwendige Befolgung desselben als Pflicht, als die eigentlichen Triebfedern der Handlungen vorgestellt werden müssen; weil sonst zwar Legalität der Handlungen, aber nicht Moralität der Gesinnungen bewirkt werden würde. Allein nicht so klar, vielmehr beim ersten Anblicke ganz unwahrscheinlich muß es jedermann vorkommen, daß auch subjektiv jene Darstellung der reinen Tugend mehr Macht über das menschliche Gemüt haben und eine weit stärkere Triebfeder abgeben könne, selbst jene Legalität der 30 Handlungen zu bewirken und kräftigere Entschließungen hervorzubringen, das Gesetz aus reiner Achtung für dasselbe jeder anderen Rücksicht vorzuziehen, als alle Anlockungen, die aus Vorspiegelungen von Ver- 
gnügen und überhaupt allem dem, was man zur Glück[152] seligkeit zählen mag ${ }^{2}$ ), oder auch alle Androhungen von Schmerz und Ubeln jemals wirken können. Gleichwohl ist es wirklich so bewandt, und wäre es nicht so mit der menschlichen Natur beschaffen, so würde auch keine Vorstellungsart des Gesetzes durch Umschweife und empfehlende Mittel jemals Moralität der Gesinnung hervorbringen. Alles wäre lauter Gleisnerei, das Gesetz würde gehaßt oder wohl gar verachtet, indessen doch

10 um eigenen Vorteils willen befolgt werden. Der Buchstabe des Gesetzes (Legalität) würde in unseren Handlungen anzutreffen sein, der Geist desselben ${ }^{\circ}$ ) aber in unseren Gesinnungen (Moralität) gar nicht, und da wir mit aller unserer Bemühung uns doch' in unserem Urteile nicht ganz von der Vernunft losmachen können, so würden wir unvermeidlich in unseren eigenen Augen als nichtswürdige, verworfene Menschen erscheinen. müssen, wenn wir uns gleich für diese Kränkung vor dem inneren Richterstuhl dadurch schadlos zu halten

20 versuchten, daß wir uns an den Vergnügen ergötzten, die ein von uns angenommenes natürliches oder göttliches Gesetz unserem Wahne nach mit dem Maschinenwesen ihrer Polizei, die sich bloß nach dem richtete, was man tut, ohne sich um die Bewegungsgründe, warum man es tut, zu bekümmern, verbunden hätte.

Zwar kann man nicht in Abrede sein, daß; um ein entweder noch ungebildetes oder auch verwildertes Gemüt zuerst ins Geleis ides Moralisch-Guten zu bringen, es einiger vorbereitenden Anleitungen bedürfe, es 80 durch seinen eigenen Vorteil zu locken oder durch den Schaden zu schrecken; allein sobald dieses Maschinenwerk, dieses Gängelband nur einige Wirkung getan hat, so muß durchaus der reine moralische Bewegungsgrund an die Seele gebracht werden, der nicht allein, dadurch daß er der einzige ist, welcher einen Charakter (praktische konsequente Denkungsart nach unveränderlichen Maximen) gründet, sondern auch darum, weil or den Menschen seine eigene Würde fühlen lehrt, dem Gemüte eine ihm selbst unerwartete Kraft gibt,

a) Hier fehlt ein Verbum wie „entspringen“.

b) Kant: „derselben“, korr. Nolte. 
Methodenlehre der reinen praktischen Vernunft. 193

sich von aller sinnlichen Anhänglichkeit, sofern sie herrschend werden will, loszureißen und in der Unabhängigkeit seiner intelligibelen Natur und der Seelengröße, dazu er sich bestimmt sieht, für die Opfer, die er darbringt, reichliche Entschädigung zu finden. Wir wollen also diese Eigenschaft unseres Gemüts, diese Empfänglichkeit eines reinen moralischen Interesses und mithin die bewegende Kraft der reinen Vorstellung der Tugend, wenn sie gehörig ans menschliche Herz gebracht wird, als die mächtigste und, wenn 10 es auf die Dauer und Pünktlichkeit in Befolgung moralischer Maximen ankommt, einzige Triebfeder zum [1jô] Guten durch Beobachtungen, die ein jeder anstellen kann, beweisen; wobei doch zugleich erinnert werden muß, da $B$, wenn diese Beobachtungen nur die Wirklichkeit eines solchen Gefühls, nicht aber dadurch zustande gebrachte sittliche Besserung beweisen, dieses der einzigen Methode, die objektiv praktischen Gesetze der reinen Vernunft durch bloße reine Vorstellung der Pflicht subjektiv praktisch zu machen, keinen Ab- 20 bruch tue, gleich als ob sie eine leere Phantasterei wäre. Denn da diese Methode noch niemals in Gang gebracht worden, so kann auch die Erfahrung noch nichts von ihrem Erfolg aufzeigen, sondern man kann nur Beweistümer der Empfänglichkeit solcher Triebfedern fordern, die ich jetzt kürzlich vorlegen und danach die Methode der Gründung und Kultur echter moralischer Gesinnungen mit wenigem entwerfen will.

Wenn man auf den Gang der Gespräche in gemischten Gesellschaften, die nicht blo $\beta$ aus Gelehrten 30 und Vernünftlern, sondern auch aus Leuten von Geschäften oder Frauenzimmern bestehen, acht hat, so bemerkt man, daß außer dem Erzählen und Scherzen noch eine Unterhaltung, nämlich das Räsonieren, darin Platz findet: weil das erstere, wenn es Neuigkeit und mit ihr Interesse bei sich führen soll, bald erschöpft, das zweite aber leicht schal wird. Unter allem Räsonieren ist aber keines, was mehr den Beitritt der Personen, die sonst bei allem Vernünfteln bald Langeweile haben, erregt und eine gewisse Lebhaftigkeit in $\mathbf{4 0}$ die Gesellschaft bringt, als das über den sittlichen Wert dieser oder jener Handlung, dadurch der Cha- 
rakter irgend einer Person ausgemacht werden soll. Diejenigen, welchen sonst alles Subtile undGrüblerische in theoretischen Fragen trocken und verdrießlich ist, treten bald bei, wenn es darauf ankommt, den moralischen Gehalt einer erzählten guten oder bösen Handlung auszumachen, und sind so genau, so grüblerisch, so subtil, alles, was die Reinigkeit der Absicht und mithin den Grad der Tugend in derselben vermindern oder auch nur verdächtig machen könnte, auszusinnen,

10 als man bei keinem Objekte der Spekulation sonst von ihnen erwartet. Man kann in diesen Beurteilungen oft den Charakter der über andere urteilenden Personen selbst hervorschimmern sehen, deren einige vorzüglich geneigt scheinen, indem sie ihr Richteramt vornehmlich über Verstorbene ausüben, das Gute, was von dieser oder jener Tat derselben erzählt wird, wider alle kränkenden Einwürfe der Unlauterkeit und zuletzt den ganzen sittlichen Wert der Person wider den Vorwurf der Verstellung und geheimen Bösartig-

20 keit zu verteidigen, andere dagegen mehr auf Anklagen [154] und Beschuldigungen sinnen, diesen Wert anzufechten. Doch kann man den letzteren nicht immer die Absicht beimessen, Tugend aus allen Beispielen der Menschen gänzlich wegvernünfteln zu wollen, um sie dadurch zum leeren Namen $\mathrm{zu}$ machen, sondern es ist oft nur wohlgemeinte Strenge in Bestimmung des echten sittlichen Gehalts nach einem unnachsichtlichen Gesetze, mit welchem und nicht mit Beispielen verglichen der Eigendünkel im Moralischen sehr sinkt, und Demut nicht

30 etwa bloß gelehrt, sondern bei scharfer Selbstprüfung von jedem gefühlt wird. Dennoch kann man den Verteidigern der Reinigkeit der Absicht in gegebenen Beispielen es mehrenteils ansehen, daß sie ihr da, wo sie die Vermutung der Rechtschaffenheit für sich hat, auch den mindesten Fleck gerne abwischen möchten, aus dem Bewegungsgrunde, damit nicht, wenn allen Beispielen ihre Wahrhaftigkeit bestritten und aller menschlichen Tugend die Lauterkeit weggeleugnet würde, diese nicht endlich gar für ein bloßes Hirn-

40 gespinst gehalten und so alle Bestrebung zu derselben als eitles Geziere und trüglicher Eigendünkel geringschätzig gemacht werde. 
Ich weiß nicht, warum die Erzieher der Jugend von diesem Hange der Vernunft, in aufgeworfenen praktischen Fragen selbst die subtilste Prüfung mit Vergnügen einzuschlagen, nicht schon längst Gebrauch gemacht haben und, nachdem sie einen bloß moralischen Katechismus zum Grunde legten, sie nicht die Biographien alter und neuer Zeit in der Absicht durchsuchten, um Belege zu den vorgelegten Pflichten bei der Hand $\mathrm{zu}$ haben, an denen sie vornehmlich durch die Vergleichung ähnlicher Handlungen unter ver- 10 schiedenen Umständen die Beurteilung ihrer Zöglinge in Tätigkeit setzten, um den minderen oder größeren moralischen Gehalt derselben $\mathrm{zu}$ bemerken, als worin sie selbst die frühe Jugend, die zu aller Spekulation sonst noch unreif ist, bald sehr scharfsichtig und dabei, weil sie den Fortschritt ihrer Urteilskraft fühlt, nicht wenig interessiert finden werden, was aber das Vornehmste ist, mit Sicherheit hoffen können, daß die öftere Ubung, das Wohlverhalten in seiner ganzen Reinigkeit zu kennen und ihm Beifall zu geben, da- 20 gegen selbst die kleinste Abweichung von ihr mit Bedauern oder Verachtung zu bemerken, ob es zwar bis dahin nur als ${ }^{2}$ ) ein Spiel der Urteilskraft, in welchem Kinder miteinander wetteifern können, getrieben wird, dennoch einen dauerhaften Eindruck der Hochschätzung auf der einen und des Abscheues auf der anderen Seite zurückgelassen werde, welche durch bloße Gewohnheit, solche Handlungen als beifalls- oder tadelswürdig öfter anzusehen, zur Rechtschaffenheit im künftigen Lebenswandel eine gate Grundlage ausmachen 30 würden. Nur wünsche ich sie mit Beispielen sogenannter edler (überverdienstlicher) Handlungen, mit welchen unsere empfindsamen Schriften soviel um sich werfen, zu verschonen und alles bloß auf Pflicht und den Wert, den ein Mensch sich in seinen eigenen Augen durch das Bewußtsein, sie nicht übertreten zu haben, geben kann und muß, auszusetzen, weil, was auf leere Wünsche und Sehnsuchten nach unersteiglicher Vollkommenheit hinausläuft, lauter Romanhelden hervorbringt, die, indem sie sich auf ihr Gefühl für das 40

a) „alg“ Zusatz Hartensteins. 
ťberschwenglich Große viel zugute tun, sich dafür von der Beobachtung der gemeinen und gangbaren Schuldigkeit, die alsdann ihnen nur unbedeutend klein scheint, freisprechen.*)

Wenn man aber fragt: was denn eigentlich die reine Sittlichkeit ist, an der als dem Probemetall man jeder Handlung moralischen Gehalt prüfen müsse, so muß ich gestehen, daß nur Philosophen die Entscheidung dieser Frage zweifelhaft machen können;

10 denn in der gemeinen Menschenvernunft ist sie zwar nicht durch abgezogene allgemeine Formeln, aber doch durch den gewöhnlichen Gebrauch, gleichsam als der Unterschied zwischen der rechten und linken Hand, längst entschieden. Wir wollen also vorerst das Prüfungsmerkmal der reinen Tugend an einem Beispiele zeigen und, indem wir uns vorstellen, daß es etwa einem zehnjährigen Knaben zar Beurteilung vorgelegt worden, sehen, ob er auch von selber, ohne durch den Lehrer dazu angewiesen zu sein, notwendig so urteilen

20 müßte. Man erzähle die Geschichte eines redlichen Mannes, den man bewegen will, den Verleumdern einer unschuldigen, übrigens nicht vermögenden Person (wie etwa Anna von Boleyn auf Anklage Heinrichs VIII. von England) beizutreten. Man bietet Gewinne, d. i. große Geschenke oder hohen Rang an, er schlägt sie [156] aus. Dieses wird bloßen Beifall und Billigung in der

*) Handlungen, aus denen große, uneigennützige, teilnehmende Gesinnung and Menschlichkeit hervorlenchtet, zn preisen, ist ganz ratsam. Aber man muß hier nicht sowohl auf die Seelenerhebnng, die sehr flüchtig nnd vorübergehend ist, als vielmehr die Herzensunterwerfung unter Pflicht, wovon ein längerer Eindruck erwartet werden kann, weil sie Grundsätze (jene aber nur Aufwallungen) mit sich führt, aufmerksam machen. Man darf nur ein wenig nachsinnen, man wird immer eine Schald finden, die er sich irgendwodurch in Ansehnng des Menschengeschlechts aufgeladen hat (sollte es auch nur die sein, daß man durch die Ungleichheit der Menschen in der bürgerlichen Verfassung Vorteile genießt, um deren willen andere desto mehr entbehren müssen), um durch die eigenliebige Einbildung des Verdienstlichen den Gedanken an Pflicht nicht zu verdrängen. 
Methodenlehre der reinen praktischen Vernunft. 197

Seele des Zuhörers wirken, weil es Gewinn ist. Nun fängt man es mit Androhung des Verlustes an. Es sind unter diesen Verleumdern seine besten Freunde, die ihm jetzt ihre Freundschaft aufsagen, nahe Verwandte, die ihn (der ohne Vermögen ist) za enterben drohen, Mächtige, die ihn in jedem Orte und Zustande verfolgen und kränken können, ein Landesfürst, der ihn mit dem Verlust der Freiheit, ja des Lebens selbst bedroht. Um ihn aber, damit das Maß des Leidens voll sei, auch den Schmerz fühlen zu lassen, den nur das 10 sittlich gute Herz recht inniglich fühlen kann, mag man seine mit äußerster Not und Dürftigkeit bedrohte Familie inn um Nachgiebigkeit anflehend, ihn selbst, obzwar rechtschaffen, doch eben nicht von festen, unempfindlichen Organen des Gefühls für Mitleid sowohl als eigene ${ }^{2}$ ) Not in einem Augenblick, darin er wünscht, den Tag nie erlebt zu haben, der ihn einem so unaussprechlichen Schmerz aussetzte, dennoch seinem Vorsatze der Redlichkeit, ohne zu wanken oder nur zu zweifeln, treu bleibend vorstellen: so wird mein 20 jugendlicher Zuhörer stufenweise von der bloßen Billigung zur Bewunderung, von da zum Erstaunen, endlich bis zur größten Verehrung und einem lebhaften Wunsche, selbst ein solcher Mann sein zu kōnnen (obzwar freilich nicht in seinem Zustande), erhoben werden; und gleichwohl ist hier die Tugend nur darum soviel wert, weil sie soviel kostet, nicht weil sie etwas einbringt. Die ganze Bewunderung und selbst Bestrebung zur Ahnlichkeit mit diesem Charakter beruht hier gänzlich auf der Reinigkeit des sittlichen Grund- 30 satzes, welche nur dadurch recht in die Augen fallend vorgestellt werden kann, daß man alles, was Menschen nur zur Glückseligkeit zählen mögen, von den Triebfedern der Handlung wegnimmt. Also muß die Sittlichkeit auf das menschliche Herz desto mehr Kraft haben, je reiner sie dargestellt wird. Woraus denn folgt, daß, wenn das Gesetz der Sitten und das Bild der Heiligkeit und Tugend auf unsere Seele überall einigen Einfluß ausüben soll, sie $^{D}$ ) diesen nur insofern

a) Akad.-Ausgabe: „eigener".

b) oder „ea" (gc. das Sittengesetz)? 
ausüben könne, als sie rein, unvermengt von $A b$ sichten auf sein Wohlbefinden als Triebfeder ans Herz gelegt wird, darum weil sie sich im Leiden am herrlichsten zeigt. Dasjenige aber, dessen Wegräumung die Wirkung einer bewegenden Kraft verstärkt, muß ein Hindernis gewesen sein. Folglich ist alle Beimischung der Triebfedern, die von eigener Glückseligkeit hergenommen werden, ein Hindernis, dem moralischen Gesetze Einfluß aufs menschliche Herz zu ver-

10 schaffen. - Ich behaupte ferner, daß selbst in jener bewunderten Handlung, wenn der Bewegungsgrund, [157] daraus sie geschah, die Hochschätzung seiner Pflicht war, alsdann ebendiese Achtung fürs Gesetz, nicht etwa ein Anspruch auf die innere Meinung von Großmut und edler verdienstlicher Denkungsart, gerade auf das Gemüt des Zuschauers die größte Kraft habe, folglich Pflicht, nicht Verdienst den nicht allein bestimmtesten, sondern, wenn sie im rechten Lichte ihrer Unverletzlichkeit vorgestellt wird, auch den eindringendsten Ein20 fluß aufs Gemüt haben müsse.

In unseren Zeiten, wo man mehr mit schmelzenden, weichherzigen Gefühlen oder hochfliegenden, aufblähenden und das Herz eher welk als stark machenden Anmaßungen über das Gemüt mehr auszurichten hofft, als durch die der menschlichen Unvollkommenheit und dem Fortschritte im Guten angemessenere trockene und ernsthafte Vorstellung der Pflicht, ist die Hinweisung auf diese Methode nötiger als jemals. Kindern Handlungen als edle, großmütige, verdienstliche zum

80 Muster aufzustellen in der Meinung, sie durch Einflößung eines Enthusiasmus für dieselben einzunehmen, ist vollends zweckwidrig. Denn da sie noch in der Beobachtung der gemeinsten Pflicht und selbst in der richtigen Beurteilung derselben soweit zurück sind, so heißt das soviel, als sie beizeiten zu Phantasten zu machen. Aber auch bei dem belehrteren und erfahreneren Teil der Menschen ist diese vermeinte Triebfeder, wo nicht von nachteiliger, wenigstens von keiner echten moralischen Wirkung aufs Herz, die man da40 durch doch hat zuwege bringen wollen.

Alle Gefühle, vornehmlich die, so ungewohnte Anstrengung bewirken sollen, müssen in dem Augen- 
blicke, da sie in ihrer Heftigkeit sind und, ehe sie verbrausen, ihre Wirkung tun, sonst tun sie nichts: indem das Herz natürlicherweise zu seiner natürlichen, gemäßigten Lebensbewegung zurückkehrt und sonach in die Mattigkeit verfällt, die ihm vorher eigen war; weil zwar etwas, was es reizte, nichts aber, das es stärkte, an dasselbe gebracht war. Grundsätze müssen auf Begriffe errichtet werden, auf alle andere Grundlage können nur Anwandlungen zustande kommen, die der Person keinen moralischen Wert, ja 10 nicht einmal eine Zuversicht auf sich selbst verschaffen können, ohne die das Bewußtsein seiner moralischen Gesinnung und eines solchen Charakters, das höchste Gut im Menschen, gar nicht stattfinden kann. Diese Begriffe nun, wie sie subjektiv praktisch werden sollen, müssen nicht bei den objektiven Gesetzen der Sittlichkeit stehen bleiben, um sie zu bewundern und in Beziehung auf die Menschheit hochzuschätzen, sondern ihre Vorstellung in Relation auf den Menschen und auf sein Individuum betrachten; da denn jenes 20 [158] Gesetz in einer zwar höchst achtungswürdigen, aber nicht so gefälligen Gestalt erscheint, als ob es $\mathrm{za}$ dem Elemente gehöre, daran er natürlicherweise gewöhnt ist, sondern wie es ihn nötigt, dieses oft nicht ohne Selbstverleugnung zu verlassen und sich in ein höheres zu begeben, darin er sich mit unaufhörlicher Besorgnis des Rückfalls nur mit Mühe erhalten kann. Mit einem Worte, das moralische Gesetz verlangt Befolgung aus Pflicht, nicht aus Vorliebe, die man gar nicht voraussetzen kann und soll.

Laßt uns nun im Beispiele sehen, ob in der Vorstellung einer Handlung als edler und großmütiger Handlung mehr subjektiv bewegende Kraft einer Triebfeder liege, als wenn diese bloß als Pflicht in Verhältnis auf das ernste moralische Gesetz vorgestellt wird. Die Handlung, da jemand mit der größten Gefahr des - Lebens Leute aus dem Schiffbruche zu retten sucht, wenn er zuletzt dabei selbst sein Leben einbüßt, wird zwar einerseits zur Pflicht, andererseits aber und gröbtenteils auch für verdienstliche Handlung angerechnet, 40 aber unsere Hochschätzung derselben wird gar sehr durch den Begriff von Pflicht gegon sich selbst, 
welche hier etwas Abbruch zu leiden scheint, geschwächt. Entscheidender ist die großmütige Aufopferung seines Lebens zur Erhaltung des Vaterlandes, und doch, ob es auch so vollkommen Pflicht sei, sich von selbst und unbefohlen dieser Absicht zu weihen, darüber bleibt einiger Skrupel übrig, und die Handlung hat nicht die ganze Kraft eines Musters und Antriebs zur Nachahmung in sich. Ist es aber unerläßliche Pflicht, deren Übertretung das moralische Ge-

i0 setz an sich und ohne Rücksicht auf Menschenwohl verletzt und dessen Heiligkeit gleichsam mit Füßen tritt (dergleichen Pflichten man Pflichten gegen Gott zu nennen pflegt, weil wir uns in ihm das Ideal der Heiligkeit in Substanz denken), so widmen wir der Befolgung desselben mit Aufopferung alles dessen, was für die innigste aller unserer Neigungen nur immer einen Wert haben mag, die allervollkommenste Hochachtung, und wir finden unsere Seele durch ein solches Beispiel gestärkt und erhoben, wenn wir an demselben

20 uns überzeugen können, daß die menschliche Natur $\mathrm{zu}$ einer so großen Erhebung über alles, was Natur nur immer an Triebfedern zum Gegenteil aufbringen mag, fähig sei. Juvenal stellt ein solches Beispiel in einer Steigerung vor, die den Leser die Kraft der Triebfeder, die im reinen Gesetze der Pflicht als Pflicht steckt, lebhaft empfinden läßt:

Esto bonus miles, tator bonus, arbiter idem Integer; ambiguae si quando citabere testis

[159] Incertaeque rei, Phalaris licet imperet, ut sis

Falsus, et admoto dictet perinria tauro:

Summum crede nefas animam praeferre pudori, Et propter vitam vivendi perdere causas. ${ }^{\text {) }}$

a) Juvenal Sat. 8, 79-84. Anf deutsch: Sei ein guter Soldat, ein guter Vormund oder auch ein unparteiischer Schiedsrichter; solltest du einmal als Zeuge in einer zweifelhaften und angewissen Sache vorgefordert werden, so mag selbst Phalaris befehlen, daß du falsch Zengnis ablegst und dir den Meineid unter Herbeiholung des Stieres gebieten: dennoch halte es für das hochste Unrecht, das Leben der Ehre vorzuziehen und um des bloßen Lebens willen das zu verlieren, was das Leben erst lebenswert macht. (Phalaris war um das Jahr 560 vor Christo Trrann von Agrigent in 
Wenn wir irgend etwas Schmeichelhaftes vom Verdienstlichen in unsere Handlungen bringen können, dann ist die Triebfeder schon mit Eigenliebe etwas vermischt, hat also einige Beihilfe von der Seite der Sinnlichkeit. Aber der Heiligkeit der Pflicht allein alles nachsetzen und sich bewußt werden, daß man es könne, weil unsere eigene Vernunft dieses als ihr Gebot anerkennt und sagt, daß man es tun solle, das heißt sich gleichsam über die Sinnenwelt selbst gänzr lich erheben und ist in demselben Bewußtsein des Ge- 10 setzes ${ }^{a}$ ) auch als Triebfeder eines die Sinnlichkeit beherrschenden Vermögens unzertrennlich, wenngleich nicht immer mit Effekt verbunden, der aber doch auch durch die öftere Beschäftigung mit derselben $\left.{ }^{b}\right)$ und die anfangs kleineren Versuche ihres Gebrauchs Hoffnung zu seiner Bewirkung gibt, um in uns nach und nach das größte, aber reine ${ }^{c}$ ) moralische Interesse daran hervorzubringen.

Die Methode nimmt also folgenden Gang. Zuerst ist es nur darum zu tun, die Beurteilung nach mora- 20 lischen Gesetzen zu einer natürlichen, alle unsere eigenen sowohl als die Beobachtung fremder freier Handlungen begleitenden Beschäftigung und gleichsam zur Gewohnheit zu machen und sie zu schärfen, indem man vorerst fragt: ob die Handlung objektiv dem moralischen Gesetze, und welchem gemäß sei; wobei man denn die Aufmerksamkeit auf dasjenige Gesetz, welches bloß einen Grund zur Verbindlichkeit an die Hand gibt, von dem unterscheidet, welches in der Tat verbindend ist (leges obligandi a legibus obli- 30 gantibus) (wie z. B. das Gesetz desjenigen, was das Bedürfnis.der Menschen, im Gegensatze dessen, was das Recht derselben von mir fordert, wovon das letztere wesentliche, das erstere aber nur außerwesent-

Sizilien; der Künstler Perillns hatte ihm einen ehernen Ochsen anfertigen müssen, um darin Missetäter durch nntergelegtes Fener zu toten.)

[Anmerk. d. H.]

-a) besser wohl: ,and ist von demselben Bewußtsein das des Gesetzes".

b) geht wohl auf "Triebfeder".

c) „rein" [Natorp]? vgl. jedoch S. 193, Zeile 7. 
liche Pflichten vorschreibt) and so verschiedene Pflichten, die in einer Handlung zusammenkommen, unterscheiden lehrt. Der andere Punkt, worauf die Aufmerksamkeit gerichtet werden muß, ist die Frage: ob die Handlung auch (subjektiv) um des moralischen Gesetzes willen geschehen, und also sie nicht allein sittliche Richtigkeit als Tat, sondern auch sittlichen Wert als Gesinnung ihrer Maxime nach habe? Nun ist kein Zweifel, daß diese Ubung und das Bewußt10 sein einer daraus entspringenden Kultur unserer bloß über das Praktische urteilenden Vernunft ein gewisses [160] Interesse, selbst am Gesetze derselben, mithin an sittlich guten Handlungen nach und nach hervorbringen müsse. Denn wir gewinnen endlich das lieb, dessen Betrachtung uns den erweiterten Gebrauch unserer Erkenntniskräfte empfinden läßt, welchen vornehmlich dasjenige befördert, worin wir moralische Richtigkeit antreffen; weil sich die Vernunft in einer solchen Ordnung der Dinge mit ihrem Vermögen, a priori 20 nach Prinzipien zu bestimmen, was geschehen soll, allein gut finden kann. Gewinnt doch ein Naturbeobachter Gegenstände, die seinen Sinnen anfangs anstößig sind, endlich lieb, wenn er die große Zweckmäßigkeit ihrer Organisation daran entdeckt und so seine Vernunft an ihrer Betrachtung weidet, und Leibniz brachte ein Insekt, welches er durch das Mikroskop sorgfältig betrachtet hatte, schonend wiederum auf sein Blatt zurück, weil er sich durch seinen Anblick belehrt gefunden und von ihm gleichsam

80 eine Wohltat genossen hatte.

Aber diese Beschäftigung der Urteilskraft, welche uns unsere eigenen Erkenntniskräfte fühlen läßt, ist noch nicht das Interesse an den Handlungen und ihrer Moralität selbst. Sie macht bloß, daß man sich gerne mit einer solchen Beurteilung unterhält und gibt der Tugend oder der Denkungsart nach moralischen $\mathrm{Ge}$ setzen eine Form der Schönheit, die bewundert, darum aber noch nicht gesucht wird (laudatur et alget) ${ }^{2}$ ); wio alles, dessen Betrachtung subjektiv ein Bewußtsein

a) = Sie wird gelobtund stirbt vor Kălte“(Jurenal 1, 74). [Anmerk. d. H.] 
der Harmonie unserer Vorstellungskräfte bewirkt, und wobei wir unser ganzes Erkenntnisvermögen (Verstand and Einbildungskraft) gestärkt fühlen, ein Wohlgefallen hervorbringt, das sich auch anderen mitteilen läßt, wobei gleichwohl die Existenz des Objekts uns gleichgültig bleibt, indem es nur als die Veranlassung angesehen wird, der über die Tierheit erhabenen Anlage der Talente in uns inne zu werden. Nun tritt aber die zweite Utbung ihr Geschäft an, nämlich in der lebendigen Darstellung der moralischen Gesinnung an 10 Beispielen die Reinigkeit des Willens bemerklich zu machen, vorerst nur als negativer Vollkommenheit desselben, sofern in einer Handlung als Pflicht gar keine Triebfedern der Neigungen als Bestimmungsgründe auf ihn einfließen; wodurch der Lehrling doch auf das Bewußtsein seiner Freiheit aufmerksam erhalten wird und, obgleich diese Entsagung eine anfängliche Empfindung von Schmerz erregt, dennoch dadurch, daß sie jenen Lehrling dem Zwange selbst wahrer Bedürfnisse entzieht, ihm zugleich eine Be- 20 freiung von der mannigfaltigen Unzufriedenheit, darin ihn alle diese Bedürfnisse verflechten, angekündigt und das Gemüt für die Empfindung der Zufriedenheit aus anderen Quellen empfänglich gemacht wird. Das Herz wird doch von einer Last, die es jederzeit ins[161] geheim drückt, befreit und erleichtert, wenn an reinen moralischen Entschließungen, davon Beispiele vorgelegt werden, dem Menschen ein inneres, ihm selbst sonst nicht einmal recht bekanntes Vermögen, die innere Freiheit, aufgedeckt wird, sich von der un- 30 gestümen Zudringlichkeit der Neigungen dermaßen loszumachen, daß gar keine, selbst die beliebteste nicht, auf eine Entschließung, zu der wir uns jetzt unserer Vernunft bedienen sollen, Einfluß habe. In einem Falle, wo ich nur allein weiß, daß das Unrecht auf meiner Seite sei und, obgleich das freie Geständnis desselben und die Anerbietung zur Genugtuung an der Eitelkeit, dem Eigennutze, selbst dem sonst nicht unrechtmäßigen Widerwillen gegen den, dessen Recht von mir geschmälert ist, so großen Widerspruch findet, 40 dennoch mich über alle diese Bedenklichkeiten wegsetzen kann, ist doch ein Bewußtsein einer Unab- 
hängigkeit ron Neigungen und von Glücksumständen and der Möglichkeit, sich selbst genug zu sein, enthalten, welche mir überall auch in anderer Absicht heilsam ist. Und nun findet das Gesetz der Pflicht durch den positiven Wert, den uns die Befolgung desselben empfinden läßt, leichteren Eingang durch die Achtung für uns selbst im Bewußtsein unserer Freiheit. Auf diese, wenn sie wohl gegründet ist, wenn der Mensch nichts stärker scheuet, als sich in der

10 inneren Selbstprüfung in seinen eigenen Augen geringschätzig und verwerflich zu finden, kann nun jede gute sittliche Gesinnung gepfropft werden; weil dieses der beste, ja der einzige Wächter ist, das Eindringen unedler und verderbender Antriebe vom Gemüte abzuhalten.

Ich habe hiermit nur auf die allgemeinsten Maximen der Methodenlehre einer moralischen Bildung und Ubung hinweisen wollen. Da die Mannigfaltigkeit der Pflichten für jede Art derselben noch besondere Be-

20 stimmungen erforderte und so ein weitläufiges Geschäfte ausmachen würde, so wird man mich für entschuldigt halten, wenn ich in einer Schrift wio diese, die nur Vorübung ist, es bei diesen Grundzügen bewenden lasse. 


\section{BeschluB.}

Zwei Dinge erfüllen das Gemüt mit immer neuer und zunehmender Bewunderung und Ehrfurcht, je öfter und anhaltender sich das Nachdenken damit beschäftigt: der bestirnte Himmel über mir und das moralische Gesetz in mir. Beide darf ich nicht als in Dunkelheiten verhüllt oder im Uberschweng- [162] lichen, außer meinem Gesichtskreise suchen und bloß vermuten; ich sehe sie vor mir und verknüpfe sie unmittelbar mit dem Bewußtsein meiner Existenz. 10 Das erste fängt von dem Platze an, den ich in der äußeren Sinnenwelt einnehme, und erweitert die Verknüpfung, darin ich stehe, ins unabsehlich Große mit Welten über Welten und Systemen von Systemen, überdem noch in grenzenlose Zeiten ihrer periodischen Bewegung, deren Anfang und Fortdauer. Das zweite fängt von meinem unsichtbaren Selbst, meiner Persönlichkeit an und stellt mich in einer Welt dar, die wahre Unendlichkeit hat, aber nur dem Verstande spürbar ist, und mit welcher (dadurch aber auch zu- 20 gleich mit allen jenen sichtbaren Welten) ich mich nicht wie dort in bloß zufälliger, sondern allgemeiner and notwendiger Verknüpfung erkenne. Der erstere Anblick einer zahllosen Weltenmenge vernichtet gleichsam meine Wichtigkeit als eines tierischen Geschöpfs, das die Materie, daraus es ward, dem Planeten (einem bloßen Punkt im Weltall) wieder zurückgeben mú , nachdem es eine kurze Zeit (man weiß nicht wie) mit Lebenskraft versehen gewesen. Der zweito orhebt dagegen meinen Wert als einer Intelli- 30 genz unendlich durch meine Persönlichkeit, in welcher das moralische Gesetz mir ein von der Tierheit und selbst von der ganzen Sinnenwelt unabhängiges Leben offenbart, wenigstens soviel sich aus der zweck- 
mäßigen Bestimmung meines Daseins durch dieses Gesetz, welche nicht auf Bedingungen und Grenzen dieses Lebens eingeschränkt ist, sondern ins Unendliche geht, abnehmen läßt.

Allein Bewunderung und Achtung können zwar zur Nachforschung reizen, aber den Mangel derselben nicht ersetzen. Was ist nun zu tun, um diese auf nutzbare und der Erhabenheit des Gegenstandes angemessene Art anzustellen? Beispiele mögen hierbei

10 zur Warnung, aber auch zur Nachahmung dienen. Die Weltbetrachtung fing von dem herrlichsten Anblicke an, den menschliche Sinne nur immer vorlegen und unser Verstand in ihrem weiten Umfange zu verfolgen nur immer vertragen kann, und endigte - mit der Sterndeutung. Die Moral fing mit der edelsten Eigenschaft in der moralischen Natur an, deren Entwicklung und Kultur auf unendlichen Nutzen hinaussieht, und endigte - mit der Schwärmerei oder dem Aberglauben. So geht es allen noch rohen Versuchen, in

20 denen der vornehmste Teil des Geschäftes auf den Gebrauch der Vernunft ankommt, der nicht, sowie der Gebrauch der Füße, sich von selbst vermittelst der öfteren Ausübung findet, vornehmlich wenn er Eigenschaften [163] betrifft, die sich nicht so unmittelbar in der gemeinen Erfahrung darstellen lassen. Nachdem aber, wiewohl spät, die Maxime in Schwang gekommen war, alle Schritte vorher wohl zu überlegen, die die Vernunft zu tun vorhat, und sie nicht anders als im Geleise einer vorher wohl überdachten Methode ihren Gang machen

$30 \mathrm{zu}$ lassen, so bekam die Beurteilung des Weltgebäudes eine ganz andere Richtung und mit dieser zugleich einen ohne Vergleichung glücklicheren Ausgang. Der Fall eines Steins, die Bewegung einer Schleuder, in ihre Elemente und dabei sich äußernde Kräfte aufgelöst und mathematisch bearbeitet, brachte zuletzt diejenige klare und für alle Zukunft unveränderliche Einsicht in den Weltbau hervor, die bei fortgehender Beobachtung hoffen kann, sich immer nur zu erweitern, niemals aber zurückgehen zu müssen fürchten darf.

40 Diesen Weg nun in Behandlung der moralischen Anlagen unserer Natur gleichfalls einzuschlagen, kann uns jenes Beispiel anrätig sein und Hoffnung zu ähn- 
lichem guten Erfolg geben. Wir haben doch die Beispiele der moralisch urteilenden Vernunft bei Hand. Diese nun in ihre Elementarbegriffe zu zergliedern, in Ermangelung der Mathematik aber ein der Chemie ähnliches Verfahren, der Scheidung des Empirischen vom Rationalen, das sich in ihnen vorfinden möchte, in wiederholten Versuchen am gemeinen Menschenverstande vorzunehmen, kann uns beides rein und, was jedes für sich allein leisten könne, mit Gewißheit kennbar machen, und so teils der Verirrung einer noch 10 rohen, ungeübten Beurteilung, teils (welches weit nötiger ist) den Genieschwüngen vorbeugen, durch welche, wie es von Adepten des Steins der Weisen zu geschehen pflegt, ohne alle methodische Nachforschung und Kenntnis der Natur geträumte Sçhätzo versprochen und wahre verschleudert werden. Mit einem Worte: Wissenschaft (kritisch gesucht und methodisch éingeleitet) ist die enge Pforte, die zur. Weisheitslehre führt, wenn unter dieser nicht bloß verstanden wird, was man tun, sondern was Lehrern 20 zur Richtschnur dienen soll, um den Weg zur Weisheit, den jedermann gehen soll, gut und kenntlich za bahnen und andere vor Irrwegen zu sichern: eine Wissenschaft, deren Aufbewahrerin jederzeit die Philosophie bleiben muß, an deren subtiler Untersuchung das Publikum keinen Anteil, wohl aber an den Lehren zu nehmen hat, die ihm nach einer solchen Bearbeitung allererst recht hell einleuchten können. 


\section{Register.}

\section{A. Personen-Register.}

„Alten", die 307784139 f. 161 179.

Anaxagoras 179 .

Aristoteles 163 Anm.

Cheselden 16.

Crusias 53.

Cyniker 163 A.

Epikur $30 \quad 6354148154180$.

Epikureer 114143 f. 161f.163A.

Fontenelle 99.

Heinrich VIII. 196.

Horaz 5\%).

Hume 1516 66-71 73.

Hutcheson 53.

Juvenal [41] 200 (202).
Leibniz 125202.

Mahomet 155.

Mandeville 53.

Mendelssohn 120.

Montaigne 53.

Mystiker, die 155 .

Plato $120163 \mathrm{~A} .179 \mathrm{f}$.

Priestley 127.

Spinoza 131.

Stoiker 13 A. 5379111143 L $148162162 \mathrm{f}$. A.

Vaucanson 130.

Voltaire 101.

Wizenmann $183 \mathrm{~A}$.

Wolf 53.

\section{B. Sach-Register.}

\section{A.}

Achtung, Gefühl der definiert 104, das einzige Gefühl a priori 95 101, ist das wahre moralische Gefühl 97 104, aus Lust und Unlust gemischt $100 \mathrm{f} .101 \mathrm{f}$., negativ und positiv 96 f., im Gegs. zur Liebe 108 f., vgl. noch 95 fr. 114118 150164188191198204.

Allgemeinheit der Gesetzgebung s. Gesetzgebung.

Analytik 1. der reinen praktischen Vernunft $911 \quad 19$ 23 ff. 55 f. 141145 f., kritische
Beleuchtung ders. 115 ff. bes. 119 , 2. der reinen spekulativen Vernunft $1956115 \mathrm{f}$. analytische und sy $\mathrm{n}$ th $\theta$ ti $\mathrm{sch} \theta$ Methode 12, Urteile 16, Einheit (Verknüpfang) $143145 \mathrm{f}$., Erkenntnis 145.

Annehmlichkeit, die (Angenehme, das) im Gegs. zum Guten (w. s.) 2728 f. 31 76-78 114.

Anschaunng, sinnliche 7385 $89115128133173 \mathrm{f}$., empirische 7284 , reine 566888 , innere 7, intellektuelle (übersinnliche) 415964129157173 . 
Anthropomorphismus 173 174176.

Antinomie der reinen spekulativen Vernunft $3 \quad 16 \quad 39$ 138 f. 146 f. 169 f., der praktischen Vernunft 145f., deren Aufhobung 146-153.

a priori (Gegs. empirisch) $14 \mathrm{f}$. vgl. 67.

Asthotik, der reinen theoretischen und praktischen Vernunft 116.

Automaton, materiale and spirituale $125 \mathrm{vgl} .130$.

Autonomie des Willens oder der reinen praktischen Vernunft als oberstes Prinzip der Sittlichkeit 435557161 165 168, der Freiheit 113 vgl. 43 141, Einfachheit dieses Prinzips 48.

\section{B.}

Bedingung, formale des praktischen Gesetzes 4344.

Bodürfnis der reinen Vernunft (= subjektive Notwendigkeit) 5117160 f. 180 If., bes. $181 \mathrm{~A}$. 183 A.; B. im Gegs. zum Recht 201, zur Vernunft (sinnliches) $-44$.

Begehrungsvermögon definiert $10 \mathrm{~A}$. vgl. 142476 , unteres and oberes $27 \mathrm{f}$. $30 \mathrm{f}$., Form und Materis desselben $26 \mathrm{f}$. $31 \mathrm{ff}$; B. and Lust $10 \mathrm{f}$. $\triangle$.

Beispiele, ihre Wirkung anf die Sittlichkeit 195 ff., warnende 206.

$\begin{array}{llll}\text { Bewunderung } & 99 & 101 & 197\end{array}$ $205 \mathrm{f}$.

BewuBtsein, reines nnd empirisches 7 A., seine Einheit 84 85; B. meiner Existenz 205. Bildung, moralische 204, vgl. Erziehung.

Kan t, Kritik der prakt. Vernunft.
Böse, das, im Gegs. zum Obol 5078 fr., zum Unangenehmen $76 \mathrm{f}$.

Bosewichter, geborene 128.

\section{C.}

Charakter definiert 192, sittlicher 199, wodurch entstehend 125 f. 127 128, Beurteilung desselben 193 If.

chemisches Verfahren, ange. wandt in der Ethik 119 f. 207. Christentum, seine Religions. lehre 158 A. 162 f., sein Mo. ralprinzip 162 f. A. 164 f., vgl. Evangelium.

\section{D.}

Deduktion (definiert 61), 1. der Grundsätze der reinen prak. tischen Vernunft 55-65, vgl. $70120 \mathrm{f}$., 2. transzendentale des hochsten Guts 145 161, 3. der Kategorien $179 \mathrm{f}_{\mathrm{s}}$ 4. der Freihoit 62.

Definitionen, gewagte $11 \mathrm{~A}$. Demut 111164104.

Dialeltik der reinen prak. tischen Vernunft 1984 $138 \mathrm{fb}_{\text {, }}$ in Bestimmung des höchsten Guts 142 ff.; natür. liche I. der reinen spekula. tiven Vernunft 133f. 188 i

Ding an sich vgl. Erschoinung.

\section{E.}

Einbildungskraft, transzendentale 89, ihr Verfahren ebd. vgl. 67.

Eigendiunkel (sittlicher) 95 f. 98 100 f. 107109111.113194.

Eigenliebes. Selbstliebe. Einheit, analytische und synthetische 143, synthetische des 14 
Mannigfaltigen der Anschauung 84, der Begehrungen 85, systematische der Erkenntnis 117.

Elementarlehre (Gegs. Meth od enlehre, w.s.) der reinen praktischen Vernunft 21-188, ihre Einteilang 19.

Empfánglichkeit des Subjelts fär Lust und Unlust 26 27, für Tugend 193.

- mpfindelnde Romanschreiber und Erzieher $111 \mathrm{vgl.} 195 \mathrm{f}$. Empfindung im Gegs. zur Vernunft $5276 \mathrm{f}$., vorübergehend 80, ihr Gegenstand 81 vgl. 275182 u. o., auch G ofühl. empirisch = zar Sinnen relt gehörig 87 rgl. 88.

Empiriomus, System des allgemeinen 15-17 $67 \mathrm{ff}$., woranf er sich grindet 16, der praktischen Vernunft $91 \mathrm{f}$., seine Seichtigkeit 121.

Empiristen 8.

Brfahrung definiert 56, im Gegs. zur Vernunft 148348 u. O., zur Notwendigkeit 67; mogliche E. $56 \quad 5961 \quad 70$ (dreimal) 173, gemeine 206, ihr Probierstein $16 \mathrm{f}$.

Lrhabenheit unserer Bestimmung 113 f, der Gottheit 106, einer Handlung 109 f., der Pflicht 111, des Sittengesetzes 206, unserer Natur 150 vgl.114. Srkenntnis, theoretische 71, praktische 710244074 133, a priori 14 f. 5659 120, jenseits der Erfahrung unmoglich 4156176 u. 0., Erweiterung in praktischer Absicht 181 ff., daron:

Erkenntnisvermogen 1114 18 , reines 18.

Erlaubtes und Unerlaubtes 13 A. 86.
Erscheinung (Gegs. zum Ding an sich) 6 f. $7 \mathrm{~A} .376369 \mathrm{f}$. $121 \mathrm{ff} .146 \mathrm{f}$., ist in der Zeit bestimmbar 121 ff. vgl. Noumena.

Erzlehnng, Prinzipien der 63 111128195 ff. 198.

Evangelium, seine Lehre (Vorschrift) $108 \quad 109111 \quad 163 \quad \Delta$. rgl. Ohristentum.

Existentialsatz 177.

Exposition (Gegs. Deduktion, w. s.) des Sittengesetzes 60.

Ewigkoit, ihre Majestät 187.

F.

Faktum der reinen praktischen Vernunft 740 f. 415556 , gleichsam oin F. 6172118184 . Fanatizismn: 173.

Fatalist 127.

Fatalităt der Handlangen 130. Form (Gegs. Materie, w. 8.) der Anschauung 16 A. 85 129, der Allgemeinheit 45, der Gesetzmåigkeit 32 91, des Gosetzes $35 \quad 86 \quad 40 \quad 4588$, dor Freiheit 95, der Verstandeswelt $56 \mathrm{f}$, des Willens 34, reinen Willens 85, die blobe oder allgemeine gesetzgebende Form $34 \quad 3637$ (viermal) $\begin{array}{lllllll}43 & 44 & 45 & 46 & 65 & 63\end{array}$ 818388 141, bloße praktische 96, mubjektive der Grundsätze und objektive des Gesetzes 40. formale Gesetze des Willens 28 vgl. 4184 141, Prinzip der Sittlichkeit 5255 .

Formel, neueder Moralität 801 . Fortschritt (Progressus), unendlicher zum Besseren $42 \mathrm{f}$. 108156 ff. 164.

Freiheit, 1. in poychologischer (komparativer 130) Beziehung 8 ff. 121 ff., durch 
innere Vorstellangen bewirkt $123 \mathrm{f} .$, = Freiheit eines Braten. wenders 125 ; 2. im ,eigentlichen" (124), nstrengsten * (87) odertranszendental en Verstande $B$ ff. $121 \mathrm{ff}$. Ihr a) orster Begriff ist nogativ 884856 62 f. oder problematisch 64 , Unabhangigkeit vom Objekt 43, von der Natar 124, von Neigungen 151 169; b) der zweite positiv = Antonomio des Willens 43 , mit absoluter Spontanertät 63 127, als Kausalităt (w. 8.) eines intelligibelen Wesens 87101136160 und Gesetz einer intolligibelen Welt 169 vgl. 55 f. 127 , das den übrigen Ideen erst objektive Realität verleiht $4 \mathrm{f} .170 \mathrm{f}$. Als solche ist sie Bedingung des moralischen Gesetzes 4 4 A. $\nabla g l$. B $\mathrm{f}$. 48 , das ihrerseits anf sie hinführt $88 \mathrm{f}$. 62 . Sio bildet den Sohlaßatein de Systems der reinen Vernunft 4. Ihre Kategorien 8. d.; Fruchtbarkeit 183, Schwierigkeit $8 \mathrm{f}$. 62124 , Unentbohrliehkeit $8 \mathrm{f}$. und Unbegreifliohkeit 9 des Freiheitsbegriffs, dessen Möglichkeit sich nicht weitor erklären laßt 60 . F. als regulatives Prinzip 63f., als Faktam $7 \mathrm{vgl}$. 19. F. and Natarnotwondigkeit (พ. s.) $7121 \mathrm{ff}$. Praktische Freiheit $=$ Unabhängigkeit des Willens von jedem anderen als dem moralischen Gesetze 124. BewuBtsein dors. $55203 \mathrm{f}$. Wio sio zu retten 122 f. $129 \mathrm{f}$. vgl. Wille (freier).

\section{G.}

Geftihl, jederzeit sinnlieh 98150 oder pathologisch (w. 8.) 97, intellektaelles ein Widerspruoh 150, im Gegs. zum Verstand 27, su Grundsätzen 199, der Lnst (w. s.) nnd Unlust $10 \mathrm{f}$. $31 \mathrm{ff}$. $7681 \mathrm{ff} .9799$, moralisches $61116 \mathrm{vgl}$. Sinn (moralischer), der Achtung s. d.

Gegenstand der reinen praktischen Vernanft 75 ff. vgl. Gat (hochstes).

Geist (Gegs. Buchstaben) des Gesetzes 9898 A. 107110192. Golehramkeit, Gelehrter (Gegs. Vernunftwissenschaft, Philosoph) 175 f. A. vgl. 69.

Geniesohw tinge (Gegs. methodische Nachforschung) 207.

Qoometrio, reine $40 \mathrm{vgl}$. $\mathrm{Ma}$. thomatik.

Gerechtigkeit der Strafo 50, Gottes $157 \mathrm{f}$.

Gesetz (praktisches) im Gegs. zn Grundsatz und Maxime 23 $273335 \mathrm{ff}$. 47, zur Vorschrift $2532 \mathrm{f}$. 44 oder Regel 28 40, unbedingt $37 \mathrm{f} .40$, a priori 81 ; das Gesetz aller Gesetzo 108; moralisches o. Sittengesetz; dynamische 55, physische $58 \mathrm{vgl}$. Naturgesetz.

Gesetzgebung, allgemeine $34 \mathrm{f}$. 3955848596 , ihro Moglichkeit als problematischer Gedanke 40.

Gesotzmäbigkeit (allgemeine) der Vernunft überhaupt 60 92, der Handlangen 110.

Gesinnang, echte moralische 92108 f. 149187 f. 193 a. ò. Gowissen, anklagendes und richtendes 126.

Gew olnheit = subjektive Notwendigkeit (w. s.) $14 \mathrm{f}, 1567 \mathrm{f}$. Gla $a b \theta$, vernünftiger 8. Vernanftgla abe.

Glüekseligkeit definiert 27159 vgl. 94 187, das Verlangen 
aller Menschen 31, empirisch bedingt 3248 , allgemeine 47, eigene $\begin{array}{llllll}27 & 30 & 14 \mathrm{f} . & 46 & 49 & \mathrm{ff} \text {. }\end{array}$ 142 fi. 198, fremdo 44 f. Alles überhaupt kommt nicht darauf an 80. Geg8. zar Nächstenliebe $107 \mathrm{~A}$. Ihr Verhsltnis zur Sittlichkeit (Tugend) 142-153; als zweiter Bestandteil des hochsten Guts 159-168 184.

Glïekseligkeitslehre

Sittenlehre) 54119 f. 166. Glückwürdigkөit $142 \quad 166$ 188.

Gott nicht Bedingung des Sittengesetzes, sondern nur des höchsten Guts $4 \mathrm{f}$,, nalmlich als Grund der Ubbereinstimmung von Sittlichkeit and Gltickseligkeit 159 f, daher nur Ideo 74 oder Postulat (w. s.) 14 A. 158 ff., seine Annahme nicht Pflicht, ondern nur notwendiges Bedürfnis 160 ; sein $\mathrm{Be}-$ griff zur Moral, nicht zar Physik gehorig 176 fr., nicht begrifflich zu erkennen 177, sondern nur moralisch notwendig 160. Seine Eigenschaften $167 \mathrm{~A} .175 \mathrm{f}$ a. 8. $G$. als allgemeines Urwesen 129179 ff., Welturheber 160 and zwar moralischer 178 184, Ideal der Heiligkeit in Substanz 200 vgl. 106, allgenugsam 129 , selbstgenugsam 152 , unendlich 157, Austeiler der Glückseligkoit $164 \quad 167 \quad$ vgl. 178, aber nicht Grand anserer moralischen Verbindlichkeit $160 \mathrm{f}$. Seine furchtbare $\mathrm{Ma}$ jestät 187. Anbetung and Liebe Gottes 168 vgl. 109; wodurch Gott Gegenstand der Religion wird $167 \triangle$. Crundgesetz der reinen prak- tischen Vernunft ( $=$ Sittengosetz 41) 39.

Grundkräfte, Grandverm o gen 61 .

Grundlegung zur Metaphysik der Sitten, dio (Schrift Kants) 98 A. 10.

Grundsätze, 1. praktische a priori iefiniert 23 , vgl. $18 \mathrm{f}$. 23-55, ihre Deduktion 55-65, Möglichkeit 116, von ihnen geht die praktische Vernunft aus $19 \mathrm{f}$. $116 \mathrm{f}$. 118, anf $\mathrm{Be}-$ griffen, nicht Gefühlen beruhend 189, der Sittlichkeit 135 ; 2 the oretie che 20115 f. Gultigkeit (Realitst), objektire von Urteilen 15, Gesetzon 33 62, Ideen 4, der Kategoriers $70 \mathrm{f}$., praktisohe $636474171 \mathrm{f}$. gut, das Gute, ist das Objekt der praktischen Vernunft 76 , im Gegs. zum Angenehmen 76 f., zum Nützlichen 77, zum Wohl 7881 , mittelbar (irgendwozn) and anmittelb ar (schlechterdings) Gates 77 fi. 116, das letztere geht auf Personen, nicht Sachen 79. Sein Begriff ist erst durch das moralische Gesetz zu bestimmen 107682 ff. 98116 .

Gut, hrchstes, Objekt a priori des moralisch bestimmten Willens 5 vgl. 67 139, bei den Alton und Noueren $84139 \mathrm{f}$. Dialektik der reinen praktischen Vernunft in Bestimmung desselben $140 \mathrm{f}$. $142 \mathrm{ff}$. Es ist Gegenstand, nicht Botimmungsgrand derreinen praktisohen Vernupft 141, ibr notwendiges Objekt $171 \mathrm{ff}$. und ganzor Zweek 169, seino Be- förderung notwendiges Objekt unseres Willens $146147 \mathrm{f}$. 156 159 ff. 182. Seine praktische 
Möglichkeit darch Freiheit des Willens 145 , seino transzendentale Dedaltion $145 \mathrm{f}$. Oberstes und vollendetes 142 , ursprüngliches und abgeleitetes 160164167169 , ganzes 144 .

\section{H.}

Helligkeit Gottes s. d., des Sittengesotzes 118118167200 , der Menschheit in unserer Person 168, der Pflioht 201, der Sitten 164, des Willens $42109156 \mathrm{f}$., des göttlichen 106167 , als Idee $13 \mathrm{~A} .158 \mathrm{~A}$. $163 \mathrm{~A}$. oder Urbild 42108.

Heiligung $158 \mathrm{~A}$.

Heteronomio (Gegs. Antonomie, w. s.) der Willkūr 43 84, erfordert Weltkenntnis 48 vgl. 67.

Himmel, der bestirnte übor mir 205.

Hypothese $=$ notwendige Annahme (Postulat) $14 \mathrm{~A}$. vgl. 161178 , unterschieden von Postulat 180 f. vgl. 182.

\section{I.}

Ich 8. Sabjekt (denkendes). Ideal der Heiligkeit 108, transzendentales des Urwesens 170. Id ealist $16 \mathrm{~A}$.

Idealitat der Zeit und des Raumes 129131.

Idee der Freihoit, Heiligkeit, Personnlichkeit s.d.; des Guten 73 A., Gottes and der Unsterblichlseit 4 f. $15171 \quad 176$ vgl. -Postulate; derWeisheit 13A., kosmologische 62170 , inteltektnelle 103, praktische (moralische) und theoretisehe 163 , immanente (konstitutive) and transzendente (regnlative) 173, im Gegs. zar Erfahrung 178 f., $=$ Vernunftbegriff 133 .

immanent s. transzendent. Imperative definiert 24, im Gegs. zu den Maximen objektiv ebd., jedoch keine Gesetze 25. Thinteilung in hypothetische and kategorische $24 \mathrm{vgl} .25$, in problematische, assortoriseho, apodiktische $13 \mathrm{~A}$,, kategorischer I. 42, = praktisches Gesetz 55 ("Satz a priori ${ }^{4}{ }^{40}$ ) 171.

Instinkt im Gegs. zar Vernunft 80124.

intelligibele(s) Existenz 127 132, Ordnung der Dingo 65 56, Subjekt 129, Substrat 128, Urheber 147, Welt 596066 112134 f. 148 169, Wesen 135 f. vgl. Freiheit, Verstandeswelt, Verstandeswesen.

Intelligenz definiert 160, allargenugsamste 42 , hochste 161 , reine 147 vgl. 74205.

Interesse definiert 103158 , aus der Triebfeder entspringend 102 f., der Neigungen 154 f., freies 105185 , praktisches 155, reines 193201 oder moralisehes $103 \quad 104 \quad 118$ 202, alles I. zuletzt praktisch 166. Ein I. nehmen 105. I. der spekulativen und der praktischen Vernunft 154 vgl. 182 f.

\section{K.}

Katech ismus, moralischer 195. Kategorien, 1. der Natur 85 oder des Verstandes, auf Noumena nicht anwendbar $6 \mathrm{f}$. 70 f. 133, ihre Dedultion 179 f., Einteilung in mathematischo und dynamische $133 \mathrm{f}$. Merkmale des reinen Verstandes 11 A., die Erfahrung ermogg- 
lichend 61 vgl. $84 \mathrm{f}$. $123 \mathrm{f}$.; 2. der Freiheit $85 \mathrm{f}$., ihre Tafel 86 vgl. 13 A. 7487.

Kausalitït, 1. der Natur (Naturmechanismus, w. 8., $7 \mathrm{~A}$. 125) 37 A. $37 \quad 55628589$ 121 f. 147181 , psychologische and mechanische 124. Ihre Besitreitung durch Hume 66 ff.; 2. empirisch unbedingte des Willons oder der Freiheit (auch: als, aus, durch Freiheit) $37 \mathrm{~A}$. $11 \mathrm{~A}$. 182024 2659 f. 62 ff. 8789121 ff. $133 \mathrm{ff} .147160$, intellektuelle 95134147 , freio 128 , der (reinen) Vernunft 84 vgl. 104 115 u. 6.

Koalitionssystem 30 , -versuche 145.

konsequento Denkungsart 6 7 f. 192, die gröBte Obliegenheit eines Philosophen 30, der Epikureer $161 \mathrm{f}$.

Kritik unterschieden vom $\mathrm{Sy}$ stem 9 vgl. 10, von der Wissenschaft 10, Kr. der reinen praktischen Vernunft $37 \mathrm{ff}$., ihre Aufgabe $10 \mathrm{vgl.} 19$, Idee 18-20, Einteilung 19.

Kants Schriften:

Kritik der reinen Vermunft $6 \mathrm{ff}$. 11 A. $12 \quad 18$ f. $56 \quad 5966 \quad 6971$ 125132136179 f. 186.

Kritik der praktischen Vernunft 3711 A. 59204.

\section{L.}

Zoben definiert 10 A. vgl. 11 A., physisehes and morslisches 115, das bloße Leben und sein Wert 114149 , sein froher Genuß 114, das zukünftige 80.

Legalitat, im Gegs. zur Moralität $93 \quad 105 \quad 151 \quad 191192$. Lebe, pathologische der
Neigung und praktische der Achtung 105-110 vgl. 168.

Lust definiert $10 \mathrm{f}$. A., ihr Verhältnis zum Begehren (Wollen) 10 f. A. $26 \mathrm{ff} .31 \mathrm{ff} .7681149 \mathrm{ff}$. vgl. Gefühl (der Lust and Unlust).

\section{M.}

materiale Prinzipien der Sittlichkeit 2752 , Tafel derselben 53 vgl. $54 \mathrm{f}$.

Materie (Gegs. Form, w. s.) des Begehrungsvermögens 26 31 f. 34 96, des praktischen Gesetzes 37, des Wollens 43 f., der Maxime 45, tierische $M$. 205.

Mathematik 9 A. 13 A. 14 A. $163167 \mathrm{ff}$. $70206 \mathrm{f}$. Ihre Sätze synthetisch, nicht analy. tisch 68. Ihre Evidenz 120.

Maximen (des Willens) definiert 2386 vgl. 23 ff. passim; beruhend auf dem Interesse 103, der Neigung 87.

Hensch, der, als Subjekt dee moralischen Gesetzes 168, seine praktische Bestimmung and seine Erkenntnis 186 ff., unterschieden rom vernünftigen Wesen 8. Wesen.

Henschhoit, Idee der 112168. Menschenvernunft, - verstand gemeiner $46 \quad 47 \quad 90$ f. 113 118163 A. 170196207.

Metaphysik äberhanpt 69 , enthält die reinen Prinzipien a priori der Physilk 176 vgl. 177, mit ihrem transzendentalen Teile ist nichts suszarichten 178, ihre dogmatischen Lehrer 132.

Methode $=$ Verfahren nach Prinzipien 191, dio der angewandten Ethik 193 vgl. 201, 
analytische and synthetische 12 , wohl überdachte 206 , chemische s. d.

Methodenlehre der reinen praktischenVernanft definiert 191 189-207.

Mittel und $\mathrm{Zweck}$ (w. s.) 77 $81112 \mathrm{f}$.

Modalitiit, (praktische) Kategorien der 86, vgl. $13 \mathrm{~A} .87$.

Möglichkeit, physische and moralische einer Handlung 75 182, des freien Willens 14, der Freiheit 120 f. 170.

Moral definiert 166, christlicho 162 f. A.

Daron:

Moralisten, kritische 9 , theologische 53 vgl. 148.

Moralität 51110168202 u.ö., M. and Legalität s. d.

Moralprinzip, kein neues $9 \mathrm{~A}$., christliches 165 , formales und materiales 8. d.

Hystizismus der praktischen Vernunft 9192 vgl. 155.

\section{N.}

Nächstenliebe $107 \mathrm{f}$.

Natur $=$ Existenz der Dinge unter Gesetzen 57, Einteilung in sinnliche und übersinnliche 56 vgl. 5791 f. $114162, \mathrm{Be}$. griff and Moglichleit der letzteren 5962 , urbildliche und nachgebildete 57. Natur and freier Wille 58, N. und Sittlichkeit 164 vgl. $89 \mathrm{ff}$.

Davon:

Naturgesetze (Gegs. Sittengesetz) $7 \mathrm{~A} .243388 \mathrm{ff}$, allgemeines 3537 185, als Typus des Freiheitsgesetzes 90.

Naturlauf (-gang) $184 \mathrm{f}$.

Naturmechanismus (-notwendigkeit) $38 \mathrm{f} . \quad 64 \quad 112$
125 u. ö. N. and Freiheit (w. s.) 7 A. 38121 ff. vgl. Kausalitä, Notwendigkeit.

Neigungen auf Gefühl gegründet 94 97, im Gegs. zur Vernunft 341181 A., zur Pflicht 49 $104 \mathrm{ff}$. $109151 \mathrm{f}$. 203 n. ö., zum praktischen Gesetz 3586 39 ff. 58105 п. 6. , zum Gefühl der Achtang $95 \mathrm{ff}$., = pathologische Liebe 107; ihre Summe 94 vgl. 187, Zadringlichkeit 203, sio haben allomal das erste Wort $186 \mathrm{f}$. Feinere and gröbere 52, blinde and knechtische 151.

Nötigung des Willens darch das moralische Gesetz 42104 105 f. 108.

Notwendigkeit, subjektive and objektive $514 \mathrm{f}$. $252732 \mathrm{f}$. 4867160 , gefühlte and ein. geseheno 16, physische und praktische 33, moralische 105. Noumena (Gegs. Phänomena) $756 \quad 64 \quad 71 \mathrm{ff} .119 \mathrm{f} .125 \mathrm{f}$. 131 f. 147 u. ö. vgl. Ding an sioh.

\section{0.}

ontologis ch $\Theta$ Prädikate Gottes 176.

Orảnung, intelligibele des Dinge 55 f. 65112 vgl. 139 , der Zwecke s. d.

\section{P.}

Paralogismen der reinen Vernunft 169 .

pathologisches (Gegs. prakti s ch) $9798 \mathrm{f}$. 154, Gefühl 99 103f., Gesetz 43 58, Liebe 107, Selbst 96, Triebfeder 110, Ursachen 102, Willkür 42.

Person, Persönlichkeit defi- 
niert 112 vgl. $869599113 \mathrm{f}$. 188194199205.

Pflicht definiert 4248 104, Formel ihres Prinzips 99 A., Einteilung 10 vgl. $13 \mathrm{~A}$. 86, das einzige moralische Gefühl 51 110, im Gegs. zum Bedürfnis 160, zu Herzensaufwallangen $110194 \mathrm{f} .196 \mathrm{~A}$., "edlen und verdienotlichen ${ }^{*}$ Handlungen $195 \mathrm{ff}$, Neigungon s. d., Pflichtwidrigem $18 \mathrm{~A}$. 86 . Aus Pflicht im Gegs, zu pflichtmäßig 105f. 150, vollkommene and unvollkommene 86, ihre Ehrwürdigkeit 114, Heiligkeit s. d., Pfl. nnd Schuldigkeit 107 110, Pflichten zagleich göttliche Gebote 165. Kants Apostrophe an die Pflicht 111 f.

Philosophie, ihr Name 140, $=$ Weisheitslehre als Wissenschaft $139 \mathrm{f}$, - Lehre vom höchsten Gut (bei den Alten) 139; systematische Philosophie als Wirsenschaft 14, praktische 10 A. 14 87, dogmatische 11 A. $\mathrm{Ph}$. and Mathematik 16, und Gelehrsamkeit 175 f. A., $\mathrm{Ph}$. als Aufbewahrerin der Wissenschaft 207.

Physik and Theologie 176178. Popularität, philosophische $112 \mathrm{f}$.

Vostulate der reinon praktischen Vernunft unterschieden von denen der reinen Mathematik 13 f. A. 40, definiert $156168 \mathrm{f}$. vgl. $13 \mathrm{f}$. A., ihre Dreizahl 169. P. der Unsterblichkeit (w. s.) 156-158, des Daseins Gottes 158-168, der Freiheit s. d., die Postulate der reinen praktischen Vernunft überhaupt 168-170. Vgl. noch $6070172181 \mathrm{f}$. praktisch = zur Willensbestim. mang hinreichend $23,-$ durch anseren Willen (durch Handlung) möglich 145146 , passim.

Primat (definiert 153) der reinen praktischen Vernunft 153-156.

Prinzipien, praktische 26 ff. 87 153 u. ö., oberstes 8392 a. ö., regulatives $63 \mathrm{f}$., theoretische 32 , a priori 41155 , formale and materiale s. d., moralisches 10 , s. Moralprinzip. Prychologie $10 \mathrm{~A}$. $11 \mathrm{~A}$.

psychologische Begriffe $11 \mathrm{~A}$. 169.

\section{Q.}

Qualitit, praktische Kategorien der 86.

Quantitä, praktische Kategorien der 86 .

\section{R.}

Rationalismus 16 vgl. 17 , der Urteilskraft 92.

$\mathrm{R}_{2}$ u $\mathrm{m}$ 16, im übrigen vgl. Z $\mathrm{\theta i}$ t. Reali tät (objektive) s. Gültig keit.

Regel, praktis che, unterschieden vom Gesetz (w. s.) 23 vgl. 23 ff. 87 ff., Einteilung 86. Regeln der Geschicklichkeit 32, der Einbildungskraft 67, generelle and aniverselle 49. Reich 1. Gottes 92163 f. 166 174 ; 2 . der Sitten 107, seine genaue Zusammenstimmung mit dem der Natur 185.

Relation, praktische Kategorien der 86.

Religion definiert 165, der Schritt von der Moral zur R. 166 vgl. 157.

Davon:

Religionslehre 158 A. 163. 
Religionsschwărmerei 109 vgl. 167.

Reue 127.

\section{S.}

Schein, dialektischer $138 \mathrm{f}$.

Sehema definiert $89 \mathrm{vgl.} 88$, im Gegs. zum Gesetz 89 f., Sch. eines Gesetzes selbst 88 .

Schopfang, Begriff der $131 \mathrm{f}$. Schulen, philosophische $46 \mathrm{vgl}$. $16 \mathrm{~A}$.

Sehwärmerei 92111206 , moralische 109111 , heroische and schmelzende 111.

Seele als letztes Subjekt 169. Seelenstärke 29162 A. 187193. Seelenanruhe $50 \mathrm{f}$.

Selbst, das unsichtbare des Menschen 205.

Belbstgesetzgebungs. Antonomie.

Selbstliebe (Gegs. Sittlichkeit) Prinzip der 2732 f. 45 47 f. 94 ff. 110201 , vernūnftige 94.

Selbstsucht 94 f.

Selbstzafriedenheit 151 vgl. 152.

Seligkeit $152164 \mathrm{vgl} .158 \mathrm{~A}$.

Sinu, innerer 2876103126 147, Täuschung desselben 150, innerer und äußerer 124, im Gegs. zam Verstand 2829 f., moralischer $50 \mathrm{f}$.

Sinnenwelt s. Verstandeswelt.

Sinnlichkeit, 1. = Sinnenvorstellung (Gegs. Verstand) 81 vgl. Sinn; 2. als moralische Triebfeder $95 \quad 98.102201 \mathrm{vgl}$. Neigung.

Sittengesetz (moralisches Gesetz) 41, sein Wortlaut 40 , ist heilig 42101113 168, rein 42 , gebietet kategorisch 48, weist auf eine intelligibelo
Welt hin 56 vgl. $57 \mathrm{ff}$. 127, ein Faktum (w. 8.) der reinen Vernunft 61 , rechtfertigt den Freiheitsbegriff 62 vgl. 38 f., bedarf selbst keiner Rechtfertigung 62, Bestimmungsgrund der Freiheit 73, des reinen Willens 7493 ff., des Begriffs des Gaten s. gat, als Triebfedor $98114 \quad 150$, demütigt 96 ff. and erhebt zugleich 102 104 , sein Joch sanft 109 , es findet von. selbst im Gemüt Eingang 112, = Antonomio $43 \mathrm{165}$, vor ihm verstummen alle Neigungen 112; anf Pflicht, nicht Vorliebe beruhend 199, fordert Heiligkeit der Sitten 164, seine feierliche Majestät 100. Seine objektive Realität 62. Es erkennt keinen Zeitnnterschied an 127, ist nicht anf Furcht oder Hoffnung zu bauen 165, führt zar Religion 165, gebietet die Existenz des höchsten Gats 171, seine Wirknng geht ins Unendliche $205 \mathrm{f}$. vgl. Gesetz (praktisches). Sittenlehre(Gegs. Glü cksoligkeitslohre) 54119 f. 166, christlicho $163 \mathrm{~A} .164$.

Sittlichkeit (vgl. Moralität), ihr oberstes Prinzip 9 A. 41 43 62f. vgl. 4749167 a. ö., erster Teil des höchsten Gats 158, reine Sittlichkeit $196 \mathrm{ff}$. S. nnd Glückseligkeit 142 f. Skeptizismus 416 67 ff. 133 . Sollen, das 5 24, S. and Können 39123201.

Spontaneïtät, absolute der Freiheit $63127 \mathrm{f} .130$.

Sprache, nene philosophische $12 \mathrm{f}$

Strafe, ihr Begriff und Zwock 49 f., Strafen und Belohnen 50 vgl. 192. 
Subjekt, denkendes 7. Substanzen and Akzidenzen 131 vgl. 129.

Symb ol 91 .

synkretistischos Zeitalter 30, System 127.

Synthesis des Gleichartigen 133, des Bedingten 134, der Begriffe 143145.

synthetisch-praktischo Sätzo a priori $40 \mathrm{f}$. 61 , theoretischo $56 \mathrm{vgl} .177$.

System der Kritik and der Wissenschaft 10 vgl. 12 191, das kritische 8, alte 11 vgl. 127.

\section{T.}

Tafel der Kategorien der Freiheit s. Kategorien 2., der materialen Prinzipien dor Sittlichkeit $153 \mathrm{vgl}$. $54 \mathrm{f}$.

technische Satze der Mathomatik oder Naturlehre $32 \mathrm{~A}$. Toilbarkeit des Raums 16.

Theologe, der 175 f. A. vgl. 53. Thoologie, die, als Zauberlaterne von Hirngespenstern 180.

Theosophen 155 rgl. 157.

Tierheit, die im Menschen 80. transzondentale Ästhetik und Logik 116, Einbildangskraft 89, Freiheit s. d., Idesl 170, Prädikate Gottes 175, Toil der Metaphysik 178.

transzendent und immanent 135170173 vgl. 172 , Vernunftgebrauch 63 vgl. 19.

Triebfedern der reinen praktischen Vernunft $=$ ubjektive Bestimmungøgründo des Willens 9398113 vgl.93-115, die mächtigste 193.

Tugend $42 \mathrm{f} .,=$ moralisch $\theta$ Gesinnung irn Kampfo 109, als Moralprinzip der Stoiker 8.
Stoiker(Personen-Register!), als Bedingung der Glückseligkeit 142 fi., im Gegs. zum Vergnügen 30 148, zur Heiligkeit 109 , ist Kraft 193197 , kein Hirngespinst 194 vgl. 164, reine T. 196 f., T. und Schönheit $202 \mathrm{f}$.

Typik dor reinen praktischon Urteilskraft 87-92.

\section{U.}

Utbersinnliche, das 7273 f. 92 133180 ; vgl. intelligibel, Natur, Noumena.

Unbedingte, das, als problematischer Begriff 3 vgl. $3963 \mathrm{ff}$.; das Unbedingt-Grito (-Praktische) 38 vel. 40818996.

Unendlichkoit, der Welt and moiner Personlichkeit 205.

Ungleichheit der Menschur $196 \mathrm{~A}$.

Unsterblichksit definiert 156 , als Idee $\$ 15171$, als Postulat 14 A. 156-158 169.

Urbild 42 vgl. 57108 163A.16s

Urgrund 181 A.

Urs a cho and Wirkung s. Ka salität.

Urtollskraft, praktische $8 \delta^{\circ}$, ihre Regel 90, Typik 87-92, vgl. 195202207.

Urwesen s. Gott.

\section{V.}

Vorbindlichkeit, moralisebo $4245 \mathrm{vgl.} 48$ 61 201, = Notigung (w. s.) 105

Verbrechen, Verbrecher 50 128.

Verfassung, bürgerliche 53.

Vergnügen 7678 , Dauer und Grad 29, feinere und gröbere 
$29 \mathrm{f}$, im übrigen vgl. Annehmlichkeit, Lust.

Vernunft $=$ Vermogen der Prinxipion $153 \mathrm{vgl}$. 202. Endliche 43 , reine $18 \mathrm{f}$. 23115 , sp $\theta-$ kalative (theoretische) und praktische $3 \mathrm{ff}$. $3859115 \mathrm{ff}$. $155 \mathrm{ff} .181$, ist ein und dieselbe 155, praktische and roino praktische 319 , objektiv- und subjektir-praktische 191, reine praktische $31404143 \mathrm{f}$. $55 \mathrm{ff} .6460 \mathrm{fr}$. 81 ff. 115159 u. ö. Deren Aufgabe 159, Bedürfnis 117, Disziplin 106, Gegenstand 75 ff., Kritik 19, Selbstbewußtsein 38, Zweck $80 \mathrm{f}$. Ihr Verhältnis zum Gefühl der Last und Unlnst 94, zar Sinnlichkeit 80 116 a. o., zum Willen 74 , zur Wiseonschaft 117. Das Ganze der Vernunft 11 A. vgl. 117.

Daron:

Fornanftbedingungen, objeltive and subjektive $184 \mathrm{f}$.

Vernunftorkenntnis - Erkenntnis (w. s.) a priori 15.

Vernunftgebrauch überhaupt 14, gemeiner 69118 , reiner 19, theoretischer 245669160 , praktischer $1846 \mathrm{f}$. 73 118, theoretischer (spekulativer) und praktiseher 1966 ff. 153 ff. 171 fi., transzendenter $19172 \mathrm{t}$, tr. and immanenter 63170 , wissenschaftlicher 69 .

Vernunftglanbe, reiner praktischer $161183 \mathrm{f} .186$.

Vernunftwesen, vornünftiges Wesen s. Wosen.

Terstand = Vermogen za denken 174, diskursiv 175; sein Verhältnis zur Anschauang 174, zar Einbildungskraft 208, zur Vernunft 72, zum Willen 72; reiner V. $3871179 \mathrm{f}$,
$=$ Vernunft 72, gemeiner s. Menschenverstand.

\section{Davon:}

Verstandeswelt, reine 66, als Grand and Urbild der Sinnenwelt $5557 \mathrm{vgl} .147$ und in. telligibele (Welt).

Verstandeswesen, reine 73 , $=$ Noumena (w. s.).

Follkommenheit, in theoretischer and praktischer Bedeatung 54, praktische $13 \mathrm{~A}$. $163 \mathrm{~A}$., innere (unsere) und zofere (Gottes) 54, metaphysische and transzendentale ebd., hochste in Substanz = Gott obd. vgl. $178 \mathrm{f}$., als materiales Prinzip der Sittlichkeit 53.

Vorschriften, praktische (Gegs. Gesetze) $25 \quad 3340 \quad 43 \quad 86 \quad$ rg. Regel.

\section{W.}

Woise, der, der Stoiker 16 ? 163 A. vgl. 140.

Weisheit, Idee der $13 \mathrm{~A} .163 \mathrm{~A}$. der Weg zu ihr geht darct die Wissenschaft $140163 \mathrm{~A}$. 180 207, theoretische und praktisch $\theta 167$, höchste $16 \hat{i}$ 167 A. 187188.

Welt, unsere und alle möglichen 177 , z2bllose 205, intelligibele s. d., vgl. Verstandoewelt. Wert, moralischer (innerer) der Person 95114188194 f. 199, unmittelbarer 51 , unendlicher der moralischen Gesinnung 202205 vgl. 188 , dor Handlung 193, der Maxime 191, des Lebens s. d.

Wesen, rernüuftiges überhaupt im Unterschied vom $\begin{array}{llllll}\text { Menschen } & 15 & 19 & 23 & 24 & 32\end{array}$ 41 f. 106109113168 .

Wille definiert 18417778115 $160,=$ praktische Vernanft 
(w. s.) 72 ; der reine Wille und sein Ursprang $38 \mathrm{rgl}$. $\$ 14272$ ff. 81168 203, im Gegs. zum pathologisch affizierten 233142 , der freie $3738 \mathrm{f}$. u. o., reine freie 44 rgl. Freiheit, dessen Moglichkeit 94 vgl. $82 \mathrm{ff}$; dor schlechthin gute Wille 8196 ; der gottliche (heilige) Wille 4298103113 , im Verh. zo dem unsrigen 115 , als materiales (unechtes) Prinzip der Sittlichkeit 58 54. Seine Ka asalität s. d., Wille and physisches Vermögen 6075 , = Vermögen der Zwecke 77. Wissenschaft and Philosophio 1469139207 , und Weisheit 140163 A. 180 207, und Vernunft 117 , kritisch gesucht und methodisch oingeleitet 207.

Wohl and Obel s. gut (and bose).

Wohlgefallen, ästhetisches 203,
W. an une selbst, unterschieden vom Wohlwollen 95149 , negatives 152.

Wollen und Können 49.

Würde des Menschen 192, der Menschheit 113, des Sittengesetze 187.

\section{Z.}

Zoit (und Raum) 567085129 ff., Bestimmbrrkeit der Dinge in der Zeit 121 ff., unter Zoitbedingangen $125 \mathrm{f}$. $\mathrm{vgl}$. 147.

Zufriedenheit, ästhetische und intellektuelle (oder Selbst-) Zufriedenheit 151 vgl. $50 \mathrm{f}$. 162203.

Zweck und Mittel s. Mittel. Ordnung der Zwecke 168, Zweck an sich selbst 113 168; das Ganze aller Zwecke 112.

ZweckmäBigkeit der Natur $17 \%$ 185202. 


\section{ARISTOTELES WERKE}

In drei Halbpergament-Bänden

Metaphysik. Übersetzt, erläutert und mit einer Lebensbeschreibung versehen von Dr. E. Rolfes. 2., verbesserte Auflage. 1. Teil (Buch I-VII). 1921. XXIV, 209 Seiten.

- 2. Teil. (Buch VIII-XIV). 1921. 226 Seiten.

Die Übersetzung, wahrlich keine leichte Aufgabe, ist vorzüglich gelungen; sie legt ïberall von einem tiefgründigen Verständnisse Zeugnis ab. Ganz besonders tritt dies noch in dem dritten Teile der Arbeit hervor: in den Anmerkungen zu den einzelnen Büchern. Uberall sieht man die gründliche Kenntnis der Platonischen und Aristotelischen Philosophie und völlige Vertrautheit mit der elnschlägigen Literatur. Prof. A. Stölzle in der Theologischen Revue.

Politik. Neu übersetzt von Dr. theol. Eugen Rolfes. 3., durchgesehene Auflage. 1922. XXXI, 341 Seiten.

Eine äußerst pünktliche Wiedergabe des Textes mit gewissenhafter Verwertung der Vorarbeiten! Der Verfasser versteht es trefflich, die nüchterne Klarheit der Sprache des großen Griechen im Deutschen wiederzugeben. Man bekommt durch seine Übersetzung eine unmittelbare Anschauung von der abwägenden Vorsicht und Zurückhaltung, die gerade bei diesem Aristotelischen Werke besonders charakteristisch ist.

Theologisches Literaturblatt.

Drei Bücher über die Seele. Neu übersetzt von Gymn.-Direktor

Dr. A. Busse. 2. Auflage. 1922. XX, 94 und 27 Seiten.

Die Leistung überflügelt die bisher gangbaren so weit, daß man jetzt nur noch diese Verdeutschung zugrunde legen darf, wenn man des Griechischen unkundig ist. Aber auch für den Leser des schweren Originals wird sie eine erwünschte Hilfe bilden.

Lit. Ratgeber des Dürerbundes.

Nikomachische Ethik. Neu übersetzt und erläutert von Dr. theol. Eugen Rolfes. 2., verbesserte und um ein Register vermehrte Aufl. 1921. XXIV, 268 Seiten.

Poetik. Neu übersetzt v. Prof. Dr. A. Gudeman. 1921. XXIV, 91 S. Organon. Übersetzt u. mit Anmerkungen versehen v. Dr. E. Rolfes. - Kategorien (nebst Einleitung des Porphyrius). 1920. VIII, $86 \mathrm{~S}$.

- Peri hermenias oder: Lehre vom Satz. 1920. VII, 42 Seiten.

- Lehre vom Schluß, oder: Erste Analytiken. 1922. X, 209 S.

- Lehre vom Beweis, oder: Zweite Analytiken. 1922. XVIII, 164 S.

- Topik. 1919:! XVII, 227 Seiten.

- Sophistische Widerlegungen. 1918. IX und 80 Seiten.

\section{Geschichte der Aristotelischen Philosophie im protestantischen Deutschland}

\section{1 Von Peter Petersen XII, $534 \mathrm{~S}$.}

Eine erschōpfende Darstellung des Einflusses des Aristoteles auf die Gedankenwelt des Protestantismus fehlte bisher. Fast war man geneigt anzunehmen, daB die Wirkungen des Aristoteles konfessionell bedingt wären. Nun zeigt dies Buch, daB die Reformatoren $L$ uther und $M$ el a $\mathrm{n} c h$ thon selbst von Aristoteles ausgingen. Es verfolgt die Wirkungen des Aristoteles weiter über Nikol a us Taurell us zu Leibniz, über Pufendorf und Christian Wolf zu Gottsched, Lessing, Goethe und den anderen Dichterheroen. 


\section{RENÉ DESCARTES WERKE}

In zwei Geschenkbänden gebunden

Diese reich haltigste deutsche Ausgabe Descartes' erhält besonderen Wert durch ein ausführliches Gesamtregister, das ein lange vermisstes wertvolles Hilfsmittel zum Studium der Schriften des Philosophen darstellt.

Abhandlung über die Methode. 3. Auflage. 1919. 82 Seiten. Die Regeln zur Leitung des Geistes. Die Erforschung der Wahrheit durch das natürliche Licht. 2. Auflage. 1920. 168 Seiten.

Die "Regeln" und die "Erforschung der Wahrheit" erscheinen hier zum ersten Male überhaupt in deutscher Übersetzung. Die Regeln bilden das methodische Orundwerk der Philosophie Descartes': es sind darin die erkenntnistheoretischen und die Untersuchungen über die grundlegenden Probleme der Mathematik in einer Klarheit enthaiten, die durch die späteren Werke nicht übertroffen, ja kaum je erreicht wird. Die "Erforschung" aber bildet eine wichtige Ergänzung $\mathrm{zu}$ manchen in den Regeln berührten Fragen.

Lateinische Ausgabe. Regulae ad directionem ingenii. Nach derOriginalausgabe von 1701 herausgegeben von A. Buch en au. 1907. IV, 66 S. (AuBerhalb der Gesamtausgabe)

Meditationen ibber die Grundlagen der Philosophie mit den sämtlichen Einwänden und Erwiderungen. In sechster Auflage zum erstenmal vollständ. übers. 1915. XIV, 493 Seiten.

Ein lange gehegter Wunsch der Veranstalter von philosophischen Seminarübungen hat hier Erfüllung gefunden. Die Objectiones und Responsiones gehören nun einmal mit Descartes' Meditationen organisch zusammen. Sie stellen einen natürlichen Kommentar dar, der durch nichts ersetzt werden kann. Allerdings gehörte ein hoher buchhändierischer Idealismus dazu, die vollständige Übersetzung dieser Stücke zu wagen, die mehr als fünfmal soviel Raum einnehmen wie die Meditationes selbst. Es ist alles geschehen, um einen genauen und lesbaren Text zu schaffen.

Theol. Literaturberich.

- (Nur Text der Meditationen.) 78 Seiten.

Lateinische Ausgabe. Meditationes de prima philosophia. Curavit A. Buchenau. 1913. (AuBerhalb der Gesamtausgabe)

Die Prinzipien der Philosophie. Mit einem Anhang, enthaltend Bemerkungen über ein gewisses Programm. 4. Auflage. 1922. 48,310 Seiten.

Die Prinzipien bilden den Versuch Descartes', seine methodologischen Orundauffassungen auf das gesamte Gebiet der Metaphysik und Naturwissenschaft anzawenden. Hier lernen wir diesen ebenso umfassenden wie scharfen Geist in seiner ganzen GröBe würdigen, der mit so spärlichen Mitteln ein durchgeführtes Weltbild schuf, dessen Wirkung immer dauern vird. Erich Becher im "Literarischen Zentralblatt".

Über die Leidenschaften der Seele. 3. Auflage. 1911. XXXII, 120 u. 30 Seiten. Mit dem Gesamtregister.

Jungmann, K. René Descartes. Eine Einführung in seine Werke. 1908. VIII, 234 Seiten.

Schneider, H. Die Stellung Gassendi's zu D. 1904. 68 Seiten.

VERLAG VON FELIX MEINER IN LEIPZIO 


\section{SPINOZA, SÄMTLICHE WERKE}

Übersetzt von O. Baensch, A. Buchenau und C. Gebhardt

\section{In 3 Halbpergamentbänden}

Dies ist die einzige deutsche Ausgabe der Werke Spinazas, die auf Grund de umwälzenden Ergebnisse der madernen Textkritik erfolgt ist. Sa bletet sie in ihrer Textgestaltung der Forschung die sicherste Grundlage; die Einleitungen bemlihen sich, das Uerständnis der Schriften S.s nach allen Seiten sicher zu stellen.

\section{Daraus" einzeln:}

Abhandlung von Gott, dem Menschen und dessen Glück. 4. Aufl. Neu übersetzt von C. Gebhardt. 1922. XXVIII, $156 \mathrm{~S}$. Ethik. Übersetzt und mit einer Einleitung und Register versehen von Ot to Baensch. 10. Auflage. 1922. 29, 276 u. 39 Seiten. In Halbpergament.

Sehr genau ist die neuere Forschung zum Spinozatext behandelt. Die Einleitung gehört zu dem Besten, was zurr Einführung in Spinozas Denkweise gegeben werden kann. Die Bedeutung dieser Übersetzung wird man darin sehen dürfen, daB sie die für uns oft schwlerig gewordenen Gedankenverschiebungen bei Spinoza klarlegt.

Zeitschrift für den deutschen Unterricht.

Theologisch-politischer Traktat. 4. Auflage. Übersetzt und eingeleitet von C. Gebhardt. 1921. 34, 362 u. 61 Seiten.

Descartes' Prinzipien der Philosophie, auf geometrische Weise begründet. - Anhang, enthaltend metaphysische Gedanken. 3. Aufl. Neu übersetzt von A. Buchenau. 1907. 8, 190 Seiten.

Abhandlung über die Verbesserung des Verstandes. - Áb. handlung vom Staate. 4. Auflage. Übersetzt und eingeleitet von Carl Gebhardt., 1907. 32, 181 u. 33 Seiten.

Briefwechsel. Übertragen u. mit Einleitung, Anmerkungen u. Register versehen von Carl Gebhardt. 1914. 38, 438 Seiten.

Goethe hat den Briefwechsel Spinozas das interessanteste Buch genannt, das man in der Welt von Aufrichtigkeit und Menschenliebe lesen könne. Er bedeutet für uns zugleich die notwendige Ergänzung der Ethik Spinozas, denn er offenbart die tiefe und reine Menschlichkeit, die hinter den mathematisch starren Sätzen jenes Buches steht. Zeitschrift für den deutschen Untervicht.

Lebensbeschreibungen und Gespräche. Herausgegeben von C. Gebhardt. 1914. XI, 147 Seiten. Mit Bild.

Eine völlig nene Erscheinung in der deutschen Literatur ist Gebhardts Übersetzung der alten Lebensbeschreibungen Spinozas, der die überlieferten Äußerungen oder Gespräche Spinozas sowie alle auf sein Leben bezüglichen Quellen belgefügt sind. Es ist ein höchst dankenswertes Buch, das volle Anerkennung verdient. Spinoza gehört-zu den Philosophen, deren Lehre der Ergänzung durch das Bild des Menschen bedarf. Deshalb verdienen die Lebensbeschreibungen Spinozas als ein Widerschein des großen Menschen starkes Interesse.

Zeitschrift für den deutschen Unterricht.

Spinoza-Brevier. Zusammengestellt und mit einer Einleitung versehen von A. Liebert. 2. Auflage. 1918. XXXIV, 169 Seiten.

Es ist als ein glücklicher Gedanke Lieberts zu bezelchnen, daB in seinem Brevier die bedeutsamsten Stellen der "Ethik" von den engen Fesseln der geometrischen Methode befreit worden sind. "Er selbst gibt in einem gehaltvollen Vorworte Aufschluß über die Grundsätze, die ihn dabei geleitet haben. . . Allen, die nicht die nötige Muße und Geduld aufbringen können, zil den Originalwerken des Philosophen zu greifen, denen jedoch jene "große und freie Aussicht über die sinnliche und sittliche Welt", die sich Goethe aus Spinozas Schriften aufzutun schien, von Interesse sein mag, sei Lieberts Brevier bestens empfohlen.

Wiener Fremdenblatt. 


\section{Wissen und Forschen}

\section{Schriften zur Einführung in die Philosophie}

Dem Bedürfnis nach Erläuterungen zu bestimmten philosophischen Klassikern und nach Einführungen in die Grundprobleme der Philosophie will diese Sammlung dienen. Frei von jeder Einseitigkeit und unter Anerkennung der Verschiedenheit der philosophischen Richtungen in der Gegenwart möchte sie einen Sammelpunkt bilden für alle Bestrebungen, die, von wissenschaftlichem Boden aus, in allgemeinverständlicher Sprache in das weite Gebiet philosophischer Lektüre und philosophischer Forschung einzuführen beabsichtigen.

Bd. I: Kants Lehre vom kategorischen Imperativ. Eine Einführung in die Grundfragen der Kantischen Ethik im Anschluß an die "Grundlegung der Metaphysik der Sitten". Von Dr. A. Buchenau. 1913. XII, 125 S.

Bd. II: Gegenwartsphilosophie und christliche Religion. Im Anschluß an Vaihinger, Rehmke, Eucken dargestellt von Dr. H. Hegenwald. 1913. XII, 196 S.

Bd. III: Grundprobleme der Kritik der reineu Vernunft. Eine Einführung in die Kantische Erkenntnistheorie. Von Stadtschulrat Dr. Artur Buchenau. 1914. VI, 194 S.

Bd. IV: Wie ist kritische Philosophie uberhaupt möglich? Ein Beitrag zur systematischen Phänomenologie der Philosophie. Von Prof. Dr. Arthur Liebert. 1919. XVII, 228 S.

Bd. V: Grundriß der Ästhetik. Von Benedetto Croce. Deutsch von Dr. Th. Poppe. 1913. IV, $85 \mathrm{~S}$.

84. VI: Die Seele. Ihr Verhältnis zum Bewußtsein und zum Leibe. Von Jos. Geyser. 1914. VI, 117 S.

Bd. Vil: Die Begruinder der modernen Psychologie. Lotze, Fechner, Helmholtz, Wundt. Vou Stanley Hall, President of Clark University. Übersetzt und mit Anmerkungen versehen von Raym. Schmidt. Mit Vorwort von Max Brahn. 1914. 28, 392 S.

Bd. VIII: Einführung in die Philosophie. Vom Standpunkte des Kritizismus. Von Dr. Kurt Sternberg. 1919. XIII, $291 \mathrm{~S}$.

8d. IX: Pestalozzis Sozialphilosophio. Eine Darstellung auf Grund der „Nachforschungen über den Gang der Natur in der Entwicklung des Menschengeschlechts". Von Dr. Art. Buchenau. 1919. VIII, $183 \mathrm{~S}$.

Bd. K: Die sittlichen Forderungen und die Frage nach ihrer Gültigkeit. Von Gust. Störring. 1920. VIII, $136 \mathrm{~S}$.

Bd. XI: Einfiihrung in die Erkenntnistheorie. Von Aug. Messer. 2., umgearb. Aufl. 1921. IV, 221 S.

Bd. XII: Geschichtsphilosophie. Eine Einführung. Von Prof. Dr. Otto Braun. 1921. VIII, $120 \mathrm{~S}$.

Bd.XIII: Zarathustra-Kommentar. Von Hans Weichelt. 2., neu bearbeitete Auflage. 1922. VI, $366 \mathrm{~S}$. 

Digitized by Microsoft ${ }^{\circledR}$ 
?

Digitized by Microsoft ${ }^{\circledR}$ 
Digitized by Microsoft ${ }^{\circledR}$ 


\section{ROBARTS LIBRARY \\ DUE DATE}

AUG 141990

B Kant; Immanuel

2770 Kritik der praktischen

1922 vernunft. 8 Aufl. 


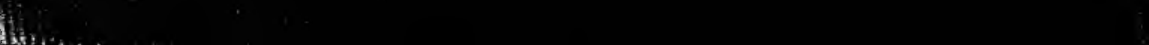

